\title{
UM ÍNDICE DE MOBILIDADE URBANA SUSTENTÁVEL
}

Tese apresentada à Escola de Engenharia de São Carlos da Universidade de São Paulo, como parte dos requisitos para obtenção do grau de Doutor em Engenharia Civil, Área de Concentração: Transportes.

Orientador: Prof ${ }^{0}$. Associado Antônio Nélson Rodrigues da Silva

\author{
São Carlos
}




\begin{abstract}
AUTORIZO A REPRODUC̄̃O E DIVULGACÃO TOTAL OU PARCIAL DESTE TRABALHO, POR QUALQUER MEIO CONVENCIONAL OU ELETRÔNICO, PARA FINS DE ESTUDO E PESQUISA, DESDE QUE CITADA A FONTE.
\end{abstract}

Ficha catalográfica preparada pela Seção de Tratamento da Informação do Serviço de Biblioteca - EESC/USP da Silva Costa ; orientador Antônio Nélson Rodrigues da Silva. -- São Carlos, 2008.

Tese (Doutorado-Programa de Pós-Graduação em Engenharia Civil e Área de Concentração Planejamento e Operação de Sistemas de Transportes -- Escola de Engenharia de São Carlos da Universidade de São Paulo, 2008.

1. Engenharia de Transportes. 2. Mobilidade urbana sustentável. 3. Indicadores urbanos. 4. Índice de mobilidade urbana sustentável. 5. Planejamento da mobilidade. I. Título. 
À Tia Regina, in memorian, pelo amor e atenção dedicados ao longo de toda a sua vida. 


\section{AGRADECIMENTOS}

Ao Prof $^{\circ}$. Antônio Nélson Rodrigues da Silva, pela valiosa orientação, pelo apoio e incentivo ao longo de toda a pós-graduação e, sobretudo, pelo exemplo de profissional ético, dedicado e comprometido com seu trabalho.

Ao Prof $^{\circ}$. Rui António Rodrigues Ramos, por suas inúmeras contribuições para o desenvolvimento do trabalho e cuidadosa revisão e, principalmente, pela sua hospitalidade e de sua família durante o período em Braga.

À Prof ${ }^{a}$. Márcia Helena Macedo, pelo apoio no desenvolvimento do trabalho, pela parceria em trabalhos acadêmicos e por viabilizar a coleta de dados da pesquisa.

Ao Prof $^{0}$ José Reynaldo Anselmo Setti, pelas sugestões feitas na qualificação e interesse demonstrado pelo trabalho.

Ao Prof ${ }^{\circ}$. Renato Luiz Sobral Anelli, pelo empenho e paciência na avaliação dos indicadores e pelas sugestões para o trabalho.

Ao Ministério das Cidades, Secretaria Nacional de Transportes e da Mobilidade Urbana, por disponibilizar os dados coletados durante o curso Gestão Integrada da Mobilidade Urbana.

A todos os pesquisadores que participaram do painel de avaliação, pela disponibilidade e interesse pelo trabalho. Agradecimento especial ao Prof $^{\circ}$. John Dickey da Virginia Tech e ao Prof $^{\circ}$. Ray Wyatt da Universidade de Melbourne pelas demais contribuições.

Aos funcionários das Secretarias de Transporte, Trânsito e Vias Públicas; Habitação e Desenvolvimento Urbano e Desenvolvimento Sustentável, Ciência e Tecnologia da Prefeitura Municipal de São Carlos, pela disponibilização dos dados para avaliação dos indicadores.

Aos professores e funcionários do Departamento de Transportes da Escola de Engenharia de São Carlos, pelos ensinamentos e suporte oferecidos ao longo de toda a pós-graduação. Agradecimento especial às secretárias Heloísa, Beth, Magali e Sueli, pelo auxílio com as questões acadêmicas.

Aos professores e funcionários do Departamento de Engenharia Civil da Escola de Engenharia da Universidade do Minho - Portugal, pelo apoio e hospitalidade. 
Agradecimento especial ao Prof $^{\circ}$. Daniel Souto Rodrigues e aos funcionários Pedro Ferreira e Paula Nunes, pelo auxílio em várias etapas do trabalho e na adaptação ao país.

Aos alunos da disciplina de pós-graduação "Os Sistemas de Informações Geográficas e a Engenharia de Transportes" e ao aluno Conrado Vidotte Plaza, pelo auxílio com o cálculo dos indicadores e contribuições para desenvolvimento do guia.

À minha família, em especial, aos meus pais Neusa e Jorge, meu irmão Fabrício (Dudu e JV) e tias Coca e Mamai pelo carinho, apoio, otimismo e, sobretudo, por compreender minha ausência nos momentos difíceis.

Ao Cláudio pela alegria, carinho, apoio e compreensão, especialmente durante a pósgraduação. À sua família, pelo apoio e entusiasmo.

Aos amigos da pós-graduação, em especial: Rochele, Adriana, Ana Furlan, Dinato, Mateus, Bruno, Andréa Julia, Alexandra, Simone, Renata, Fabíola, Cira, Karenina, Manuel Lucas, Cida, Mário e Marcos pela amizade e convívio.

À irmã Fabiana, pelo incentivo e pelos valiosos conselhos, pela hospitalidade em Brasília e pelas divertidas conversas.

Aos amigos da Vetec Engenharia, em especial, Sandra, Thiago, Caio, Márcio, Lucas, Leonardo, Leandro e Eric $(\mathrm{OHL})$, pelo companheirismo e incentivo ao trabalho e à pósgraduação.

Aos amigos da Geométrica Engenharia de Projetos, pela amizade e incentivo.

À Capes pelo apoio financeiro concedido nos primeiros meses de trabalho.

À CCInt - USP e ao Banco Santander Banespa pelo apoio financeiro concedido durante o estágio na Universidade do Minho. 


\section{RESUMO}

COSTA, M. S. (2008). Um Índice de Mobilidade Urbana Sustentável. Tese (Doutorado) Escola de Engenharia de São Carlos, Universidade de São Paulo, São Carlos, 2008.

Esta pesquisa tem como objetivos: identificar os conceitos que estruturam o referencial de mobilidade urbana sustentável, desenvolver uma ferramenta para diagnóstico e monitoração da mobilidade urbana e realizar a sua avaliação a partir de uma aplicação em uma cidade de médio porte. O processo de construção do referencial de mobilidade urbana sustentável, feito a partir de workshops realizados em onze cidades brasileiras através da metodologia Multicritério de Apoio à Decisão Construtivista (MCDA-C), revelou questões-chave que devem ser consideradas para a implementação do conceito. Ao mesmo tempo, forneceu as bases para a construção da ferramenta denominada de Índice de Mobilidade Urbana Sustentável - IMUS. O índice é constituído de uma hierarquia de critérios que agrega nove Domínios, trinta e sete Temas e oitenta e sete Indicadores. Seu sistema de pesos permite identificar a importância relativa de cada critério de forma global e para cada Dimensão da sustentabilidade (social, econômica e ambiental). Seu método de agregação permite a compensação entre critérios bons e ruins. O índice apresenta ainda escalas de avaliação para cada Indicador, permitindo verificar o desempenho em relação a metas préestabelecidas e realizar análises comparativas entre diferentes regiões geográficas. A aplicação do IMUS para a cidade de São Carlos, estado de São Paulo, indicou a viabilidade de sua utilização para a monitoração da mobilidade e avaliação de impactos de políticas públicas em cidades de médio porte, e revelou aspectos importantes sobre as condições de mobilidade no município. O resultado global do IMUS para a cidade alcançou valor em torno de 0,58 , considerado médio segundo a escala de avaliação proposta para o índice. A aplicação do índice permitiu identificar fatores críticos e fatores de maior impacto para a melhoria de aspectos globais e setoriais da mobilidade urbana, fornecendo subsídios para a proposição de políticas e estratégias visando melhorar a mobilidade urbana sustentável. A compatibilidade dos resultados obtidos segundo o cálculo dos indicadores e análise expedita feita por um especialista sugere que o IMUS fornece resultados confiáveis para o acompanhamento das condições de mobilidade urbana em cidades e médio e grande porte.

Palavras-chave: mobilidade urbana sustentável, indicadores urbanos, indicadores de mobilidade, índice de mobilidade urbana sustentável, planejamento da mobilidade. 


\section{ABSTRACT}

COSTA, M. S. (2008). An Index of Sustainable Urban Mobility. PhD. Thesis - Escola de Engenharia de São Carlos, Universidade de São Paulo, São Carlos, 2008.

The objectives of this research are: (i) to identify the concepts that shape the sustainable urban mobility framework; (ii) to develop a tool for assessing and monitoring urban mobility conditions; and (iii) to evaluate the proposed tool through an actual application in a mediumsized city. The main elements of the sustainable urban mobility framework were identified in workshops conducted in eleven Brazilian cities. The use of a Multicriteria Decision Analysis Constructivist (MCDA-C) approach in the workshops revealed key elements that shall be considered in the concept implementation. In addition, it provided the basic elements for the development of the so-called Index of Sustainable Urban Mobility - I_SUM. The index is formed by a hierarchy of criteria with nine Domains, thirty-seven Themes, and eighty-seven Indicators. The weighting system makes it possible to identify the relative importance of each criterion for the global Index as well as for each sustainability Dimension (social, economic, and environmental). Furthermore, the aggregation procedure adopted allows for trade-offs, therefore compensating good and bad performances found among the indicators. The index is also associated with evaluation procedures for each Indicator, which makes it possible to compare index values with predefined goals and to carry out comparative analyses between different geographic regions. The application of I_SUM to São Carlos, a city in the state of São Paulo, has shown the feasibility of its use to monitor local mobility conditions and to evaluate impacts of public policies in medium-sized cities, revealing important mobility aspects in the city. The global I_SUM value for the city was 0.58 , what can be considered a reasonable value when compared with the reference values proposed for the index. The use of the index highlighted critical factors and those that have significant impact on the global and certain dimensions of urban mobility. These inputs might be useful for the formulation of policies and strategies aiming at achieving greater sustainable urban mobility. Lastly, the comparison between the value obtained with the index calculation procedures and that estimated by an expert suggests that I_SUM can give reliable estimates of mobility conditions in medium and large-sized cities.

Keywords: urban sustainable mobility, urban indicators, mobility indicators, index of sustainable urban mobility, mobility planning. 


\section{LISTA DE FIGURAS}

Figura 4.1: Arborescência de pontos de vista.

Figura 5.1: Pirâmide de Sistema de Indicadores por Público-alvo.

Figura 6.1: Método de desenvolvimento da pesquisa.

Figura 6.2: Níveis hierárquicos de critérios do IMUS.

Figura 6.3: Exemplo de gráfico produzido com os resultados do IMUS.

Figura 7.1: Cidades onde foi realizado o Curso Gestão Integrada da Mobilidade Urbana. ...84

Figura 7.2: Árvore de Temas e Indicadores de Mobilidade para Porto Alegre e Região Metropolitana. .88

Figura 7.3: Mapa cognitivo construído para Porto Alegre e Região Metropolitana, 89

Figura 7.4: Árvore de Alternativas, PVFs e Indicadores de Mobilidade Sustentável para Porto Alegre e Região Metropolitana. .90

Figura 7.5: Árvore de Temas e Indicadores de Mobilidade para Florianópolis e Região Metropolitana. 91

Figura 7.6: Árvore de Alternativas, PVFs e Indicadores de Mobilidade Sustentável para Florianópolis e Região Metropolitana......

Figura 7.7: Árvore de Temas e Indicadores de Mobilidade para Vitória e Região Metropolitana.

Figura 7.8: Árvore de Alternativas, PVFs e Indicadores de Mobilidade Sustentável para

Vitória e Região Metropolitana. 95

Figura 7.9: Árvore de Temas e Indicadores de Mobilidade para Belo Horizonte e Região Metropolitana. .96

Figura 7.10: Árvore de Alternativas, PVFs e Indicadores de Mobilidade Sustentável para Belo Horizonte e Região Metropolitana. 97 
Figura 7.11: Árvore de Temas e Indicadores de Mobilidade para Goiânia e Região Metropolitana.

Figura 7.12: Árvore de Alternativas, PVFs e Indicadores de Mobilidade Sustentável para Goiânia e Região Metropolitana. 100

Figura 7.13: Árvore de Temas e Indicadores de Mobilidade para Recife e Região Metropolitana. 103

Figura 7.14: Árvore de Alternativas, PVFs para Recife e Região Metropolitana. 104

Figura 7.15: Árvore de Temas e Indicadores de Mobilidade para Aracaju e Região Metropolitana. 105

Figura 7.16: Árvore de Alternativas, PVFs e Indicadores de Mobilidade Sustentável para Aracaju e Região Metropolitana. 106

Figura 7.17: Árvore de Temas e Indicadores de Mobilidade para Maceió e Região Metropolitana. 107

Figura 7.18: Árvore de Alternativas, PVFs e Indicadores de Mobilidade Sustentável para Maceió e Região Metropolitana. 108

Figura 7.19: Árvore de Temas e Indicadores de Mobilidade para Fortaleza e Região Metropolitana. 109

Figura 7.20: Árvore de Alternativas, PVFs e Indicadores de Mobilidade Sustentável para Fortaleza e Região Metropolitana. 110

Figura 7.21: Árvore de Temas e Indicadores de Mobilidade para Palmas e municípios vizinhos.

Figura 7.22: Árvore de Alternativas, PVFs e Indicadores de Mobilidade Sustentável para Palmas e municípios vizinhos.

Figura 7.23: Árvore de Temas e Indicadores de Mobilidade para Manaus e municípios vizinhos. 114

Figura 7.24: Árvore de Alternativas, PVFs e Indicadores de Mobilidade Sustentável para Manaus e municípios vizinhos. 115 
Figura 7.25: Enfoques dos indicadores de mobilidade urbana para Porto Alegre e Região Metropolitana.

Figura 7.26: Enfoques dos indicadores de mobilidade urbana para Florianópolis e Região Metropolitana.

Figura 7.27: Enfoques dos indicadores de mobilidade urbana para Vitória e Região Metropolitana. 119

Figura 7.28: Enfoques dos indicadores de mobilidade urbana para Belo Horizonte e Região Metropolitana.

Figura 7.29: Enfoques dos indicadores de mobilidade urbana para Goiânia e Região Metropolitana.

Figura 7.30: Enfoques dos indicadores de mobilidade urbana para Recife e Região Metropolitana. 123

Figura 7.31: Enfoques dos indicadores de mobilidade urbana para Aracaju e Região Metropolitana.

Figura 7.32: Enfoques dos indicadores de mobilidade urbana para Maceió e Região Metropolitana. 125

Figura 7.33: Enfoques dos indicadores de mobilidade urbana para Fortaleza e Região Metropolitana. 126

Figura 7.34: Enfoques dos indicadores de mobilidade urbana para Palmas e municípios vizinhos.

Figura 7.35: Enfoques dos indicadores de mobilidade urbana para Manaus e municípios vizinhos.

Figura 7.36: Árvore de Alternativas e PVFs para a Região Sul. 129

Figura 7.37: Árvore de Alternativas e PVFs para a Região Sudeste. 129

Figura 7.38: Árvore de Alternativas e PVFs para a Região Centro-oeste. 130

Figura 7.39: Árvore de Alternativas e PVFs para a Região Nordeste. 130

Figura 7.40: Árvore de Alternativas e PVFs para a Região Norte. 130 
Figura 7.41: Importância relativa das dimensões da sustentabilidade nas regiões

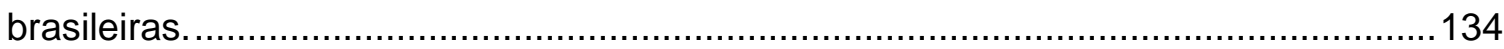

Figura 7.42: Ocorrência dos Domínios nas cidades pesquisadas. .................................139

Figura 8.1: Hierarquia de Domínios e Temas do IMUS. .................................................143

Figura 8.2: Escala de avaliação dos critérios do IMUS..................................................154

Figura 8.3: Exemplo de tabela de avaliação dos Temas do IMUS. ...................................154

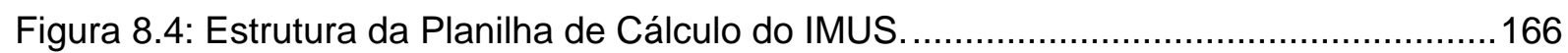

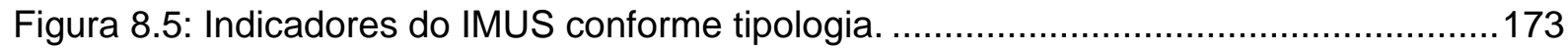

Figura 8.6: Indicadores Quantitativos e Qualitativos conforme subgrupo.........................174

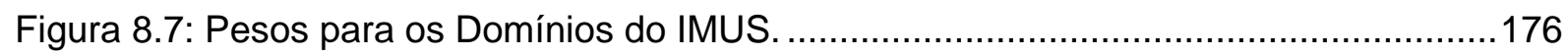

Figura 9.1: Localização do município de São Carlos - SP. ...................................................184

Figura 9.2: Planilha de Cálculo do IMUS para a cidade de São Carlos (processo de

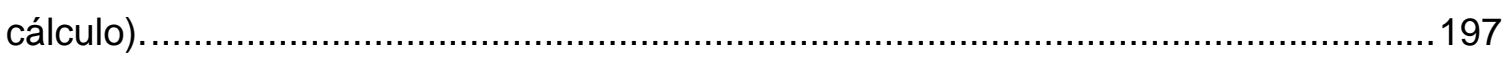

Figura 9.3: Análise da disponibilidade e qualidade dos dados para cálculo do IMUS........201

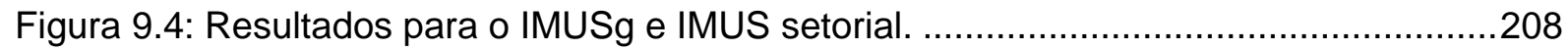

Figura 9.5: Resultados normalizados para os indicadores do IMUS, calculados para a cidade de São Carlos. ................................................................................................ 210

Figura 9.6: Resultados normalizados para os dez indicadores com maiores pesos global e por Dimensões, calculados para São Carlos............................................................211

Figura 9.7: Resultados da análise de sensibilidade para o IMUSg.................................217

Figura 9.8: Resultados para os indicadores segundo processo de cálculo e avaliação expedita. 221 


\section{LISTA DE TABELAS}

Tabela 2.1: Estudos e iniciativas sobre transporte e mobilidade sustentável.

Tabela 5.1: Níveis de prioridade para coleta dos indicadores propostos pelo TRB (2008)...56

Tabela 5.2: Potenciais indicadores de mobilidade sustentável. .57

Tabela 5.3: Indicadores do Sistema de Informações da Mobilidade Urbana - ANTP. .60

Tabela 5.4: Indicadores apresentados pela NTU na Pesquisa Mobilidade da População Urbana. .60

Tabela 6.1: Critérios para avaliação de indicadores de transportes e meio ambiente. .78

Tabela 7.1: Características das regiões brasileiras. 131

Tabela 7.2: Referencial para classificação das Alternativas nas Dimensões da Sustentabilidade 132

Tabela 7.3: Classificação dos PVFs nas Dimensões da Sustentabilidade. 136

Tabela 8.1: Sistemas que compõem a base de referência para a busca de indicadores....144

Tabela 8.2: Estrutura de auxílio à busca de indicadores. 147

Tabela 8.3: Indicadores selecionados para compor o IMUS. 151

Tabela 8.4: Estrutura Hierárquica de Critérios do IMUS e respectivos Pesos. 157

Tabela 8.5: Escala de Avaliação para o Indicador 1.1.2 - Transporte público para pessoas com necessidades especiais. 159

Tabela 8.6: Escala de Avaliação para o Indicador 1.2.3 - Vagas de estacionamento para pessoas com necessidades especiais.

Tabela 8.7: Escala de Avaliação para o Indicador 1.1.1 - Acessibilidade ao transporte público. 160

Tabela 8.8: Escala de Avaliação para o Indicador 7.5.3 - Densidade populacional urbana. ...160 
Tabela 8.9: Escala de Avaliação para o Indicador 4.1.1 - Integração entre níveis de governo

Tabela 8.10: Escala de Avaliação para o Indicador 1.4.1 - Ações para acessibilidade universal.

Tabela 8.11: Escala de Avaliação para o Indicador 6.1.1 - Extensão e conectividade da rede viária.

Tabela 8.12: Exemplo de apresentação dos pesos para um dos critérios do IMUS

Tabela 8.13: Indicadores do IMUS conforme tipologia.

Tabela 8.14: Pesos para os Temas que compõem o IMUS

Tabela 8.15: Pesos globais e setoriais para os Indicadores que compõem o IMUS.

Tabela 8.16: Dez indicadores com maiores pesos para os resultados global e por Dimensões

Tabela 9.1: Dados demográficos e socioeconômicos do município de São Carlos.

Tabela 9.2: Síntese da avaliação de qualidade e disponibilidade de dados para os indicadores do IMUS.

Tabela 9.3: Estrutura do IMUS para a cidade de São Carlos. 198

Tabela 9.4: Resultados do IMUS quanto à disponibilidade e qualidade dos dados. 199

Tabela 9.5: Resultados obtidos para o IMUS global e setorial, a partir do processo de cálculo.

Tabela 9.6: Scores absoluto e normalizado para os indicadores do Domínio Acessibilidade, calculados para São Carlos.

Tabela 9.7: Scores absoluto e normalizado para os indicadores do Domínio Aspectos Ambientais, calculados para São Carlos.

Tabela 9.8: Scores absoluto e normalizado para os indicadores do Domínio Aspectos Sociais, calculados para São Carlos

Tabela 9.9: Scores absoluto e normalizado para os indicadores do Domínio Aspectos Políticos, calculados para São Carlos. 
Tabela 9.10: Scores absoluto e normalizado para os indicadores do Domínio Infra-estrutura de Transportes, calculados para São Carlos...........................................................214

Tabela 9.11: Scores absoluto e normalizado para os indicadores do Domínio Modos Nãomotorizados.

Tabela 9.12: Scores absoluto e normalizado para os indicadores do Domínio Planejamento Integrado.

Tabela 9.13: Scores absoluto e normalizado para os indicadores do Domínio Tráfego e Circulação Urbana.

Tabela 9.14: Scores absoluto e normalizado para os indicadores do Domínio Sistemas de Transporte Urbano. 215

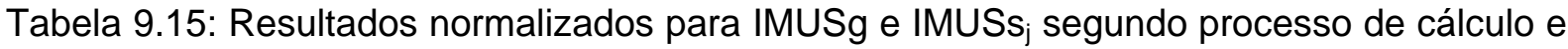
análise de sensibilidade. 216

Tabela 9.16: Variações ocorridas no IMUSs $s_{\mathrm{j}}$ nas etapas de análise de sensibilidade. 218

Tabela 9.17: Comparação entre os resultados obtidos para o IMUS segundo os dois métodos de avaliação dos indicadores. 220

Tabela 9.18: Indicadores com resultados semelhantes nos dois processos de avaliação. .221

Tabela 9.19: Proporção de indicadores com resultados compatíveis nos dois processos de avaliação. 223

Tabela 10.1: Aspectos a serem observados na formulação de políticas públicas para a mobilidade urbana sustentável na cidade de São Carlos. 234 


\section{SUMÁRIO}

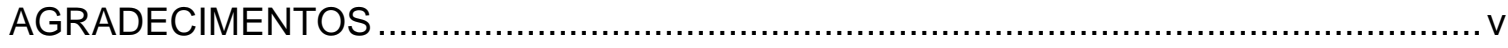

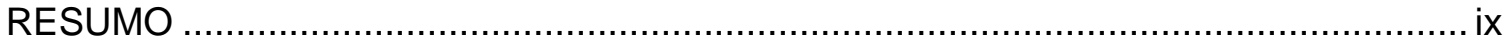

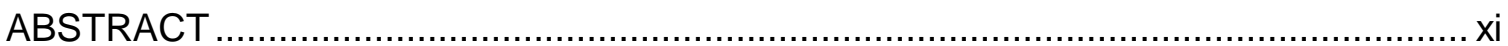

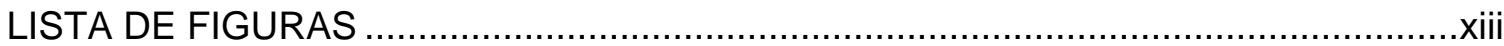

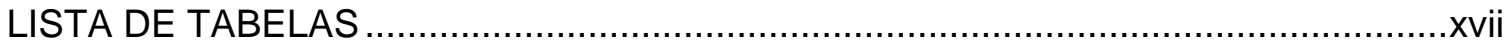

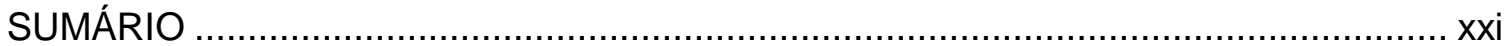

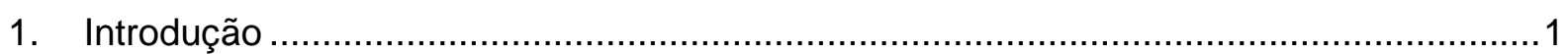

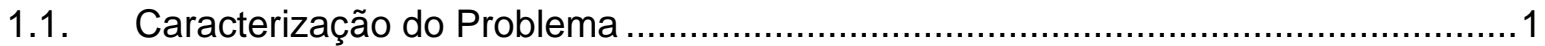

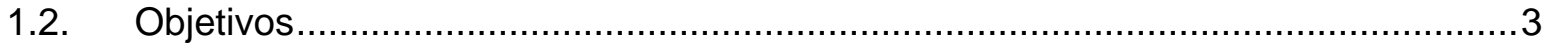

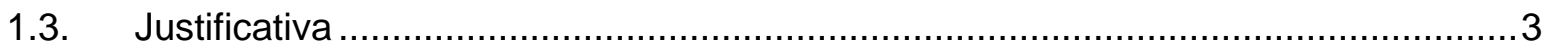

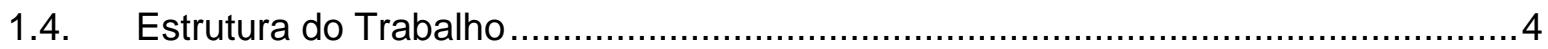

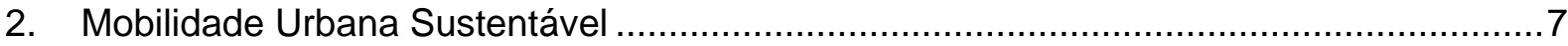

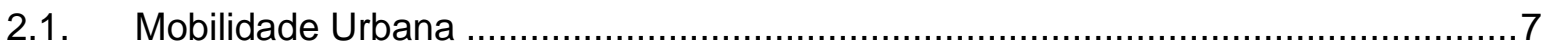

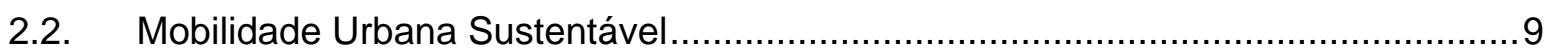

2.2.1. Iniciativas para a Mobilidade Urbana Sustentável ......................................13

2.3. Mobilidade, Sustentabilidade e Qualidade de Vida Urbana ..............................17

3. Planejamento e Gestão da Mobilidade Urbana no Brasil ..........................................21

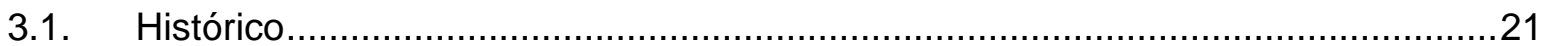

3.2. A Mobilidade Segundo as Novas Políticas Urbanas .........................................24

3.3. Desafios da Política Nacional de Mobilidade Urbana ........................................28

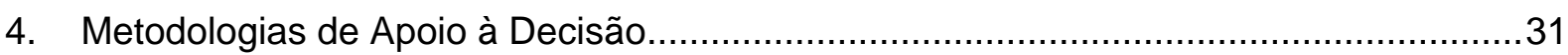

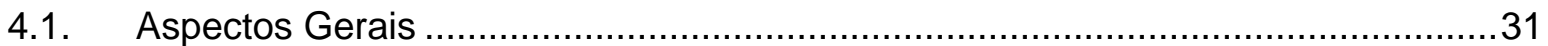




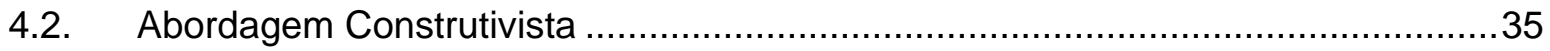

5. Indicadores Urbanos e de Mobilidade Sustentável..................................................45

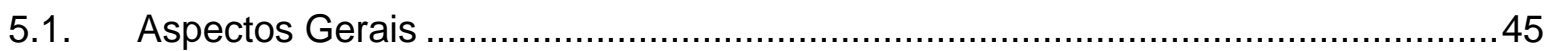

5.2. Indicadores de Mobilidade Urbana Sustentável ...............................................50

5.3. Seleção de Indicadores de Mobilidade Sustentável ............................................54

5.4. Indicadores de Transportes e Mobilidade no Brasil..............................................59

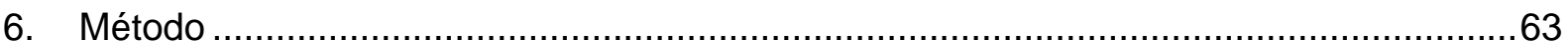

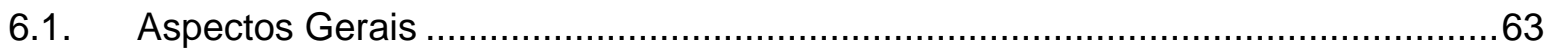

6.2. Referencial de Mobilidade Urbana Sustentável.............................................64

6.2.1. Identificação de Indicadores de Mobilidade Urbana para o Enfoque

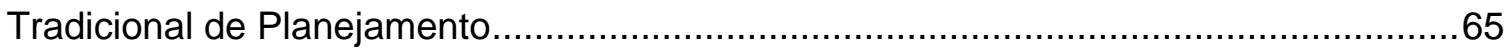

6.2.2. Construção do Conceito de Mobilidade Urbana Sustentável ........................66

6.2.3. Identificação de Indicadores para os Pontos de Vista Fundamentais ............68

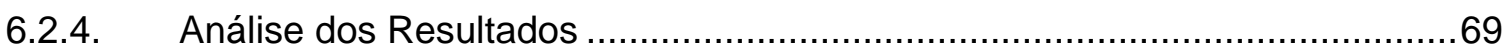

6.3. Construção do Índice de Mobilidade Urbana Sustentável (IMUS) .........................70

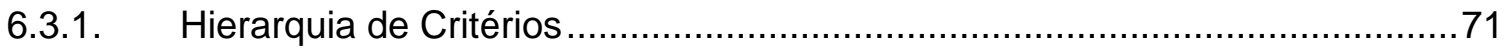

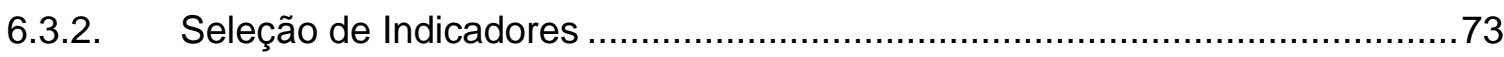

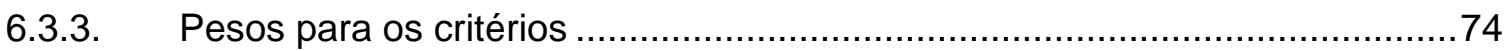

6.3.4. Normalização dos Critérios........................................................................... 74

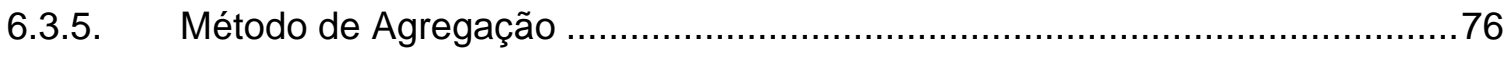

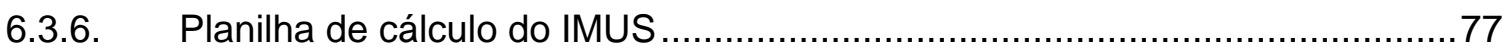

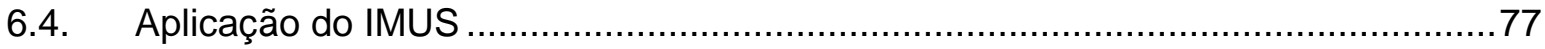

6.4.1. Coleta de Dados e Avaliação Expedita ……............................................... 79 


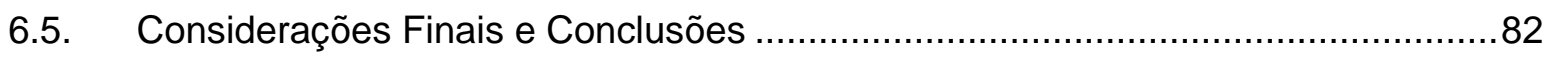

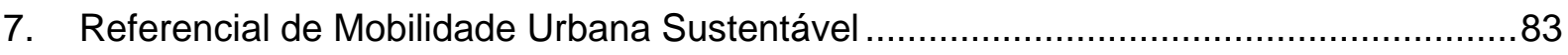

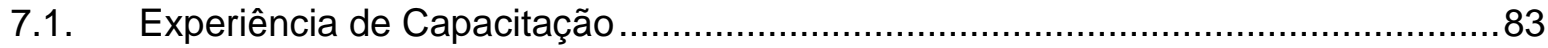

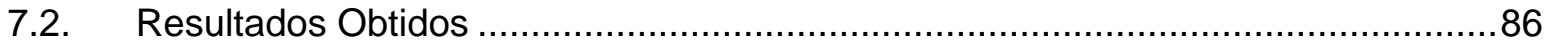

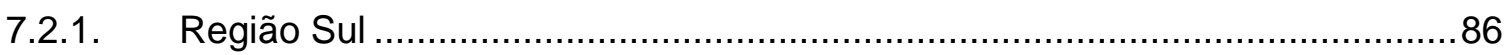

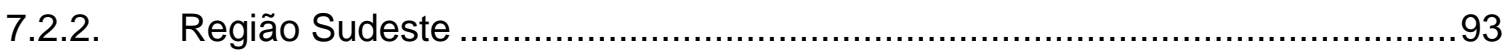

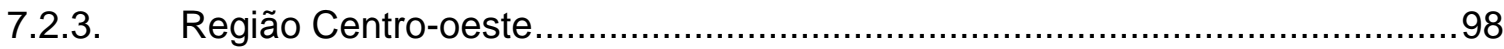

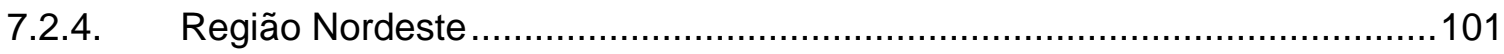

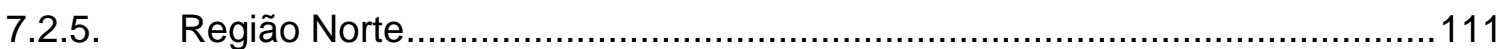

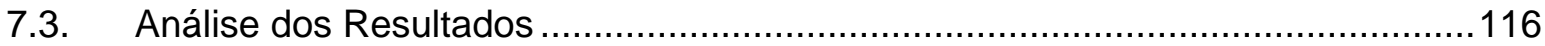

7.3.1. Análise dos Resultados por Região - Enfoque Tradicional x Novo

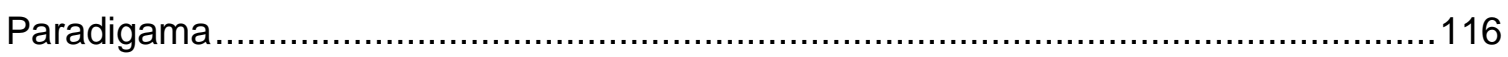

7.3.2. Análise dos Resultados para as Regiões Brasileiras .................................129

7.3.3. Síntese do Referencial de Mobilidade Urbana Sustentável em Cidades

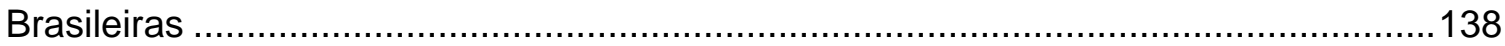

8. Índice de Mobilidade Urbana Sustentável.............................................................. 141

8. Índice de Mobilidade Urbana Sustentável.......................................................... 141

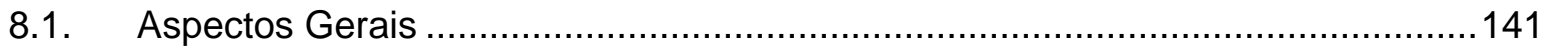

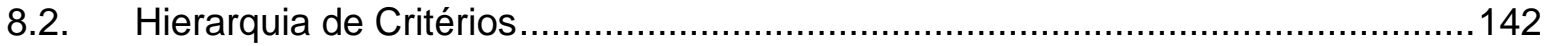

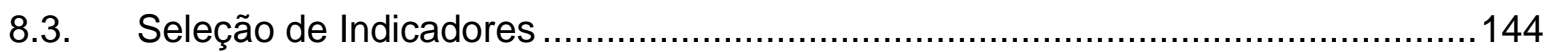

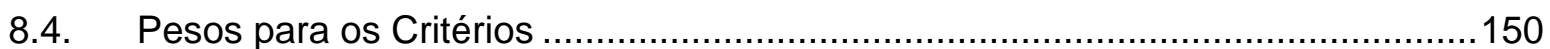

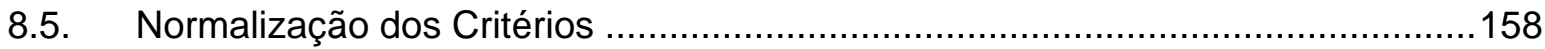

8.6. Agregação dos Critérios e Planilha de Cálculo do IMUS ..................................163 


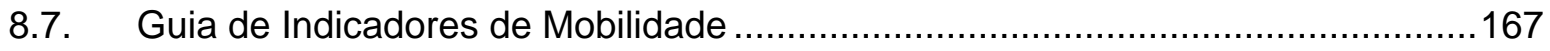

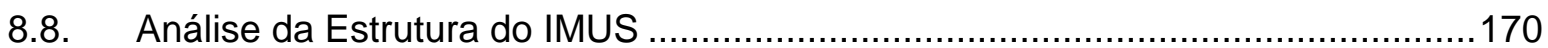

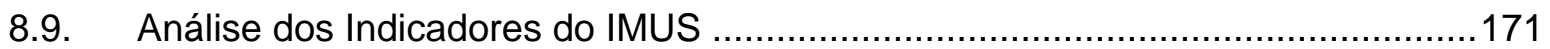

8.10. Análise do Sistema de Pesos para os Critérios................................................174

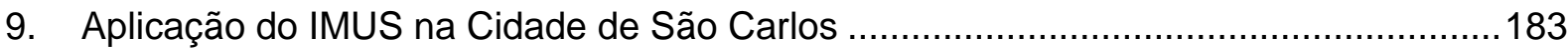

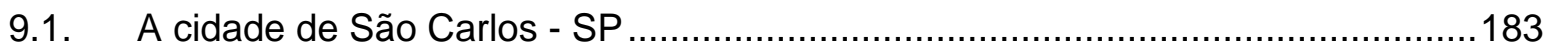

9.2. Coleta e Avaliação da Qualidade dos Dados para Cálculo do IMUS ...................185

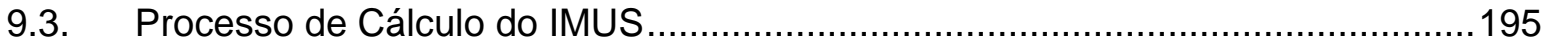

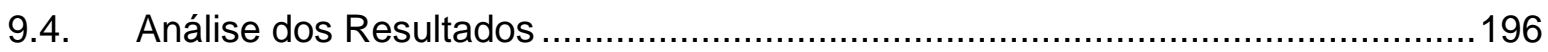

9.4.1. Disponibilidade e Qualidade dos Dados ..................................................... 196

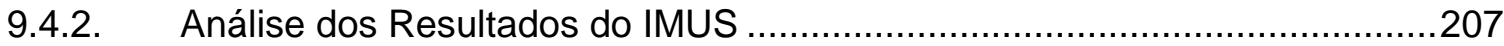

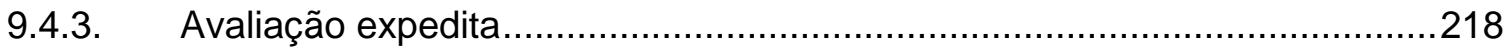

9.4.4. Comparação dos Resultados do Processo de Cálculo e Avaliação

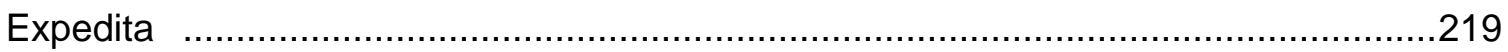

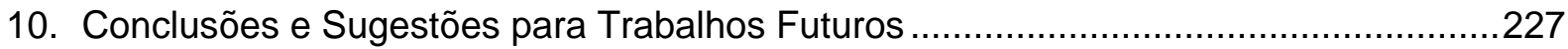

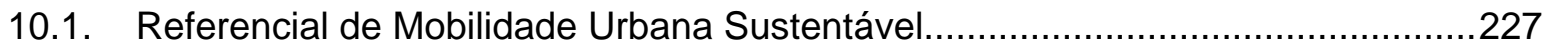

10.2. Índice de Mobilidade Urbana Sustentável - IMUS ..........................................228

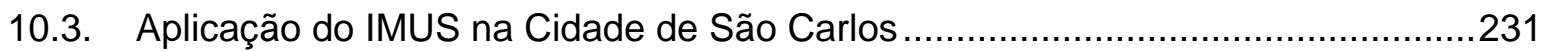

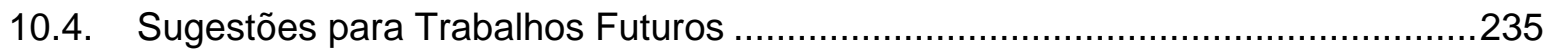

\section{REFERÊNCIAS BIBLIOGRÁFICAS}




\section{ANEXOS}

(Disponibilizados somente em versão digital no CD-ROM)

ANEXO A - Material do Curso de Capacitação Gestão da Mobilidade Urbana

ANEXO B - Resultados do Curso de Capacitação Gestão da Mobilidade Urbana

ANEXO C - Construção da Hierarquia de Critérios

ANEXO D - Sistemas de Indicadores Urbanos

ANEXO E - Guia de Elaboração dos Indicadores do IMUS

ANEXO F - Painel de Especialistas

ANEXO G - Sistema de Pesos para os Critérios

ANEXO H - Planilha de Cálculo do IMUS

ANEXO I - Cálculo do IMUS para São Carlos -SP 



\section{INTRODUÇÃO}

Este capítulo aborda alguns aspectos relacionados à construção do referencial de mobilidade urbana sustentável e ao desenvolvimento de ferramentas para sua monitoração, os quais constituem os principais problemas abordados nesta pesquisa. São apresentados ainda os objetivos e a justificativa para a proposição deste trabalho. Na etapa final é apresentada a estrutura deste documento.

\subsection{Caracterização do Problema}

No contexto das cidades, a busca pelo desenvolvimento sustentável tem provocado a revisão das formas de compreender e planejar o meio urbano. Nas discussões ocorridas durante este processo, as quais envolvem planejadores, administradores públicos, comunidade acadêmica e sociedade em geral, alguns aspectos têm merecido destaque, entre eles:

- A preocupação com os atuais padrões de desenvolvimento das cidades, marcados pelo crescimento desordenado e espalhamento urbano, reflexos da especulação imobiliária e da incapacidade do poder público de controlar a expansão do território;

- A degradação ambiental evidenciada pela poluição, ruído, escassez de espaços abertos e áreas verdes;

- A desigualdade social, a segregação espacial e as disparidades no acesso às oportunidades e atividades urbanas;

- A descontinuidade das ações e investimentos, produto da atuação setorizada e muitas vezes não coordenada do poder público no gerenciamento do espaço urbano, resultando em desperdício de recursos e não atendimento das necessidades mais urgentes da população;

- As dificuldades impostas à circulação de pessoas e bens, causadas pela falta de integração entre o planejamento urbano e de transportes e do incentivo aos modos individuais em detrimento dos coletivos, além do declínio da qualidade ambiental das cidades em função de seus sistemas de mobilidade. 
As preocupações relacionadas aos transportes e à mobilidade são de especial interesse para o desenvolvimento urbano sustentável, uma vez que os atuais padrões de mobilidade têm refletido em inúmeras deseconomias para as cidades, além de afetarem de forma direta a qualidade de vida de seus cidadãos. As questões de mobilidade, por sua vez, foram tratadas até o presente momento apenas como uma questão de acesso físico aos meios de transporte, o que pode estar na origem de muitos dos problemas urbanos hoje detectados. Deste modo, a forma de planejar as cidades e seus sistemas de circulação tem sido revista, resultando em novas estratégias de atuação e na construção de um novo paradigma para a mobilidade urbana.

Este novo paradigma reconhece que os problemas de mobilidade não se limitam apenas ao acesso a esses meios de transporte. Estes problemas envolvem também questões ambientais, econômicas, sociais e comportamentais mais complexas, aspectos ligados ao planejamento físico das cidades, além de preocupações com o financiamento e a gestão sistêmica da mobilidade. Desta forma, o novo paradigma em desenvolvimento volta-se para a melhoria das condições de mobilidade e acessibilidade da população buscando, em última análise, a melhoria da qualidade de vida e a construção e manutenção do que se denomina de mobilidade urbana sustentável.

No Brasil, a difusão do conceito de mobilidade urbana sustentável tem sido feita sobretudo através de estudos e pesquisas acadêmicas, como também através de ações e políticas empreendidas em nível federal, sob a coordenação do Ministério das Cidades, criado em 2003. No entanto, ainda que constituídos por diretrizes e eixos fundamentais já bastante difundidos, os conceitos de sustentabilidade urbana e de mobilidade urbana sustentável permanecem complexos e até mesmo subjetivos, podendo apresentar variações conforme o enfoque de análise, localização geográfica e contexto econômico e social a que se aplicam. Assim, ainda que a busca pela mobilidade sustentável já compartilhe de esforços no país, observa-se o desconhecimento dos eixos que estruturam o conceito no nível dos municípios brasileiros, bem como ferramentas adequadas para monitoração dos aspectos relacionados à mobilidade urbana.

Face ao exposto, algumas considerações podem ser feitas:

- As diferenças regionais, bem como a multiplicidade dos problemas de mobilidade hoje enfrentados pelas cidades, impedem o estabelecimento de uma política única para o setor. Assim, os municípios necessitam desenvolver políticas próprias, em consonância com as políticas federais, porém, considerando as especificidades locais; 
- A formulação de políticas públicas exige um profundo conhecimento dos problemas de mobilidade dos centros urbanos, de forma a identificar as limitações e potencialidades para a implementação do conceito de mobilidade urbana sustentável;

- Até o presente momento, não há disponibilidade de um índice agregado que se configure em uma ferramenta efetiva para diagnóstico e monitoração da mobilidade urbana, especialmente em cidades brasileiras, que reflita os principais aspectos para efetivação do conceito de mobilidade sustentável, e que permita medir os impactos de políticas públicas na direção da sustentabilidade.

Todos estes aspectos motivaram a realização desta pesquisa, cujos objetivos principais são descritos a seguir.

\subsection{Objetivos}

Os objetivos desta pesquisa são:

- Identificar os conceitos que estruturam o referencial de mobilidade urbana sustentável em cidades brasileiras;

- Com base nestes conceitos, desenvolver uma ferramenta para avaliação e monitoração da mobilidade urbana, capaz de revelar as condições atuais e medir os impactos de medidas e estratégias visando a mobilidade sustentável;

- Avaliar a ferramenta proposta a partir de sua aplicação prática em uma cidade brasileira, visando identificar tanto aspectos positivos, como aqueles que necessitam ser aprimorados para o seu emprego efetivo na elaboração de políticas públicas para a mobilidade urbana sustentável.

\subsection{Justificativa}

Os problemas de mobilidade urbana apresentados hoje pelas cidades têm origens e naturezas diversas. Entre as questões que mais afetam a qualidade de vida dos centros urbanos, certamente os aspectos relacionados à mobilidade têm impacto significativo, especialmente no que se refere ao aumento dos custos e tempos de viagem, poluição atmosférica, ruído, acidentes de trânsito, fragmentação do espaço urbano, entre outros.

A complexidade desses problemas, bem como suas conexões com questões ambientais, econômicas, sociais e culturais das cidades exigem o desenvolvimento de ferramentas adequadas, que permitam a total compreensão destes fenômenos, bem como suas interrelações. 
Neste sentido, índices ou indicadores urbanos se configuram em excelentes ferramentas para diagnóstico das condições de mobilidade e acompanhamento do impacto de políticas públicas, à medida que permitem acompanhar a evolução de determinados fenômenos e ações. Estas ferramentas já têm sido amplamente utilizadas nos processos de planejamento e gestão urbana, incluindo aspectos relacionados à mobilidade, como pode ser visto através de inúmeras experiências desenvolvidas especialmente em âmbito internacional.

No entanto, ainda que indicadores de mobilidade sustentável já estejam amplamente disponíveis, alguns aspectos relacionados a estas ferramentas ainda não foram devidamente explorados. Estes aspectos referem-se principalmente a construção de índices que agreguem as diferentes dimensões da sustentabilidade e que permitam a avaliação dos impactos de estratégias e ações em campos específicos, possibilitando atuar tanto de forma integrada como setorizada, para a implementação do conceito de mobilidade urbana sustentável.

Desta forma, este trabalho se justifica por dois aspectos. Primeiramente, por sua proposição de identificar, através de um processo sistemático, o referencial de mobilidade urbana sustentável em um determinado contexto. Em segundo lugar, por propor uma ferramenta de monitoração compatível com cada contexto, auxiliando na compreensão das interligações existentes entre os diversos aspectos que envolvem a mobilidade urbana. Ao mesmo tempo, busca incorporar as dimensões da sustentabilidade e os impactos de ações neste nível para as condições globais de mobilidade, permitindo identificar aspectos que inibem ou potencializam a implementação do conceito em nível urbano.

Em última análise, a avaliação proporcionada pela ferramenta proposta deverá fornecer subsídios para a formulação de políticas públicas de mobilidade mais eficientes e mais próximas do referencial de sustentabilidade adotado, além de permitir identificar ações prioritárias em situações onde há limitações de ordem econômica e financeira.

\subsection{Estrutura do Trabalho}

Este trabalho é composto por dez capítulos, incluindo o capítulo de Introdução. Esses capítulos estão assim estruturados:

- Nos Capítulos 2, 3 e 4 é apresentado o referencial teórico desta pesquisa. O Capítulo 2 discute aspectos relacionados ao conceito de mobilidade urbana sustentável e iniciativas para sua efetivação no Brasil e em outros países, bem como a relação entre mobilidade, sustentabilidade e qualidade de vida urbana. $O$ Capítulo 3 aborda o histórico do planejamento e gestão da mobilidade no Brasil, a 
partir do período da Primeira República até os dias atuais, onde se observa o desenvolvimento de novas políticas públicas que têm buscado incorporar o conceito de sustentabilidade. O Capítulo 4 apresenta metodologias de apoio à decisão, dando destaque à abordagem construtivista, que serve de base para a construção do referencial de mobilidade urbana sustentável em cidades brasileiras. O Capítulo 5 discute aspectos referentes a indicadores urbanos e de mobilidade, abordando suas principais características e critérios de seleção. Neste capítulo são sintetizadas ainda algumas experiências em desenvolvimento no país;

- O Capítulo 6 descreve o Método de desenvolvimento do trabalho, incluindo as etapas de construção do referencial de mobilidade urbana sustentável em cidades brasileiras, de construção do Índice de Mobilidade Urbana Sustentável e de aplicação e avaliação do mesmo;

- O Capítulo 7 trata do referencial de mobilidade urbana sustentável, apresentando os resultados obtidos para as onze cidades brasileiras onde foi desenvolvida uma atividade de capacitação de técnicos e gestores públicos;

- O Capítulo 8 aborda as etapas de construção do Índice de Mobilidade Urbana Sustentável e a estrutura final de critérios e indicadores, bem como o sistema de pesos definido para os mesmos. Neste capítulo é feita a análise da estrutura obtida, identificando os diferentes tipos de indicadores e sua importância relativa para os resultados global e setorial do índice;

- O Capítulo 9 apresenta a aplicação do índice para a cidade de São Carlos, estado de São Paulo, discutindo aspectos relacionados ao desenvolvimento e adequação da ferramenta e aos resultados obtidos segundo avaliação desenvolvida para a cidade;

- No Capítulo 10 são feitas considerações gerais e apresentadas as principais conclusões da pesquisa, bem como recomendações para trabalhos futuros. 


\section{MOBILIDADE URBANA SUSTENTÁVEL}

Neste capítulo é apresentada uma síntese dos conceitos de mobilidade e mobilidade urbana sustentável com base na revisão da literatura, destacando os diferentes aspectos considerados em alguns trabalhos e estudos desenvolvidos nos últimos anos referentes ao tema. Neste capítulo são abordadas ainda algumas iniciativas em nível nacional e internacional para difusão e efetivação do conceito. Para concluir, é discutida a influência da mobilidade sobre aspectos relacionados à sustentabilidade e qualidade de vida nos centros urbanos.

\subsection{Mobilidade Urbana}

As cidades têm como papel principal maximizar a troca de bens e serviços, cultura e conhecimentos entre seus habitantes, mas isso só é possível se houver condições de mobilidade adequadas para seus cidadãos. Neste sentido, a mobilidade é um atributo associado à cidade, e corresponde à facilidade de deslocamento de pessoas e bens na área urbana. A mobilidade traduz as relações dos indivíduos com o espaço em que habitam, com os objetos e meios empregados para seu deslocamento e com os demais indivíduos que integram a sociedade (Ministério das Cidades, 2006a).

O EUROFORUM (2007) define mobilidade para pessoas como a capacidade em participar de diferentes atividades em diferentes lugares e, para bens, a possibilidade de acesso às atividades relacionadas à sua produção e comercialização, as quais ocorrem freqüentemente em diferentes lugares. Para o transporte de passageiros as atividades representam a residência, o trabalho, a educação, o lazer e as compras. Para o transporte de cargas, as atividades representam a extração de matéria-prima, o processamento, a estocagem, a venda, a reciclagem, etc. O EUROFORUM (2007) destaca ainda que as cidades necessitam dar suporte à mobilidade de forma a cumprir sua função social e proporcionar crescimento econômico, ao mesmo tempo em que devem buscar limitar o 
crescimento do tráfego motorizado e seus impactos negativos sobre as pessoas e sobre o meio ambiente.

Influenciam a mobilidade fatores como as dimensões do espaço urbano, a complexidade das atividades nele desenvolvidas, a disponibilidade de serviços de transporte e as características da população, especialmente no que diz respeito a questões como renda, faixa etária e gênero. Do mesmo modo, as condições de mobilidade afetam diretamente o desenvolvimento econômico das cidades, a interação social e o bem-estar de seus habitantes (Macário, 2005; Ministério das Cidades, 2006a; ANTP, 2003a).

O aumento da mobilidade, resultado do incremento dos fluxos de pessoas e bens, tem implicado em impactos negativos sobre o ambiente local e global, sobre a qualidade de vida e sobre o desempenho econômico das cidades. Estes impactos incluem congestionamentos, emissão de poluentes, ruído, fragmentação de comunidades, acidentes, uso de energia não-renovável e produção de resíduos sólidos. Para complicar ainda os problemas existentes, as medidas mitigadoras destes impactos têm implicado no aumento dos custos para expansão da infra-estrutura urbana (Bertolini et al., 2008).

Diante dos atuais problemas de transporte, a abordagem tradicional de planejamento baseada na "predição e provisão" não é mais uma opção, uma vez que as incertezas relacionadas ao comportamento da demanda e a dificuldade em atender adequadamente seu crescimento são cada vez maiores. Ao mesmo tempo, a abordagem de gerenciamento da demanda por transportes ou gerenciamento da mobilidade defendida por alguns estudos (ver por exemplo Litman, 2003; VTPI, 2007; MOST, 2003) é também problemática, uma vez que a mobilidade tem se tornado condição essencial para participação ativa na vida econômica e social. Enquanto observa-se um grande interesse em se explorar esta abordagem alternativa de gerenciamento da mobilidade, uma resposta clara ainda não foi encontrada, ampliando a necessidade de se explorar questões relacionadas ao planejamento da mobilidade (Bertolini et al., 2008).

O agravamento dos problemas de transportes e a necessidade de uma nova abordagem para o planejamento da mobilidade têm motivado a adoção dos conceitos de sustentabilidade, resultando em uma série de estudos e documentos, os quais apresentam definições distintas para o tema, ao mesmo tempo em que abordam diferentes questões em sua formulação. Estes conceitos, bem como os principais aspectos abordados nas iniciativas em promover o transporte sustentável, são resumidos a seguir. 


\subsection{Mobilidade Urbana Sustentável}

Os conceitos de sustentabilidade e desenvolvimento sustentável originalmente têm como foco questões ambientais em longo prazo, como a utilização de recursos naturais e degradação ambiental, incluindo questões relacionadas às mudanças climáticas. Fazem a distinção entre crescimento, representado por ganhos quantitativos, e desenvolvimento, representado por ganhos qualitativos, tendo como foco produtos do bem estar social, tais como saúde e desenvolvimento educacional, mais do que o acesso a bens materiais. Uma vez que a sustentabilidade se esforça para proteger os recursos naturais e os sistemas ecológicos, enfatiza a conservação ética e as políticas favoráveis a minimizar o consumo de recursos como ar, água e solo (TRB, 2008).

No que diz respeito às questões de mobilidade, há diversas fontes para a definição de transporte sustentável, impedindo o estabelecimento de uma definição única. A dificuldade em se obter um conceito único está associada, entre outros fatores (Gudmundsson, 2004):

- A idéia de transporte sustentável em si mesma é contestada, uma vez que há um amplo conjunto de metodologias sendo aplicadas para medir vários aspectos do conceito;

- O setor de transportes consiste em uma série de subsistemas técnicos e sociais interagindo para produzir benefícios sociais, ao mesmo tempo em que provocam impactos negativos no meio ambiente;

- O transporte não pode ser visto de forma isolada do resto da sociedade, o que significa que a sustentabilidade dos sistemas de transportes deve ser de fato considerada como parte das mudanças em todo sistema socioeconômico

Ainda que não seja possível identificar uma definição úndica para transporte sustentável, há definições já bastante aceitas e difundidas sobre o tema. Um primeiro conceito trabalhado pela OECD, posteriormente complementado pelo Grupo de Especialistas em Transportes e Meio Ambiente da Comissão Européia e aceito como referência pelo Conselho Europeu de Ministros de Transportes, define como um transporte sustentável aquele que contribui para o bem-estar econômico e social, sem prejudicar a saúde humana e o meio ambiente. Integrando as dimensões social, econômica e ambiental, pode ser definido como aquele que:

- "Permite a satisfação das necessidades básicas de acesso e mobilidade de pessoas, empresas e sociedade, de forma compatível com a saúde humana e o equilíbrio do ecossistema, promovendo igualdade dentro das gerações e entre as mesmas; 
- Possui custos aceitáveis, funciona eficientemente, oferece a possibilidade de escolha do modo de transporte e apóia uma economia dinâmica e o desenvolvimento regional;

- Limita as emissões e os resíduos em função da capacidade da Terra para absorvêlos, utiliza recursos renováveis a um ritmo inferior ou igual a sua renovação, utiliza os recursos não renováveis a um ritmo inferior ou igual ao desenvolvimento de substitutos renováveis e reduz ao mínimo o uso do solo e a emissão de ruído" (OECD, 2000, apud Mourelo, 2002; TRB, 2008).

Estendendo o conceito de desenvolvimento sustentável apresentado pelo Brundtland Report, (WCED, 1987), pode considerar-se que transporte sustentável é aquele que satisfaz as necessidades atuais de transporte sem pôr em perigo a capacidade das futuras gerações em atender estas necessidades (Gudmundsson, 2004; Richardsson, 2005). Além disso, freqüentemente é feita referência ao tripé da sustentabilidade baseado nas dimensões econômica, social e ambiental (World Bank, 1996, TRB, 2001; Gudmundsson, 2004; Richardsson, 2005).

Algumas disciplinas acadêmicas oferecem bases para o estabelecimento de conceitos de transporte sustentável mais específicos, como é o caso das ciências ambientais e das ciências econômicas. Para as ciências ambientais, a sustentabilidade dos sistemas de transportes está relacionada à capacidade de suporte e ao que se denomina de carregamentos críticos. No contexto da ecoeficiência, a sustentabilidade refere-se a um aumento da produção econômica sem um equivalente aumento dos danos ambientais. Para as ciências econômicas, está associada à preservação do capital social. Outros conceitos incluem a necessidade de internalizar os custos ambientais externos nos preços de transportes (Gudmundsson, 2004).

A multiplicidade de definições se reflete também nas diferentes denominações que o conceito de transporte sustentável tem recebido ao redor do mundo e inclusive no Brasil, refletindo preocupações e interesses específicos das comunidades interessadas em desenvolvê-lo. Entre as diferentes denominações encontradas estão: mobilidade sustentável, transporte ambientalmente sustentável, transporte urbano limpo, transporte humano, mobilidade cidadã, mobilidade para todos, entre outros (Ministério das Cidades, 2006a).

No Brasil, a difusão do conceito de mobilidade sustentável tem sido coordenada pelo Ministério das Cidades, através da Secretaria Nacional de Transportes e da Mobilidade Urbana. Conforme a referida Secretaria, mobilidade sustentável é o conjunto de políticas de 
transporte e circulação que visa proporcionar o acesso amplo e democrático ao espaço urbano, através da priorização dos modos de transporte coletivo e não-motorizados de maneira efetiva, socialmente inclusiva e ecologicamente sustentável (ANTP, 2003b; Ministério das Cidades, 2006a; SEMOB, 2008).

Ao mesmo tempo que emergem diferentes definições para mobilidade sustentável, inúmeros aspectos têm sido destacados nas iniciativas em se promover o conceito. Algumas questões incorporadas na definição de transporte sustentável dizem respeito a:

- Maior integração entre as questões econômicas e ambientais na tomada de decisão e a necessidade de maior participação e engajamento dos cidadãos nos processos políticos;

- Mudanças para novas tecnologias e energias alternativas;

- Otimização da logística dos fluxos de transporte;

- Mitigação dos congestionamentos urbanos, poluição do ar e ruído;

- Conservação de recursos e eficiência econômica dos transportes (Gudmundsson 2004).

Para a Comissão das Comunidades Européias (2007), repensar a mobilidade urbana passa por otimizar a utilização de todos os meios de transporte e a integração entre diferentes modos coletivos (trem, bonde, metrô, ônibus, táxi, etc.) e individuais/privados (automóvel, motocicleta, bicicleta e caminhada). Passa igualmente pelo alcance de objetivos comuns de prosperidade econômica e de gestão de transportes como garantia da mobilidade, qualidade de vida e proteção do meio ambiente. Deve ainda conciliar os interesses dos transportes de mercadorias e de passageiros, independentemente do meio de transporte utilizado. Deste modo, para serem eficazes, as políticas de mobilidade urbana devem adotar uma abordagem tão integrada quanto possível, combinando as respostas mais adaptadas a cada problema individual: inovação tecnológica, desenvolvimento de sistemas de transportes não poluentes, seguros e inteligentes, incentivos econômicos e alterações nos sistemas regulatórios (Comissão das Comunidades Européias, 2007).

O EUROFORUM (2007) destaca os principais problemas atuais e desafios futuros da mobilidade urbana no contexto da União Européia:

- Crescimento desigual de diferentes modos de transporte, observado através do predomínio do transporte rodoviário, especialmente para o transporte de passageiros. Modos mais eficientes e ambientalmente amigáveis como o transporte público, bicicleta e caminhada representam uma fatia muito pequena do mercado; 
- Aumento dos congestionamentos nos centros urbanos, resultado do desequilíbrio entre os modos de transporte e do intenso crescimento do transporte rodoviário na Europa, implicando em custos que chegam a 1\% do Produto Interno Bruto;

- Impactos nocivos sobre o meio ambiente e saúde pública, relacionados à emissão de poluentes como partículas sólidas e gases acidificantes pelos sistemas de transportes, emissão de ruído e acidentes de trânsito.

Em função dos aspectos observados, foi definido um conjunto de princípios para a mobilidade urbana nas cidades européias para o ano de 2020 , os quais são resumidos a seguir. Estes princípios refletem, no entanto, a busca de soluções para problemas que são comuns a muitas cidades ao redor do mundo, inclusive cidades brasileiras, podendo ser observados na definição de políticas de mobilidade urbana sustentável em qualquer contexto:

- As cidades devem ser facilmente e igualmente acessíveis para pessoas e bens. Um transporte urbano bem organizado promove a redução da segregação sócioespacial;

- O transporte urbano deve ser desenvolvido dentro de um sistema mais sustentável e voltado ao usuário, oferecendo serviços integrados e infra-estruturas de forma a contribuir para a qualidade de vida e bem-estar da população das cidades;

- Todos os campos do planejamento urbano e desenvolvimento devem ser efetivamente conectados. A principal contribuição deve ser feita através da integração entre o planejamento do desenvolvimento da cidade e uso do solo e o planejamento de transportes e gerenciamento da demanda;

- A poluição do ar relacionada às emissões de tráfego deve ser reduzida graças a um maior equilíbrio modal, integrando transporte público, bicicleta e caminhada, ao aumento do uso do transporte privado compartilhado, aumento da eficiência dos veículos e redução dos congestionamentos;

- Conceitos inovadores e tecnologias devem reduzir a emissão de ruído causado pelo transporte urbano;

- As questões de segurança viária devem ser incorporadas com destaque nas políticas de transporte urbano;

- Deve-se buscar a internalização de todos os custos externos dentro dos sistemas de transporte, de modo a facilitar o estabelecimento de um sistema de preços mais justo para a mobilidade e permitir que a população seja melhor informada para um uso mais eficiente dos sistemas de transporte urbano;

- A taxação da infra-estrutura deve ser vista não apenas como uma taxa, mas também como um custo associado à escassez de um determinado bem; 
- Deve ser dada continuidade à monitoração dos padrões de mobilidade, de estruturas regulatórias e práticas, de performance econômica e ambiental, sobre bases de indicadores comuns e metas mensuráveis em nível europeu. Comparações e pontos de referência com outras cidades devem ser estabelecidos;

- A estrutura regulatória do transporte público deve incentivar a competição e prover incentivos aos operadores para otimizar sua eficiência técnica e o desenvolvimento de iniciativas inovadoras (EUROFORUM, 2007).

Os diversos enfoques no tratamento das questões de mobilidade urbana, somados às especificidades locais, têm resultado no desenvolvimento de iniciativas, estudos e ferramentas para análise e desenvolvimento de ações para a mobilidade com características distintas ao redor do mundo. Considerações sobre algumas das principais iniciativas para a Mobilidade Urbana Sustentável em desenvolvimento são apresentadas a seguir.

\subsubsection{Iniciativas para a Mobilidade Urbana Sustentável}

Iniciativas para promover o conceito de transporte sustentável já são bastante comuns em países desenvolvidos, e começam a emergir em países em desenvolvimento, como é o caso do Brasil. Estas iniciativas são observadas tanto no meio acadêmico, com destaque a estudos, pesquisas, ferramentas de análise, sistemas de indicadores, entre outros, como no meio técnico e profissional, e mais recentemente nas esferas política e administrativa. Neste ultimo caso, merecem destaque políticas nacionais de transporte sustentável e estratégias no nível das cidades, observadas especialmente em países da Europa.

Alguns países da Europa e da América do Norte são pioneiros na pesquisa de um novo conceito de mobilidade e no desenvolvimento e aplicação de indicadores para a monitoração das políticas e estratégias implementadas. Na Europa, o foco principal das medidas desenvolvidas está sobre a integração das questões ambientais nas demais políticas públicas. Nos Estados Unidos, sistemas de indicadores são desenvolvidos em todos os níveis, formalizando os planos e programas e mantendo forte ligação com os objetivos estabelecidos pelo governo. No Canadá, ferramentas para medir a performance de políticas públicas também incluem relatórios sobre desenvolvimento sustentável baseados na observação de indicadores, combinando elementos e estruturas presentes nas experiências da Europa e Estados Unidos (Gudmundsson, 2001).

$\mathrm{Na}$ Europa há ainda uma extensa pesquisa sobre questões de desenvolvimento, planejamento de transportes e uso do solo, tais como TRANSPLUS, ECOCITY, SCATTER, entre outros. O projeto LUTR faz a ligação entre muitos destes projetos (EUROFORUM, 2007). 
No caso do Brasil, o movimento em direção a mobilidade urbana sustentável tem seus primeiros esforços empreendidos pelo Governo Federal. Entre outras iniciativas, merece destaque o programa de treinamento para técnicos e planejadores em nível municipal (vista de forma mais detalhada no Capítulo 7), em que o principal objetivo foi trabalhar um novo conceito de mobilidade inteiramente adaptado à realidade dos municípios onde o curso foi realizado (Silva et al., 2007). Somam-se a esta iniciativa programas como:

- A Plataforma Catarinense de Mobilidade Sustentável, que consiste em um programa do Governo do Estado de Santa Catarina, que conta com a participação das municipalidades, universidades e da sociedade civil organizada, para incentivar e dar suporte ao desenvolvimento de políticas de transporte sustentáveis em cidades catarinenses (DEINFRA, 2008);

- O Projeto MOVIMAN Porto Alegre, financiado pela União Européia e pelo município de Porto Alegre e desenvolvido entre os meses de junho de 2005 a setembro de 2006. O objetivo principal do projeto foi a busca por novas formas de cooperação entre administração pública, empresas locais, empresas de transporte e usuários, com o objetivo de alcançar satisfação eficiente, econômica e ecológica de todas as necessidades inerentes à mobilidade (EPTC, 2006).

A grande quantidade de iniciativas desenvolvidas limita uma análise pormenorizada das mesmas, mesmo que focalizando aquelas desenvolvidas somente nos últimos cinco anos. Deste modo, e de forma a proporcionar uma visão geral do que vem sendo empreendido em matéria de mobilidade sustentável, especialmente na Europa, a Tabela 2.1 apresenta uma relação de estudos, pesquisas e iniciativas de natureza diversa relacionadas ao tema. Algumas destas iniciativas focam em aspectos específicos da mobilidade urbana, tais como: transporte não-motorizado, eficiência energética, novas tecnologias, impactos ambientais, estratégias de gerenciamento da demanda por transportes, entre outros. Abordam ainda questões de integração entre o planejamento de transportes e uso do solo.

Muitas das iniciativas listadas na Tabela 2.1 contemplam sistemas de indicadores para monitoração de aspectos relacionados à sustentabilidade dos sistemas de transportes. Alguns destes sistemas foram utilizados como referência para o estabelecimento de uma base de dados de indicadores de sustentabilidade e mobilidade urbana que auxiliasse na definição de indicadores, conforme será visto no Capítulo 8. 
Tabela 2.1: Estudos e iniciativas sobre transporte e mobilidade sustentável.

\begin{tabular}{|c|c|c|}
\hline Estudo/Iniciativa & Informações & Endereço na Internet \\
\hline Artists & $\begin{array}{l}\text { Projeto da União Européia com o objetivo de melhorar as condições de vias } \\
\text { arteriais em cidades da Europa. }\end{array}$ & $\begin{array}{l}\text { Disponível em: http://www.tft.lth.se/artists/ } \\
\text { Acesso em: } 22 \text { jun. } 2006\end{array}$ \\
\hline \multirow{2}{*}{$\begin{array}{l}\text { Banco Mundial - } \\
\text { Cities on the Move }\end{array}$} & Estratégia de transporte urbano do Bando Mundial. & $\begin{array}{l}\text { Disponível: } \\
\text { http://siteresources.worldbank.org/INTURBANTRANSPORT/Resources/ } \\
\text { portuguese cities on the move.pdf } \\
\text { Acesso em: } 9 \text { out. } 2007 .\end{array}$ \\
\hline & $\begin{array}{l}\text { Estudos de caso sobre experiências em transporte público urbano, incluindo } \\
\text { países da América Latina. }\end{array}$ & $\begin{array}{l}\text { Disponível em: } \\
\text { http://www.worldbank.org/transport/urbtrans/pubtrans.htm } \\
\text { Acesso em: } 9 \text { out. } 2007 .\end{array}$ \\
\hline Civitas & $\begin{array}{l}\text { Iniciativa financiada pela União Européia para auxiliar as cidades a } \\
\text { desenvolverem sistemas de transportes menos poluentes, mais sustentáveis } \\
\text { e eficientes. }\end{array}$ & $\begin{array}{l}\text { Disponível em: http://www.civitas-initiative.org/main.phtml?lan=en } \\
\text { Acesso em: } 10 \text { mar. } 2008 .\end{array}$ \\
\hline Ecocity & $\begin{array}{l}\text { Desenvolvimento urbano direcionado a estruturas adequadas para o } \\
\text { transporte sustentável. }\end{array}$ & $\begin{array}{l}\text { Disponível em: http://www.ecocityprojects.net/ } \\
\text { Acesso em: } 28 \text { jul. } 2008 .\end{array}$ \\
\hline $\begin{array}{l}\text { European Program for } \\
\text { Mobility Management }\end{array}$ & $\begin{array}{l}\text { Rede de governos de países europeus que têm desenvolvido estratégias de } \\
\text { gerenciamento da mobilidade. }\end{array}$ & $\begin{array}{l}\text { Disponível em: http://www.epommweb.org/ } \\
\text { Acesso em: } 28 \text { jul. } 2008 .\end{array}$ \\
\hline \multirow{2}{*}{$\begin{array}{l}\text { European Transport Policy in } \\
2010\end{array}$} & $\begin{array}{l}\text { Livro Branco dos Transportes - Panorama da situação atual dos transportes } \\
\text { na Europa e conjunto de metas estabelecidas para o ano de } 2010 \text {. }\end{array}$ & $\begin{array}{l}\text { Disponível em: } \\
\text { http://ec.europa.eu/transport/white paper/documents/doc/lb texte com } \\
\text { plet pt.pdf } \\
\text { Acesso em: } 10 \text { mar. } 2008 .\end{array}$ \\
\hline & $\begin{array}{l}\text { Livro Verde dos Transportes - definição da política européia em matéria de } \\
\text { mobilidade urbana. }\end{array}$ & $\begin{array}{l}\text { Disponível em: } \\
\text { http://ec.europa.eu/transport/clean/green paper urban transport/doc/2 } \\
0070925 \text { gp urban mobility pt.pdf } \\
\text { Acesso em: } 10 \text { mar. } 2008 \text {. }\end{array}$ \\
\hline Konsult & $\begin{array}{l}\text { Base de informações sobre estratégias de transportes e instrumentos } \\
\text { políticos do Instituto de Estudos de Transportes da Universidade de Leeds, } \\
\text { Reino Unido. }\end{array}$ & $\begin{array}{l}\text { Disponível em: http://www.socscinet.com/transport/konsult/ } \\
\text { Acesso em: } 28 \text { jul. } 2008 .\end{array}$ \\
\hline LUTR & $\begin{array}{l}\text { Conecta diferentes projetos na área de mobilidade urbana sustentável, } \\
\text { incluindo uso do solo, transportes e meio ambiente. }\end{array}$ & $\begin{array}{l}\text { Disponível em: http://www.lutr.net/ } \\
\text { Acesso em: } 28 \text { jul. } 2008\end{array}$ \\
\hline Mobidays & $\begin{array}{l}\text { Projeto promovido pela União Européia com objetivo de analisar alguns } \\
\text { projetos financiados pela mesma e verificar sua aplicação no mercado, além } \\
\text { de promover a disseminação de seus resultados. }\end{array}$ & $\begin{array}{l}\text { Disponível em: http://www.mobidays.eul } \\
\text { Acesso em: } 28 \text { jul. } 2008\end{array}$ \\
\hline Moses & $\begin{array}{l}\text { Projeto com o objetivo de desenvolver serviços de mobilidade para reduzir a } \\
\text { dependência ao automóvel privado em escala européia, sem restrição da } \\
\text { mobilidade. }\end{array}$ & $\begin{array}{l}\text { Disponível em: http://www.ist-world.org/ } \\
\text { Acesso em: } 28 \text { jul. } 2008\end{array}$ \\
\hline Niches & $\begin{array}{l}\text { Projeto que visa facilitar a coordenação de atividades de pesquisa acadêmica } \\
\text { por parte de instituições, indústria, operadores e autoridades de transporte na } \\
\text { área de conceitos inovadores de transporte urbano. }\end{array}$ & $\begin{array}{l}\text { Disponível em:www.niches-transport.org } \\
\text { Acesso em: } 28 \text { jul. } 2008\end{array}$ \\
\hline PAGENOME-COMPASS & $\begin{array}{l}\text { Compass (ou Comprehensive Public Administration Support System) é uma } \\
\text { wiki, ou coleção de páginas na Internet, desenvolvida no contexto do Public }\end{array}$ & $\begin{array}{l}\text { Disponível em: http://pagenome-compass.pbwiki.com/ } \\
\text { Acesso em: } 10 \text { mar. } 2008 .\end{array}$ \\
\hline
\end{tabular}


comportamento da administração pública é similar ao funcionamento dos

genes humanos.

\begin{tabular}{|c|c|c|}
\hline Pilot & $\begin{array}{l}\text { Projeto europeu que apresenta a preparação dos planos de transporte urbano } \\
\text { sustentável das cidades de Braila, Évora, Lancaster e Tallinn. }\end{array}$ & $\begin{array}{l}\text { Disponível em: http://www.pilot-transport.org/ } \\
\text { Acesso em: } 28 \text { jul. } 2008 .\end{array}$ \\
\hline Plume & $\begin{array}{l}\text { Construído com base em outros projetos existentes em nível europeu, } \\
\text { enfatiza questões de uso do solo e planejamento da mobilidade, envolvendo } \\
\text { governos nacionais, usuários e especialistas. }\end{array}$ & $\begin{array}{l}\text { Disponível em: http://www.ist-world.org/ } \\
\text { Acesso em: Acesso em: } 28 \text { jul. } 2008 .\end{array}$ \\
\hline Propolis & $\begin{array}{l}\text { Pesquisa sobre políticas de transportes e uso do solo para promover a } \\
\text { sustentabilidade urbana. }\end{array}$ & $\begin{array}{l}\text { Disponível em: http://www1.wspgroup.fi/lt/propolis/ } \\
\text { Acesso em: } 22 \text { mar. } 2007 .\end{array}$ \\
\hline Prospects & $\begin{array}{l}\text { Tem por objetivo de auxiliar autoridades a responderem aos desafios da } \\
\text { "Política Comum de Transporte" que visa promover a mobilidade sustentável } \\
\text { em cidades européias. }\end{array}$ & $\begin{array}{l}\text { Disponível em: http://www ivv.tuwien.ac.at/projects/prospects.html } \\
\text { Acesso em: } 22 \text { mar. } 2007 .\end{array}$ \\
\hline Scatter & $\begin{array}{l}\text { Tem por objetivo avaliar os mecanismos e efeitos associados ao } \\
\text { espalhamento urbano, avaliar medidas com o objetivo de reduzir o } \\
\text { espalhamento urbano e auxiliar as cidades no desenvolvimento de políticas. }\end{array}$ & $\begin{array}{l}\text { Disponível em: http://scatter.stratec.be/ } \\
\text { Acesso em: } 28 \text { jul. } 2008 .\end{array}$ \\
\hline Summa & $\begin{array}{l}\text { Tem como foco a operacionalização do conceito de mobilidade sustentável e } \\
\text { a avaliação de políticas relacionadas a aspectos econômicos, sociais e } \\
\text { ambientais da sustentabilidade. }\end{array}$ & $\begin{array}{l}\text { Disponível em: http://www.summa-eu.org/ } \\
\text { Acesso em: } 21 \text { mar. } 2007 .\end{array}$ \\
\hline $\begin{array}{l}\text { Sustainable Development } \\
\text { Gateway }\end{array}$ & $\begin{array}{l}\text { Portal do Instituto Internacional para o desenvolvimento sustentável com } \\
\text { estudos e projetos sobre transporte sustentável. }\end{array}$ & $\begin{array}{l}\text { Disponível em: http://www.sdgateway.net/topics/111.htm } \\
\text { Acesso em: } 28 \text { jul. } 2008 .\end{array}$ \\
\hline Sutra & $\begin{array}{l}\text { Tem por objetivo desenvolver uma abordagem e metodologia consistente } \\
\text { para análise dos problemas de transporte e auxiliar no desenvolvimento de } \\
\text { estratégias de desenvolvimento sustentável. }\end{array}$ & $\begin{array}{l}\text { Disponível em: http://www.ess.co.at/SUTRA/ } \\
\text { Acesso em: } 23 \text { mar. } 2007 .\end{array}$ \\
\hline $\begin{array}{l}\text { The Online TDM } \\
\text { Encyclopedia }\end{array}$ & $\begin{array}{l}\text { Extensa relação de fontes de dados e informações sobre transportes em nível } \\
\text { internacional, especialmente na Europa, Ásia e América do Norte. }\end{array}$ & $\begin{array}{l}\text { Disponível em: http://www.vtpi.org/tdm/tdm80.htm } \\
\text { Acesso em: } 11 \text { mar. } 2008 .\end{array}$ \\
\hline Transplus & $\begin{array}{l}\text { Tem por objetivo identificar boas práticas na organização dos transportes e } \\
\text { uso do solo visando reduzir a dependência do automóvel em cidades } \\
\text { européias. }\end{array}$ & $\begin{array}{l}\text { Disponível em: http://www.transplus.net/ } \\
\text { Acesso em: } 23 \text { mar. } 2007 .\end{array}$ \\
\hline $\begin{array}{l}\text { UITP Mobility in Cities } \\
\text { Database }\end{array}$ & $\begin{array}{l}\text { Base de dados sobre mobilidade da Associação Internacional de Transporte } \\
\text { Público. }\end{array}$ & $\begin{array}{l}\text { Disponível em: http://uitp.org/publications/MCD2-order/ } \\
\text { Acesso em: } 28 \text { jul. } 2008 .\end{array}$ \\
\hline $\begin{array}{l}\text { UN (Sustainable } \\
\text { Development Case Studies) }\end{array}$ & $\begin{array}{l}\text { Estudos de caso sobre desenvolvimento sustentável das Nações Unidas, que } \\
\text { inclui estudos e referências sobre transporte e mobilidade. }\end{array}$ & $\begin{array}{l}\text { Disponível em: } \\
\text { http://webapps01.un.org/dsd/caseStudy/public/Welcome.do } \\
\text { Acesso em: } 28 \text { jul. } 2008 .\end{array}$ \\
\hline Urbamove & $\begin{array}{l}\text { Agenda para a mobilidade urbana na Europa da Conferência Européia de } \\
\text { Institutos de Pesquisa de Transportes. }\end{array}$ & $\begin{array}{l}\text { Disponível em: http://www.lara.prd.fr/docu/UrbamoveFinal.pdf } \\
\text { Acesso em: Acesso em: } 28 \text { jul. } 2008 .\end{array}$ \\
\hline $\begin{array}{l}\text { World Business Council for } \\
\text { Sustainable Development } \\
\text { (Sustainable Mobility) }\end{array}$ & $\begin{array}{l}\text { Publicações e estudos de caso do Conselho Mundial de Negócios para o } \\
\text { Desenvolvimento Sustentável sobre transportes e mobilidade. }\end{array}$ & $\begin{array}{l}\text { Disponível em: http://www.wbcsd.org/ } \\
\text { Acesso em: } 21 \text { mar. } 2007 .\end{array}$ \\
\hline
\end{tabular}




\subsection{Mobilidade, Sustentabilidade e Qualidade de Vida Urbana}

Ainda que a disponibilidade de transporte seja fundamental para o desenvolvimento das atividades urbanas, não só o acesso físico aos diferentes modos e tecnologias determina as condições de mobilidade nas cidades. Especialmente nas grandes áreas urbanas, inúmeras situações hoje experimentadas acabam por refletir em problemas de mobilidade para seus habitantes, cabendo citar:

- A precariedade da infra-estrutura urbana, onde a ausência de passeios públicos, iluminação adequada e a insuficiência dos equipamentos de drenagem acabam por trazer problemas para a circulação de pedestres e veículos. Todos estes fatores causam desconforto para motoristas e pedestres, além de congestionamentos de tráfego e acidentes;

- A apropriação ilegal do espaço público, seja por ambulantes, bares ou estabelecimentos comerciais em geral, que traz prejuízos para a circulação de pedestres e pessoas com restrição de mobilidade;

- A ausência de arborização urbana, com conseqüente perda da qualidade ambiental, contribuindo para a criação de espaços pouco atrativos para pedestres;

- As deficiências ou ausência de planejamento urbano e a má organização das cidades, com o conseqüente aumento dos tempos de deslocamento e dos custos de transporte, além da necessidade de maiores investimentos em infra-estrutura urbana para atender a crescente demanda por transporte individual.

Em função destes aspectos, pode-se dizer que os problemas de mobilidade são multidimensionais e não envolvem exclusivamente questões ligadas ao acesso aos meios de transporte. Estes envolvem também questões mais complexas do cotidiano, além de aspectos ligados ao planejamento físico e organização das cidades. Todos estes fatores exercem, por sua vez, influência direta sobre a sustentabilidade das cidades. Em última análise, pode-se referir que os problemas de mobilidade, segundo diversas formas e dimensões têm contribuído para o declínio da qualidade de vida da população das cidades.

Segundo Ferraz e Torres (2001), as atividades comerciais, industriais, educacionais, recreativas, entre outras, que são essenciais à vida nas cidades modernas, somente são possíveis com o deslocamento de pessoas e de produtos. Assim, o transporte urbano é tão importante para a qualidade de vida da população quanto os serviços de abastecimento de água, coleta de esgoto, fornecimento de energia elétrica e telefonia. Em função destes aspectos, proporcionar uma mobilidade adequada para todas as classes sociais se constitui 
em uma ação essencial para o processo de desenvolvimento econômico e social das cidades.

Para Hall e Pfeiffer (2000), algumas questões relacionadas à sustentabilidade urbana têm sido amplamente discutidas, incluindo questões relacionadas aos transportes e à mobilidade. Neste sentido as preocupações concentram-se em torno da sustentabilidade ambiental, em virtude dos atuais níveis de congestionamento e poluição inaceitáveis, resultado da explosão do uso do automóvel privado. Outras questões dizem respeito à provisão de redes de transporte público adequadas, redistribuição dos empregos e serviços visando à redução dos deslocamentos e controle do crescimento urbano.

No que se refere à relação entre mobilidade e sustentabilidade urbana, as cidades que implementam políticas de mobilidade sustentável garantem maior dinamismo das funções urbanas, maior e melhor circulação de pessoas e mercadorias. Todos estes aspectos se traduzem na valorização do espaço público, na sustentabilidade e no desenvolvimento econômico e social da cidade (IBAM e Ministério das Cidades, 2005)

Para Pereira et al. (2004) a melhoria da qualidade de vida nas cidades passa também pela promoção de um transporte mais humano e eficiente. Para estes autores, um transporte desorganizado ou mal planejado pode se tornar um problema de grandes proporções, levando as cidades a situações insuportáveis, onde a deterioração acentuada dos sistemas de transportes existentes pode levar à perda da qualidade de vida e aumento significativo do custo de vida nas cidades.

Para o ITRANS (2004), o acesso às oportunidades de emprego, aos locais de moradia e de oferta de muitos serviços essenciais depende das condições de transporte. Em outras palavras, os problemas de mobilidade podem ser, com freqüência, agravantes da exclusão social e da pobreza.

Para Gomide (2003) a existência de um serviço de transporte coletivo acessível, eficiente e de qualidade, pode aumentar a disponibilidade de renda e tempo dos mais pobres, propiciar o acesso aos serviços sociais básicos e às oportunidades de trabalho. Neste sentido, estratégias de combate à exclusão social devem, fundamentalmente, garantir o amplo acesso aos serviços públicos essenciais, entre eles o transporte coletivo.

Os múltiplos aspectos identificados pelos vários autores e estudos evidenciam os impactos que a mobilidade tem sobre a dinâmica e desenvolvimento das cidades. No entanto, em função dos graves problemas que tem apresentado e das limitações que vem impondo à realização das atividades diárias dos cidadãos e das empresas, a mobilidade tem sido hoje 
fator determinante para o declínio da qualidade de vida e insustentabilidade das cidades brasileiras. Questões como a baixa qualidade do transporte coletivo; dissociação entre o planejamento de transportes e o planejamento urbano; consumo excessivo de tempo e de recursos e imposição de barreiras físicas que dificultam à acessibilidade são algumas das faces dos problemas atuais de mobilidade na grande maioria das cidades.

Segundo o Ministério das Cidades (2006b) tal situação tem raízes sociais, políticas e econômicas. No entanto, as políticas adotadas até o presente momento têm sido as principais responsáveis pelos problemas diagnosticados. Neste sentido, o próximo capítulo tem como objetivo discutir os mecanismos que conduziram aos atuais padrões de mobilidade urbana, dando destaque ao processo de gestão vigente até o momento e o novo paradigma que se apresenta em desenvolvimento no país. 


\section{PLANEJAMENTO E GESTÃO DA MOBILIDADE URBANA NO BRASIL}

Neste capítulo são tratados aspectos referentes ao desenvolvimento e ao planejamento dos transportes no Brasil, buscando fazer um paralelo entre a abordagem tradicional de tratamento das questões de mobilidade urbana e o novo paradigma.

\subsection{Histórico}

De um modo geral, no Brasil, até o presente momento, a questão da mobilidade urbana foi tratada essencialmente como uma questão de provisão de serviços de transporte, conforme já mencionado no Capítulo 1. Segundo Andrade et al. (2005), compatibilizar a oferta de transportes com a demanda, tanto para o transporte de passageiros como para o de bens, foi considerado até então o problema central do planejamento de transportes.

O livro "Transportes no Brasil: História e Reflexões" (GEIPOT, 2001) apresenta uma análise detalhada sobre a evolução do planejamento de transportes no Brasil, desde o período colonial até anos mais recentes. Esta análise é sintetizada aqui a partir da Primeira República, período onde efetivamente começaram a ser desenvolvidas as redes de transporte urbano no país.

Na Primeira República, período entre os anos de 1889 e 1930, as cidades aceleraram seu crescimento populacional, impulsionadas pelo fim da escravidão e pela imigração. As transformações ocorridas obrigaram o governo a atender as demandas por serviços essenciais como eletricidade, iluminação pública, abastecimento de água, coleta de esgoto, gás, telefone e também transporte público. O objetivo foi a substituição das redes de bondes puxados a burro por bondes elétricos, mais rápidos, amplos e confortáveis, o que exigiu recorrer ao capital estrangeiro, uma vez que os investimentos eram significativos. Nessa época também se instalou e consolidou a concorrência dos ônibus, que passaram a competir com os bondes. A principal característica do transporte público desse período foi a 
forte concentração por qual passou o setor, levando em muitas situações ao monopólio da prestação dos serviços.

As décadas de trinta e quarenta do século XX representaram o declínio dos serviços de bondes e a ascensão dos ônibus. Em função da rápida expansão dos núcleos urbanos, muitas áreas ficaram desprovidas de atendimento pelos bondes, pois sua rede não conseguia atender ao ritmo de crescimento urbano. Nesse período começou a se sobressair a cultura do automóvel e do ônibus, iniciando uma corrida dos administradores urbanos para a construção de novas vias de circulação como forma de suprir a demanda crescente provocada pelo aumento significativo do número de automóveis em circulação. Essa demanda era muitas vezes atendida com o sacrifício de diversos aspectos relacionados com a qualidade de vida urbana.

No período após a Segunda Guerra Mundial, nas décadas de quarenta e cinqüenta do século passado, a urbanização toma um novo impulso com a industrialização das cidades, que atraiu uma grande parcela de migrantes do campo. No que tange aos transportes, destaca-se a relativa omissão do poder público frente aos serviços públicos de transporte e as políticas em prol do automóvel. No campo da infra-estrutura, uma parcela considerável de recursos foi canalizada para a construção de estradas. Já no campo industrial, o governo elevou a implantação de uma indústria automobilística à máxima prioridade, de forma a suprir a procura emergente.

Estando o governo federal e os governos estaduais ausentes no campo dos transportes urbanos e não havendo nenhuma diretriz nacional para o trato institucional dos serviços, as diferentes municipalidades foram construindo suas próprias histórias. Algumas tentaram impor uma operadora pública principal, inclusive fazendo grandes investimentos em novos sistemas de trolebus. Outras, reconheceram a força dos pequenos operadores privados, tentando conduzí-los para uma estrutura mais moderna e profissional. Outra das opções adotada foi conceder os serviços a grandes e modernas empresas operadoras, e uma última foi deixar os serviços ao sabor dos acontecimentos, assumindo uma evolução espontânea.

Durante o Regime Militar, desde o final dos anos 1960 até meados dos anos 1980, as principais cidades brasileiras atingiram seu ápice de crescimento, se transformando em grandes aglomerações urbanas que extravasavam os limites dos municípios iniciais. Este crescimento se refletiu no aumento dos problemas de mobilidade urbana, sendo que a maior parte da população tornou-se dependente da oferta de meios de transporte coletivo.

Neste contexto, o triunfo do automóvel e de sua modalidade coletiva, o ônibus, foi completo. "Humanizar" as cidades e tratar de seus problemas de transporte passou a ser interpretado 
como provê-las com redes de vias expressas, viadutos e túneis. Apesar de algumas cidades terem elaborado algum plano diretor mais abrangente de vias expressas (como foi o caso do Rio de Janeiro em 1965), sua construção raramente seguiu um esquema mais sistêmico de planejamento de transportes. As obras foram surgindo aproveitando as oportunidades e conveniências das políticas locais, ao ponto de diversos municípios de uma mesma conurbação urbana apresentarem projetos conflitantes. Mal programadas, especialmente no que diz respeito aos aspectos de financiamento, freqüentemente estas obras sofriam descontinuidade em sua implantação.

A situação sofreu uma rápida virada em 1973, com a primeira crise do petróleo, o que implicou no reconhecimento por parte do governo federal da fragilidade do modelo rodoviarista e da importância do transporte coletivo para amenizar esta dependência. No final do ano de 1973 o GEIPOT (criado em 1965 com a denominação de Grupo Executivo de Integração da Política de Transportes, com o objetivo de prestar apoio técnico e administrativo aos órgãos do Poder Executivo em matéria de transportes) elaborou o primeiro documento que tratou da questão dos transportes urbanos em termos nacionais. Este abordou o tema enfatizando o disciplinamento dos espaços urbanos, a racionalização do uso das infra-estruturas de transportes, a inclusão do transporte urbano no Plano Nacional de Viação, bem como, identificou a necessidade de criação de órgãos específicos para gerenciar os transportes urbanos. Assim, pela primeira vez o transporte urbano entra no rol de preocupações do governo federal, viabilizando uma série de iniciativas que provocaram melhorias nos deslocamentos urbanos, sobretudo da população mais pobre.

Após a década de 1970, os planos de transporte foram os principais instrumentos empregados na gestão do transporte urbano. Tais esforços foram coordenados pelo governo federal, por meio do GEIPOT e da Empresa Brasileira de Transportes Urbanos (EBTU). Deste período destacam-se: a ação pública federal no tratamento das questões do transporte urbano; a disseminação de uma cultura de planejamento de transportes; a implantação de vários órgãos de gestão do transporte nos municípios e a formação de um quadro de dirigentes públicos e técnicos (GEIPOT, 2001; Ministério das Cidades, 2006b).

A ênfase dada à provisão de infra-estrutura para o transporte rodoviário, a priorização do transporte individual em detrimento do coletivo, a desconsideração dos modos nãomotorizados e a total desarticulação entre o planejamento urbano e de transportes marcaram o modelo de planejamento vigente nesta época. Somaram-se a estes o desperdício de recursos financeiros, a falta de controle social e a desconsideração das questões ambientais no planejamento dos transportes urbanos no Brasil. Este modo de pensar, focado essencialmente na disponibilidade de serviços e infra-estrutura de 
transportes, implicou em um modelo de atuação baseado na elaboração de planos viários e de transporte público, muitas vezes desarticulados entre si e sem continuidade, resultado das alterações ocorridas em virtude de mudanças nas administrações municipais.

Entrando na fase da crise dos anos 1980, pode-se dizer que o planejamento de transportes não parou, mas foi adaptado a circunstâncias menos favoráveis a grandes investimentos.

O que se pode concluir, ainda segundo o GEIPOT (2001), é que o hiato entre o planejamento urbano e de transportes raramente conseguiu ser fechado. O máximo de aproximação que se conseguiu entre o planejamento urbano e de transportes foi contemplar prognósticos de uso do solo para fins de previsão da demanda por transportes e incluir os principais eixos de transporte nos planos municipais. Contudo, o tratamento dado à circulação era secundário. Do mesmo modo, poucas cidades conseguiram manter a cultura do planejamento sistêmico de transportes e, menos ainda, aplicaram seus resultados de forma consistente.

Para Bertolini et al. (2008), há uma persistente separação entre transportes e uso do solo nos processos de planejamento urbano, demandando uma abordagem integrada. Ao contrário do amplo consenso a respeito do tema no meio acadêmico e profissional, observase na prática pouca integração entre transporte e uso do solo. O resultado são políticas inconsistentes que carecem de maior integração.

A pluralidade e o conseqüente agravamento dos problemas de mobilidade urbana resultantes deste modo fragmentado de planejar as cidades e seus sistemas de transportes têm estimulado a revisão dos conceitos vigentes e o desenvolvimento de um novo paradigma para a mobilidade urbana, o qual começa também a ser observado no Brasil.

\subsection{A Mobilidade Segundo as Novas Políticas Urbanas}

O novo paradigma da mobilidade urbana no Brasil tem suas bases na Constituição Federal de 1988, que pela primeira vez incorporou um capítulo sobre política urbana no texto constitucional (Capítulo II, Artigos 182 e 193). Segundo a Constituição Federal, é da responsabilidade do município executar a política de desenvolvimento urbano, conforme diretrizes gerais fixadas em lei, com o objetivo de ordenar o pleno desenvolvimento das funções sociais da cidade e garantir o bem-estar de seus habitantes. Ainda, estabelece a obrigatoriedade de elaboração do Plano Diretor para cidades com mais de 20 mil habitantes, que deve se constituir no instrumento básico da política de desenvolvimento e expansão urbana. Define ainda o serviço de transporte coletivo como um serviço público de caráter essencial, de responsabilidade dos municípios. 
Embora a Constituição Federal tenha lançado as bases para o debate em torno da política urbana no país é, no entanto, através do Estatuto das Cidades (Lei Federal N 10.257 de 2001 que regulamenta os artigos 182 e 183 da Constituição Federal) e da criação do Ministério das Cidades em 2003, que as questões de integração entre o planejamento urbano e de transportes começaram a ser amplamente discutidas no país.

O Estatuto das Cidades, juntamente com a Medida Provisória $N^{0}$ 2.220/01 (que dispõe sobre a concessão de uso especial definida no artigo 183 da Constituição Federal) dá as diretrizes para a política urbana do país, nos níveis federal, estadual e municipal. Esse Estatuto visa garantir o cumprimento da função social da propriedade urbana e a justa distribuição dos ônus e benefícios da urbanização, e reafirma o Plano Diretor como instrumento básico da política de desenvolvimento e expansão urbana.

O Estatuto engloba um conjunto de princípios - através dos quais se expressa uma concepção de cidade e respectivos processos de planejamento e gestão urbanos - e uma série de instrumentos que são meios para atingir as finalidades desejadas. Entretanto, delega aos municípios, a partir de um processo público e democrático, a explicitação clara destas finalidades (Santoro e Cymbalista, 2001).

O artigo 41 do Estatuto estabelece a obrigatoriedade de existência de um Plano de Transporte Integrado para as cidades com mais de 500 mil habitantes, o qual deve fazer parte do Plano Diretor Municipal, ou ser compatível com o mesmo. Esta disposição foi complementada pela Resolução $\mathrm{N}^{0} 34$ de 01 de julho de 2005, do Conselho das Cidades, onde a denominação do Plano de Transporte Urbano Integrado foi alterada para Plano Diretor de Transportes e Mobilidade, ou simplesmente PlanMob (IBAM e Ministério das Cidades, 2005).

O Plano Diretor de Transporte e Mobilidade é definido como "um instrumento da política de desenvolvimento urbano, integrado ao Plano Diretor do município, da região metropolitana ou da região integrada de desenvolvimento, contendo diretrizes, instrumentos, ações e projetos voltados a proporcionar o acesso amplo e democrático às oportunidades que a cidade oferece, através do planejamento da infra-estrutura de mobilidade urbana, dos meios de transporte e seus serviços, possibilitando condições adequadas ao exercício da mobilidade da população e da logística de distribuição de bens e serviços" (Ministério das Cidades, 2006b)

A Resolução $\mathrm{N}^{0} 34$ estabeleceu também os princípios e diretrizes gerais a serem observadas na elaboração dos Planos de Mobilidade, assim definidos: 
- "I-Garantir a diversidade das modalidades de transporte, respeitando as características das cidades, priorizando o transporte coletivo, que é estruturante, sobre o individual, os modos não motorizados e valorizando o pedestre;

- II - Garantir que a gestão da Mobilidade Urbana ocorra de modo integrado com o Plano Diretor Municipal;

- III - Respeitar as especificidades locais e regionais;

- IV - Garantir o controle da expansão urbana, a universalização do acesso à cidade, a melhoria da qualidade ambiental, e o controle dos impactos no sistema de mobilidade gerados pela ordenação do uso do solo" (Ministério das Cidades, 2006b).

Através da elaboração do PlanMob busca-se consolidar um novo conceito de planejamento da mobilidade, com escopo ampliado, que deve ser incorporado pelos municípios. Neste sentido, o PlanMob apresenta características fundamentais, que o tornam distinto dos planos de transporte tradicionais. Entre essas características estão: a consideração da dimensão estratégica da gestão da mobilidade urbana, principalmente no que diz respeito aos aspectos institucionais e de financiamento; a abordagem adequada dos conflitos sociais de apropriação dos espaços públicos ou de mercado, e ampla participação popular em todas as suas etapas (Ministério das Cidades, 2006b).

O PlanMob constitui assim o instrumento de efetivação da política de mobilidade urbana, estabelecendo diretrizes, instrumentos, ações e projetos voltados à organização dos espaços de circulação e dos serviços de trânsito e transporte público. Este instrumento deve estar de acordo com as diretrizes da Política Nacional de Mobilidade Urbana, a qual vem sendo construída pelo Ministério das Cidades no contexto da Política Nacional de Desenvolvimento Urbano (PNUD).

O Ministério das Cidades, criado em 2003, concentrou em uma única Pasta as políticas públicas de trânsito e transporte urbano que, até então, encontravam-se dispersas, articulando também outras políticas setoriais essenciais para o desenvolvimento urbano do ponto de vista econômico, social e estratégico. O Ministério está estruturado em quatro Secretarias Nacionais denominadas de Habitação, Saneamento Ambiental, Transporte e Mobilidade Urbana e Programas Urbanos; um Departamento Nacional de Trânsito (DENATRAN) e duas empresas públicas, a Companhia Brasileira de Trens Urbanos (CBTU) e a Empresa de Trens Urbanos de Porto Alegre SIA (TRENSURB), que se constituem na estrutura para o desenvolvimento e a condução da PNUD (Ministério das Cidades, 2006b).

Dentro da PNDU preconizada pelo Ministério das Cidades, a Política Nacional de Mobilidade Urbana (PNMU) se configura no instrumento para difusão do conceito de mobilidade urbana 
sustentável considerado pelo Ministério das Cidades e pela Secretaria Nacional de Transporte e Mobilidade Urbana (SEMOB). A PNMU está fundamentada nos seguintes princípios, conforme o artigo 5 do Projeto de Lei $N^{0} 1.687 / 2007$ :

- "I - acessibilidade universal;

- II - desenvolvimento sustentável das cidades, nas dimensões socioeconômicas e ambientais;

- III - eqüidade no acesso dos cidadãos ao transporte público coletivo;

- IV - eficiência, eficácia e efetividade na prestação dos serviços de transporte urbano;

- V - transparência e participação social no planejamento, controle e avaliação da política de mobilidade urbana;

- $\mathrm{VI}$ - segurança nos deslocamentos das pessoas;

- VII - justa distribuição dos benefícios e ônus decorrentes do uso dos diferentes meios e serviços; e

- VIII - eqüidade no uso do espaço público de circulação, vias e logradouros" (Ministério das Cidades, 2007a).

A PNMU é orientada pelas seguintes diretrizes, conforme o artigo 6 do Projeto de Lei $\mathrm{N}^{0} 1.687 / 2007$ :

- "I - integração com as políticas de uso do solo e de desenvolvimento urbano;

- II - prioridade dos meios não-motorizados sobre os motorizados, e dos serviços de transporte coletivo sobre o transporte individual motorizado;

- III - complementaridade entre os meios de mobilidade urbana e os serviços de transporte urbano;

- IV - mitigação dos custos ambientais, sociais e econômicos dos deslocamentos de pessoas e bens na cidade;

- V - incentivo ao desenvolvimento científico-tecnológico e ao uso de energias renováveis e não-poluentes; e

- VI - priorização de projetos de transporte coletivo estruturadores do território e indutores do desenvolvimento urbano integrado" (Ministério das Cidades, 2007a).

Além das diretrizes da PNMU e dos princípios defendidos pelo Ministério das Cidades por meio da SEMOB, os municípios contam ainda com uma série de instrumentos legais orientadores utilizados como guia para a implementação de sua política urbana, cabendo destacar:

- Lei de Uso e Ocupação do Solo, que define a localização das diferentes funções urbanas; 
- Operações Urbanas, utilizadas para reestruturar o uso e ocupação do solo de acordo com problemas identificados no âmbito urbanístico ou social;

- Controle de Pólos Geradores de Tráfego, através da análise de projetos arquitetônicos e estudos de impacto sobre o sistema viário de acesso e entorno (Ministério das Cidades, 2006a).

\subsection{Desafios da Política Nacional de Mobilidade Urbana}

O Ministério das Cidades busca, portanto, estabelecer um modelo de referência para a organização da mobilidade urbana, deixando aos níveis de governo estaduais, metropolitanos e municipais a liberdade necessária para configurar seus sistemas de mobilidade. Ao Governo Federal cabe o papel de estruturar e articular as diversas políticas públicas, e orientar de forma estratégica o sistema de mobilidade através da PNMU. Aos municípios, conurbações ou regiões metropolitanas cabe fixar estratégias para seus sistemas de mobilidade em conformidade com a política nacional, bem como 0 desenvolvimento de planos adequados às necessidades de seus cidadãos.

Desta forma, o conjunto de princípios orientadores da PNMU deve servir como um guia para os municípios, auxiliando na gestão da mobilidade urbana. No entanto, cada cidade possui particularidades que limitam a elaboração de uma solução única para enfrentar os problemas de mobilidade. Assim, as políticas formuladas devem levar em consideração tais peculiaridades para definir suas diretrizes. Isto significa que em um país como o Brasil, onde as diferenças econômicas, sociais e de estruturação dos sistemas de mobilidade dos municípios são acentuadas, os planos de mobilidade deverão assumir características distintas, e deverão adaptar os respectivos conceitos ao contexto social e às necessidades e potencialidades de cada zona urbana.

Para IBAM e Ministério das Cidades (2005) as diferentes situações que apresentam as cidades brasileiras em termos de suas características regionais, história, tamanho da população e desenvolvimento institucional resultam, por sua vez, em uma grande diversidade de modos e condições de mobilidade. Assim, para cada município há, portanto, diferentes formas de se adaptar e reger o Estatuto das Cidades, bem como as diretrizes da PNMU.

Com base nestes fatores, a construção do conceito de mobilidade urbana sustentável no nível dos municípios, bem como o processo de elaboração de políticas públicas para sua efetivação, se constitui em um problema complexo e multidimensional. Isto porque engloba um número extenso de variáveis, envolve a participação de diferentes atores e pode 
apresentar diferenças significativas de um município para outro em função dos aspectos ora analisados.

Deste modo, para a maior compreensão dos elementos que o estruturam e a forma como estes interagem entre si em contextos geográficos distintos, pode-se dispor de metodologias e ferramentas auxiliares concebidas para facilitar a sistematização de idéias e tornar mais efetiva e prática a atividade de planejamento e tomada de decisão. Entre as ferramentas utilizadas, as metodologias de apoio à decisão podem orientar as investigações e contribuir para a sistematização das estratégias e ações identificadas nos diferentes municípios analisados. Contudo, estas ferramentas ainda não se encontram totalmente disseminadas entre os diversos decisores e técnicos envolvidos na definição e execução de medidas no âmbito da mobilidade urbana sustentável.

Assim, a capacitação dos técnicos deve ser uma das prioridades para se garantir que o processo em curso poderá alcançar os objetivos preconizados. Por outro lado, a utilização de ferramentas que permitem identificar qual a condição de mobilidade de uma zona urbana, estruturada de acordo com as várias dimensões em análise, e os ganhos decorrentes de determinadas intervenções, associadas a opções estratégicas, é um aspecto fundamental para que os agentes de decisão e a população em geral se envolvam diretamente em aspectos de planejamento e gestão urbana, que normalmente estão apenas acessíveis a técnicos e especialistas. 


\section{METODOLOGIAS DE APOIO À DECISÃO}

Neste capítulo são discutidos alguns aspectos relacionados à tomada de decisão e às metodologias de apoio a tomada de decisão, bem como sua aplicação no planejamento de transportes e da mobilidade. Destaque especial é dado a Metodologia Multicritério de Apoio à Decisão - Construtivista, a qual serve no presente trabalho como base para o método aplicado nas cidades brasileiras para identificação dos conceitos-chave relacionados à mobilidade urbana sustentável.

\subsection{Aspectos Gerais}

Bana e Costa (2001) define como apoio à decisão a atividade, suportada por modelos mais ou menos formalizados, com o objetivo de elaborar recomendações que respondam o mais objetivamente possível às questões que se colocam aos agentes de decisão, facilitando a construção e a avaliação de alternativas. As metodologias multicritério de decisão, por sua vez, auxiliam na interação entre atores para a construção de uma estrutura e uma linguagem de comunicação partilhada por todos. Servem de guia para a criação de novas oportunidades de ação para atender a objetivos estratégicos, dando suporte para a avaliação e comparação de opções e o estabelecimento de compromissos entre diferentes organizações e sistemas de valores.

O autor define ainda análise de decisão, como o desenvolvimento e aplicação de metodologias e técnicas para ajudar a melhorar as tomadas de decisões em organizações públicas e privadas, na indústria e nos serviços, em contextos que envolvem: incerteza, risco, múltiplos objetivos, avaliação de estratégias e alternativas, alocação de recursos, decisão em grupo, negociação, etc. Nestes processos, sete etapas são fundamentais:

- Definir o problema;

- Especificar valores;

- Identificar opções;

- Compreender as conseqüências; 
- Estabelecer compensações;

- Clarificar incerteza;

- Analisar tolerância de risco (Bana e Costa, 2001a).

Para Ostanello (1990), as situações de tomada de decisão podem ser bastante diversas e feitas de forma diferentemente complexa, em função das características técnicas, organizacionais e políticas dos problemas decorrentes de cada contexto. Esses fatores não só condicionam o processo de análise, como podem determinar a evolução da interação entre o cliente (interessado na decisão) e o analista (aquele que auxilia na estruturação do problema de decisão). Neste sentido, as metodologias de apoio à decisão devem auxiliar o cliente a estruturar o problema e a aprender com a situação, facilitar a comunicação entre os atores e a negociação, ampliar o comprometimento e alcançar resultados políticos e organizacionais válidos.

Para Roy (1993), decisões são feitas quando se escolhe ou não fazer uma determinada ação. Assim, considera que a decisão em si não pode ser vista separadamente do processo de decisão. Neste sentido, o processo de decisão é definido como atividades sucessivas e paralelas de interação e confrontação entre os diferentes atores envolvidos na decisão e seus pontos de vista.

Como apoio à decisão, o autor define a atividade que uma pessoa exerce, através do uso de um modelo explícito mas não necessariamente formalizado, de forma a obter elementos e respostas para questões colocadas por um ator do processo de decisão. Estes elementos buscam clarear as decisões e usualmente permitir que sejam feitas recomendações, ou simplesmente favorecem o aumento da consistência entre os objetivos e sistemas de valores dos atores, ao longo do processo.

Roy (1990) destaca ainda que um modelo consiste em um esquema que permite a representação de um determinado fenômeno, auxiliando na investigação e facilitando a comunicação entre os atores. A representação deste fenômeno pode se dar de uma forma mais intuitiva, ou de uma forma mais rigorosa, neste caso, baseada exclusivamente em fatos, dados quantitativos e lógica.

Malczewski (1999) identifica uma série de elementos que estruturam um processo de decisão:

- Objetivo ou conjunto de objetivos que devem ser atingidos;

- Decisor ou grupo de decisores envolvidos no processo e suas preferências no que diz respeito aos critérios de avaliação; 
- Conjunto de critérios de avaliação (elementos e/ou atributos) com base nos quais os decisores irão avaliar as alternativas de ação;

- Conjunto de alternativas de decisão ou variáveis de ação;

- Conjunto de variáveis externas ou fora do controle dos decisores (estados da natureza);

- Conjunto de conseqüências ou resultados associados a cada uma das alternativas.

Os modelos tradicionais da teoria de decisão, empregados geralmente em pesquisa operacional, economia, finanças, entre outras, baseiam-se no pressuposto que uma alternativa "A" é considerada melhor do que uma alternativa "B" se seu valor para uma determinada função for maior ou menor do que o valor obtido para "B". Este sistema implica na desconsideração de qualquer incompatibilidade, indiferença, ou preferência em relação às alternativas (Bana e Costa e Vincke, 1990).

A abordagem tradicional monocritério, empregada até o final da década de sessenta do século passado, considerava que as decisões são tomadas sob o ponto de vista de um único decisor, para um conjunto bem definido de alternativas possíveis, comparáveis entre si com base em um único critério e que os problemas possuem uma formulação matemática bem definida (Roy, 1990).

O interesse prático por modelos multicritério de apoio à decisão cresceu quando a esfera de aplicação dos métodos quantitativos de gestão migrou dos problemas operacionais com uma única função-objetivo, bem definida, para níveis mais complexos de decisão, onde os problemas são multidimensionais. Neste sentido, a principal característica da análise multicritério é a estruturação dos problemas em termos de um número de critérios individualizados, cada um representando um eixo de avaliação, conduzindo a um processo de tomada de decisão mais robusto. A abordagem facilita ainda a aprendizagem sobre os vários componentes dos problemas complexos de decisão, ajudando os decisores a avaliar as alternativas segundo múltiplos pontos de vista, seja no contexto de decisão individual, seja em contextos de decisão em grupo (Bana e Costa, 2001).

Tanto em uma avaliação monocritério, como numa avaliação multicritério o sucesso do processo de decisão está na forma como cada critério (ou critérios) é construído. Em uma análise multicritério, o conjunto de critérios representa os diferentes eixos através dos quais os vários atores do processo de decisão justificam, transformam e demonstram suas preferências. Desta forma, as comparações feitas a partir destes critérios são interpretadas como preferências parciais, isto é, preferências restritas aos aspectos levados em consideração para a definição do critério. Os pontos de vista sobre os quais são definidos os 
critérios devem ser entendidos e aceitos por todos os atores, ainda que estes discordem sobre a importância relativa dos mesmos. Além disso, os critérios devem ser suficientemente familiares para que os atores possam fazer discussões a respeito dos mesmos (Bouyssou, 1990).

No que diz respeito ao conjunto de critérios ou família de critérios, outros aspectos devem ser destacados. Em função de limitações da mente humana e a necessidade de se agregar informações inter-critérios, não é recomendado um número maior do que doze critérios no nível mais elevado da hierarquia. Além disso, uma família de critérios deve guardar também certas características para ser efetivamente útil para o processo de apoio à decisão, entre as quais:

- Legibilidade, relacionada a um número suficientemente pequeno de critérios, permitindo ao analista avaliar toda a informação necessária para a implementação de um processo de agregação;

- Operacionalidade, relacionada à sua validação pelos atores para a continuidade do processo de decisão;

- Exaustividade, englobando todos os pontos de vista importantes para o problema;

- E ser mínima, não devendo incluir critérios desnecessários para o processo de decisão (Roy, 1990).

Além da dificuldade em se definir uma família de critérios que represente todos os pontos de vista relevantes para o processo de decisão, há muitas vezes dificuldade em se quantificar a importância relativa dos critérios, uma vez que os mesmos podem ter graus de importância variáveis para diferentes decisores. Desta forma, é necessário definir a importância relativa de cada critério no processo de decisão, o que é feito normalmente atribuindo um determinado peso a cada critério interveniente. A correta atribuição de pesos é importante para que sejam mantidas as preferências dos decisores (Silva et al., 2004).

Outra questão reside na comparação dos critérios para a tomada de decisão. Normalmente os valores de diferentes critérios não são comparáveis entre si, o que inviabiliza a sua agregação imediata. Para resolver este problema é necessário normalizar para uma mesma escala de valores a forma de avaliar os diferentes critérios. Para tal, existem diferentes processos de normalização, os quais podem ser vistos em maior detalhe em Mendes (1999), Silva et al., (2004).

Uma vez normalizados os scores dos critérios para um intervalo fixo, estes podem ser agregados de acordo com a regra de decisão. Neste sentido, muitos métodos podem ser utilizados para a combinação de critérios. Alguns destes métodos (combinação linear 
ponderada, média ponderada ordenada, entre outros) podem ser vistos em Mendes (1999), Malczewski, (1999) e Silva et al., (2004).

No que se refere à utilização dos modelos multicritério, estes podem auxiliar na tomada de decisão em nível nacional e local, em uma companhia, fábrica ou departamento, ou mesmo dentro de uma família. Nestes contextos, as decisões se relacionam a planos de desenvolvimento, políticas de desenvolvimento regional, estratégias para implementação de serviços de trem de alta velocidade, localizações para indústrias ou empreendimentos, etc. (Roy, 1990).

Para Bana e Costa (2001) quando as atividades de planejamento e gestão são entendidas como indissociáveis da interação com os agentes envolvidos nos processos de decisão, surge a necessidade de aplicar metodologias de avaliação que tornem possível considerar e confrontar diretamente diferentes objetivos e pontos de vista. Em resposta, surgem metodologias multicritério de apoio à decisão orientadas diretamente para a avaliação interativa, permitindo a integração de fatores quantitativos e qualitativos e o adequado tratamento da subjetividade presente no processo de decisão.

Neste sentido, é apresentada a seguir uma metodologia multicritério de apoio a decisão que permite integrar critérios qualitativos e quantitativos, bem como atender às particularidades do processo de planejamento urbano e de transportes, especialmente no que diz respeito à multiplicidade de atores e seus diferentes pontos de vista.

\subsection{Abordagem Construtivista}

Os sistemas de transportes são complexos e esta complexidade deriva do pluralismo de seus veículos e infra-estruturas e das pessoas e organizações envolvidas. Esta complexidade é multiplicada pela existência de diferentes modos e seus diferentes papéis, legislação e corpo regulatório, provedores de serviços, construtores, sistemas financeiros, tecnologias, modelos de uso do solo e o mais importante, o comportamento humano (Richardsson, 2005).

Uma característica tem emergido no processo de planejamento dos transportes: a importância da colaboração, integração e troca entre profissionais e políticos de múltiplos setores. O processo emergente de planejamento de transportes é muito mais multi, inter e trans disciplinar do que o planejamento tradicional. Isso demanda não só a integração de profissionais de diferentes setores, como também de diferentes agências de transportes. A nova abordagem do planejamento de transportes reconhece que a colaboração entre disciplinas e setores políticos, o engajamento de atores e a aceitabilidade pública são 
fatores-chave para o progresso. Isto exige que o processo de planejamento se torne muito mais uma atividade orientada à comunicação, o que obriga a adoção de técnicas para mediação de conflitos e comunicação com não-especialistas (Bertolini et al., 2008).

Neste contexto se destaca a metodologia Multicritério de Apoio à Decisão - Construtivista (em inglês, Multicriteria Decision Aid - Constructivist ou MCDA-C), que consiste em uma técnica de avaliação que leva em consideração os diversos aspectos considerados importantes pelo decisor. Tem como base três convicções:

- Interação entre sujeito e objeto, ou seja, a avaliação é necessariamente baseada nos valores e percepções do sujeito;

- Construtivismo, que considera que o entendimento do problema é feito paulatinamente;

- Participação, que implica que os atores participem ativamente do processo de estruturação do problema, interagindo entre si (Bana e Costa, 1993 apud Saboya, 2005).

A aplicação da metodologia MCDA-C no contexto deste trabalho se dá em função de duas características principais:

- A metodologia pressupõe que os responsáveis pela tomada de decisão não sabem ao certo qual o problema em análise, muito menos conhecem a priori todos os elementos nele envolvidos. Desta forma a compreensão do assunto se faz de forma gradativa, à medida que o problema vai sendo estruturado e debatido. É comum, portanto, que o entendimento da questão evolua ao longo do processo, ao passo em que são adquiridas novas informações e há o amadurecimento da opinião dos atores envolvidos;

- A solução do problema é focada nos valores e objetivos envolvidos, não nas alternativas disponíveis.

Este método tem sido utilizado para subsidiar processos de tomada de decisão, permitindo ao decisor: identificar claramente seus objetivos, mensurar esses objetivos e visualizar o impacto das alternativas no conjunto de objetivos. Além disso, o método considera que o processo de tomada de decisão não deve ser feito somente com base em critérios objetivos e quantitativos, destacando a necessidade de se incorporar fatores subjetivos, ainda que estes impliquem em dificuldades operacionais para o processo de análise. Desta forma, o modo como o decisor percebe a realidade é condicionante para a forma como é estruturado o problema (Saboya, 2005). 
Todo o processo decisório pressupõe a participação de pessoas. Raramente as decisões são tomadas individualmente por um órgão do governo, presidente de uma companhia ou diretor, envolvendo normalmente a participação de indivíduos ou entidades. Neste sentido, a metodologia MCDA-C apresenta uma nomenclatura própria para identificar os indivíduos ou grupos de indivíduos envolvidos no processo, denominados de atores, qualificando-os conforme a influência (direta ou indireta) que exercem sobre o problema. Os atores do processo decisório são assim identificados por categoria:

- Decisor - indivíduo ou entidade para qual foi delegada a responsabilidade pela tomada de decisão. O decisor detém o controle sobre os meios necessários para que o processo aconteça e para que as ações posteriores sejam efetivadas;

- Facilitador - responsável por intermediar o processo, auxiliando o decisor a coletar as informações necessárias, e a estruturar o modelo de avaliação. Ao facilitador compete ainda elaborar recomendações para o decisor no final do processo de avaliação;

- Intervenientes - pessoas ou grupos que podem influenciar diretamente nas decisões através de seu sistema de valores;

- Agentes Externos (ou "Agidos") - influenciam indiretamente o processo decisório, não possuindo contato direto com o decisor. No entanto, são afetados pelas decisões tomadas e podem também pressionar os demais atores e influenciar seu sistema de valores (Roy, 1996; Wolff, 2005; Saboya, 2005; Pereira Neto, 2001).

O processo de tomada de decisão utilizando o método MCDA-C tem início com a identificação da problemática de referência, que consiste na forma como o facilitador deve prover ajuda ao decisor, dando resposta às seguintes questões:

- Que tipos de resultados o decisor espera obter?

- Em que direção será conduzida a investigação?

- Que forma devem ter as recomendações? (Roy, 1996; Saboya, 2005).

A definição da problemática de referência permite a identificação clara dos tipos de situações de estruturação e de avaliação que o decisor necessita para o contexto decisório específico. É, portanto, parte essencial do trabalho do facilitador, uma vez que define como este conduzirá o processo de entendimento do problema junto aos demais atores.

As problemáticas de referência são comumente classificadas em quatro categorias definidas a seguir, conforme Roy (1996) e Saboya (2005). Estas problemáticas podem ser adotadas individualmente, consideradas seqüencialmente, ou ainda combinadas, de forma a constituir uma problemática mista. 
A problemática da escolha (P. $\alpha$ ) envolve a seleção de um conjunto tão reduzido quanto possível de ações consideradas as "melhores", para dar resposta ao problema do decisor. Estas ações, no entanto, não são necessariamente as melhores em termos absolutos, mas também aquelas que são viáveis ou suficientes para que as demais sejam desconsideradas. Esta problemática resulta em uma recomendação, indica uma decisão que deve ser tomada ou simplesmente propõe uma metodologia de seleção que pode ser usada repetidas vezes para identificar as melhores ações.

A problemática da triagem ou alocação em categorias (P.ß) envolve a categorização das ações conforme suas prováveis conseqüências. No entanto, não é obrigatório haver uma relação de ordem entre as ações (como por exemplo, ações "boas" ou "más"), que podem corresponder simplesmente a diferentes grupos. Esta problemática resulta em uma recomendação ou defende a aceitação ou rejeição de determinadas ações.

A problemática da ordenação (P.Y) consiste na ordenação das ações conforme critérios de importância ou prioridade definidos pelo decisor. Envolve, deste modo, a elaboração de um método de ordenamento. Difere da problemática da escolha pelo fato da classe de mais alta prioridade não possuir necessariamente um número mínimo de ações. Esta problemática resulta em uma recomendação ou sugere uma ordem parcial ou completa formada por classes que contêm ações consideradas equivalentes.

A problemática da descrição (P.ঠ), que se aplica a este trabalho, envolve a descrição detalhada das ações potenciais e de suas conseqüências. Neste sentido, o interesse é apenas descrever e compreender melhor os aspectos relevantes para o contexto decisório. O facilitador, portanto, deve auxiliar o decisor a obter informações sobre as ações. Esta problemática resulta em uma recomendação ou simplesmente descreve sistematicamente e formalmente as ações e suas conseqüências em termos qualitativos e quantitativos.

Após a descrição, o decisor pode julgar que não é necessário formular um modelo decisório para avaliá-las, uma vez que o nível de informação obtido permite que o mesmo as avalie de forma holística, sem o estabelecimento de um modelo formal. Assim, esta problemática tanto pode estar incluída nas demais descritas anteriormente, como pode ser tratada como uma problemática específica, já que muitas vezes a descrição do problema é tudo o que o decisor necessita.

Identificados os atores envolvidos e definida(s) a(s) problemática(s) de referência, a metodologia MCDA-C propõe as seguintes etapas para o processo de apoio à decisão:

- Estruturação do problema; 
- Avaliação;

- Conclusões e recomendações.

A fase de estruturação do problema compreende, de um modo geral, as seguintes atividades:

- Definição do rótulo do problema;

- Levantamento dos Elementos Primários de Avaliação (EPAs);

- Criação de conceitos orientados à ação;

- Construção do mapa de relações meios e fins;

- Identificação dos Pontos de Vista Fundamentais (PVFs);

- Construção dos descritores.

Estas etapas são descritas a seguir com base nos trabalhos de Noronha (2003), Moreira (2003), Diniz (2003), Paula (2005) e Saboya (2005), que utilizaram a metodologia MCDA-C para a solução de problemas de decisão de natureza diversa. Todos estes trabalhos baseiam-se por sua vez nos estudos de Goodwin e Wright (1991), Bana e Costa (1992), Keeney e Raiffa (1993), Roy (1996), e Ensslin et al. (2001) e que consolidaram o referencial teórico da metodologia MCDA-C.

A definição do rótulo do problema permite resumir qual será o contexto decisório, auxiliando a estabelecer os limites da análise. O rótulo é elaborado pelo decisor em conjunto com o facilitador, e consiste em uma frase ou título que resume o processo que será desenvolvido e os objetivos que se deseja alcançar.

A definição do rótulo do problema é seguida pela identificação dos aspectos que irão estruturar todo o processo de avaliação, constituídos pelos elementos primários de avaliação (EPAs). Os EPAs consistem em objetivos, metas, valores, ações, opções, alternativas e perspectivas expressas pelos decisores e que revelam os aspectos fundamentais relacionados ao problema em questão.

Os EPAs podem ser obtidos por meio de levantamentos indiretos, através de lista de desejos elaborada pelos participantes, ou diretamente utilizando-se a técnica de brainstorming (tempestade de idéias, como é traduzida). Por meio da técnica os atores do processo decisório podem expressar livremente suas opiniões, sem críticas ou invalidação de qualquer conceito. O brainstorming parte do princípio que a quantidade cria qualidade, ou seja, quanto maior o número de idéias, maior a chance delas contribuírem para a solução do problema. Uma variação deste método é denominado de ideawriting ou brainwriting, que permite que as idéias sejam expressas de forma escrita ao invés de serem expressas verbalmente, superando assim algumas limitações impostas pelo brainstorming (Hwang e 
Lin, 1987, apud Noronha, 2003). Seja qual for a metodologia adotada, ao facilitador cabe o papel de conduzir o processo, mantendo-se neutro ao longo do mesmo, sem emitir nenhuma opinião.

O conjunto de EPAs obtido deve ser transformado em um conjunto de conceitos orientados à ação. Estes são construídos atribuindo-se um verbo no infinitivo à idéia expressa no EPA, compondo o primeiro pólo do conceito, denominado de pólo positivo. Para que o conceito fique completo e tenha sentido é necessário ainda explicitar seu outro pólo, denominado de pólo negativo, que consiste no seu oposto psicológico. Como exemplo, a idéia "planejamento integrado" pode ser transformada em um conceito da seguinte forma:

"Planejar de forma integrada ... Pólo Positivo
Planejar de forma setorial"

Pólo Negativo

A etapa seguinte do método MCDA-C pressupõe a identificação das relações estabelecidas entre os conceitos através da construção de mapas cognitivos ou mapas de relações meios e fins. Os mapas de relações meios e fins expressam a estrutura de ligação entre os conceitos, ou seja, as relações de causa e efeito existentes, e são definidos a partir da organização e estruturação dos conceitos extraídos a partir das interações feitas entre o facilitador e os decisores. Este mapa influencia o pensamento do decisor e, conseqüentemente suas representações mentais a respeito do contexto decisório.

O mapa é construído dispondo-se os conceitos obtidos na etapa anterior e identificando-se as relações (traçando-se setas) que evidenciam as conexões existentes entre os mesmos. Para esta operação adota-se a seguinte convenção:

- Os conceitos "mais operacionais" (meios para se atingir outros objetivos) são posicionados mais abaixo dos conceitos estratégicos;

- Os conceitos "mais estratégicos" são posicionados na porção superior do mapa;

- As setas são traçadas dos conceitos operacionais em direção aos estratégicos, ou seja, dos conceitos meios para os conceitos fins.

Uma vez que na etapa de identificação dos EPAs um número significativo de conceitos pode ter sido gerado, a construção do mapa de relações meios e fins pode ser facilitada agrupando-se previamente os conceitos em áreas de preocupação ou clusters. Os clusters representam, portanto, conjuntos de conceitos cujas ligações internas são bastante fortes, correspondendo a idéias referentes a um mesmo aspecto ou tema. Os mapas cognitivos são então construídos para cada área de preocupação, estabelecendo-se as relações entre os conceitos. 
O mapa cognitivo permite, portanto, visualizar de maneira global o problema, além de identificar possíveis lacunas no entendimento da questão. Assim, deve ser possível durante sua construção adicionar idéias que possam ter sido esquecidas ou não consideradas em um primeiro momento, ampliando o conhecimento sobre o problema. A adição de conceitos, no entanto, deve ser limitada pelo facilitador em função do tempo e da quantidade de conhecimento adquirido até o momento.

A partir da análise do mapa é possível conhecer melhor o que os decisores pensam sobre o problema e iniciar a identificação dos pontos de vista fundamentais (PVFs), que refletem os aspectos essenciais considerados pelos decisores. A análise do mapa baseia-se na análise de sua forma, identificando-se os conceitos denominados "cabeça" e "cauda" e a estrutura hierárquica dos mesmos. Estes conceitos são assim definidos:

- Conceitos "cabeça" refletem os objetivos estratégicos ou fins dos decisores e dos quais não partem flechas de ligação;

- Os conceitos "cauda" revelam os meios, ações, alternativas e opções para se atingir os objetivos estratégicos e dos quais partem as setas de ligação.

A partir da identificação dos PVFs é possível construir a estrutura arborescente que permite a melhor visualização, organização e hierarquização dos conceitos relevantes para os decisores, formada pelo objetivo estratégico, pelas áreas de interesse e pelos PVFs. Eventualmente, há a necessidade de se detalhar ou explicar melhor um PVF, decompondoo em dois ou mais pontos de vista elementares (PVEs). A Figura 4.1 ilustra um exemplo de árvore de pontos de vista fundamentais ou hierarquia de valores.

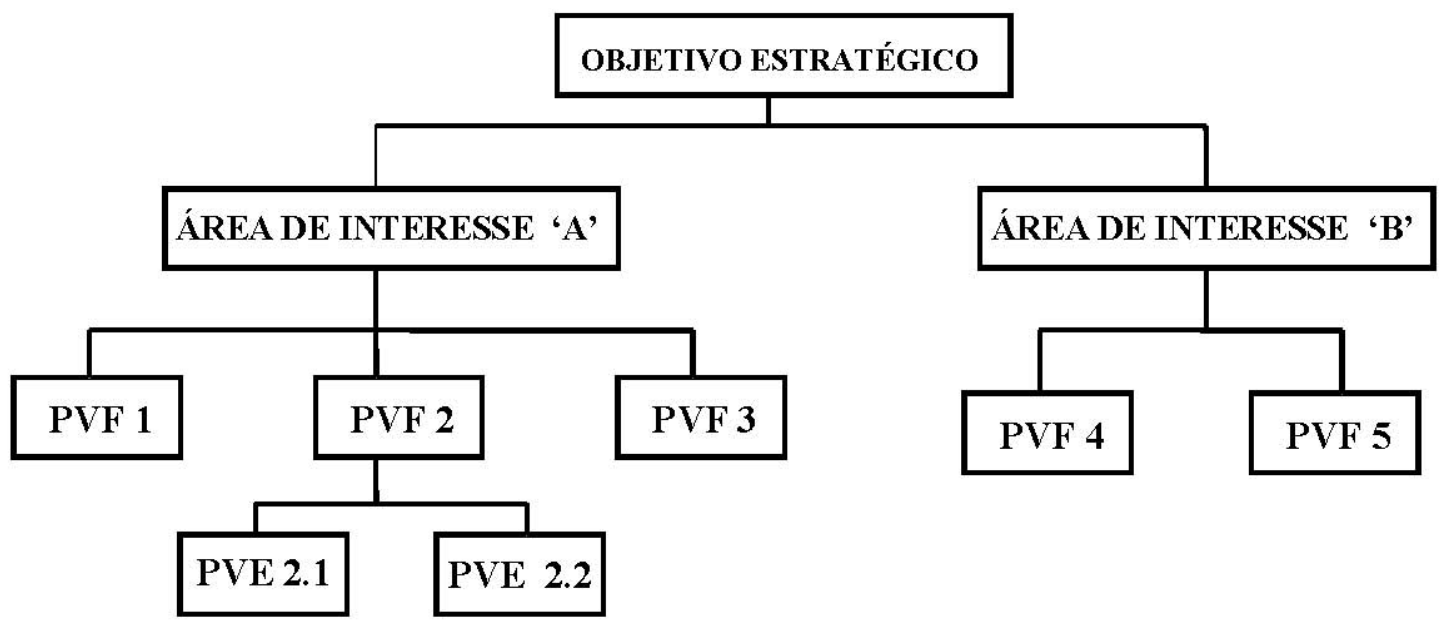

Figura 4.1: Arborescência de pontos de vista.

Fonte: Pereira Neto (2001). 
A etapa de construção da arborescência de PVFs é seguida pela construção de descritores. Os descritores correspondem a níveis de impacto utilizados para descrever as prováveis conseqüências das ações em termos de cada PVF ou PVE. São, portanto, escalas utilizadas para mensurar os objetivos, representando o quanto estes foram alcançados. Por incorporarem julgamentos de valor, os descritores ajudam os atores a esclarecer os objetivos e a gerar subsídios para a criação de novas alternativas.

Os descritores podem ser de três tipos:

- Naturais - aqueles para os quais existe uma escala facilmente atribuível e que são interpretados de maneira semelhante por todos;

- Construídos - representam objetivos não facilmente mensuráveis para os quais não existe uma escala facilmente aplicável;

- Aproximados (ou Proxy) - descritores indiretos utilizados quando não existem descritores naturais e não é possível construir descritores que meçam diretamente um determinado objetivo.

Os descritores devem ser ordenados em termos de preferência dos decisores. Aos níveis de impacto devem ainda ser associados valores de referência, correspondentes ao nível neutro (para qual é atribuído o valor "zero") e ao nível bom (para qual é atribuído o valor "cem") que representam, respectivamente, o pior nível admissível e a melhor ação viável.

De posse dos descritores é possível iniciar a etapa de avaliação do modelo multicritério, com base nos eixos definidos na fase de estruturação. A fase de avaliação compreende as seguintes etapas:

- Construção das funções de valor;

- Construção das taxas de substituição ou compensação;

- Determinação do perfil de impacto das ações e avaliação global;

- Análise de sensibilidade.

As funções de valor são representações matemáticas dos julgamentos dos decisores, atribuídas por meio de uma escala numérica ao nível dos descritores. Através das funções de valor é feita a representação quantitativa do grau de atratividade de cada nível de impacto dos pontos de vista fundamentais com relação à escala ancorada em níveis préfixado (bom e neutro). As funções de valores podem ser obtidas por diferentes métodos, onde se pode destacar: método de pontuação direta, método de bissecção e método de julgamento semântico (como por exemplo o método Macbeth, que por meio de software determina as funções de valor que representam os julgamentos dos decisores - para mais detalhes do método ver Bana e Costa e Vansnick, 1995, e Ensslin et al., 2001). 
A etapa seguinte do processo de avaliação consiste na obtenção das taxas de substituição ou compensação. As taxas de substituição são utilizadas para determinar a importância relativa dos pontos de vista identificados no modelo multicritério. Desta forma, definem fatores que revelam a contribuição de um dado ponto de vista no valor global do perfil de uma ação, ou seja, o percentual de participação do objetivo na avaliação. Portanto, o cálculo das taxas de substituição é feito a partir de comparações feitas entre os objetivos do modelo, e não mais no nível dos descritores. Os métodos mais difundidos para obtenção das taxas de substituição são: trade-off, swing weights e de comparação par a par, utilizando procedimentos semelhantes aos empregados na obtenção das funções de valor, através do software Macbeth.

Concluída a etapa de determinação das taxas de substituição, a etapa seguinte contempla a avaliação da performance das ações com relação a cada um dos objetivos que compõem o modelo multicritério. Deste modo é possível verificar para cada ação seus pontos fracos e fortes, permitindo a definição dos perfis de impacto do modelo. Nesta etapa deve-se identificar, para cada descritor, o nível de impacto da alternativa que está sendo analisada, isto é, identificar qual o nível que descreve com maior exatidão as características da mesma ou da conseqüência esperada. Comparando-se os perfis de desempenho das alternativas verificam-se as melhores e piores opções, bem como os aspectos em que estas se destacam.

As avaliações finais servem como base para as recomendações e para a decisão a ser tomada. No entanto, a metodologia MCDA-C não se preocupa somente em dar uma solução ao problema do decisor. Sua principal preocupação está no processo de apoio à decisão e na estrutura final do modelo decisório. Assim, a aprendizagem, interação e participação dos decisores em todo o processo é fundamental para o sucesso da aplicação da metodologia MCDA-C. 


\section{INDICADORES URBANOS E DE MOBILIDADE SUSTENTÁVEL}

Neste capítulo são apresentadas algumas definições, características e aplicações dos indicadores urbanos, destacando as diferenças existentes entre os indicadores tradicionais e os indicadores de sustentabilidade. São abordadas também algumas etapas fundamentais para a identificação e seleção de indicadores de sustentabilidade para uma comunidade. Os indicadores de mobilidade sustentável são tratados de forma detalhada neste capítulo, abordando suas características, aplicações e aspectos que devem ser considerados na construção de sistemas para monitoração da mobilidade urbana. Uma relação de indicadores propostos em trabalhos conduzidos em diversos países é apresentada neste capítulo. Em uma etapa final são feitas considerações a respeito dos indicadores de transportes e mobilidade em desenvolvimento no Brasil.

\subsection{Aspectos Gerais}

Indicadores são variáveis selecionadas que podem ajudar a tornar os objetivos operacionais e reduzir a complexidade no gerenciamento de determinados sistemas. Podem funcionar como balizadores em análises técnicas e elaboração de políticas, bem como ser direcionados para o debate com o público em geral. Quando os indicadores são referenciados a metas ou objetivos eles tornam-se medidas de performance, revelando as condições de um sistema, organizações ou políticas (Gudmundsson, 2004).

Indicadores são construídos sobre dados de origem diversa, condensando informação complexa de uma forma simplificada, fornecendo uma mensagem significativa sobre o sistema de interesse. São utilizados em diferentes formas de comunicação, desde análises científicas a interações cotidianas, análises políticas e tomada de decisão. Entre as inúmeras atividades que podem subsidiar encontram-se: alocação de recursos, comparação de diferentes locais ou áreas geográficas, cumprimento de normas ou critérios legais e análise de tendências no tempo e no espaço (Gudmundsson, 2004, Direcção Geral do Ambiente, 2000). 
Para Maclaren (1996), indicadores são simplificações de fenômenos complexos. No entanto, como o próprio nome sugere, provêm somente uma indicação da condição ou estado de um determinado fenômeno. Assim, uma vez que raramente um único indicador poderá fornecer um retrato completo de uma situação, é usual que se utilize um conjunto de indicadores para caracterizar as diferentes dimensões e aspectos de um determinado problema. Os indicadores podem revelar ainda tendências históricas e prover informação indireta sobre o futuro de um fenômeno ou sistema. Neste sentido, se associados a metas ou pontos de referência, permitem observar com maior clareza os progressos em relação a um determinado objetivo.

Além de quantificável, um indicador deve guardar também as seguintes características:

- Ser relevante para o sistema ou fenômeno que se deseja medir;

- Ser compreensível, ou seja, permitir que sua mensagem seja facilmente compreendida pelo público a que se destina;

- Ser confiável, ou seja, deve transmitir uma informação confiável sobre o sistema que está medindo;

- Basear-se em dados acessíveis, ou seja, deve prover informação em ocasiões oportunas, enquanto ainda há tempo para a ação (Sustainable Measures, 2006).

Os indicadores urbanos, neste contexto, permitem extrair os elementos fundamentais sobre os quais se estruturam idéias básicas para o planejamento estratégico e gestão de uma cidade, nas suas múltiplas dimensões. Além disso, a análise da evolução de indicadores se constitui em uma importante ferramenta para fundamentar e valorizar decisões e, se necessário, orientar e reconduzir ações. Um sistema de indicadores urbanos deve permitir analisar a estrutura da cidade e o comportamento de seus cidadãos, além de investigar e identificar oportunidades e deficiências existentes e acompanhar a implementação e impactos das estratégias propostas (Martinez e Leiva, 2003).

Os indicadores de sustentabilidade urbana se diferenciam, no entanto, dos indicadores tradicionais. Ao invés de tratarem isoladamente os aspectos sociais, econômicos e ambientais, abordam em sua formulação características como integração, visão em longo prazo, equilíbrio e participação de diferentes atores. Para Maclaren (1996), os indicadores de sustentabilidade permitem retratar as ligações existentes entre as dimensões social, econômica e ambiental, se constituindo em ferramentas integradas para avaliação da sustentabilidade urbana. São capazes ainda de medir a eqüidade intergerações e intragerações, levando em consideração a distribuição de condições (sociais, econômicas e ambientais) dentro de uma comunidade ou entre regiões geográficas. 
Para se constituírem em bons indicadores de sustentabilidade, os mesmos devem ser:

- Cientificamente válidos;

- Representativos de um amplo leque de condições;

- Sensíveis a mudanças;

- Relevantes para as necessidades de seus potenciais usuários;

- Comparáveis com indicadores desenvolvidos em outras localidades;

- De custo razoável para coleta e aplicação;

- Atrativos à mídia;

- Inequívocos, evidentes (Maclaren, 1996).

A identificação de indicadores se constitui em um processo importante no desenvolvimento e implementação de estratégias de desenvolvimento sustentável. Esta etapa pode estar, no entanto, inserida em um extensivo processo de elaboração de Relatórios de Sustentabilidade Urbana. Neste sentido, Maclaren (1996) destaca as principais etapas de construção destes relatórios, resultando na obtenção de um conjunto de indicadores de sustentabilidade. Estas etapas são assim definidas:

\section{Etapa 1: Definição dos objetivos para a sustentabilidade urbana para os quais os indicadores são necessários}

Estes objetivos podem ter sido definidos em documentos anteriores ou podem ser desenvolvidos especialmente para o relatório de sustentabilidade. Nesta etapa, um exercício onde a comunidade expressa sua visão sobre a sustentabilidade se constitui em uma técnica útil para a definição dos objetivos. Este exercício é desenvolvido tipicamente através de uma abordagem com múltiplos participantes, permitindo identificar o estado que a comunidade deseja alcançar em períodos pré-estabelecidos, no que diz respeito à sustentabilidade.

\section{Etapa 2: Escopo}

Nesta fase deve ser definido o escopo do relatório de sustentabilidade, identificando o público alvo e o propósito para o qual serão desenvolvidos os indicadores. Deve ser possível indicar ainda o número aproximado de indicadores que serão necessários e os limites espacial (contexto geográfico) e temporal (horizonte de tempo para mensuração dos indicadores) do relatório.

O número e a estrutura dos indicadores costumam variar de acordo com o público a que se destinam. Cientistas e analistas mostram-se interessados em dados brutos e em conjuntos de indicadores altamente detalhados, dando enfoque à validade científica e à complexidade 
do sistema. Responsáveis pelo desenvolvimento de políticas preferem informação que é diretamente relacionada a objetivos políticos, critérios de avaliação e metas préestabelecidas. Mídia e público em geral se interessam por um conjunto reduzido de indicadores que são facilmente compreendidos e que são representativos das questões consideradas por eles importantes.

\section{Etapa 3: Escolha de uma estrutura apropriada para os indicadores}

Com base na revisão da literatura sobre o desenvolvimento de relatórios do estado do ambiente e relatórios de qualidade de vida urbana, Maclaren (1996) identifica seis estruturas gerais que podem ser usadas para o desenvolvimento de indicadores de sustentabilidade, baseadas em:

- Dimensões da sustentabilidade (social, econômica e ambiental);

- Objetivos e metas relacionados ao desenvolvimento sustentável;

- Setores geralmente de responsabilidade do poder público, tais como: moradia, transportes, uso do solo ou serviços públicos;

- Assuntos ou temas, organizados em torno de uma lista de questões-chave relacionadas à sustentabilidade, como o gerenciamento de resíduos, ruído, poluição do ar, educação, saúde, emprego, etc;

- Princípio de causa e efeito, conhecida tipicamente como modelo pressão-estadoresposta;

- Combinação dos modelos anteriores, minimizando as desvantagens que estes modelos podem eventualmente apresentar.

\section{Etapa 4: Definição de critérios para seleção de indicadores.}

Consiste na seleção de critérios gerais sobre os quais os indicadores serão avaliados. Estes critérios são relacionados à validade e à viabilidade de implementação dos indicadores, e não às propriedades dos indicadores de sustentabilidade propriamente ditas.

Estas propriedades, já mencionadas anteriormente neste capítulo, referem-se à validade científica, representatividade, sensibilidade, relevância, comparabilidade, custo, atratividade à mídia e evidência.

\section{Etapa 5: Identificação de um conjunto de potenciais indicadores.}

Indicadores podem ser identificados consultando experiências anteriores de outras cidades ou regiões. Especialistas devem ser envolvidos nesta etapa em função de seus conhecimentos específicos, dando suporte aos decisores envolvidos no processo. 
Atividades de brainstorming, workshops, ou questionários de pesquisa podem ser utilizados nesta etapa.

\section{Etapa 6: Avaliação e seleção do conjunto final de indicadores}

Nesta etapa o conjunto de potenciais indicadores é avaliado com base nos critérios estabelecidos na Etapa 4 e no contexto da estrutura selecionada na Etapa 3. O resultado deve gerar um conjunto final de indicadores que melhor atenda aos critérios estabelecidos e satisfaça as exigências impostas pela estrutura conceitual.

A avaliação dos indicadores pode ser feita através de métodos simples, tais como, confrontando cada indicador aos critérios de avaliação e identificando "ausência" ou "presença" dos mesmos, apresentando o resultado através de uma matriz de avaliação. Métodos mais complexos podem permitir a atribuição de pesos e revelar a importância relativa de cada critério e medir o desempenho do indicador através de uma escala de pontos. Uma aplicação prática, onde um conjunto de indicadores para cidades médias brasileiras e portuguesas foi obtido através da atribuição de pesos para diferentes critérios e indicadores, pode ser visto em Costa (2003).

\section{Etapa 7: Coleta de dados e análise dos resultados dos indicadores}

Uma vez coletados os dados para cálculo dos indicadores, a etapa seguinte consiste em determinar como o indicador apresenta o progresso (ou distanciamento) em relação aos objetivos definidos para a sustentabilidade. Neste sentido, a contribuição de cada indicador (positiva ou negativa) para os objetivos pré-estabelecidos deve ser claramente definida.

\section{Etapa 8: Preparação e Apresentação do Relatório de Sustentabilidade Urbana}

O Relatório de Sustentabilidade Urbana deve conter, no mínimo, uma descrição do significado de cada indicador, sua importância, tendências históricas e uma avaliação de como o indicador mostra o progresso em relação à sustentabilidade. Com o objetivo de destacar os aspectos de integração do relatório de sustentabilidade, é recomendável discutir as inter-relações existentes entre os indicadores. Podem ainda ser apresentadas recomendações para a melhoria do processo de coleta de dados e avaliação dos indicadores, bem como para a formulação de políticas públicas.

\section{Etapa 9: Avaliação do desempenho dos indicadores}

A avaliação do desempenho dos indicadores deve ser feita periodicamente, à medida que os dados necessários para a sua mensuração sejam disponibilizados. Este processo 
permite acompanhar a evolução dos indicadores, verificando sua eficiência em medir os progressos em relação aos objetivos pré-estabelecidos.

Dependendo das respostas dadas pelos indicadores, das dificuldades encontradas para a coleta de dados e aplicação, entre outros aspectos, eles podem ser revistos, adaptados, ou até mesmo eliminados do sistema. Esta avaliação pode implicar ainda na adição de novos indicadores ao sistema, dependendo das necessidades dos decisores e das mudanças no contexto de análise.

\subsection{Indicadores de Mobilidade Urbana Sustentável}

Uma vez que os conceitos de sustentabilidade têm sido incorporados no processo de planejamento e gestão das cidades e de seus sistemas de mobilidade, tem crescido a necessidade de incorporar ferramentas práticas que auxiliem o processo. Neste contexto, tem se destacado o desenvolvimento de indicadores de sustentabilidade, os quais têm sido incorporados de diferentes formas e com diferentes estruturas, auxiliando políticos, planejadores e gestores a lidar com a complexidade dos atuais problemas das cidades (Gudmundsson, 2004; TRB, 2008).

Para Gudmundsson (2004), o uso de indicadores para avaliação e monitoração tem sido freqüente em políticas de transportes, especialmente para comparar desenvolvimento dos sistemas ou políticas ao longo do tempo e no espaço. No entanto, os processos de avaliação e monitoração são distintos. Enquanto que a avaliação se constitui tipicamente em um evento único, a atividade de monitoração se constitui em um processo contínuo, provendo repetidos feedbacks para o processo de tomada de decisão (Gudmundsson, 2004).

Países da Europa e América do Norte são pioneiros na pesquisa de um novo conceito de mobilidade e no desenvolvimento e aplicação de indicadores para sua monitoração. Na Europa, o foco principal destas medidas está sobre a integração das questões ambientais nas demais políticas públicas. Nos Estados Unidos, sistemas de indicadores são desenvolvidos em todos os níveis, formalizando planos estratégicos estabelecidos pelo governo. No Canadá, ferramentas para medir o desempenho de políticas públicas também incluem relatórios sobre desenvolvimento sustentável baseados na observação de indicadores, combinando elementos e estruturas presentes nas experiências da Europa e Estados Unidos (Gudmundsson, 2001).

No Brasil, a noção de sustentabilidade ambiental, econômica e social tem sido recentemente incorporada no processo de planejamento urbano, especialmente no que se refere ao 
planejamento da mobilidade (Silva et al., 2007). Neste sentido, a análise da evolução de indicadores se constitui em uma importante ferramenta neste processo, uma vez que permite analisar a estrutura das cidades, identificar oportunidades e deficiências e acompanhar a implementação e impactos das estratégias visando a mobilidade sustentável.

À medida que se acumulam experiências de desenvolvimento de indicadores de mobilidade sustentável ao redor do mundo, algumas características têm sido observadas. De um modo geral, os indicadores desenvolvidos têm auxiliado a atingir objetivos econômicos, sociais e ambientais propostos por cenários alternativos e pacotes de políticas. Outros têm enfocado aspectos específicos da sustentabilidade, tais como acessibilidade, mobilidade e capacidade ambiental.

Independente de seu enfoque ou abrangência, o conjunto/sistema de indicadores de mobilidade sustentável tem como desafio:

- Representar a situação presente (desenvolvimento) e cenários futuros (sustentabilidade);

- Considerar todas as dimensões (social, econômica, ambiental e institucional);

- Identificar a parcela de contribuição dos transportes para os problemas globais;

- Incluir critérios de sustentabilidade e metas para interpretação de performances;

- Ser desenvolvido com base em dados de qualidade e reproduzíveis;

- Incorporar a participação de diferentes atores no desenvolvimento dos indicadores;

- Adotar um número apropriado de indicadores; e

- Ser desenvolvido para máxima utilização e impacto (Gudmundsson, 2004).

Com relação às características do sistema de indicadores de mobilidade sustentável, alguns aspectos merecem ser destacados, associados especialmente ao nível de análise, tipologias e estruturas e tamanho dos sistemas.

Os indicadores de mobilidade podem refletir vários níveis de análise, entre eles:

- Um processo de tomada de decisão onde o objetivo é ampliar a qualidade da metodologia de planejamento;

- Respostas a determinadas intervenções no sistema de transportes, representadas por mudanças nos padrões de viagens;

- Impactos físicos dos sistemas de transportes, tais como emissões e taxas de acidentes;

- Efeitos dos sistemas de transportes sobre as pessoas e ambiente, incluindo lesões, mortes ou danos nos sistemas naturais; 
- Impactos econômicos, como custos para a sociedade resultantes de acidentes e degradação ambiental (TRB, 2008).

Com relação às tipologias e estruturas que podem apresentar, a Agência Européia de Meio Ambiente define os seguintes tipos de indicadores, apresentados no trabalho de Gudmundsson (2004):

- Os indicadores descritivos medem o estado ou tendências de algumas entidades ou áreas;

- Os indicadores de performance comparam estados ou tendências com padrões, normas ou referências;

- Os indicadores de eficiência incluem proporções, relações ou combinações de tendências descritivas;

- Os indicadores de efetividade de políticas monitoram o papel das políticas nas mudanças observadas;

- E índices, que agregam uma série de indicadores de forma a transmitir uma mensagem.

No que diz respeito ao número de indicadores ou tamanho dos sistemas, enquanto cientistas são habituados a manipular um grande número de dados e informações (conseguindo incorporar toda essa informação na sua análise), decisores e público em geral preferem informação selecionada sobre questões-chave (pois a sobrecarga de informação geralmente gera mais entropia na percepção dos fenômenos).

A Figura 5.1 apresenta o conceito simplificado de pirâmide de indicadores, onde diferentes categorias de públicos-alvos são associadas aos diferentes tamanhos de sistemas. No topo da pirâmide encontram-se índices ou indicadores-chave direcionados a decisores e público em geral. Na porção intermediária, encontram-se os indicadores de média agregação, que compõem sistemas de análise, em geral. $\mathrm{Na}$ base da pirâmide encontram-se os sistemas compostos por uma ampla variedade de dados e estatísticas básicas, direcionados a técnicos e acadêmicos. 


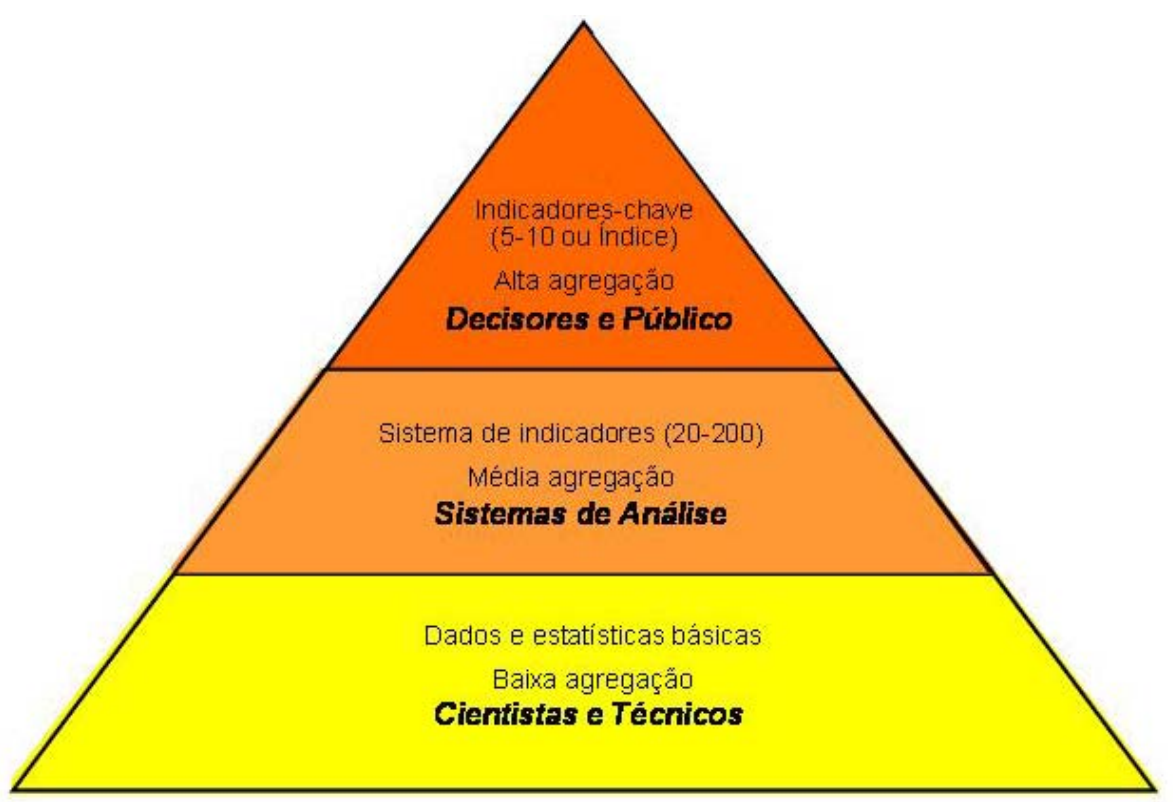

Figura 5.1: Pirâmide de Sistema de Indicadores por Público-alvo.

Fonte: Adaptado de Gudmundsson (2004).

Outras características operacionais importantes dos indicadores de mobilidade dizem respeito a:

- Qualidade dos dados de base;

- Provisão de uma figura representativa;

- Simplicidade, redução da complexidade;

- Sensibilidade às mudanças;

- Fundamentação teórica baseada em termos técnicos e científicos;

- Compatibilidade com padrões internacionais sobre sua validade;

- Atualização em intervalos regulares, de acordo com processos confiáveis (Gudmundsson, 2004).

Com relação à viabilidade e efetividade dos indicadores de mobilidade, estatísticas confiáveis são essenciais, sendo particularmente importantes para o planejamento da mobilidade sustentável. Ainda que dados sobre transportes sejam coletados, sua qualidade é altamente variável e geralmente incompatível com outras jurisdições. Isto significa desperdício de recursos e perda da oportunidade de promover a melhoria na compreensão de importantes tendências e suas relações (TRB, 2008).

Neste sentido, indicadores de mobilidade sustentável exigem padrões internacionais para as estatísticas básicas, ao mesmo tempo em que é necessário esclarecer quais as informações devem ser coletadas, como devem ser coletadas e quais os padrões de qualidade exigidos. 
Devido à alta variabilidade das estatísticas existentes, é muitas vezes difícil compreender certas tendências e impactos das atividades de transporte (TRB, 2008).

Levando em conta todos estes aspectos, o processo de seleção e construção de sistemas de indicadores de mobilidade deve observar ainda algumas questões metodológicas, discutidas a seguir.

\subsection{Seleção de Indicadores de Mobilidade Sustentável}

Uma vez definido um conceito de mobilidade urbana sustentável, mover-se dos objetivos mais abrangentes para os objetivos mais específicos é parte essencial para a definição de indicadores. Esta etapa desempenha um importante papel no processo de efetivação do conceito de mobilidade urbana sustentável, de forma a torná-lo um conceito manipulável e mensurável e a prover informação para a tomada de decisão (Black et al. 2002, Gudmundsson, 2004).

Para Gudmundsson (2004), a abordagem mais difundida para operacionalização do conceito de transporte sustentável é simplesmente listar os principais problemas ou questões que devem ser incluídas na análise. Isto tipicamente inclui problemas ambientais (como ruído, poluição, aquecimento global), questões econômicas (como investimentos em infra-estrutura de transportes, custos de exploração) e questões sociais (como acessibilidade para todos, educação e cidadania). A forma como estabelecer a lista de questões a serem abordadas pode se dar partindo das definições ou princípios de sustentabilidade mais gerais, para questões mais setoriais, caracterizando a abordagem denominada top-down (de cima para baixo). Ou inversamente, confrontando os atuais problemas de transporte com possíveis implicações em termos de desenvolvimento sustentável, caracterizando a abordagem bottom-up (de baixo para cima).

O autor destaca ainda outras abordagens para operacionalização e mensuração do conceito de transporte sustentável utilizando indicadores, assim definidas:

- Na primeira abordagem o conceito de "Transporte Sustentável" serve como metáfora de uma ampla agenda política onde as questões de transportes levam em consideração inclusive questões de desenvolvimento sustentável. Neste contexto, o planejamento, elaboração de políticas públicas e avaliação incorporam tipicamente indicadores, tais como o crescimento dos volumes de transporte ou emissões de dióxido de carbono;

- Na segunda abordagem o conceito de "Transporte Sustentável" é tomado literalmente como significado de transporte que pode ser mantido, dadas certas 
limitações de tempo e espaço impostas pelo ambiente e/ou por certas demandas da sociedade. Esta abordagem deriva de uma reflexão explícita sobre o significado de sustentabilidade e o que se deve medir no contexto mais específico do transporte;

- A terceira abordagem representa um misto entre as duas anteriores, onde explorações do significado literal do conceito de sustentabilidade são usadas como guia para construção de indicadores, que podem ser utilizados em qualquer contexto político ou de pesquisa sobre "Transporte Sustentável".

A primeira abordagem é comumente adotada por administrações, governos, políticas, etc, enquanto que a segunda é mais acadêmica. Já a terceira tem sido utilizada por pesquisadores ou especialistas para avaliar e criticar as tendências de evolução dos transportes e políticas públicas do setor. Em qualquer abordagem, o uso de indicadores para monitorar o transporte sustentável envolve uma série de tarefas. A primeira consiste na conceitualização, onde é definido o que será monitorado, neste caso, aspectos de desenvolvimento sustentável dos transportes. A segunda tarefa é a operacionalização, onde os conceitos são feitos mensuráveis através da seleção de parâmetros e tipos de indicadores. A terceira tarefa é a utilização, que se refere ao modo como os indicadores são esboçados em uma análise ou política, ou seja, sua contextualização (Gudmundsson, 2004).

Segundo TRB (2008) há uma série de princípios que auxiliam na seleção de indicadores. Estes princípios, vão ao encontro das características dos indicadores urbanos e de mobilidade sustentável discutidas anteriormente nos itens 5.1 e 5.2, ao mesmo tempo em que podem ser usadas no contexto de qualquer uma das abordagens relacionadas por Gudmundsson (2004). Estes princípios são descritos a seguir:

- Abrangência e equilíbrio - os sistemas devem incluir indicadores das principais categorias das questões sociais, econômicas e ambientais.

- Os dados devem ser facilmente coletados - a seleção dos indicadores deve ser baseada na facilidade de coleta dos dados para sua construção e na sua qualidade. Sempre que possível, a coleta de dados deve ser padronizada para permitir a comparação entre unidades geográficas, comparações entre períodos de tempo e diferentes grupos.

- Fácil compreensão e utilidade - devem ser de fácil compreensão do público em geral e úteis aos tomadores de decisão. Indicadores, detalhes da análise e dos dados de base devem estar disponíveis para todos os envolvidos no processo de tomada de decisão. 
- Desagregação - os dados dos indicadores devem poder ser desagregados de várias formas para dar suporte a tipos específicos de análises, para diferentes grupos sociais, modos de transporte e unidades geográficas.

- Unidades de referência - são unidades normalizadas para facilitar a comparação dos impactos: por ano, per capita, por viagem, por veículo-ano ou por unidade monetária. A seleção de unidades de referência pode influenciar em como os problemas são definidos e como as soluções são priorizadas.

- Níveis de análise - os indicadores devem permitir, sempre que possível, medir os últimos impactos de determinadas questões, bem como os efeitos intermediários.

- Metas de desempenho - são objetivos específicos mensuráveis para se atingir determinado estado desejável, bem como reduções específicas de determinados parâmetros para uma data específica. São úteis para monitorar e avaliar os progressos em direção à sustentabilidade. Como algumas metas são dinâmicas, devem ser feitas atualizações ao longo do tempo visando obter melhores informações ou novos padrões.

TRB (2008) destaca ainda que a padronização de indicadores de sustentabilidade pode permitir a comparação entre comunidades, análise de tendências e avaliação de opções políticas para dar suporte às metas globais de sustentabilidade. Neste sentido, estrutura uma lista de potenciais indicadores de sustentabilidade que deve ser avaliada por membros do comitê e especialistas, de modo a ser formalmente adotada por profissionais da área de transportes e mobilidade urbana. Os indicadores relacionados em TRB (2008), propostos com base nos trabalhos de CST (2003), Marsden et al. (2005) e Litman (2007) podem apresentar diferentes níveis de prioridade para coleta, definida conforme a escala apresentada na Tabela 5.1. A lista completa de indicadores é apresentada na Tabela 5.2, incluindo a direção desejada para sua tendência, nível de desagregação e prioridade.

Tabela 5.1: Níveis de prioridade para coleta dos indicadores propostos pelo TRB (2008).

\begin{tabular}{cl}
\hline Nível de Prioridade & \multicolumn{1}{c}{ Descrição } \\
\hline A & Deve ser coletado em todas as situações \\
\hline B & Deve ser coletado, se possível \\
\hline C & $\begin{array}{l}\text { Deve ser coletado quando há a necessidade de se monitorar } \\
\text { uma condição específica da comunidade }\end{array}$ \\
\hline
\end{tabular}


Tabela 5.2: Potenciais indicadores de mobilidade sustentável.

\begin{tabular}{|c|c|c|c|c|c|}
\hline Categ. & Subcategoria & Indicador & Direção Desejada & Desagregação & Prioridade \\
\hline \multirow{3}{*}{$\begin{array}{l}\stackrel{n}{\frac{1}{d}} \\
\stackrel{\mathbb{T}}{>}\end{array}$} & Veículos & Propriedade de veículos motorizados & $\begin{array}{ll} & \text { Para baixa renda } \\
\downarrow & \text { Para alta renda }\end{array}$ & $\begin{array}{l}\text { Por tipo de veículo, por perfil } \\
\text { demográfico, por localização }\end{array}$ & A \\
\hline & Mobilidade & Viagens por veículo motorizado & $\begin{array}{ll} & \text { Para baixa renda } \\
\downarrow & \text { Para alta renda } \\
\end{array}$ & $\begin{array}{l}\text { Tipo de viagem, características do } \\
\text { indivíduo, condições de viagem }\end{array}$ & A \\
\hline & Divisão Modal & $\begin{array}{l}\text { Parcela de viagens por auto, transporte } \\
\text { público e modos não-motorizados }\end{array}$ & $\begin{array}{l}\text { Reduzir as viagens } \\
\text { por automóvel }\end{array}$ & $\begin{array}{l}\text { Tipo de viagem, características do } \\
\text { indivíduo, condições de viagem }\end{array}$ & A \\
\hline \multirow{4}{*}{ 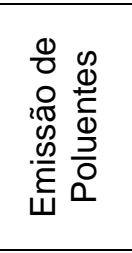 } & Emissões & Total de emissões por veículos & Reduzir & $\begin{array}{l}\text { Tipo de emissão, modo, } \\
\text { localização }\end{array}$ & B \\
\hline & Exposição à poluição do ar & $\begin{array}{l}\text { Exposição a baixos níveis de qualidade } \\
\text { do ar }\end{array}$ & Reduzir & Grupos demográficos afetados & A \\
\hline & Mudanças climáticas & Emissões de $\mathrm{CO}_{2}$ e $\mathrm{CH}_{4}$ & Reduzir & Por modo & A \\
\hline & Fontes de emissão & Emissões de veículos e edificações & Reduzir & Tipos de emissões e modo & $\mathrm{B}$ \\
\hline \multirow{2}{*}{ 을 } & Ruído de tráfego & $\begin{array}{l}\text { População exposta a ruído superior a } \\
55 \text { LAeq, } T\end{array}$ & Reduzir & $\begin{array}{l}\text { Grupos demográficos, localização, } \\
\text { modo de transporte }\end{array}$ & B \\
\hline & Ruído de transporte aéreo & $\begin{array}{l}\text { População exposta a ruído de } \\
\text { transporte aéreo superior a } 57 \text { LAeq,T }\end{array}$ & Reduzir & $\begin{array}{l}\text { Grupos demográficos, localização, } \\
\text { modo de transporte }\end{array}$ & $\mathrm{B}$ \\
\hline \multirow{3}{*}{ 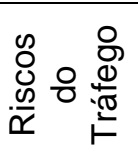 } & Vítimas de acidentes & Mortos e feridos em acidentes & Reduzir & Modo, via, tipo e causa da colisão & A \\
\hline & Acidentes & Relatórios de acidentes & Reduzir & Modo, via, tipo e causa da colisão & A \\
\hline & Custos dos acidentes & $\begin{array}{l}\text { Custos econômicos dos acidentes de } \\
\text { tráfego }\end{array}$ & Reduzir & Modo, via, tipo e causa da colisão & B \\
\hline \multirow{5}{*}{ 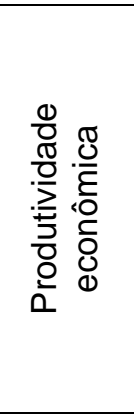 } & Custos dos transportes & $\begin{array}{l}\text { Despesas dos consumidores com } \\
\text { transporte }\end{array}$ & Reduzir & Modo, tipo de usuário e localização & A \\
\hline & $\begin{array}{l}\text { Custos das viagens (tempo } \\
\text { e dinheiro) }\end{array}$ & Acesso ao emprego & Reduzir & Modo, tipo de usuário e localização & A \\
\hline & Confiabilidade & $\begin{array}{l}\text { Custos per capita dos } \\
\text { congestionamentos }\end{array}$ & Reduzir & Modo, localização & $\mathrm{B}$ \\
\hline & Custos da infra-estrutura & $\begin{array}{l}\text { Gastos com rodovias, transporte } \\
\text { público, estacionamentos, portos, etc }\end{array}$ & $\begin{array}{c}\text { Reduzir, por } \\
\text { unidade de viagem } \\
\text { (eficiência) }\end{array}$ & Modo, localização & $A$ \\
\hline & Custos de frete & Eficiência do transporte de carga & Aumentar & Modo, área geográfica & $\mathrm{B}$ \\
\hline
\end{tabular}




\begin{tabular}{|c|c|c|c|c|c|}
\hline Categ. & Subcategoria & Indicador & Direção Desejada & Desagregação & Prioridade \\
\hline \multirow{3}{*}{ 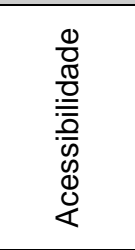 } & Opções de mobilidade & $\begin{array}{l}\text { Qualidade da caminhada, ciclismo, } \\
\text { transporte público, direção, táxi, etc }\end{array}$ & Aumentar & $\begin{array}{l}\text { Motivo de viagem, localização, } \\
\text { usuário }\end{array}$ & A \\
\hline & $\begin{array}{l}\text { Acessibilidade ao uso do } \\
\text { solo }\end{array}$ & $\begin{array}{l}\text { Qualidade da acessibilidade ao uso do } \\
\text { solo }\end{array}$ & Aumentar & $\begin{array}{l}\text { Motivo de viagem, localização, } \\
\text { usuário }\end{array}$ & $\mathrm{B}$ \\
\hline & Substitutos da mobilidade & $\begin{array}{l}\text { Acesso a Internet e qualidade dos } \\
\text { serviços de entrega domiciliar }\end{array}$ & Aumentar & $\begin{array}{l}\text { Motivo de viagem, localização, } \\
\text { usuário }\end{array}$ & B \\
\hline \multirow{3}{*}{ 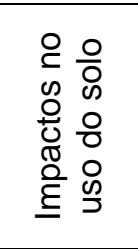 } & Espalhamento & $\begin{array}{l}\text { Área per capita de solo } \\
\text { impermeabilizado }\end{array}$ & Reduzir & $\begin{array}{l}\text { Por localização e tipo de } \\
\text { desenvolvimento }\end{array}$ & $\mathrm{B}$ \\
\hline & $\begin{array}{l}\text { Uso do solo para } \\
\text { transportes }\end{array}$ & $\begin{array}{l}\text { Área utilizada para infra-estrutura de } \\
\text { transportes }\end{array}$ & Reduzir & Por modo & $\mathrm{B}$ \\
\hline & $\begin{array}{l}\text { Degradação ecológica e } \\
\text { cultural }\end{array}$ & $\begin{array}{l}\text { Habitat e locais culturais degradados } \\
\text { por infra-estrutura de transportes }\end{array}$ & Reduzir & $\begin{array}{l}\text { Tipo de habitat e recurso, } \\
\text { localização }\end{array}$ & $\mathrm{B}$ \\
\hline \multirow{3}{*}{$\begin{array}{l}\frac{0}{0} \\
\frac{\pi}{0} \\
: \frac{7}{5} \\
\frac{0}{山}\end{array}$} & $\begin{array}{l}\text { Acessibilidade ao } \\
\text { transporte }\end{array}$ & $\begin{array}{l}\text { Parcela do orçamento familiar } \\
\text { necessária para prover transporte de } \\
\text { qualidade }\end{array}$ & Reduzir & Demografia, grupos especiais & A \\
\hline & Acessibilidade à moradia & Acessibilidade à moradia confortável & Aumentar & $\begin{array}{l}\text { Por grupos demográficos, } \\
\text { especialmente de baixa renda e } \\
\text { com deficiência física }\end{array}$ & $\mathrm{C}$ \\
\hline & Acessibilidade & $\begin{array}{l}\text { Qualidade da acessibilidade para } \\
\text { pessoas com deficiência }\end{array}$ & Aumentar & $\begin{array}{l}\text { Por área geográfica, modo, tipo de } \\
\text { deficiência }\end{array}$ & $\mathrm{B}$ \\
\hline \multirow{4}{*}{ 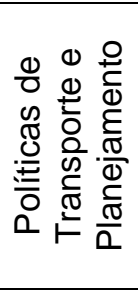 } & Eficiência econômica & Preços baseados nos custos & Aumentar & $\begin{array}{l}\text { Por modo, tipo de custo (viária, } \\
\text { estacionamento, etc) }\end{array}$ & $\mathrm{B}$ \\
\hline & Planejamento estratégico & $\begin{array}{l}\text { Planejamento individual, sistemas de } \\
\text { suporte e objetivos estratégicos }\end{array}$ & Aumentar & Por modo, agência & $\mathrm{B}$ \\
\hline & Eficiência do planejamento & Planejamento completo e neutro & Aumentar & Por modo, agência & C \\
\hline & Satisfação do usuário & Resultados de pesquisas com usuários & Aumentar & $\begin{array}{l}\text { Por grupo (deficientes, crianças, } \\
\text { baixa renda) }\end{array}$ & $\mathrm{B}$ \\
\hline
\end{tabular}




\subsection{Indicadores de Transportes e Mobilidade no Brasil}

Seguindo a tendência internacional, o Brasil tem apresentado recentemente algumas iniciativas de elaboração e aplicação de indicadores para monitorar tendências e dar suporte a políticas públicas, especialmente em nível urbano. No entanto, na maioria das experiências observadas, o enfoque da sustentabilidade ainda é secundário, prevalecendo os indicadores tradicionais relacionados especialmente a número de viagens, divisão modal e parâmetros de desempenho dos sistemas de transporte.

Entre os sistemas específicos para monitoração da mobilidade recentemente desenvolvidos no país encontra-se o Sistema de Informações da Mobilidade Urbana, desenvolvido pela ANTP (2006). O sistema, disponibilizado na Internet na página da associação, agrega informações para um conjunto de 438 municípios brasileiros, com população superior a 60 mil habitantes.

O Sistema de Informações da Mobilidade Urbana tem como objetivos principais:

- "Geração de indicadores agregados nacionais que permitam uma avaliação do que representa o setor em patrimônio investido, custos gerais e participação no PIB, bem como nos processos de consumo de espaço e energia, e de produção de externalidades como a poluição e os acidentes;

- Geração de indicadores específicos que permitam análises comparativas com indicadores similares observados internacionalmente, contribuindo para a elaboração de políticas públicas no setor;

- Geração de indicadores voltados à análise de séries históricas, visando a monitoração dos impactos de políticas públicas para o setor;

- Geração de indicadores e quantitativos que permitam uma qualificação das propostas da ANTP e demais entidades interessadas em defender políticas públicas para o setor, em especial junto à opinião pública e aos poderes executivo, legislativo e judiciário" (ANTP, 2006).

O sistema monitora indicadores divididos nos setores Transporte Público e Trânsito, apresentando informações em duas etapas: a primeira composta por dados básicos levantados junto aos órgãos responsáveis pelas informações nas cidades pesquisadas; a segunda, relacionada aos dados coletados devidamente tratados e disponibilizados em formato adequado aos interessados. Os indicadores obtidos nesta segunda etapa, para os dois setores, são mostrados na Tabela 5.3. 
Tabela 5.3: Indicadores do Sistema de Informações da Mobilidade Urbana - ANTP.

\begin{tabular}{ll}
\hline & Transporte Público \\
\hline Passageiros Transportados (ano) & Custo operacional (R\$/ano) \\
\hline Viagem/ habitante/ano & Custo operacional/km (R\$) \\
\hline km em serviço (ano) & Tarifa dez/06 (R\$) \\
\hline PMA & Tarifas compradas com a renda média \\
\hline Frota & Recursos humanos no TC (RH) \\
\hline Frota/mil habitantes & RH/veículo \\
\hline Arrecadação tarifária (R\$/ano) & Quantidade de táxi \\
\hline Arrecadação/ passageiro (R\$) & Táxi/mil habitantes \\
\hline & Trânsito \\
\hline Recursos humanos no trânsito (RH) & Interseções semafóricas (IS) \\
\hline RH/mil habitantes & IS/mil habitantes \\
\hline Recursos materiais no trânsito (RM) & Equipamento eletrônico de fiscalização (EEF) \\
\hline RM/mil habitantes & EEF/mil habitantes \\
\hline
\end{tabular}

A Associação Nacional das Empresas de Transportes Urbanos (NTU) divulgou em 2006 a Pesquisa Mobilidade da População Urbana, com o objetivo de fornecer subsídios para a formulação de políticas de transporte de passageiros no âmbito nacional. A pesquisa, que englobou cidades brasileiras com mais de 100 mil habitantes (totalizando 255 municípios em 2005), divulgou resultados para um conjunto de indicadores, distribuídos em três categorias, conforme mostra a Tabela 5.4.

Tabela 5.4: Indicadores apresentados pela NTU na Pesquisa Mobilidade da População Urbana.

\begin{tabular}{l}
\hline \multicolumn{1}{c}{ Padrões de Mobilidade } \\
\hline Freqüência dos deslocamentos \\
Motivos das viagens \\
Modos de transporte utilizados \\
Duração da viagem \\
Disponibilidade de meios de \\
transporte \\
Propriedade de veículos
\end{tabular}

\begin{tabular}{l}
\multicolumn{1}{c}{ Tópicos Especiais } \\
\hline Auxílios e benefícios \\
Vale-transporte \\
Desconto na tarifa para \\
estudantes \\
Gratuidade para idosos \\
Acessibilidade das pessoas \\
portadoras de deficiência \\
Substituição do ônibus por outros \\
modos de transporte \\
Comprometimento da renda com \\
transporte \\
\hline
\end{tabular}

\section{Opiniões sobre o Transporte}

Transporte entre os problemas da cidade

Qualidade e preço no transporte urbano

Gravidade dos problemas no transporte por ônibus

Uma iniciativa pioneira na institucionalização de indicadores para a monitoração urbana foi apresentada pela cidade de São Paulo. Através da Lei Municipal $\mathrm{N}^{0} 14.173$, publicada em 26 de junho de 2006, a Prefeitura Municipal de São Paulo tem o compromisso de estabelecer indicadores de desempenho relativos à qualidade dos serviços públicos no município, acompanhar sua evolução e apresentar periodicamente os resultados a sociedade. As áreas monitoradas incluem: Saúde Pública; Educação Básica; Segurança no Trânsito; Proteção do Meio Ambiente; Limpeza Pública e Transportes Públicos. 
Os indicadores relacionados aos setores Segurança no Trânsito e Transportes Públicos são apresentados a seguir:

\section{- Segurança no Trânsito}

- Número proporcional de acidentes fatais ocorridos no trânsito em cem mil habitantes, no conjunto e no período considerado;

- Número proporcional de acidentes no trânsito com lesões em cem mil habitantes, ocorridos no conjunto e no período considerado;

- Média aritmética mensal dos congestionamentos, medida em quilômetros, nos horários de pico.

\section{- Transportes Públicos}

- Tempo médio de espera nos terminais de transferência utilizados para o embarque de passageiros para o transporte urbano;

- Tempo médio de espera nas paradas intermediárias entre o terminal de transferência de saída e o de chegada;

- Tempo médio para o deslocamento dos trabalhadores de seus domicílios aos locais de trabalho;

- Velocidade média do deslocamento do ônibus em horário normal e em horário de pico;

- Nível médio de pontualidade por empresa;

- Nível de limpeza da área de circulação dos terminais de transferência;

- Nível de limpeza dos banheiros públicos dos terminais de transferência;

- Nível de limpeza, conservação e manutenção da frota.

O Observatório Cidadão Nossa São Paulo (2008) disponibiliza em sua página na Internet, um conjunto de indicadores sociais, ambientais, econômicos, políticos e culturais sobre a cidade de São Paulo, que incluem os tópicos relacionados na Lei Municipal N 14.173/2006. Os indicadores são especializados para o município como um todo e para as 31 subprefeituras em que o mesmo incide. Neste contexto, são apresentadas análises comparativas entre as subprefeituras, para os principais indicadores que compõem o sistema.

Uma vez que os sistemas de indicadores de mobilidade urbana sustentável se constituem em ferramentas ainda pouco exploradas no Brasil, este trabalho apresenta uma abordagem que incide na identificação de aspectos-chave para a definição do conceito de mobilidade sustentável e cria um índice que agrega esses conceitos segundo um sistema de indicadores, voltado à monitoração das condições de mobilidade. O método proposto para desenvolvimento destas atividades é apresentado a seguir. 


\section{MÉTODO}

Neste capítulo é apresentado o método de desenvolvimento do trabalho, bem como os procedimentos para identificação dos dados básicos que compõem o Índice de Mobilidade Urbana Sustentável. São abordados ainda os procedimentos de coleta de dados e análise dos resultados para cada etapa.

\subsection{Aspectos Gerais}

A revisão bibliográfica sintetizada nos capítulos de 2 a 5 estabelece o referencial teórico para esta pesquisa, permitindo identificar metodologias adequadas aos seus objetivos. A partir dos aspectos analisados na etapa anterior, foi estruturado o método de desenvolvimento do trabalho, que contempla, em linhas gerais, as seguintes atividades:

- Estruturação do referencial de mobilidade urbana sustentável em um conjunto de cidades brasileiras através de reuniões com técnicos e gestores urbanos;

- Análise dos dados obtidos nas cidades pesquisadas de forma a construir uma hierarquia de critérios agregando os principais elementos identificados nessas reuniões;

- Desenvolvimento de um índice para monitoração da mobilidade, com base na hierarquia de critérios elaborada na etapa anterior;

- Aplicação e verificação dos resultados do índice para uma cidade brasileira, por meio do cálculo dos indicadores que o compõem;

- Análise dos resultados obtidos para o índice na cidade pesquisada;

- Discussão sobre os procedimentos de cálculo do índice e proposições para sua melhoria, de forma a permitir sua aplicação em outras cidades.

As etapas de estruturação do referencial de mobilidade urbana sustentável e de construção do Índice de Mobilidade Urbana Sustentável (referido neste trabalho como IMUS) se constituem nas principais atividades do método proposto. Neste sentido, os procedimentos para sua realização são descritos de forma bastante geral simplificada, possibilitando que os 
mesmos possam ser reproduzidos com facilidade em qualquer contexto. Isso permite o desenvolvimento de ferramentas inteiramente adaptadas a diferentes situações, representadas por diferentes cidades ou regiões metropolitanas.

A Figura 6.1 apresenta as principais etapas que constituem o método deste trabalho. Cada uma dessas etapas é descrita a seguir. No caso do Referencial Teórico, como já mencionado, este foi apresentado nos Capítulos 2 a 5. Por outro lado, para as demais etapas são apresentados os principais fundamentos assumidos, detalhados nos respectivos capítulos que retratam a pesquisa realizada.

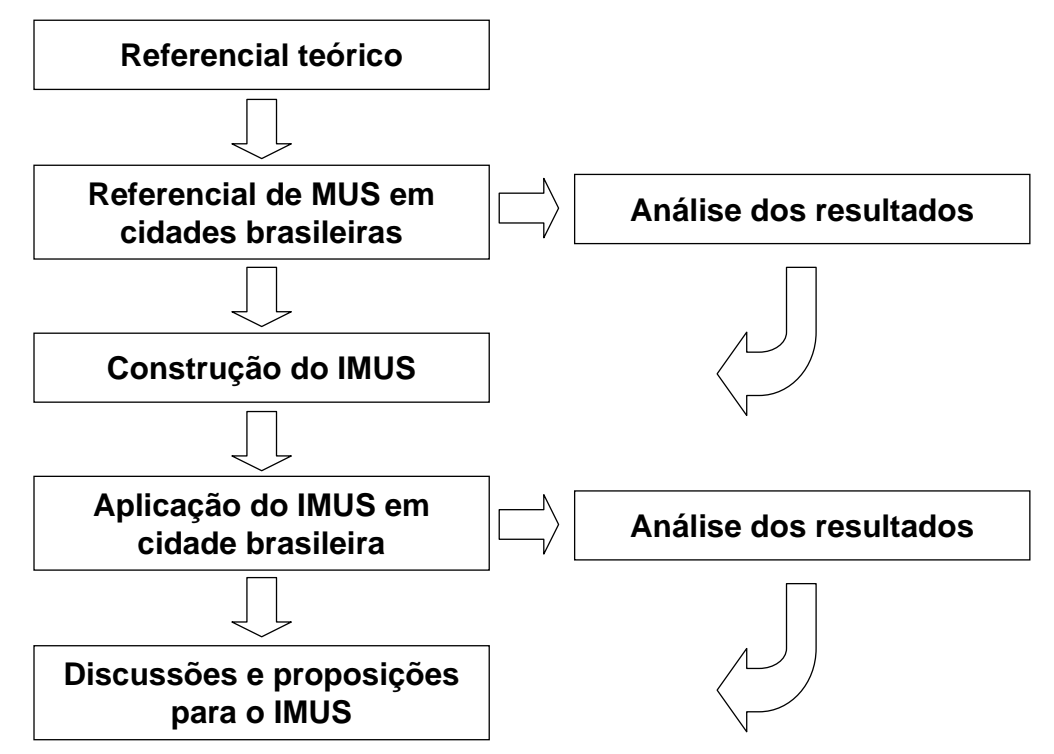

Figura 6.1: Método de desenvolvimento da pesquisa.

\subsection{Referencial de Mobilidade Urbana Sustentável}

A primeira etapa do trabalho consiste na construção do referencial de mobilidade urbana sustentável em cidades brasileiras. Para tal, é proposta uma abordagem para caracterização do conceito, para ser aplicada em reuniões com grupos de gestores públicos e planejadores, envolvidos em atividades relacionadas ao planejamento urbano e de transportes.

As reuniões ou workshops devem reunir profissionais de diferentes áreas de atuação, vinculados às secretarias municipais, órgãos de gestão municipal e regional, empresas públicas, órgãos de gestão e fiscalização de trânsito e transportes, entre outros, de forma a reunir os principais atores envolvidos no processo de gestão do desenvolvimento urbano, ambiental e da mobilidade.

A abordagem a ser aplicada nos workshops tem como base a metodologia MCDA-C, cujos principais aspectos foram sintetizados no Capítulo 4. Em função das características da 
análise proposta e da limitação de tempo para desenvolvimento das atividades junto a técnicos e gestores, o método baseou-se essencialmente na fase de Estruturação prevista na metodologia MCDA-C, desenvolvendo-a com adaptações até a etapa de Identificação dos Pontos de Vista Fundamentais (PVFs). Além disso, foram previstas etapas complementares que incluem a identificação de indicadores de mobilidade em fases específicas da avaliação, de modo a evidenciar alguns aspectos-chave considerados neste estudo. Entre estes aspectos, encontram-se as diferenças existentes entre a abordagem tradicional de tratamento das questões de mobilidade urbana e o novo paradigma emergente, buscando evidenciar os diferentes enfoques nas duas abordagens.

Assim, em função da forma como foi concebida e estruturada, a principal característica da abordagem proposta é sua possibilidade de aplicação em diferentes contextos, permitindo a identificação dos elementos fundamentais para o tema mobilidade sustentável em um município, região, organização, entidade ou grupo de gestores.

As etapas para a construção do referencial de mobilidade urbana sustentável a partir da metodologia MCDA-C são descritas a seguir.

\subsubsection{Identificação de Indicadores de Mobilidade Urbana para o Enfoque Tradicional de Planejamento}

De modo a caracterizar o tratamento dado às questões de mobilidade urbana no contexto analisado, propõe-se em uma etapa inicial a elaboração de uma relação de indicadores de mobilidade utilizados pelos técnicos e gestores participantes do exercício. Assim, os indicadores gerados devem estar vinculados ao modelo vigente de planejamento da mobilidade urbana, revelando quais são os elementos comumente considerados em sua gestão.

Para a identificação destes indicadores o facilitador (ver Capítulo 4) solicita aos participantes da atividade que listem em uma folha de papel cerca de cinco indicadores utilizados cotidianamente em suas atividades profissionais, no órgão, secretaria ou instituição aos quais são vinculados. As listas são recolhidas pelo Facilitador que irá guardá-las para posterior classificação dos indicadores nelas contidos, agrupando-os em grandes áreas ou temas relacionados à mobilidade urbana. Estes indicadores são retomados na última etapa de construção do referencial de mobilidade urbana sustentável, para serem comparados a outros indicadores gerados durante a análise. 


\subsubsection{Construção do Conceito de Mobilidade Urbana Sustentável}

As etapas subseqüentes compreendem a estruturação do conceito de mobilidade urbana sustentável como base nos valores e perspectivas dos participantes da atividade, levando em consideração seu conhecimento da realidade local, e as especificidades e necessidades identificadas. Para tal, são promovidas discussões buscando construir o conceito de mobilidade sustentável para o contexto de análise (município, região metropolitana, estado ou outra área geográfica) e definir ações para sua efetiva implementação. As análises e debates devem permitir dispor de um conjunto de aspectos-chave a serem considerados na formulação de políticas de mobilidade sustentável, destacando os aspectos indispensáveis no ponto de vista dos participantes.

Nesta fase do trabalho, o método MCDA-C é implementado em planilhas eletrônicas, de modo a permitir o registro e a manipulação das informações obtidas. A opção por implementar o método neste ambiente se deu em função de facilitar o acompanhamento do processo pelos participantes da atividade e permitir que os mesmos possam reproduzir facilmente os procedimentos em situações posteriores. Assim, é desnecessária a aquisição de software especializado para o desenvolvimento das atividades que constituem a metodologia.

Guardadas algumas adaptações, a maioria dos conceitos relacionados nesta fase são aqueles já definidos no Capítulo 4. Desta forma, estes são abordados de forma sintetizada neste capítulo.

Ao longo do processo são manipuladas quatro planilhas específicas e desenvolvidos os procedimentos descritos a seguir para cada uma delas. Os modelos de planilhas eletrônicas utilizadas neste trabalho constam no Anexo A - "Material do Curso de Capacitação Gestão da Mobilidade Urbana".

\subsubsection{Caracterização do problema (Planilha 1 - Anexo A)}

$\mathrm{Na}$ planilha inicial são identificados os dados básicos de análise, compreendendo os objetivos e atores envolvidos no processo, conforme descrito a seguir:

- Objetivo ou Meta: Objetivo principal a que se destina a análise. No caso específico desta avaliação, o objetivo se constitui em "Identificar Ações para a Mobilidade Sustentável";

- Decisor: Indivíduo ao qual foi delegada a responsabilidade de resolver o problema. Neste caso o decisor se configura pelo conjunto de técnicos e gestores em nível municipal, estadual ou metropolitano; 
- Facilitador: Pessoa responsável em auxiliar o decisor no processo de construção do modelo de negociação e avaliação, ou seja, o coordenador da atividade;

- Intervenientes: Indivíduos ou instituições que podem influenciar diretamente as decisões através de seu sistema de valores. Neste caso se constituem nos técnicos e gestores presentes, ou as instituições que representam.

- Agidos: Indivíduos ou instituições que influenciam indiretamente as decisões. Não possuem contato direto com o decisor. Nesta situação os Agidos representam a comunidade das cidades ou região, representados por meio dos Intervenientes.

- Horizonte de tempo: Referencial estabelecido pelos participantes para as metas e objetivos identificados.

\subsubsection{Identificação dos Elementos Primários de Avaliação (EPAs) e construção dos Conceitos Orientados à Ação (Planilha 2 - Anexo A)}

Os Elementos Primários de Avaliação (EPAs) se constituem em idéias e conceitos relacionados ao tema em análise, conforme definido no Capítulo 4. Neste caso, representam metas, objetivos, ações, idéias, perspectivas e valores expressos pelos participantes com relação à questão mobilidade urbana sustentável em seu contexto específico ou região geográfica.

Os EPAs são obtidos por meio da técnica de brainstorming, de forma a estimular a criatividade e a geração de idéias por parte dos participantes, que devem expressar verbalmente seus pensamentos. Nesta etapa, o Facilitador se restringe a conduzir o processo, mantendo-se neutro ao longo de todo ele. Para estimular a geração de idéias podem ser apresentadas imagens, textos ou outros recursos que estimulem a participação do grupo. O número de EPAs identificados deve ser limitado em função do tempo disponível para desenvolvimento da atividade.

O conjunto de EPAs obtido é então transformado em um conjunto de conceitos orientados à ação, atribuindo-se um verbo no infinitivo à idéia expressa no EPA, compondo o primeiro pólo do conceito, denominado de pólo positivo. O pólo negativo é então definido, completando o conceito. Estes elementos foram definidos de forma detalhada no Capítulo 4.

De posse dos conceitos completos, é feita uma análise do conjunto e são identificadas as grandes linhas de ação ou Alternativas que melhor caracterizam as idéias obtidas. Esta atividade é desenvolvida com a ampla participação do grupo, de modo a assegurar que os eixos identificados reflitam com maior precisão possível o perfil de pensamento do grupo. 
As Alternativas identificadas nesta etapa são registradas na parte superior da planilha onde constam os EPAs (Planilha 1) e são automaticamente transferidas para a Planilha 3 para auxiliar na construção do mapa cognitivo.

\subsubsection{Construção do Mapa Cognitivo (Planilha 3 - Anexo A)}

A construção do mapa cognitivo, ou mapa de relações meios e fins, permite a identificação das relações de causa e efeito estabelecidas entre os conceitos. O mapa é construído para cada estratégia ou linha de ação definida na fase anterior, o que exige a classificação prévia das idéias geradas. Após a classificação, a construção do mapa é feita traçando-se setas que representam as conexões existentes entre os conceitos "mais operacionais", posicionados abaixo na hierarquia, e os conceitos definidos como "mais estratégicos", dispostos na porção superior do mapa. Relações existentes entre conceitos de diferentes eixos também são identificadas nesta etapa.

Durante a construção do mapa cognitivo, lacunas no entendimento do problema podem ser identificadas, implicando na adição de novos EPAs e conceitos orientados a ação. Uma vez construído o mapa, este deve ser visualizado por inteiro pelo grupo e validado junto ao Facilitador.

\subsubsection{Identificação dos Pontos de Vista Fundamentais (Planilhas 3 e 4 - Anexo A)}

A etapa seguinte consiste na identificação dos Pontos de Vista Fundamentais (PVFs) a partir da análise do mapa cognitivo e da identificação dos conceitos considerados fundamentais pelos decisores com relação à questão. A análise pode ser feita identificandose os conceitos denominados "cabeça" e "cauda" e a estrutura hierárquica dos mesmos.

De posse de um conjunto preliminar de PVFs obtido a partir da identificação dos conceitos "cabeça", o grupo é questionado sobre a representatividade dos mesmos, confirmando se estes sintetizam os aspectos fundamentais relacionados à questão. Se identificada a necessidade de se acrescentar outro conceito à lista de PVFs, isto pode ser feito nesta etapa do exercício. Após esta verificação, e com o conjunto final de PVFs é feita a representação da arborescência, formada pelo objetivo estratégico, pelas áreas de interesse e por todos os PVFs.

\subsubsection{Identificação de Indicadores para os Pontos de Vista Fundamentais}

A etapa final da atividade em grupo compreende a elaboração de uma nova relação de indicadores de mobilidade, relacionados nesta fase aos PVFs. 
Uma vez obtida a lista de PVFs, o Facilitador solicita aos participantes que associem a cada um destes, indicadores adequados à sua monitoração, anotando-os na própria planilha eletrônica. Desta forma, o processo de identificação dos indicadores é interativo, e permite que os mesmos sejam automaticamente classificados em grandes áreas ou temas, à medida que são associados aos PVFs.

Os indicadores são utilizados em duas etapas do exercício como ferramentas para refletir a opinião e conhecimento dos participantes com relação ao tema mobilidade urbana sustentável. Na primeira etapa estes refletem a forma como a questão vem sendo tratada até o presente momento no âmbito da cidade (ou outra região geográfica). Estes indicadores são extraídos das listas elaboradas pelos participantes na etapa inicial da atividade, os quais devem ter sido classificados previamente pelo Facilitador em temas gerais relacionadas a mobilidade urbana. Os indicadores da segunda etapa refletem a assimilação dos conceitos discutidos, a atenção dada às novas questões levantadas ao longo do processo e possivelmente a ruptura do modo tradicional de ver e planejar a mobilidade urbana.

As duas listas são apresentadas aos participantes da atividade. A partir daí são discutidas questões como:

- Semelhanças e diferenças entre os indicadores gerados na primeira e na segunda etapa;

- Questões relacionadas ao modo tradicional de planejamento de transportes e ao novo paradigma da mobilidade urbana;

- Consolidação dos PVFs como referencial de mobilidade urbana sustentável para o contexto da cidade ou da região, concluindo assim a etapa de caracterização e estruturação do conceito.

\subsubsection{Análise dos Resultados}

A análise dos resultados obtidos na etapa de definição do referencial de mobilidade urbana sustentável tem dois objetivos principais:

- Verificar as diferenças locais no tratamento das questões relativas à mobilidade urbana;

- Analisar as diferenças regionais (assumindo que o processo é aplicado a diferentes contextos geográficos) na estruturação do referencial de mobilidade urbana sustentável;

- Elaborar uma síntese dos principais aspectos considerados pelos técnicos e gestores participantes da atividade em relação à mobilidade em sua região de 
atuação, enfatizando os principais problemas e potencialidades para o desenvolvimento sustentável do sistema de transportes;

Em um primeiro momento os resultados são analisados por cidade, visando destacar as diferenças encontradas entre os elementos identificados na primeira fase da atividade de capacitação e os elementos identificados na fase final do exercício. Esta análise tem por objetivo identificar eventuais variações no tratamento das questões de mobilidade urbana, relacionadas à abordagem tradicional, e ao novo paradigma em desenvolvimento no país, ao qual são associados os conceitos de sustentabilidade e mobilidade urbana sustentável. Esta análise é desenvolvida comparando-se os temas abordados pelos indicadores identificados na primeira etapa, com as Alternativas identificadas na segunda fase do exercício. Desta forma, permite identificar a evolução dos conceitos subjacentes às grandes áreas de preocupação expressas pelos participantes do curso durante a construção do referencial de mobilidade urbana sustentável para a cidade ou Região Metropolitana, ou Aglomeração Urbana.

Uma segunda abordagem contempla uma análise comparativa entre os resultados obtidos para múltiplos contextos geográficos. No sentido de destacar as diferenças regionais encontradas, a análise dos dados obtidos nesta fase é feita a partir de dois enfoques principais:

- O primeiro relacionado às dimensões fundamentais que estruturam o conceito de sustentabilidade urbana (social, econômica e ambiental), buscando identificar a importância relativa de cada dimensão, por meio da análise das Alternativas identificadas em cada contexto;

- O segundo relacionado aos temas abordados, expressos por meio dos PVFs, de modo a verificar os enfoques específicos para as questões de ordem social, econômica e ambiental em cada contexto.

Para análise dos dados são utilizados diagramas hierárquicos que permitem organizar diferentes camadas de informação, indo desde os objetivos mais elevados da sustentabilidade, até os níveis mais baixos e precisos que constituem as bases da hierarquia (uma aplicação deste método pode ser vista em Black et al., 2002). Estes diagramas são construídos para cada cidade ou região e comparados com base nos enfoques definidos anteriormente.

\subsection{Construção do Índice de Mobilidade Urbana Sustentável (IMUS)}

A partir dos referenciais de mobilidade sustentável obtidos nas reuniões com técnicos e especialistas nas cidades pesquisadas, segundo os respectivos contextos temporais e 
geográficos, é possível identificar aspectos comuns e divergentes. Contudo, de forma a reunir diferentes referenciais segundo um modelo comum de monitoração da mobilidade será proposto um índice de mobilidade urbana sustentável .

Os índices são ferramentas que agregam indicadores através de métodos aritméticos ou regras de decisão, permitindo simplificar parâmetros complexos, como já mencionado no Capítulo 5. Neste sentido, para a construção de um índice de mobilidade urbana sustentável, algumas atividades fundamentais devem ser desenvolvidas:

- A primeira, relacionada à forma como os diferentes elementos associados ao tema mobilidade sustentável se relacionam entre si, definindo uma hierarquia de critérios que serve como base para a construção do índice;

- A segunda, relacionada à identificação de indicadores direcionados a monitorar cada um dos temas ou tópicos que compõem a hierarquia;

- A terceira, relacionada à determinação da importância relativa (através de pesos) dos diferentes critérios (temas e indicadores) que compõem a estrutura hierárquica do índice, permitindo assim identificar de que forma influenciam o resultado final do mesmo;

- A quarta, relacionada ao método de normalização dos critérios, de forma a permitir sua agregação e comparação;

- A quinta, relacionada ao método de combinação dos critérios, ou seja, o modo como estes são agregados para se chegar a uma determinada avaliação;

- A sexta, relacionada a forma de avaliação do índice, ou seja, o modo como os resultados são apresentados e interpretados, de forma a apoiar os processos de tomada de decisão.

As etapas necessárias à construção do IMUS são descritas a seguir.

\subsubsection{Hierarquia de Critérios}

Na primeira etapa de construção do IMUS é estruturada a hierarquia de critérios, com base nos elementos que refletem o referencial de mobilidade sustentável em múltiplas cidades brasileiras, segundo a etapa definida no item 6.2.

Os conjuntos de Alternativas, que refletem grandes linhas de ação, PVFs, que refletem temas específicos, e Indicadores, relacionados à monitoração dos aspectos discutidos nos workshops, obtidos na etapa anterior são agregados em uma única estrutura, a fim de reduzir o conjunto de elementos e estabelecer uma hierarquia de critérios comum a todas as cidades pesquisadas. 
A constituição de uma estrutura única/comum tem início com a apreciação das Alternativas, desenvolvendo processos sucessivos de análise dos conceitos, comparação e fusão daqueles que expressam idéias semelhantes. As etapas de agregação das Alternativas compreendem:

- Representação das Alternativas com a denominação que receberam durante a atividade de capacitação;

- Agrupamento das Alternativas com nomenclatura idêntica;

- Agrupamento das Alternativas com pelo menos um tópico em comum ou denominação semelhante;

- Identificação dos agrupamentos com menor número de Alternativas, verificação do nível dos PVFs para detalhamento do conceito expresso em cada Alternativa e realocação dos PVFs para agrupamentos maiores, quando verificada semelhança entre as idéias expressas;

- Atribuição de nomes aos agrupamentos resultantes, que melhor descrevem as idéias expressas nas Alternativas e PVFs agregados.

Para a redução do conjunto de PVFs agregados às Alternativas são realizados os seguintes procedimentos:

- Resgate dos conceitos completos que originaram os PVFs (pólo positivo que representa um conceito orientado à ação e pólo negativo que representa o oposto psicológico), a partir dos registros efetuados nos workshops;

- Identificação da idéia-chave de cada PVF com base no conceito completo;

- Agrupamento dos PVFs dentro de cada Alternativa, de acordo com as idéias-chave. Os indicadores associados a cada PVF são realocados junto com o mesmo;

- Denominação dos PVFs de acordo com o conceito mais amplo que expressa.

Devido à sua abrangência, as Alternativas passam a ser identificadas nesta etapa como Domínios. Para sua consolidação, os Domínios obtidos são comparados aos resultados finais obtidos a partir da construção do referencial de mobilidade urbana sustentável nas cidades pesquisadas, verificando se os mesmos refletem as principais questões identificadas nesta etapa do trabalho. Já os PVFs, por tratarem de questões específicas associadas a cada Domínio, passam a ser identificados como Temas na hierarquia de critérios que compõe o IMUS.

Para cada um dos Temas identificados são associadas as três dimensões consideradas na sustentabilidade (Social, Econômica e Ambiental) a fim de relacionar os impactos que cada ação pode vir a ter em cada uma dessas dimensões. 
A hierarquia de critérios que representa as relações estabelecidas entre os elementos que compõem o índice é mostrada na Figura 6.2.

\section{IMUS}

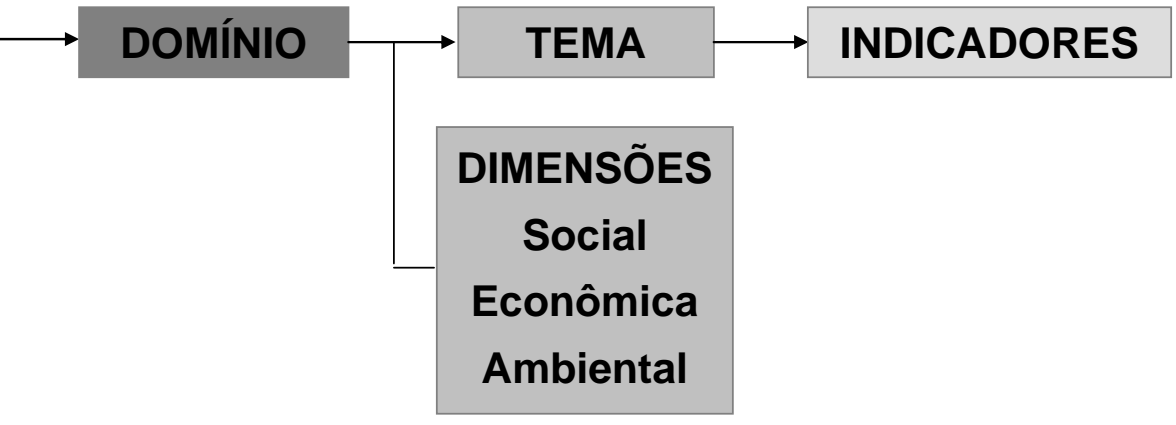

Figura 6.2: Níveis hierárquicos de critérios do IMUS.

\subsubsection{Seleção de Indicadores}

Uma vez definida a hierarquia de Domínios e Temas, a etapa posterior consiste na identificação de indicadores para cada um dos Temas que integram a estrutura.

Esta etapa é desenvolvida a partir de dois conjuntos de informação: uma base de referência composta por indicadores urbanos oriundos de sistemas desenvolvidos no Brasil e no exterior; e o conjunto de indicadores relacionados aos PVFs, obtido nos workshops realizados nas cidades pesquisadas.

Para a identificação destes indicadores é estabelecida primeiramente uma estrutura auxiliar para a busca no sistema de referência. Esta estrutura é composta pelos Domínios, Temas e suas respectivas definições, tópicos abordados em cada tema (com base nas informações obtidas nas cidades) e palavras (ou parte de palavras) e expressões que auxiliem na identificação destes tópicos. Para cada Tema é associado um Identificador (ID), utilizado em uma etapa posterior para agrupar os indicadores dos diferentes sistemas dentro dos Temas e Domínios que compõem o IMUS.

Através da busca pelas palavras e expressões na base de referência e da atribuição do respectivo identificador associado ao Tema aos indicadores que as contêm, é identificada uma relação preliminar de indicadores para cada tópico. Este mesmo procedimento é aplicado ao conjunto de indicadores relacionados aos PVFs obtidos nos workshops, classificando os mesmos dentro dos Temas que compõem o IMUS.

Os dois conjuntos resultantes são então ordenados de acordo com o ID. A etapa posterior consiste no cruzamento dos conjuntos permitindo destacar os indicadores mais 
representativos por Tema, e comuns a ambos os conjuntos. A partir deste cruzamento são identificados os potenciais indicadores que irão compor o índice.

Para filtragem e determinação dos indicadores finais são analisadas as informações técnicas e metodológicas disponíveis em seus sistemas de origem, privilegiando a seleção daqueles que apresentam informações mais claras e detalhadas para seu desenvolvimento, incluindo definição, dados de base, procedimentos de cálculo, entre outros aspectos. Além disso, é analisada sua relevância para o Tema em questão, com base no número de vezes que o indicador foi citado nos workshops e da ênfase dada ao mesmo durante a atividade desenvolvida junto aos gestores e planejadores.

Não é determinado, a priori, nenhum limite para o número de indicadores por Tema, no entanto, é necessário associar pelo menos um indicador por Tema, de forma a permitir sua monitoração.

Selecionados os indicadores, os mesmos são descritos de forma detalhada, a fim de facilitar seu cálculo para a composição do IMUS. Esta descrição deverá ser feita por meio de um Guia de Indicadores, que agregue aspectos conceituais e metodológicos a respeito de cada indicador, o que permitirá um correto entendimento na sua futura adoção prática.

\subsubsection{Pesos para os critérios}

Uma vez definida a hierarquia de critérios e associados os indicadores para cada um dos Temas que a compõem, a etapa seguinte compreende a atribuição de pesos para os diferentes critérios.

O sistema de pesos para os critérios pode ser obtido través de diferentes abordagens, incluindo a realização de painéis de especialistas, consulta popular via Internet ou telefone, consulta a técnicos e gestores urbanos, workshops com diferentes segmentos da sociedade, entre outros. Pode ainda utilizar diferentes métodos de definição dos pesos. Alguns destes métodos podem ser vistos em Malczewski (1999) e Silva et al. (2004), conforme mencionado no Capítulo 4.

O método utilizado para a definição dos pesos para os critérios que compõem o IMUS é apresentado de forma detalhada no Capítulo 8.

\subsubsection{Normalização dos Critérios}

A etapa seguinte compreende a definição dos processos de normalização dos valores obtidos para os indicadores. O processo de normalização é necessário, uma vez que os 
valores que caracterizam diferentes critérios não são comparáveis entre si e são representados freqüentemente através de diferentes escalas, o que inviabiliza a sua agregação imediata. Desta forma, eles são normalizados para uma mesma escala de valores.

A maior parte dos processos de normalização utiliza um valor máximo e outro mínimo para a definição de uma escala, em que a forma mais simples para obtenção dos valores intermediários é uma variação linear (ver, por exemplo, Eastman, 1997; Silva et al., 2002).

Para cálculo do IMUS o processo consiste na obtenção de um score normalizado para os valores dos indicadores, definido entre os limites mínimo e máximo de 0,00 e 1,00, respectivamente. O método para obtenção deste score varia de um indicador para outro, dependendo da natureza da informação associada ao mesmo (informação quantitativa ou qualitativa). Além disso, no caso dos indicadores quantitativos, diferentes funções podem ser utilizadas para reger a variação entre o limite mínimo, a partir do qual os valores de score do critério começam a ter relevância para a decisão, e o limite máximo, a partir do qual valores mais elevados não trazem contribuição adicional para a decisão.

Para facilitar o processo de normalização do score dos indicadores do IMUS e atender às diferentes características dos mesmos, são determinadas tabelas com a escala de avaliação para cada indicador. Nestas tabelas são associados aos limites mínimo e máximo fixados ( 0,00 e 1,00, respectivamente), valores de referência para o score do indicador. Estes valores correspondem a padrões internacionais difundidos na literatura, limites propostos pelo pesquisador e outras referências, que permitem uma avaliação geral da situação representada por cada indicador.

A normalização é feita com base nos valores apresentados na escala de avaliação através de associação direta ou interpolada. Com base na escala é feita também a avaliação expedita dos indicadores, conforme detalhado no Capítulo 9. A escala de avaliação é utilizada ainda para associação direta do score normalizado para os indicadores de caráter qualitativo, para os quais não é necessário desenvolver procedimentos de cálculo, exigindo somente a associação do valor que representa a condição do indicador.

Uma vez que esta questão diz respeito à implementação do IMUS e não ao Método propriamente dito, o detalhamento das escalas de avaliação é feito no Capítulo 8 e no Anexo E - "Guia de Elaboração dos Indicadores do IMUS" deste documento. 


\subsubsection{Método de Agregação}

Uma vez normalizados, os scores dos indicadores podem ser agregados de acordo com uma regra de decisão. Uma descrição extensiva destes métodos pode ser vista em Malczewski (1999). O método de agregação proposto para o IMUS consiste em uma combinação linear ponderada, onde os critérios são combinados através de uma média ponderada. Este método de agregação já foi utilizado anteriormente em índices de qualidade de vida e medidas de sustentabilidade dos sistemas de mobilidade, entre outras aplicações (ver, por exemplo, Mendes, 1999 e Lautso, K. et al., 2004).

Conforme Silva et al. (2004), a característica mais importante deste procedimento é o fato de permitir a compensação entre critérios, o que significa que uma qualidade (score obtido para um critério) muito pobre numa dada alternativa pode ser compensada por um conjunto de boas qualidades (scores mais altos a respeito de outros critérios).

A partir da estrutura adotada de Domínios, Temas e Indicadores, e a inserção das Dimensões da Sustentabilidade (Figura 6.2), o processo de agregação dos critérios resulta em um índice global e em três índices setoriais, uma para cada dimensão. Este processo é mostrado nas Equações 6.1 e 6.2, respectivamente:

$$
\operatorname{IMUSg}=\sum_{i=1}^{n} w_{i}^{D} \cdot w_{i}^{T} \cdot w_{i}^{I} \cdot x_{i}
$$

em que: IMUSg: Índice Global;

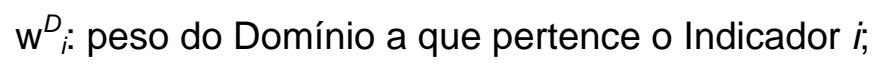

$\mathrm{w}^{T}$ : peso do Tema a que pertence o Indicador $i$;

$w_{i}^{i}$ : peso do Indicador $i$;

$x_{i}$ : score (valor normalizado) obtido para o Indicador $i$.

$\mathrm{IMUSS}_{j}=\sum_{i=1}^{n} w_{i}^{S D_{j}} \cdot w_{i}^{D} \cdot w_{i}^{T} \cdot w_{i}^{I} \cdot x_{i}$, com $S D_{j}=$ Dimensão Social ou Econômica ou Ambiental

em que: IMUSs;: Índice Setorial para a Dimensão $s_{j}$;

$W_{i}^{S D j}$ : peso da Dimensão de sustentabilidade $s_{j}$ no Tema a que pertence o Indicador $i$

$w_{i}^{P}, w_{i}^{T}, w_{i}^{\prime}, x_{i}:$ conforme definições acima.

Em função dos processos de normalização e agregação dos critérios propostos para o IMUS, os resultados para o índice global (IMUSg) situam-se no intervalo entre 0,00 e 1,00. 
Já os índices setoriais (IMUSs ) para as Dimensões Social, Econômica e Ambiental podem variar dentro do intervalo entre 0,00 e 0,34.

\subsubsection{Planilha de cálculo do IMUS}

A normalização dos critérios e agregação pode ser feita em planilha de cálculo específica, onde consta a hierarquia de critérios (Domínios, Temas e Indicadores) e seus respectivos pesos. Uma vez inseridos os scores dos indicadores estes podem ser automaticamente normalizados, conforme sua escala de avaliação.

Os resultados para os índices globais e setoriais são calculados com base nas Equações 6.1 e 6.2. A partir destes resultados podem ser gerados automaticamente gráficos que mostram os resultados obtidos. A planilha deve permitir ainda a redistribuição automática dos pesos dos Indicadores e Temas, uma vez que deixe de ser inserido o score de um determinado Indicador.

\subsection{Aplicação do IMUS}

Uma vez estruturado o IMUS, com base nos critérios identificados nas cidades pesquisadas, e definidos os processos de cálculo, normalização e agregação dos indicadores, a etapa seguinte consiste na aplicação do índice para uma cidade brasileira, de modo a validar a ferramenta como instrumento de monitoração da mobilidade urbana.

As primeiras atividades para validação do índice consistem na escolha da cidade para sua aplicação e análise da disponibilidade de dados para o cálculo de todos os indicadores que compõem o IMUS. Neste sentido, deve ser avaliada a disponibilidade de dados a curto, médio e longo prazo, bem como sua qualidade para desenvolvimento dos indicadores.

Para a análise da viabilidade de aplicação do IMUS é adotada abordagem semelhante à aplicada pela OECD e desenvolvida pelo Working Group on the State of the Environment WGSOE, na análise do conjunto de indicadores para integração das questões ambientais nas políticas de transportes (OECD, 1999). A metodologia propõe a avaliação dos indicadores com base nos critérios:

- Relevância política, que diz respeito à utilidade do indicador para os usuários. No caso específico do sistema proposto pela OECD, diz respeito à relevância para as políticas ambientais e de transportes;

- Consistência analítica, que diz respeito à fundamentação teórica do indicador em termos técnicos e científicos e; 
- Mensurabilidade, relacionada à disponibilidade e qualidade dos dados necessários para a formulação do indicador.

A avaliação dos indicadores propostos pela OECD com base nos critérios acima é feita observando a seguinte escala:

Tabela 6.1: Critérios para avaliação de indicadores de transportes e meio ambiente.

\begin{tabular}{lccc}
\hline \multirow{2}{*}{ Critérios de Seleção } & \multicolumn{3}{c}{ Avaliação } \\
\cline { 2 - 4 } & $\mathbf{1}$ & $\mathbf{2}$ & $\mathbf{3}$ \\
\hline Relevância política & Alta & Média & Baixa \\
\hline Consistência analítica & Boa & Média & Pobre \\
\hline Mensurabilidade & & & \\
\hline Disponibilidade de Dados & Curto prazo & Médio prazo & Longo prazo \\
\hline $\begin{array}{l}\text { Qualidade dos dados, incluindo } \\
\text { comparabilidade internacional }\end{array}$ & Alta & \multirow{2}{*}{ Média } & \multirow{2}{*}{ Baixa } \\
\hline
\end{tabular}

Fonte: Adaptado de (OECD, 1999).

Para a avaliação da viabilidade de aplicação dos indicadores que compõem o IMUS para uma cidade brasileira, a metodologia aplicada pela OECD é adaptada. Neste caso, é considerada somente a avaliação do critério relacionado à Mensurabilidade, representado pela disponibilidade e qualidade dos dados necessários à formulação dos indicadores, uma vez que os demais critérios já foram incorporados na seleção de indicadores que compõem o IMUS. Neste sentido os dados devem estar prontamente disponíveis ou apresentarem uma razoável relação benefício/custo para sua obtenção, estarem documentados adequadamente e possuírem qualidade conhecida. Além disso, deve ser possível atualizálos regularmente, seguindo processos confiáveis de atualização e coleta de dados.

Para cada indicador devem ser identificados seus dados de base, ou seja, os dados necessários para seu cálculo. Posteriormente é feita a verificação de sua disponibilidade em fontes de dados tais como: Prefeitura Municipal; estudos e projetos efetuados pelas universidades e centros de pesquisa, levantamentos efetuados para a elaboração do Plano Diretor Municipal; bases de dados do Instituto Brasileiro de Geografia e Estatística (IBGE), responsável pela execução dos Censos Populacionais e demais pesquisas que retratam o perfil socioeconômico da população brasileira e outras bases de dados em nível estadual e federal.

A qualidade dos dados disponíveis deve ser avaliada conforme sua atualização, abrangência e desagregação (regiões da cidade), além de sua documentação e conhecimento da metodologia utilizada para sua obtenção. 
O cruzamento das informações relacionadas à disponibilidade e qualidade dos dados de base permite identificar os indicadores viáveis para serem mensurados em curto prazo e com boa qualidade dos dados. A aplicação do índice consiste, portanto, no cálculo e avaliação destes indicadores, os quais permitirão obter os resultados globais e setoriais do IMUS, para a cidade pesquisada.

\subsubsection{Coleta de Dados e Avaliação Expedita}

Para cálculo do IMUS é realizado um procedimento de coleta de dados por meio de fontes diretas (Prefeitura Municipal, Secretarias, órgãos de gestão de trânsito e transportes, etc) e indiretas (página oficial da Prefeitura Municipal na Internet, dados e estudos publicados por instituições de ensino e pesquisa, etc). Após o cálculo dos indicadores, estes são combinados, gerando resultados globais e setoriais para o índice.

De forma a verificar os resultados obtidos, pode ser feita uma avaliação expedita dos indicadores, por profissional ou especialista com amplo conhecimento do sistema de mobilidade e desenvolvimento urbano do município. Esta avaliação deve ser feita com base nas escalas definidas para os indicadores, as quais devem constar junto à metodologia de cálculo do mesmo. Neste sentido, deve ser identificado um profissional ou grupo de profissionais que atenda a estas exigências, realizando uma entrevista para avaliação dos indicadores que compõem o IMUS.

A avaliação expedita tem por objetivo principal a validação do processo de cálculo, verificando se o mesmo gera resultados consistentes para avaliação de um sistema de mobilidade urbana, compatíveis com os resultados obtidos através do processo de avaliação expedita, feita por profissional(is) envolvido(s) diretamente no planejamento e gestão do sistema de mobilidade urbana do município analisado. Ao mesmo tempo, em função da experiência e conhecimento do(s) especialista(s) convidado(s) a fazer(em) a avaliação, será possível avaliar eventuais discrepâncias existentes nas metodologias de cálculo propostas para os indicadores, permitindo identificar ajustes ou adaptações necessárias nos processos de coleta, tratamento dos dados e cálculo propriamente dito, para melhor estimar os parâmetros avaliados pelo índice.

No Capítulo 9 será detalhada a implementação das etapas de cálculo do IMUS em uma cidade brasileira, incluindo a apresentação dos dados coletados e os resultados da análise expedita para a cidade em que o mesmo é aplicado, os procedimentos de cálculo dos indicadores e a planilha contendo os scores e resultados para o IMUSg e IMUSs $\mathrm{j}_{\mathrm{j}}$. 


\subsubsection{Análise dos Resultados}

A avaliação do IMUS é feita com base nos resultados obtidos para o índice global (Equação 6.1) e para os índices setoriais (Equação 6.2). Estes resultados podem ser expressos através de gráficos, como mostra a Figura 6.3. O gráfico permite verificar os valores obtidos para as três Dimensões da sustentabilidade (Social, Econômica e Ambiental) e a análise de sua contribuição para o valor global do IMUS, comparando com os resultados global e setorial máximos que poderiam ser atingidos.

IMUS

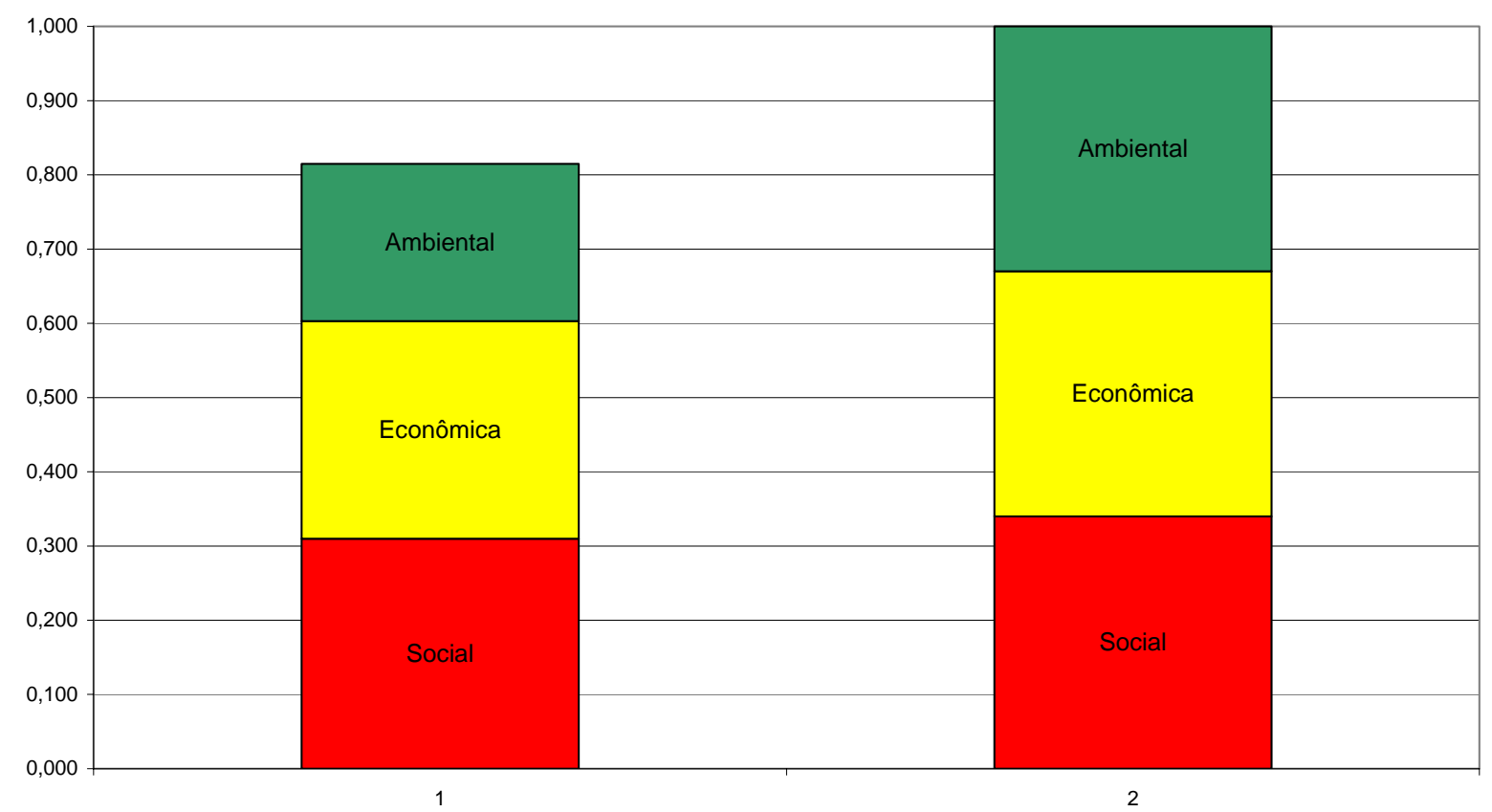

Figura 6.3: Exemplo de gráfico produzido com os resultados do IMUS.

No gráfico da Figura 6.3, são apresentados valores hipotéticos para os resultados do IMUS para cada Dimensão e para o valor global do índice, resultado da contribuição das três Dimensões. Uma vez que os limites mínimo e máximo do IMUS situam-se entre os valores 0,00 e 1,00, resultados globais próximos a 0,00 indicam performance ruim em relação à mobilidade sustentável. Já valores próximos a 1,00 representam ganhos em termos de sustentabilidade, ou seja, indicam uma melhor situação do sistema de mobilidade analisado.

Através dos resultados obtidos com o cálculo do IMUS, gestores e planejadores podem decidir a respeito das melhores estratégias a adotar observando os Temas e Indicadores que contribuem de forma mais efetiva para a melhoria dos resultados da Dimensão crítica. Isto é possível avaliando os indicadores pontualmente e verificando sua contribuição para cada Dimensão e para o índice como um todo. Esta avaliação auxilia as cidades a identificar 
aspectos que não contribuem para a mobilidade sustentável e aqueles que contribuem para tal. Conseqüentemente, qualquer política pública formulada para melhorar a mobilidade urbana deve necessariamente tratar dos aspectos identificados como críticos.

Uma vez promovida uma determinada Dimensão da sustentabilidade através da melhoria de seus Temas e Indicadores mais representativos, conseqüentemente o valor global do IMUS será aumentado, resultando em uma melhora global em termos de sustentabilidade.

A estrutura proposta para o IMUS permite também a avaliação baseada em um número reduzido de indicadores, em situações em que não é possível o cálculo de todos os indicadores que compõem o índice em função da inexistência ou indisponibilidade de dados, ou outros aspectos. Neste caso, é necessário fazer a redistribuição dos pesos dos Indicadores dentro de cada Tema, de forma que o somatório dos mesmos mantenha-se igual a 1,00. O mesmo procedimento pode ser feito para os Temas dentro dos Domínios, em casos em que nenhum Indicador do respectivo Tema possa ser calculado.

No caso dos Domínios este pressuposto não deve ser admitido, uma vez que a desconsideração de qualquer um destes elementos poderia comprometer ou fragilizar o cálculo do IMUS, implicando em uma avaliação que pode ser excessivamente otimista ou excessivamente pessimista, à medida que são desconsiderados elementos fundamentais que estruturam o índice. Em casos como este, onde a indisponibilidade de dados impede o cálculo de um ou mais Domínios, o cálculo do índice ainda se constitui em uma avaliação importante para as cidades. No entanto, os resultados globais e setoriais devem ser vistos com cautela, buscando concentrar o foco da análise nos resultados específicos dos Indicadores e Temas avaliados. A principal contribuição, no entanto, vem do diagnóstico em relação à ausência de dados de base para cálculo dos indicadores, alertando sobre a importância de se empreender processos sistemáticos de coleta e atualização de dados, de forma a proporcionar uma avaliação completa do IMUS.

Os resultados do IMUS para a cidade onde o mesmo será aplicado serão analisados em termos de seu valor global e setorial, para as três Dimensões da sustentabilidade. Neste sentido, serão identificada(s) a(s) Dimensão(ões) críticas para a mobilidade sustentável, bem como os Indicadores e Temas que apresentam maior peso ou contribuição para este resultado. A partir desta análise são pontuados os aspectos que merecem tratamento especial, no sentido de formular políticas públicas para sua melhoria e conseqüentemente, melhoria do valor global do IMUS.

Neste etapa será feita ainda a análise comparativa dos resultados obtidos através do processo de cálculo e avaliação expedita, confrontando os resultados globais e setoriais 
obtidos para o IMUS por meio das duas abordagens, bem como os resultados obtidos para cada um dos indicadores.

\subsection{Considerações Finais e Conclusões}

Com base na análise da estrutura obtida para IMUS, representada pela hierarquia de critérios e pelos pesos atribuídos através do painel de especialistas, da viabilidade de aplicação do índice para a cidade selecionada, além dos resultados global e setorial, são discutidos aspectos referentes à ferramenta e aos resultados observados para a cidade avaliada.

A partir destas análises são delineadas as principais conclusões do estudo e feitas proposições para trabalhos futuros, relacionados ao desenvolvimento da ferramenta e sua aplicação efetiva para monitoração da mobilidade. 


\section{REFERENCIAL DE MOBILIDADE URBANA SUSTENTÁVEL}

Neste capítulo são apresentados os resultados obtidos a partir de workshops realizados em cidades brasileiras, os quais constituem o referencial para o conceito de mobilidade urbana sustentável nas cidades pesquisadas. Esses resultados são analisados por cidade e comparativamente entre as regiões. São enfocados dois aspectos principais: as diferenças percebidas com relação ao modelo tradicional de tratamento das questões de mobilidade urbana em cidades brasileiras e o novo paradigma em desenvolvimento, além de diferenças locais e regionais no que diz respeito aos aspectos abordados na construção do conceito de mobilidade urbana sustentável.

\subsection{Experiência de Capacitação}

A etapa de construção do referencial de mobilidade urbana sustentável, além de dar suporte à construção do IMUS, foi desenvolvida com os seguintes objetivos:

- Identificar o enfoque que tem sido dado à abordagem das questões de mobilidade nas cidades pesquisadas até o presente momento;

- Identificar as diferenças de enfoque existentes entre a abordagem tradicional e o novo paradigma da mobilidade urbana em desenvolvimento;

- Caracterizar o conceito de mobilidade urbana sustentável com foco nas especificidades do contexto analisado.

Neste sentido, o método proposto para a construção deste referencial, apresentado no item 6.2, foi aplicado em um conjunto de cidades brasileiras. A atividade foi desenvolvida no contexto de um curso de capacitação de técnicos e gestores públicos promovido pelo Ministério das Cidades, o qual foi responsável pela seleção das cidades-sede do evento.

O principal objetivo do curso, denominado de Gestão Integrada da Mobilidade Urbana, foi a capacitação técnica e gerencial dos agentes responsáveis pela implantação das políticas locais de Mobilidade Urbana no país. Em paralelo, buscava prover um retrato mais detalhado dos problemas e das condições de gestão da mobilidade nas diferentes regiões, 
através do envolvimento dos órgãos e instituições responsáveis pelo planejamento e gerenciamento da mobilidade em nível urbano e metropolitano.

O curso foi estruturado em cinco módulos assim denominados:

- Módulo I: Política Nacional da Mobilidade Urbana ;

- Módulo II: Cidadão, Cidade e Mobilidade Urbana Sustentável;

- Módulo III: Planejamento Estratégico da Mobilidade Urbana;

- Módulo IV: Gestão da Mobilidade Urbana: Organização Institucional e Regulação;

- Módulo IV: Financiamento dos Transportes urbanos.

As atividades relacionadas à construção do referencial de mobilidade urbana integravam o Módulo II do curso de capacitação, sendo desenvolvidas durante 8 das 40 horas previstas para a realização do curso.

Uma experiência piloto da atividade foi desenvolvida em maio de 2005 com municípios da Região Metropolitana de Recife, Pernambuco. Entre os meses de março e novembro de 2006, mais dez regiões metropolitanas e aglomerações urbanas foram investigadas. A Figura 7.1 mostra as onze cidades pesquisadas, distribuídas nas cinco regiões do país.

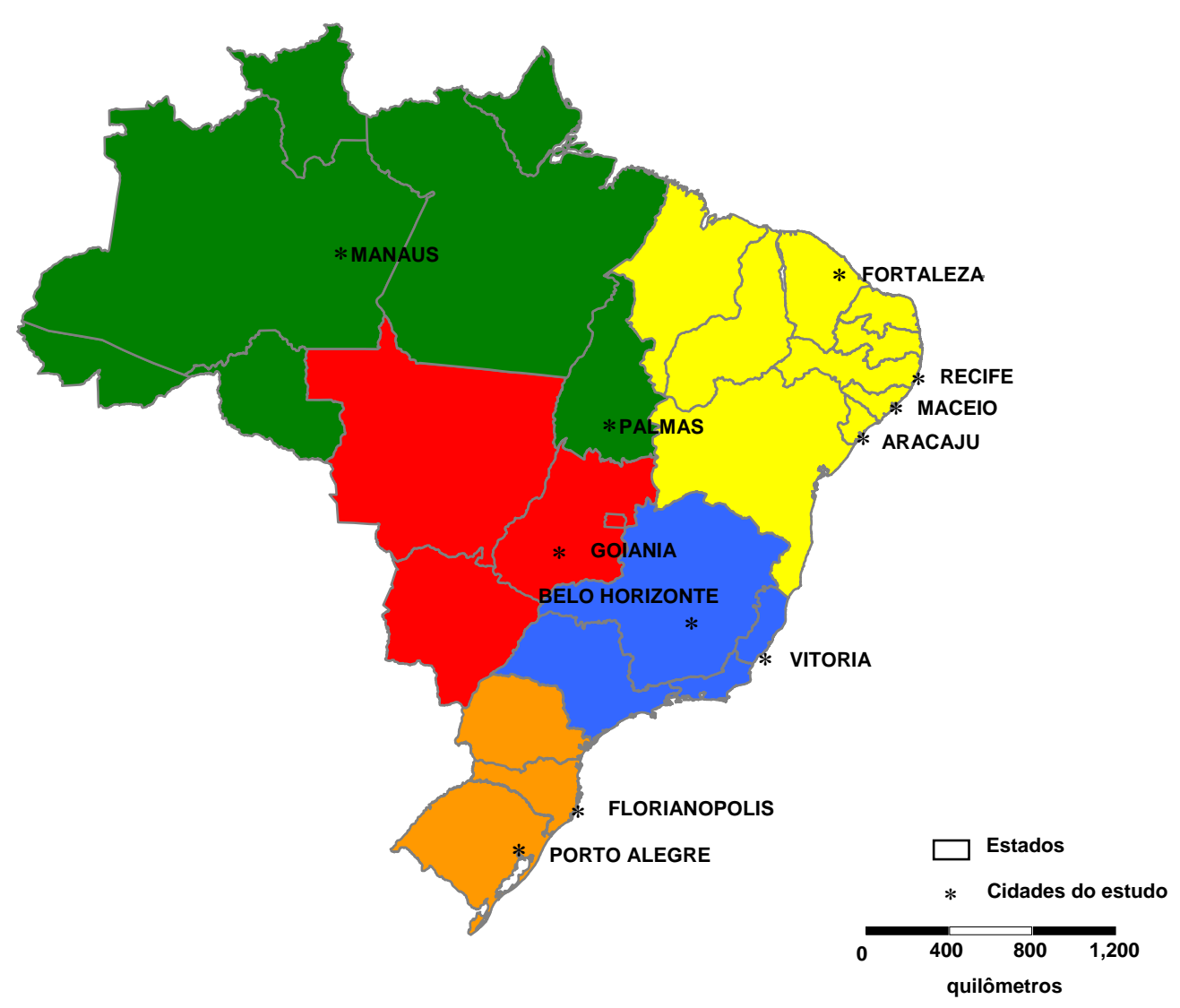

Figura 7.1: Cidades onde foi realizado o Curso Gestão Integrada da Mobilidade Urbana. 
Cada reunião contou com cerca de quarenta participantes de diferentes áreas de formação, os quais desempenham atividades relacionadas ao planejamento e gestão da mobilidade urbana, atuando em esfera municipal, metropolitana ou no nível da aglomeração urbana. Entre os órgãos e instituições representados estavam secretarias de planejamento urbano, transportes, meio ambiente, habitação e infra-estrutura, operadores de serviços de transportes, órgãos de gerenciamento e fiscalização de trânsito, entre outros.

Na etapa inicial dos workshops, de caráter expositivo, os participantes tiveram contato com alguns conceitos já bastante difundidos sobre sustentabilidade urbana e mobilidade sustentável.

As atividades práticas compreenderam, em um primeiro momento, a avaliação dos aspectos referentes ao atual modelo vigente de planejamento, por meio da elaboração de uma lista de indicadores utilizados nas atividades diárias dos participantes do curso, tal como previsto no item 6.2.1.

A seqüência dos trabalhos se deu com base nas atividades descritas no item 6.2.2, iniciando com a caracterização dos atores envolvidos no processo, partindo para a identificação dos Elementos Primários de Avaliação e culminando com a seleção dos Pontos de Vista Fundamentais para a questão. Conforme descrito no método, estas atividades foram desenvolvidas com auxílio de planilhas eletrônicas, facilitando o registro dos dados obtidos. Os modelos de planilhas utilizadas constam no Anexo A - "Material do Curso de Capacitação Gestão da Mobilidade Urbana".

Através dos procedimentos descritos no Capítulo 6 foi possível estruturar, em cada contexto, o referencial de mobilidade urbana sustentável com base nos valores, perspectivas e conhecimento da realidade local por parte dos participantes da atividade.

Os resultados apresentados aqui referem-se às Alternativas identificadas, que representam grandes áreas de preocupação com relação à questão, e PVFs, que revelam enfoques mais específicos para os temas abordados, sintetizando assim os principais aspectos relacionados à promoção do conceito de mobilidade urbana sustentável em nível local. Todos estes termos foram obtidos nos workshops após as discussões promovidas com os técnicos e gestores envolvidos na atividade, e refletem aspectos como: problemas de mobilidade enfrentados na região, limitadores para implementação de sustentabilidade e objetivos, metas e perspectivas com relação à efetivação do conceito. 
A seguir são sintetizados os resultados obtidos nos workshops realizados nas onze cidades brasileiras, permitindo ilustrar a diversidade encontrada nas cidades das cinco regiões. A análise dos resultados obtidos é feita no item 7.3.

\subsection{Resultados Obtidos}

Os resultados obtidos nas etapas de construção do referencial de mobilidade urbana sustentável são sintetizados por região e cidade onde foi realizado o curso de capacitação, por meio de hierarquias ou árvores de critérios que evidenciam as relações estabelecidas entre os principais elementos identificados.

Neste capítulo os resultados são apresentados agregados em grandes áreas de preocupação relacionadas à mobilidade urbana, no caso dos Indicadores relacionados na primeira etapa do exercício, e nas Alternativas identificadas durante a segunda fase dos workshops, no caso dos PVFs. O primeiro conjunto de dados corresponde ao modelo vigente ou tradicional de tratamento das questões de mobilidade urbana. O segundo conjunto de dados corresponde ao novo paradigma de tratamento das questões de mobilidade urbana no país, identificado aqui como mobilidade urbana sustentável.

Os dados brutos obtidos, incluindo a relação de Indicadores de Mobilidade, Elementos Primários de Avaliação, Conceitos Orientados (Pólo Positivo e Pólo Negativo), Alternativas, Mapa Cognitivo, PVFs e Indicadores de Mobilidade Sustentável são apresentados por cidade no Anexo B - "Resultados do Curso de Capacitação Gestão da Mobilidade Urbana".

\subsubsection{Região Sul}

Na Região Sul os workshops foram realizados nas cidades de Porto Alegre e Florianópolis.

\subsubsection{Porto Alegre - RS}

No workshop realizado em Porto Alegre no dia 16 de maio de 2006, com técnicos e gestores da capital e Região Metropolitana, a etapa inicial de identificação de indicadores de mobilidade resultou em um conjunto de trinta e nove elementos, classificados em quatro categorias pelo Facilitador, conforme os temas abordados. A estrutura de indicadores obtida é mostrada na Figura 7.2.

$\mathrm{Na}$ etapa seguinte foi feita a caracterização do conceito de mobilidade urbana sustentável através da identificação de EPAs e construção dos Conceitos Orientados à Ação abrangendo os Pólos Positivo e Negativo, totalizando quarenta e sete conceitos. Novamente 
os elementos obtidos foram classificados pelo Facilitador, desta vez com participação do grupo, resultando em um conjunto de cinco Alternativas.

De posse dos conceitos e das Alternativas, foi construído o Mapa Cognitivo, explicitando as relações existentes entre os elementos identificados na etapa anterior. A análise do mapa, identificando-se os conceitos "cabeça" e as linhas de raciocínio culminou na identificação de um conjunto preliminar de PVFs. Após a consolidação deste com o grupo, foi obtida a arborescência de Alternativas e PVFs, que refletem os aspectos importantes para a caracterização do conceito de MUS para Porto Alegre e Região Metropolitana.

A Figura 7.3 apresenta o mapa cognitivo construído durante o workshop realizado na cidade de Porto Alegre, de forma a ilustrar o processo de identificação dos PVFs. Mapas semelhantes foram construídos para as demais cidades avaliadas e constam no Anexo B Resultados do Curso de Capacitação Gestão da Mobilidade Urbana.

$\mathrm{Na}$ etapa final foi identificado um novo conjunto de Indicadores de Mobilidade Sustentável, associados a cada um dos PVFs, conforme mostra a Figura 7.4.

\subsubsection{Florianópolis - SC}

A Figura 7.5 mostra a estrutura de trinta e um indicadores obtida na primeira etapa do exercício realizado em Florianópolis no dia 24 de abril de 2006, e que contou também com a participação de técnicos e gestores dos municípios da Região Metropolitana. Do mesmo modo, os indicadores foram classificados pelo Facilitador em diferentes categorias, conforme o enfoque e os temas abordados nesta etapa.

$\mathrm{Na}$ etapa posterior foram definidos os EPAs e os Conceitos Orientados a Ação, e a identificação dos Pólos Positivo e Negativo, totalizando quarenta e quatro conceitos. Agrupados pelo Facilitador, estes conceitos resultaram em quatro Alternativas distintas.

Com base nos mesmos procedimentos desenvolvidos no exercício feito na cidade de Porto Alegre, foi elaborado para Florianópolis o Mapa Cognitivo, explicitando as relações existentes entre os conceitos e Alternativas definidas na etapa anterior. Através da análise do Mapa Cognitivo foram consolidados cinco PVFs, refletindo os elementos fundamentais para o conceito de mobilidade urbana sustentável na cidade e Região Metropolitana segundo os valores dos técnicos que participaram do workshop.

A etapa final do exercício compreendeu a identificação de indicadores para o conjunto de PVFs selecionados. A estrutura final de Alternativas, PVFs e Indicadores de Mobilidade Urbana Sustentável obtida para Florianópolis e Região Metropolitana é apresentada na Figura 7.6. 


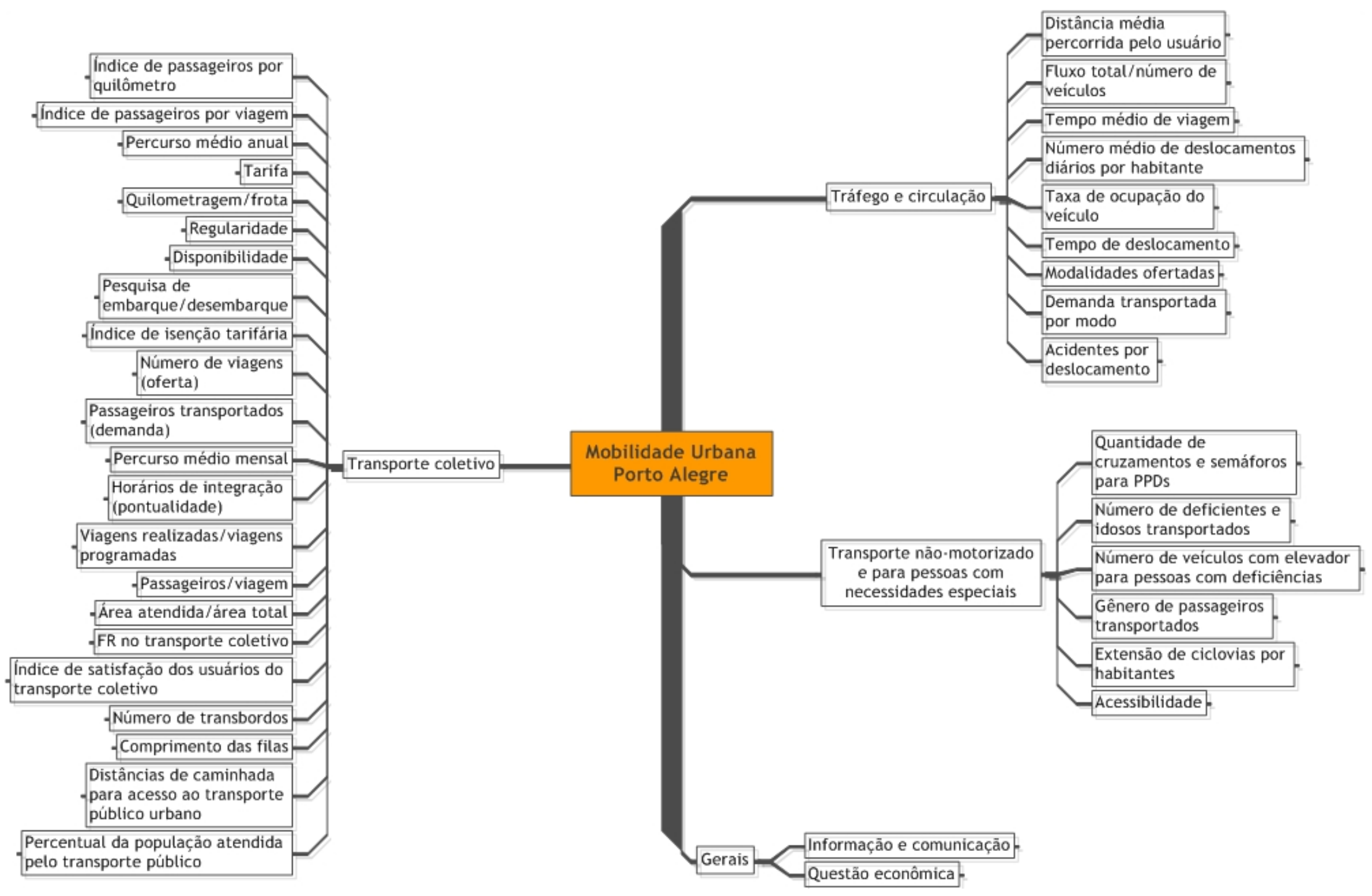

Figura 7.2: Árvore de Temas e Indicadores de Mobilidade para Porto Alegre e Região Metropolitana. 


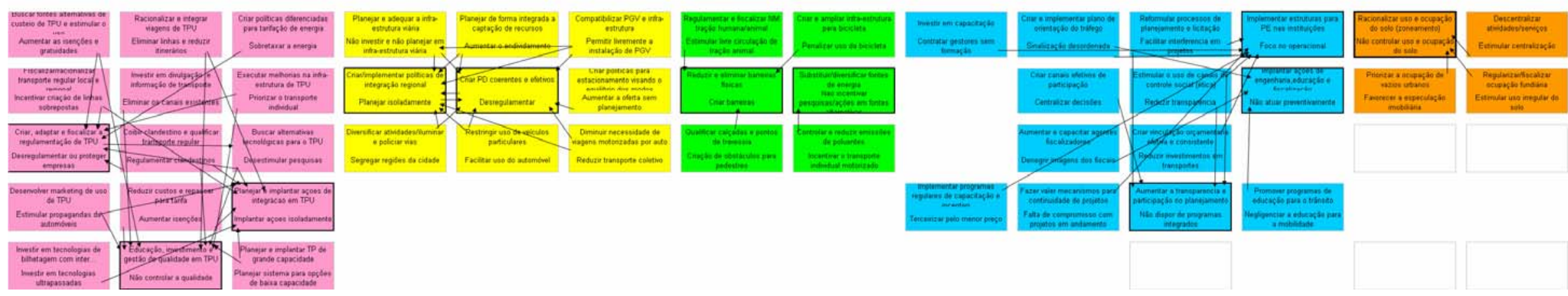

Figura 7.3: Mapa cognitivo construído para Porto Alegre e Região Metropolitana, 


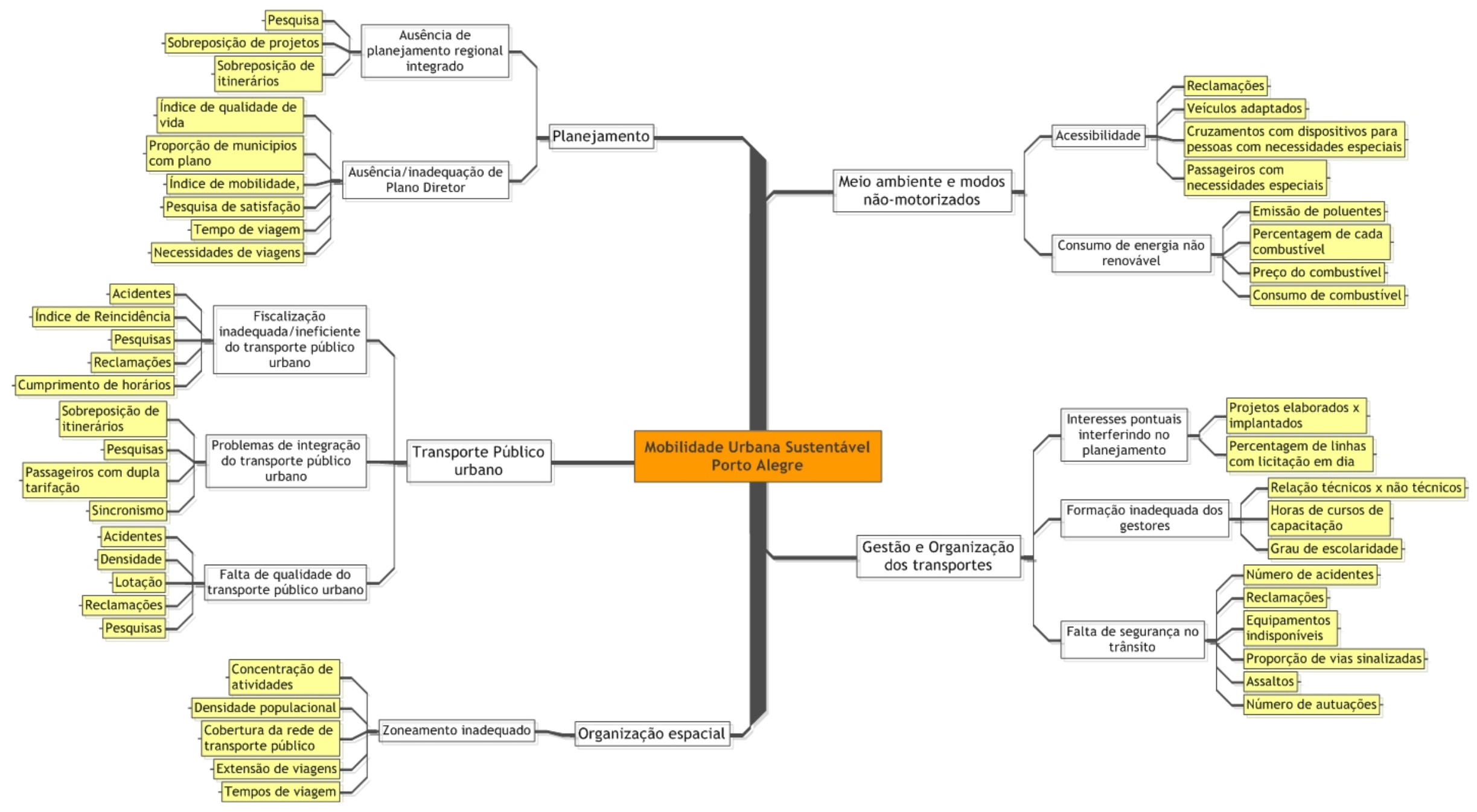

Figura 7.4: Árvore de Alternativas, PVFs e Indicadores de Mobilidade Sustentável para Porto Alegre e Região Metropolitana. 


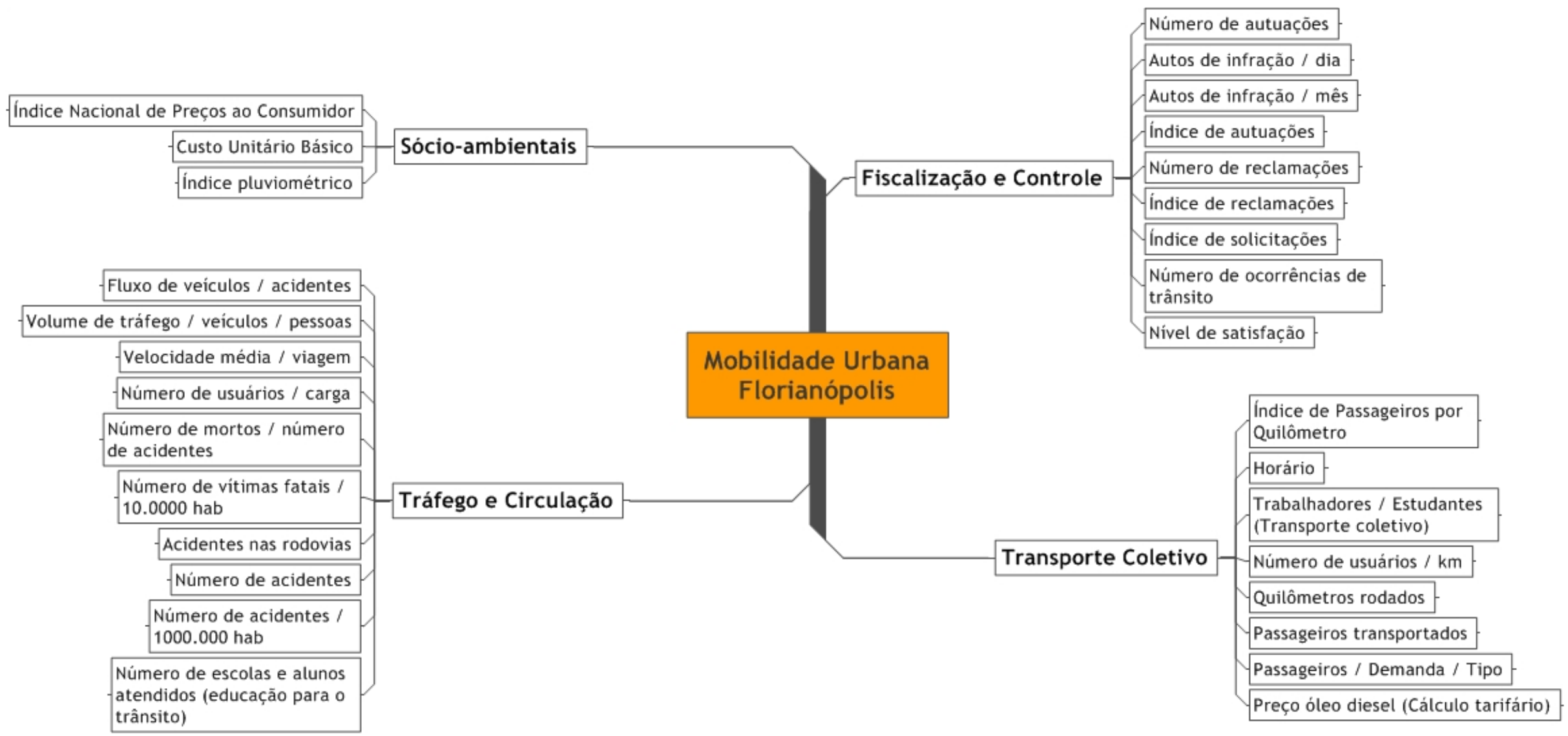

Figura 7.5: Árvore de Temas e Indicadores de Mobilidade para Florianópolis e Região Metropolitana. 


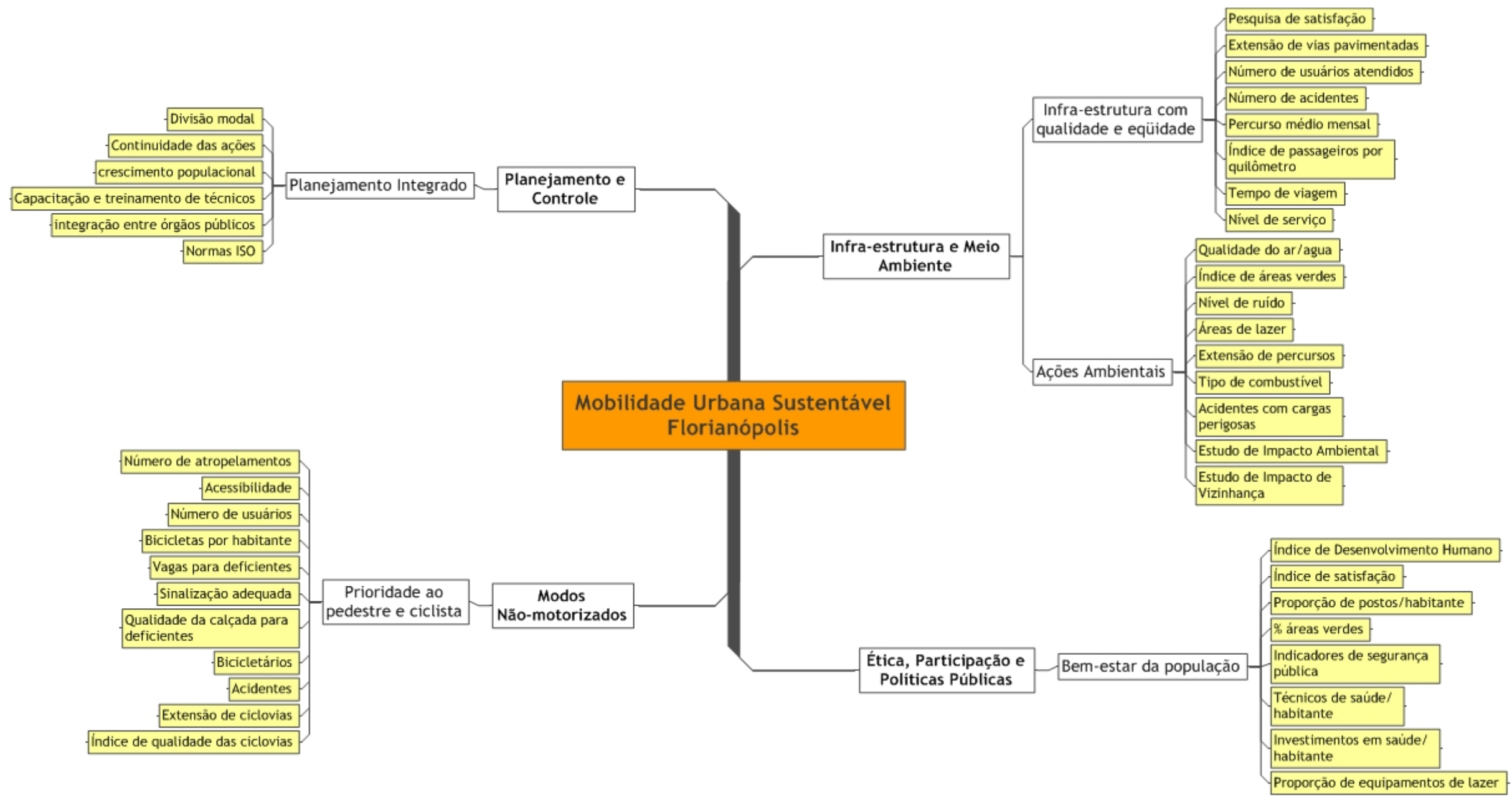

Figura 7.6: Árvore de Alternativas, PVFs e Indicadores de Mobilidade Sustentável para Florianópolis e Região Metropolitana. 


\subsubsection{Região Sudeste}

Na Região Sudeste os workshops foram realizados nas cidades de Vitória e Belo Horizonte.

\subsubsection{Vitória - ES}

A Figura 7.7 mostra a estrutura de quarenta indicadores agrupados em diferentes temas, obtida na primeira etapa do exercício realizado em Vitória no dia 14 de agosto de 2006, e que contou também com a participação de técnicos e gestores dos municípios da Região Metropolitana.

A estruturação do conceito de mobilidade urbana sustentável para Vitória resultou na identificação de cinqüenta EPAs, transformados em Conceitos Orientados à Ação, através da definição de seus pólos Positivo e Negativo. Estes conceitos foram agregados em cinco Alternativas.

$\mathrm{Na}$ etapa posterior foram consolidados seis PVFs, para os quais foram associados Indicadores de Mobilidade Urbana Sustentável. A estrutura final de Alternativas, PVFs e Indicadores de Mobilidade Urbana Sustentável obtida para Vitória e Região Metropolitana é apresentada na Figura 7.8.

\subsubsection{Belo Horizonte - MG}

A Figura 7.9 mostra a estrutura de cinqüenta e quatro indicadores agrupados em diferentes temas, obtida na primeira etapa do exercício realizado em Belo Horizonte no dia 16 de outubro de 2006, e que contou também com a participação de técnicos e gestores de municípios da Região Metropolitana.

A estruturação do conceito de mobilidade urbana sustentável para Belo Horizonte e Região Metropolitana resultou na identificação de sessenta EPAs, transformados em Conceitos Orientados à Ação, através da definição de seus pólos Positivo e Negativo. Estes conceitos foram agregados em seis Alternativas.

Na etapa posterior foram consolidados nove PVFs, para os quais foram listados Indicadores de Mobilidade Urbana Sustentável. A estrutura final de Alternativas, PVFs e Indicadores de Mobilidade Urbana Sustentável obtida para Belo Horizonte e Região Metropolitana é apresentada na Figura 7.10. 


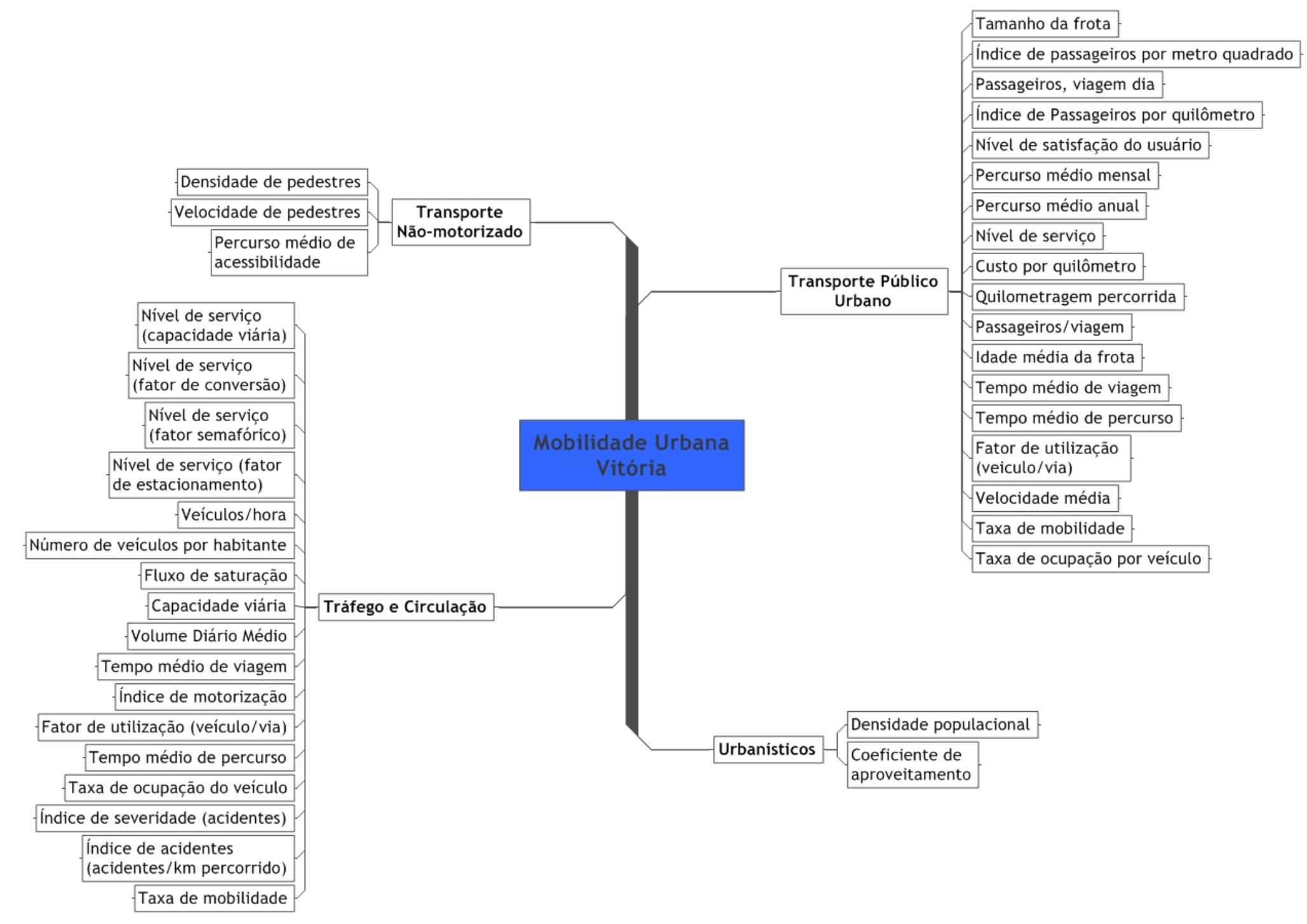

Figura 7.7: Árvore de Temas e Indicadores de Mobilidade para Vitória e Região Metropolitana. 


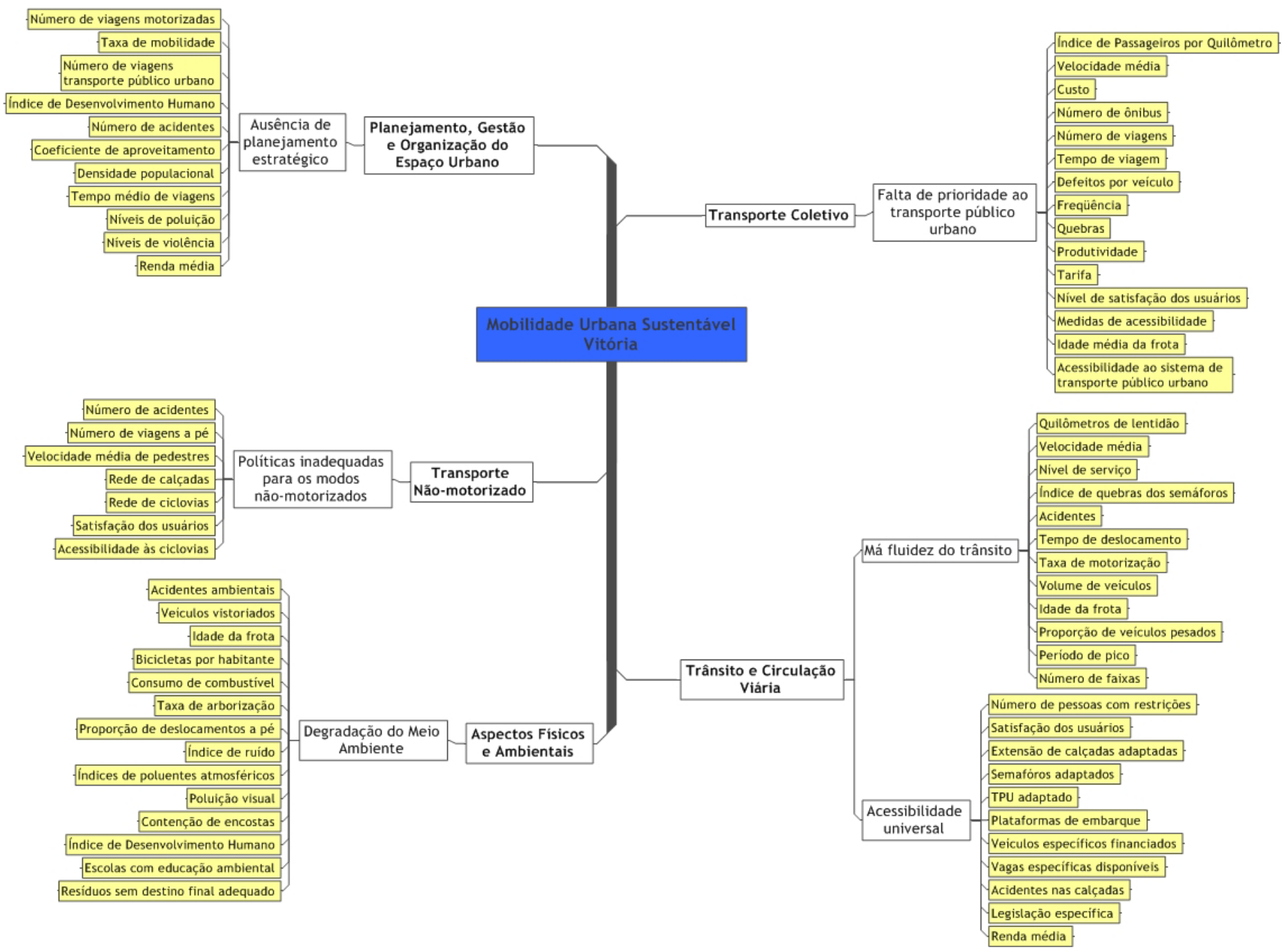

Figura 7.8: Árvore de Alternativas, PVFs e Indicadores de Mobilidade Sustentável para Vitória e Região Metropolitana. 


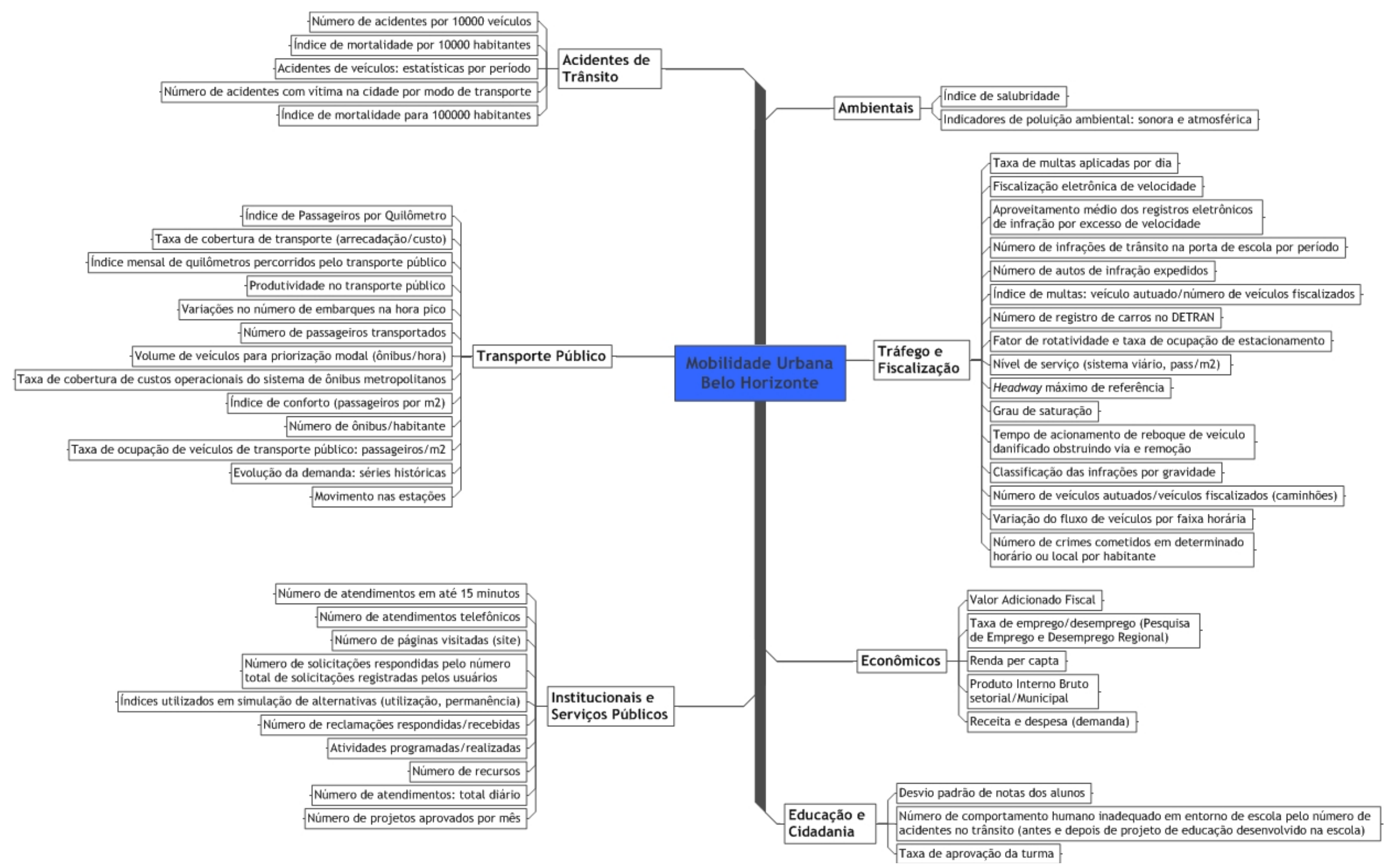

Figura 7.9: Árvore de Temas e Indicadores de Mobilidade para Belo Horizonte e Região Metropolitana. 


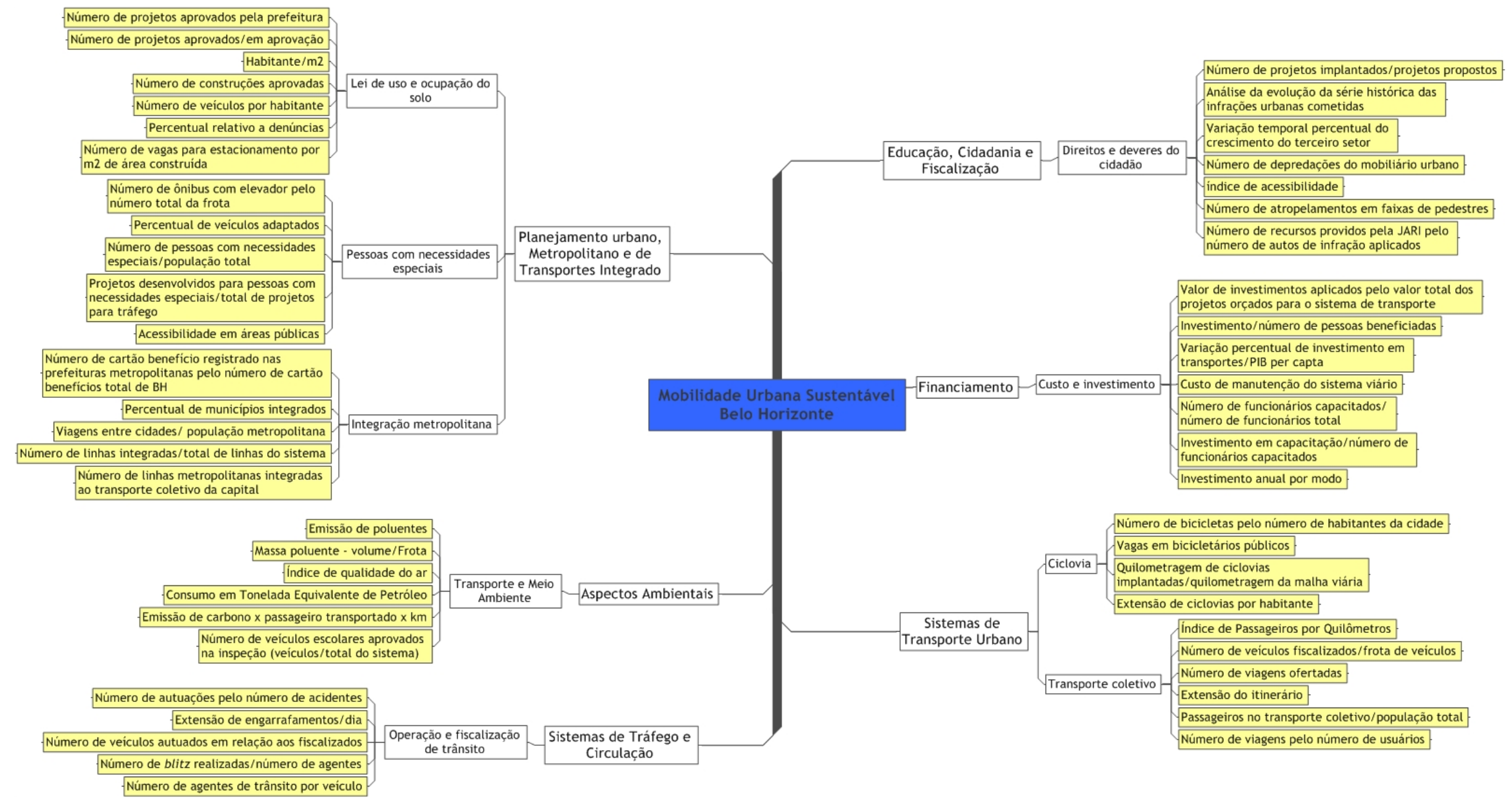

Figura 7.10: Árvore de Alternativas, PVFs e Indicadores de Mobilidade Sustentável para Belo Horizonte e Região Metropolitana. 


\subsubsection{Região Centro-oeste}

Na Região Centro-oeste o workshop foi realizado na cidade de Goiânia.

\subsubsection{Goiânia - GO}

A Figura 7.11 mostra a estrutura de trinta indicadores agrupados em diferentes temas, obtida na primeira etapa do exercício realizado em Goiânia no dia 03 de abril de 2006, e que contou também com a participação de técnicos e gestores de municípios da Região Metropolitana.

A estruturação do conceito de mobilidade urbana sustentável para Goiânia resultou na identificação de quarenta e três EPAs, transformados em Conceitos Orientados à Ação, através da definição de seus pólos Positivo e Negativo. Estes conceitos foram agregados em cinco Alternativas.

$\mathrm{Na}$ etapa posterior foram consolidados oito PVFs, para os quais foram associados Indicadores de Mobilidade Urbana Sustentável. A estrutura final de Alternativas, PVFs e Indicadores de Mobilidade Urbana Sustentável obtida para Goiânia e Região Metropolitana é apresentada na Figura 7.12. 


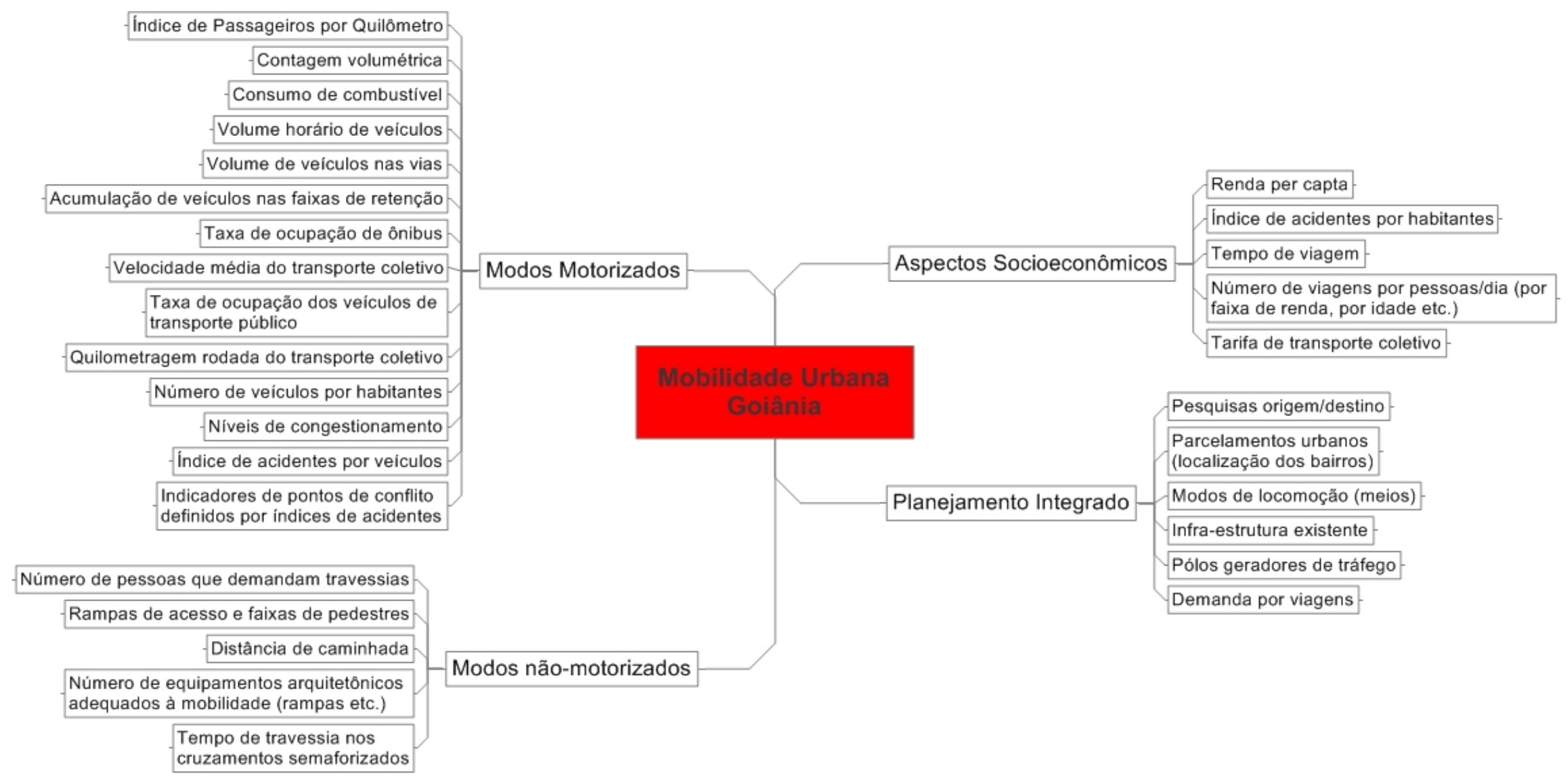

Figura 7.11: Árvore de Temas e Indicadores de Mobilidade para Goiânia e Região Metropolitana. 


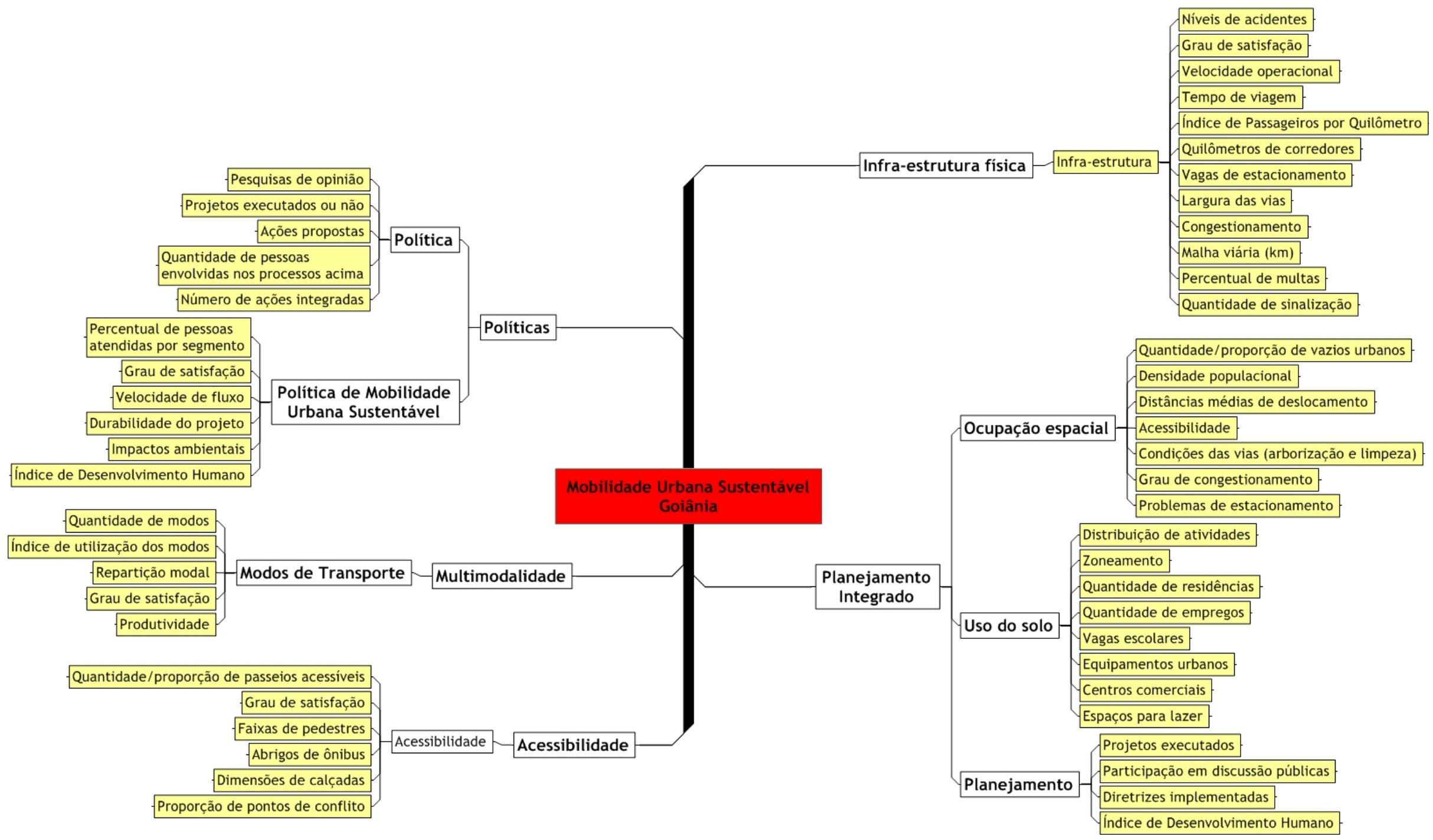

Figura 7.12: Árvore de Alternativas, PVFs e Indicadores de Mobilidade Sustentável para Goiânia e Região Metropolitana. 


\subsubsection{Região Nordeste}

Na Região Nordeste os workshops foram realizados nas cidades de Recife, Aracaju, Maceió e Fortaleza.

\subsubsection{Recife - PE}

Uma vez que o workshop realizado no dia 2 de maio de 2005 consistiu em uma experiência piloto do Curso de Capacitação, na ocasião, a adaptação da metodologia MDCA-C para o contexto de análise ainda não havia sido implementada, o que implicou em uma coleta diferenciada dos dados na cidade de Recife e Região Metropolitana. No entanto, os resultados obtidos referem-se também a Indicadores de Mobilidade identificados em uma primeira fase do workshop, e em Estratégias e Idéias-chave relacionadas ao conceito de Mobilidade Urbana Sustentável, equivalentes às Alternativas e PVFs, respectivamente, identificados nas demais cidades.

A Figura 7.13 apresenta a estrutura de trinta e oito Indicadores de Mobilidade obtidos para Recife e Região Metropolitana.

A Figura 7.14 apresenta a estrutura de Estratégias (Alternativas) e Idéias-chave (PVFs) obtidos para a região. Neste caso, na última etapa do exercício não foram associados Indicadores de Mobilidade Urbana Sustentável ao nível dos PVFs, tal como foi realizado nas demais cidades pesquisadas.

Tanto os indicadores da primeira fase do exercício como os conceitos da fase final foram classificados em agrupamentos com a mesma denominação, de forma a facilitar a análise comparativa dos conceitos obtidos nas duas etapas, relacionado ao enfoque dado às questões de mobilidade urbana.

\subsubsection{Aracaju - SE}

A Figura 7.15 mostra a estrutura de vinte e nove indicadores agrupados em diferentes temas, obtida na primeira etapa do exercício realizado em Aracaju no dia 13 de março de 2006, e que contou também com a participação de técnicos e gestores de municípios da Região Metropolitana.

A estruturação do conceito de mobilidade urbana sustentável para Aracaju resultou na identificação de cinqüenta EPAs, transformados em Conceitos Orientados à Ação, através da definição de seus pólos Positivo e Negativo. Estes conceitos foram agregados em quatro Alternativas. 
$\mathrm{Na}$ etapa posterior foram consolidados nove PVFs, para os quais foram associados Indicadores de Mobilidade Urbana Sustentável. A estrutura final de Alternativas, PVFs e Indicadores de Mobilidade Urbana Sustentável obtida para Aracaju e Região Metropolitana é apresentada na Figura 7.16.

Em Aracaju os participantes da atividade optaram por identificar os PVFs por meio dos Pólos Positivos dos conceitos (ou Conceitos Orientados à Ação), uma vez que na opinião dos técnicos e gestores, este elemento melhor representava a idéia selecionada pelo grupo.

\subsubsection{Maceió - AL}

A Figura 7.17 mostra a estrutura de trinta e sete indicadores agrupados em diferentes temas, obtida na primeira etapa do exercício realizado em Maceió no dia 10 de julho de 2006, e que contou também com a participação de técnicos e gestores de municípios da Região Metropolitana.

A estruturação do conceito de mobilidade urbana sustentável para Maceió resultou na identificação de cinqüenta EPAs, transformados em Conceitos Orientados à Ação, através da definição de seus pólos Positivo e Negativo. Estes conceitos foram agregados em cinco Alternativas.

$\mathrm{Na}$ etapa posterior foram consolidados onze PVFs, para os quais foram associados Indicadores de Mobilidade Urbana Sustentável. A estrutura final de Alternativas, PVFs e Indicadores de Mobilidade Urbana Sustentável obtida para Maceió e Região Metropolitana é apresentada na Figura 7.18.

\subsubsection{Fortaleza - CE}

A Figura 7.19 mostra a estrutura de trinta e quatro indicadores agrupados em diferentes temas, obtida na primeira etapa do exercício realizado em Fortaleza no dia 27 de novembro de 2006, e que contou também com a participação de técnicos e gestores de municípios da Região Metropolitana.

A estruturação do conceito de mobilidade urbana sustentável para Fortaleza resultou na identificação de cinqüenta e oito EPAs, transformados em Conceitos Orientados à Ação, através da definição de seus pólos Positivo e Negativo. Estes conceitos foram agregados em seis Alternativas.

$\mathrm{Na}$ etapa posterior foram consolidados oito PVFs, para os quais foram associados Indicadores de Mobilidade Urbana Sustentável. A estrutura final de Alternativas, PVFs e Indicadores de Mobilidade Urbana Sustentável obtida para Fortaleza e Região Metropolitana é apresentada na Figura 7.20. 
-Indice de acidentes

relaçăo à deslocamentos na via

- Velocidade média do transporte coletivo

Tempo de roda parada

indice de saturação

da vi

Número de veiculos por dia e horário por tipo

de veiculo em determinada via

Número de veículos privados por hab.

Porcentagem de vias estrutur

Capacidade de oferta de transporte público $x$

Capacidade de of
populaçáo local

- Indice de motorizaçăo

Número total de passageiros no

sistema de tran

- Frota de veículos por tipo

Velocidade média no tráfego

orcentagem de vias pavimentadas em

Indice de ocupação dos veículos particulares

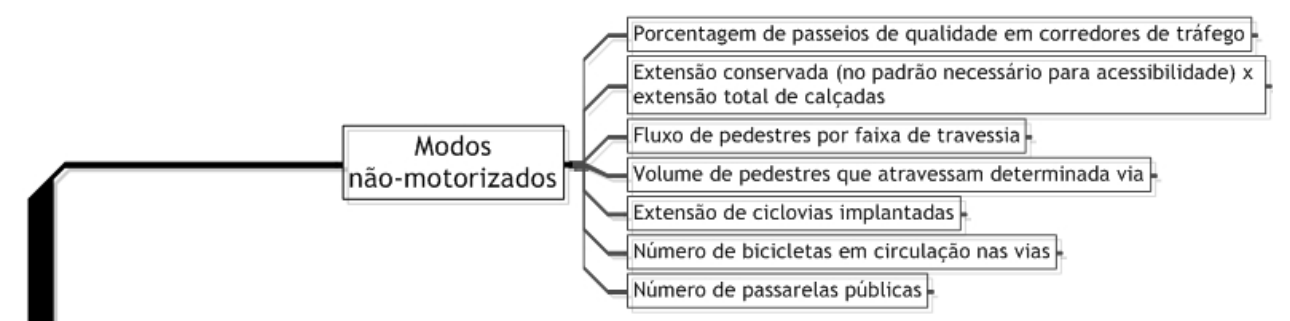

Mobilidade Urbana Recife

\section{Modos motorizados}
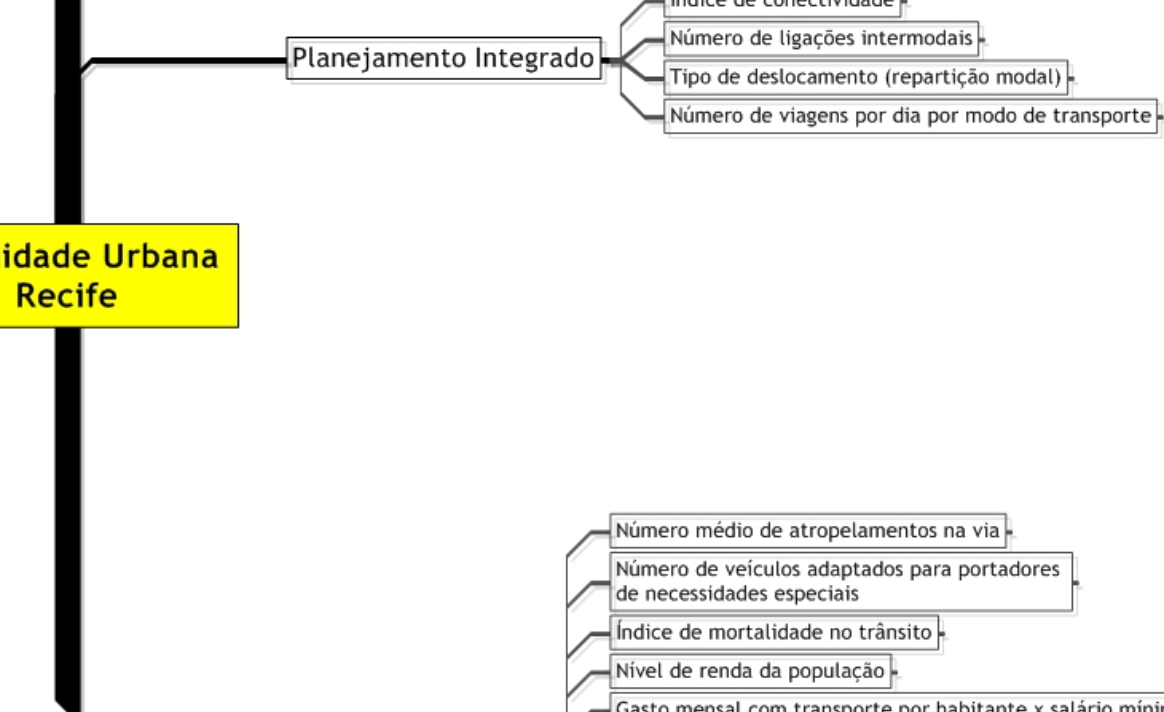

Taxa de emissão de gás carbônico.

Viagens por dia por habitante.

Indice de Desenvolvimento Humano + mobilidade.

Indice de utilização do transporte público.

Figura 7.13: Árvore de Temas e Indicadores de Mobilidade para Recife e Região Metropolitana 


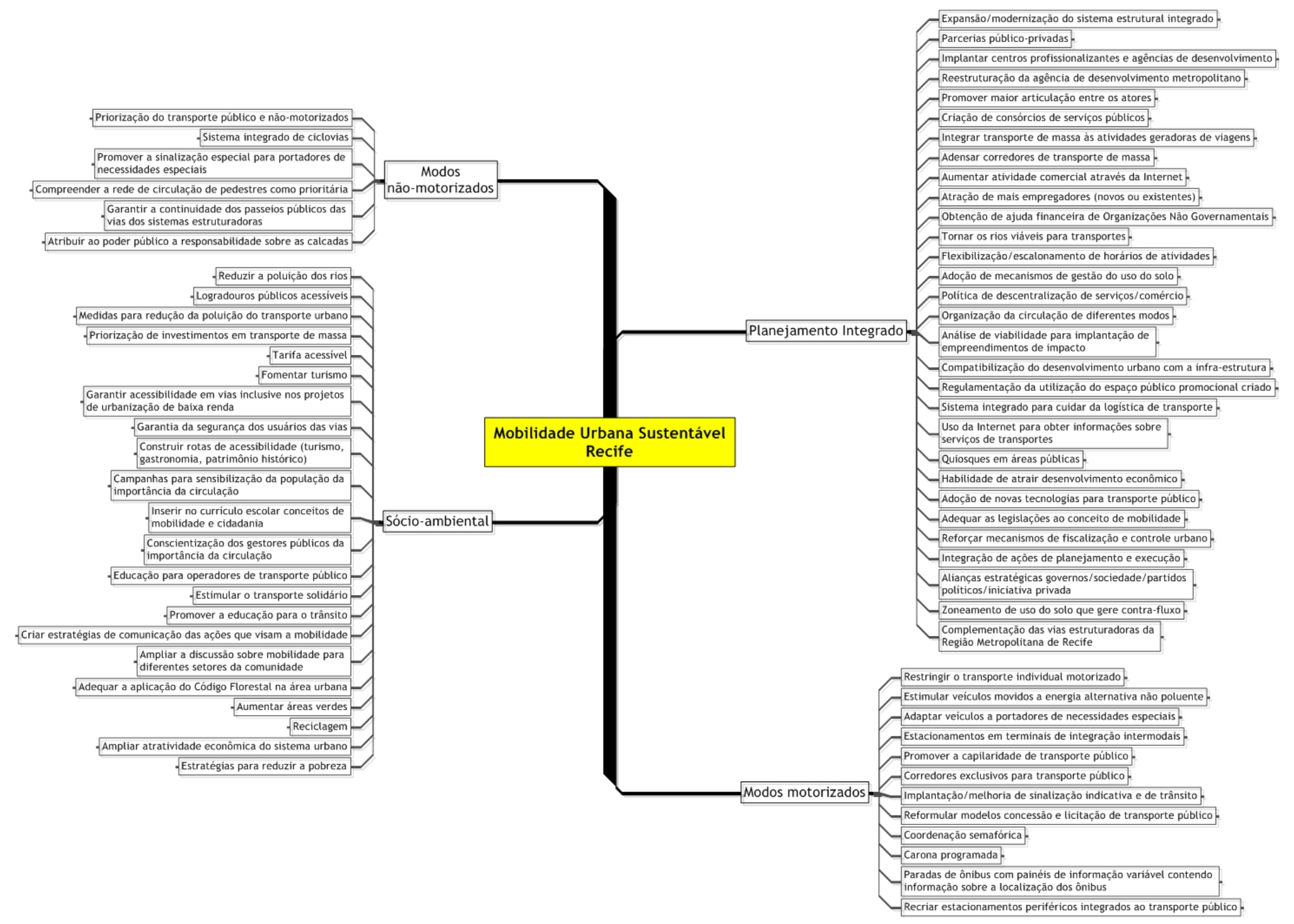

Figura 7.14: Árvore de Alternativas, PVFs para Recife e Região Metropolitana. 


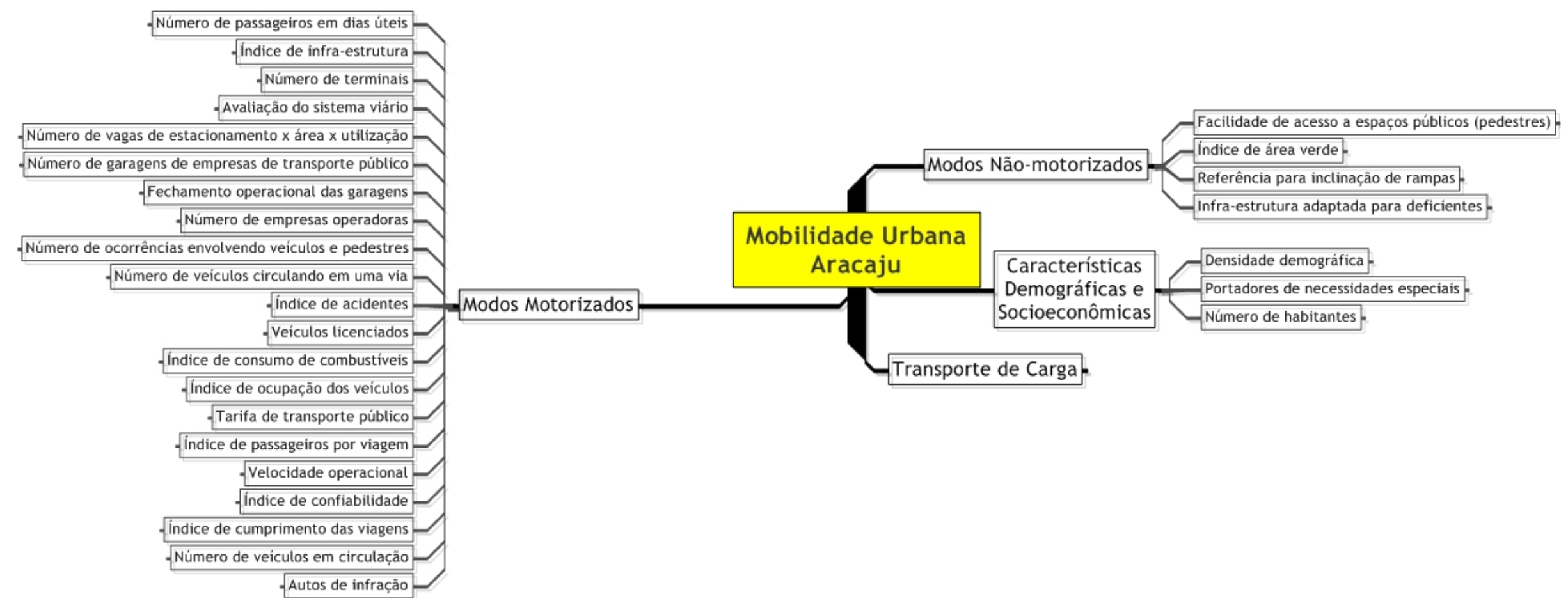

Figura 7.15: Árvore de Temas e Indicadores de Mobilidade para Aracaju e Região Metropolitana. 


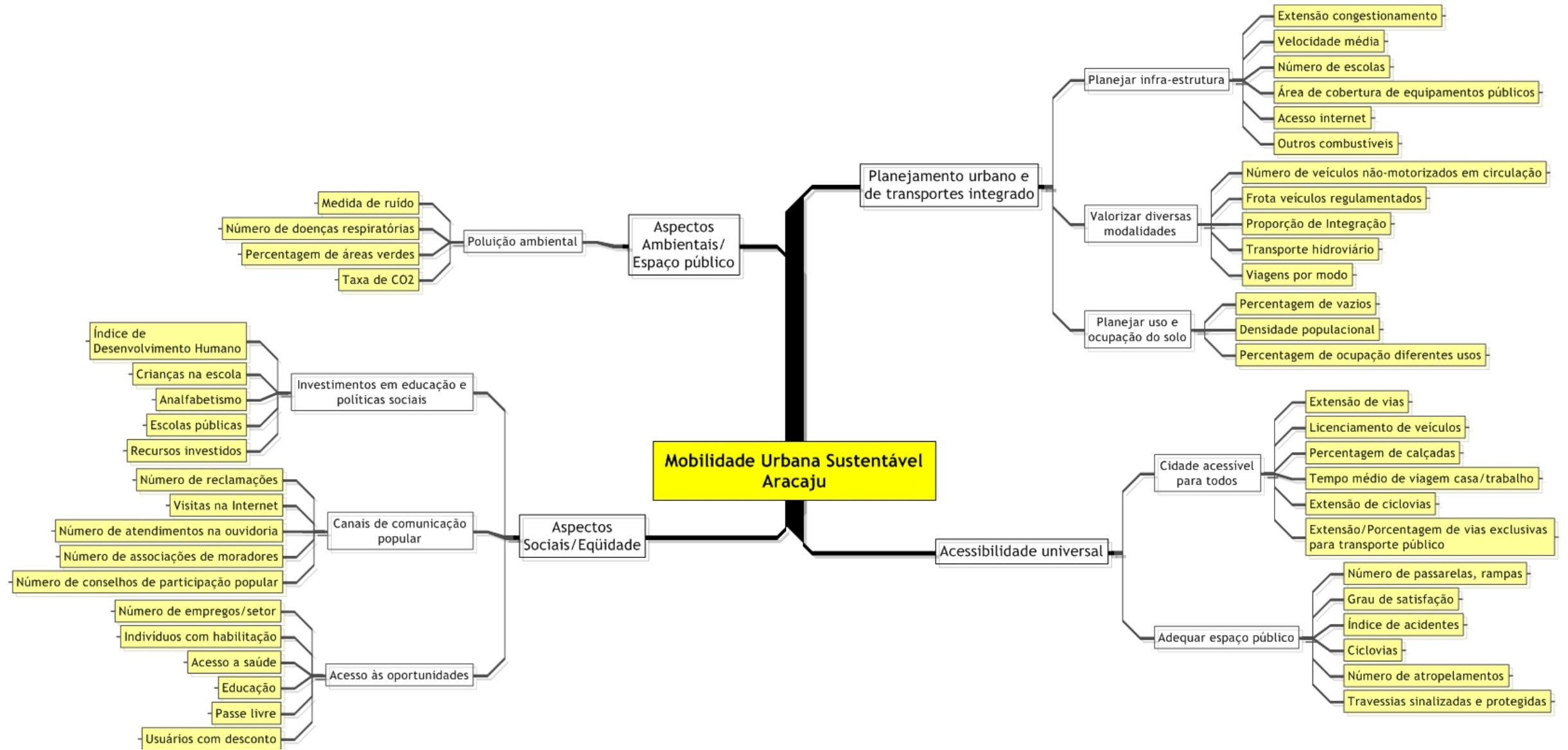

Figura 7.16: Árvore de Alternativas, PVFs e Indicadores de Mobilidade Sustentável para Aracaju e Região Metropolitana. 


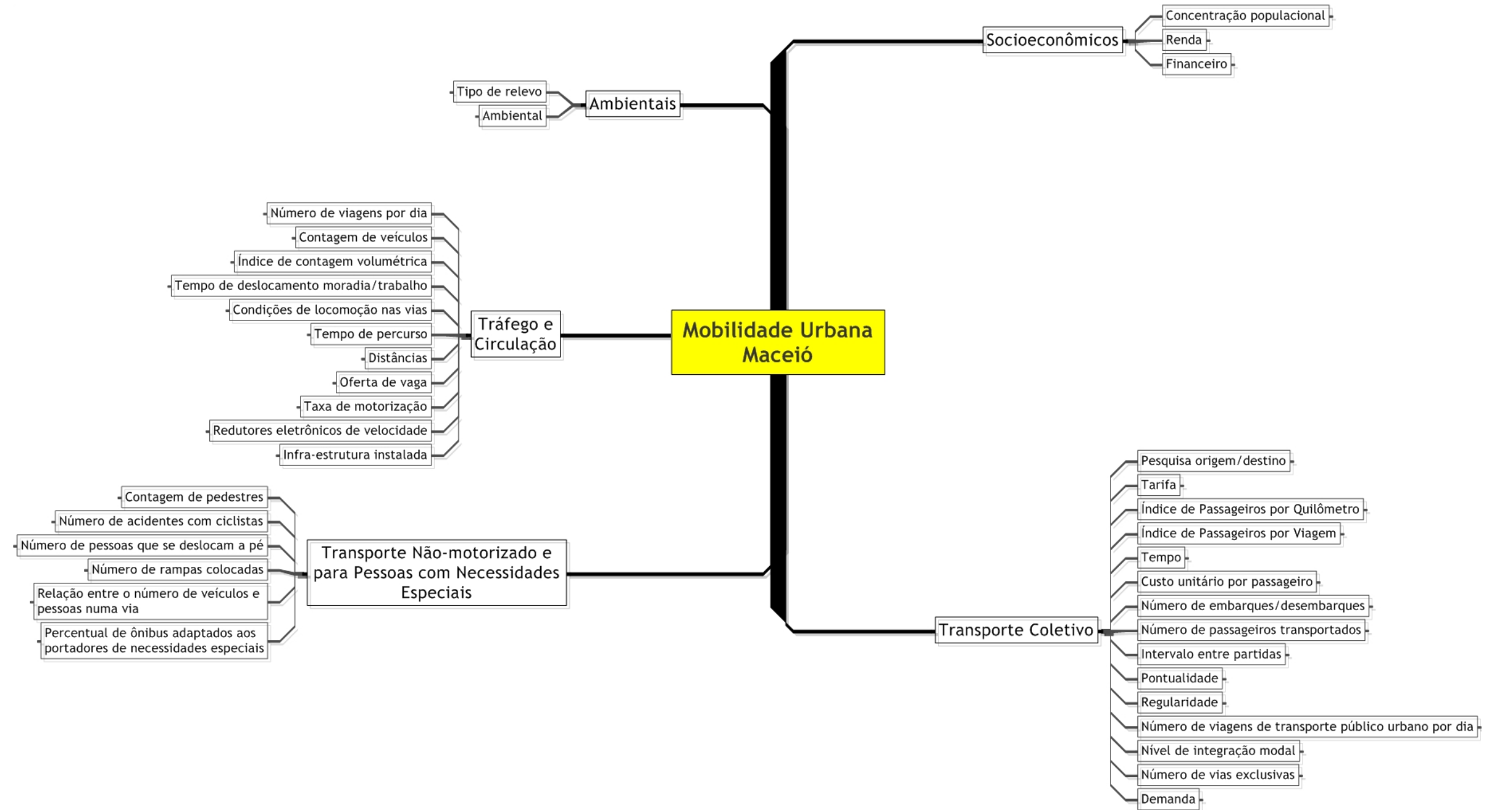

Figura 7.17: Árvore de Temas e Indicadores de Mobilidade para Maceió e Região Metropolitana. 


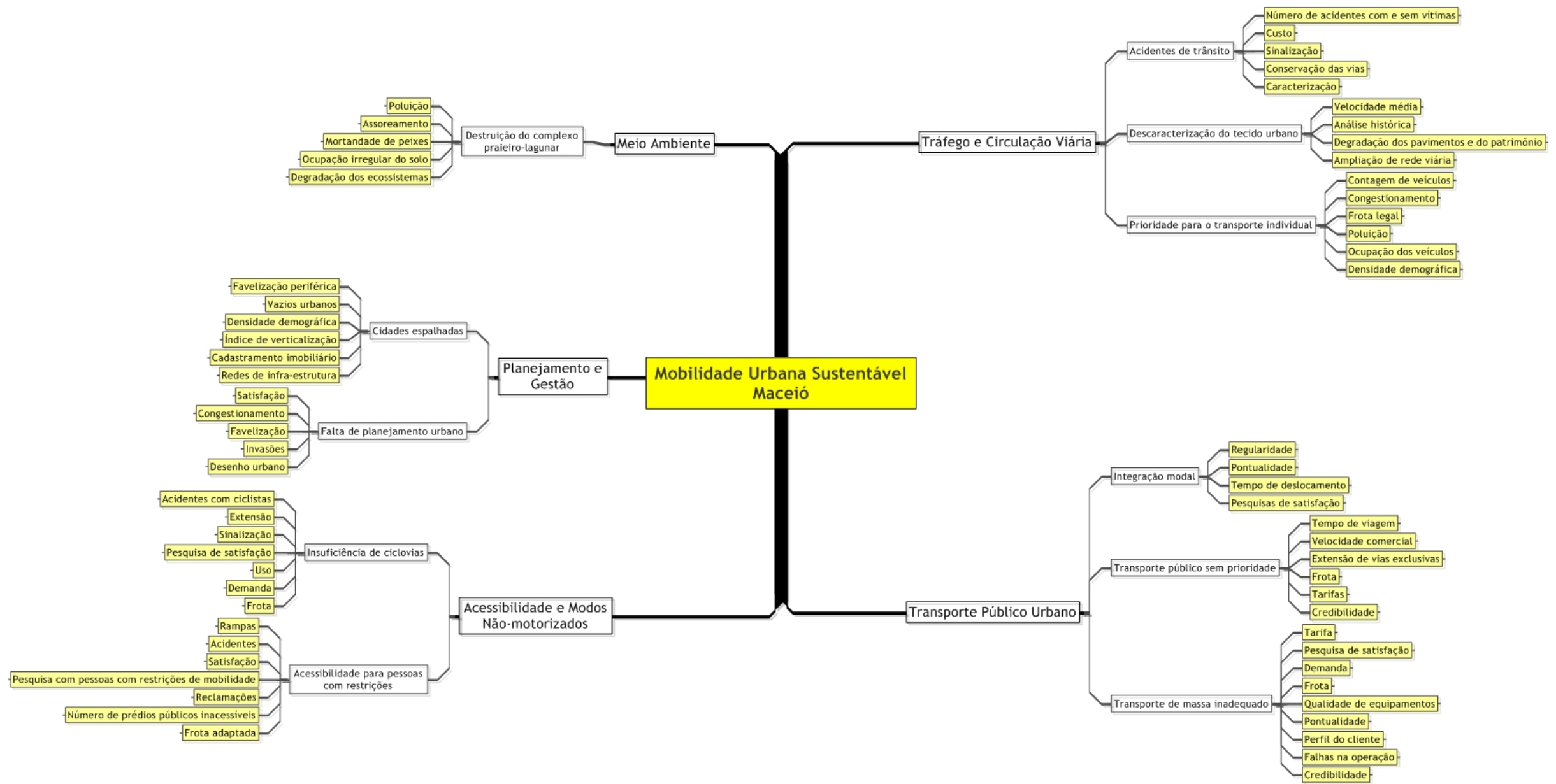

Figura 7.18: Árvore de Alternativas, PVFs e Indicadores de Mobilidade Sustentável para Maceió e Região Metropolitana. 


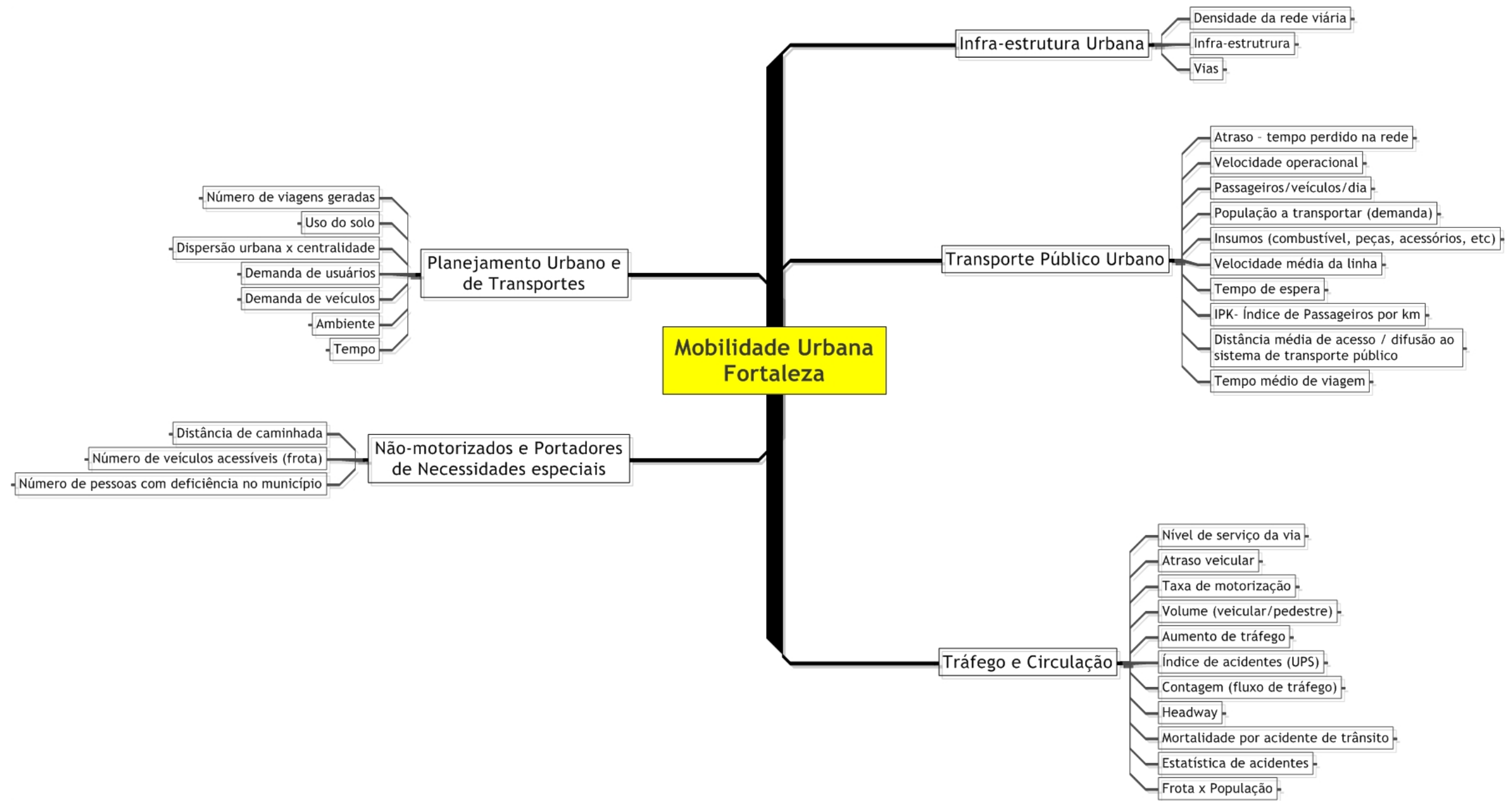

Figura 7.19: Árvore de Temas e Indicadores de Mobilidade para Fortaleza e Região Metropolitana. 


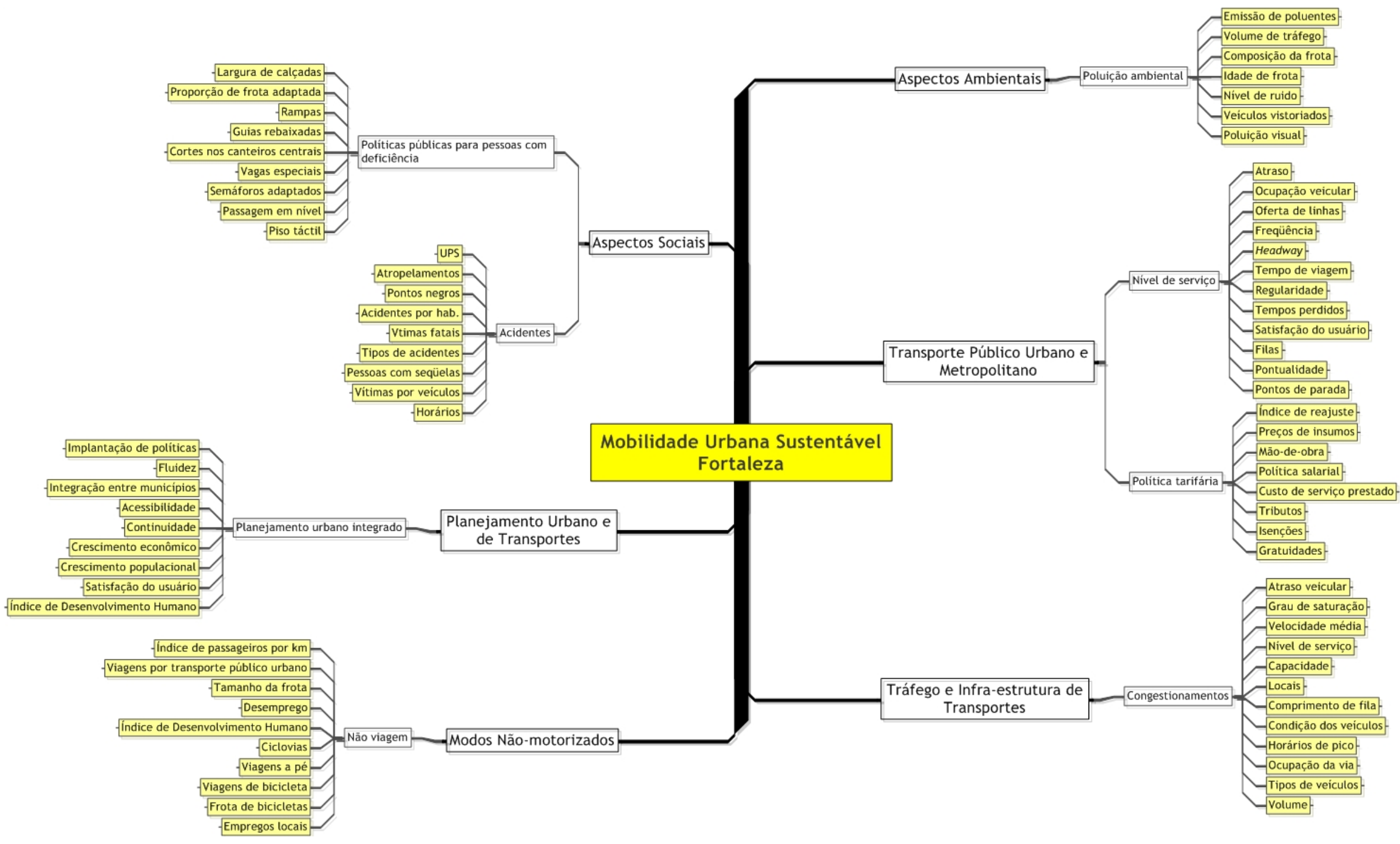

Figura 7.20: Árvore de Alternativas, PVFs e Indicadores de Mobilidade Sustentável para Fortaleza e Região Metropolitana. 


\subsubsection{Região Norte}

Na Região Norte os workshops foram realizados nas cidades de Palmas e Manaus.

\subsubsection{Palmas - TO}

A Figura 7.21 mostra a estrutura de trinta e um indicadores agrupados em diferentes temas, obtida na primeira etapa do exercício realizado em Palmas no dia 28 de agosto de 2006, e que contou também com a participação de técnicos e gestores de municípios vizinhos.

A estruturação do conceito de mobilidade urbana sustentável para Palmas resultou na identificação de cinqüenta e seis EPAs, transformados em Conceitos Orientados à Ação, através da definição de seus pólos Positivo e Negativo. Estes conceitos foram agregados em cinco Alternativas.

$\mathrm{Na}$ etapa posterior foram consolidados onze PVFs, para os quais foram associados Indicadores de Mobilidade Urbana Sustentável. A estrutura final de Alternativas, PVFs e Indicadores de Mobilidade Urbana Sustentável obtida para Palmas e municípios vizinhos é apresentada na Figura 7.22.

\subsubsection{Manaus - AM}

A Figura 7.23 mostra a estrutura de trinta e nove indicadores agrupados em diferentes temas, obtida na primeira etapa do exercício realizado em Manaus no dia 11 de setembro de 2006, e que contou também com a participação de técnicos e gestores de municípios vizinhos.

A estruturação do conceito de mobilidade urbana sustentável para Manaus resultou na identificação de setenta EPAs, transformados em Conceitos Orientados à Ação, através da definição de seus pólos Positivo e Negativo. Estes conceitos foram agregados em seis Alternativas.

$\mathrm{Na}$ etapa posterior foram consolidados oito PVFs, para os quais foram associados Indicadores de Mobilidade Urbana Sustentável. A estrutura final de Alternativas, PVFs e Indicadores de Mobilidade Urbana Sustentável obtida para Manaus e municípios vizinhos é apresentada na Figura 7.24. 


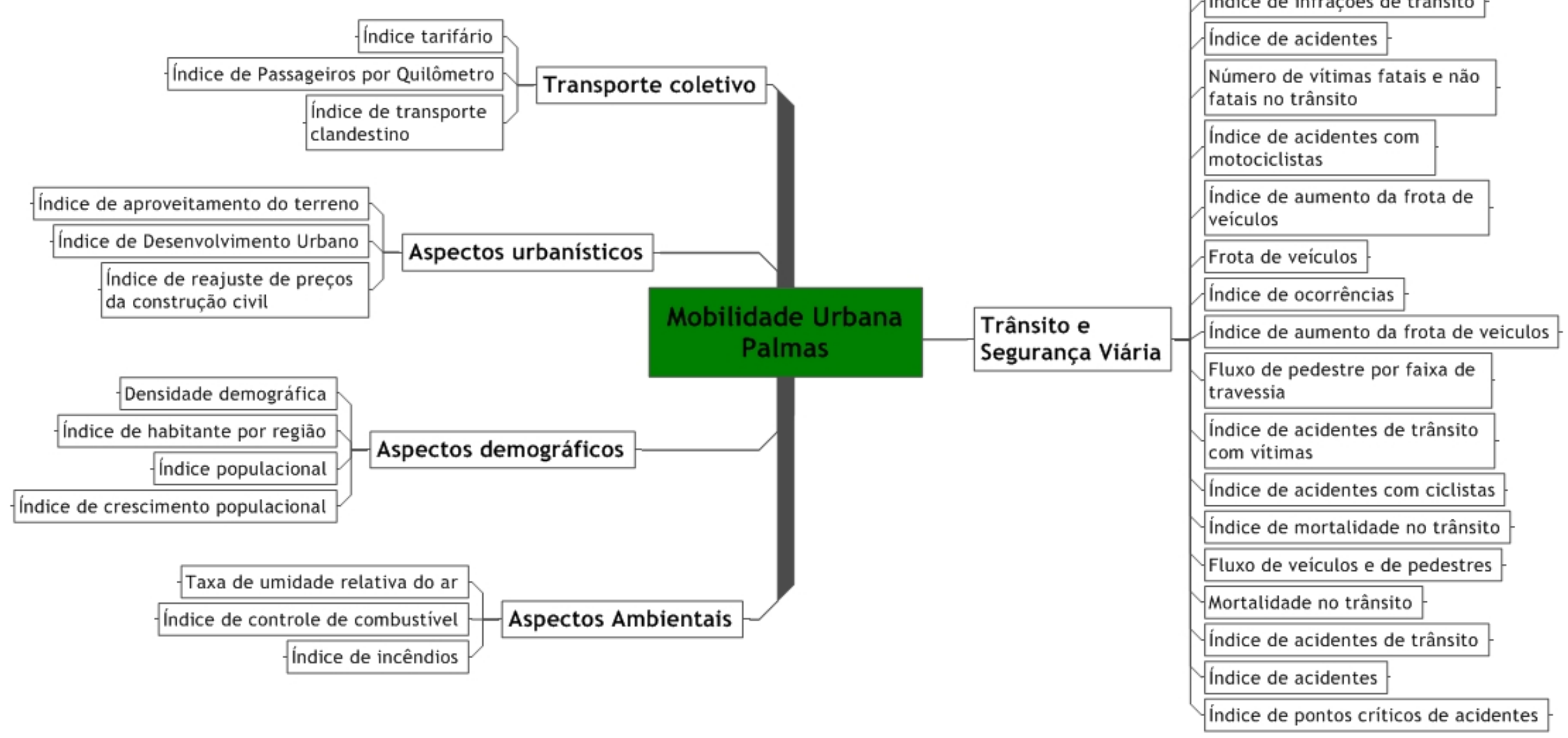

Figura 7.21: Árvore de Temas e Indicadores de Mobilidade para Palmas e municípios vizinhos. 


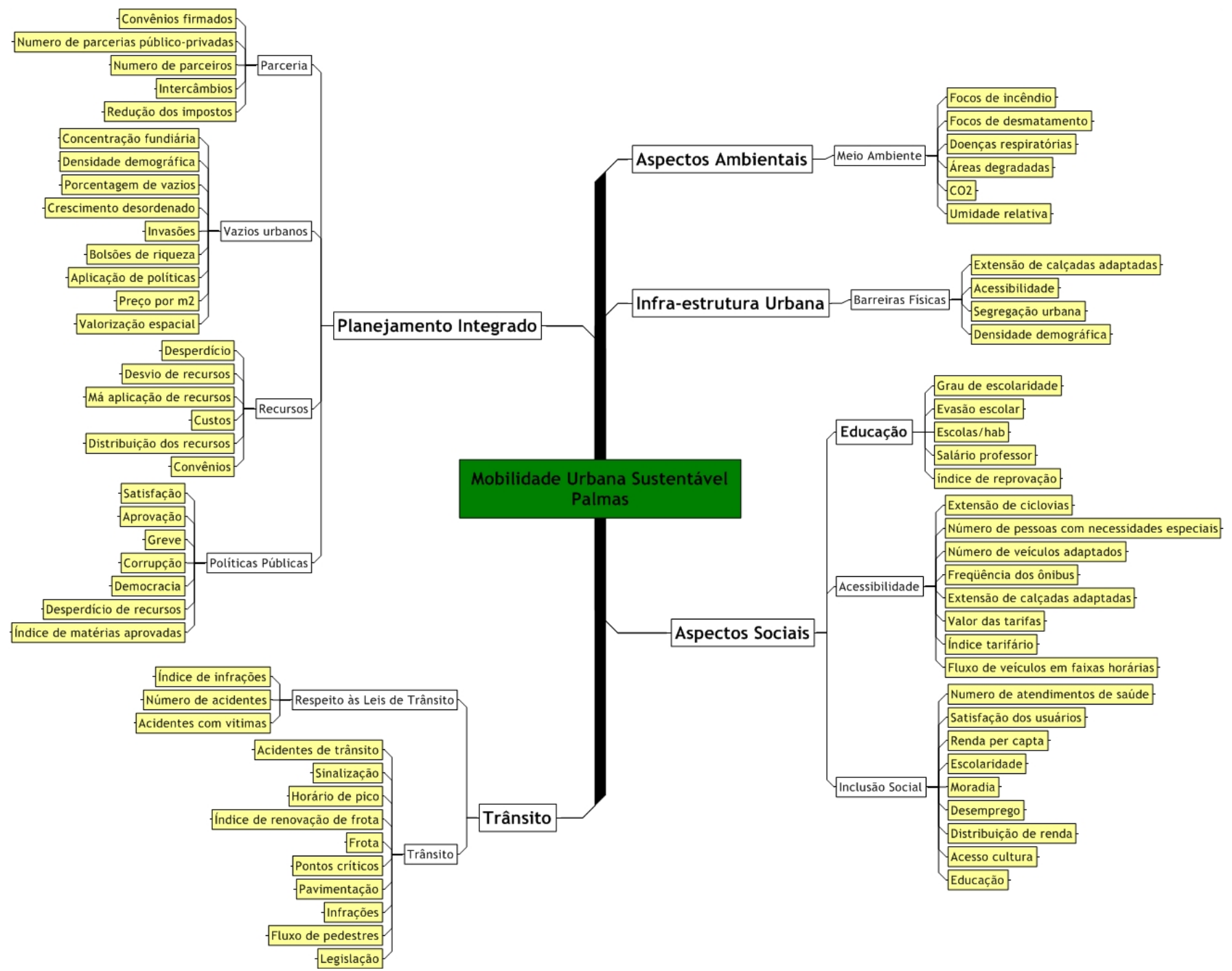

Figura 7.22: Árvore de Alternativas, PVFs e Indicadores de Mobilidade Sustentável para Palmas e municípios vizinhos. 


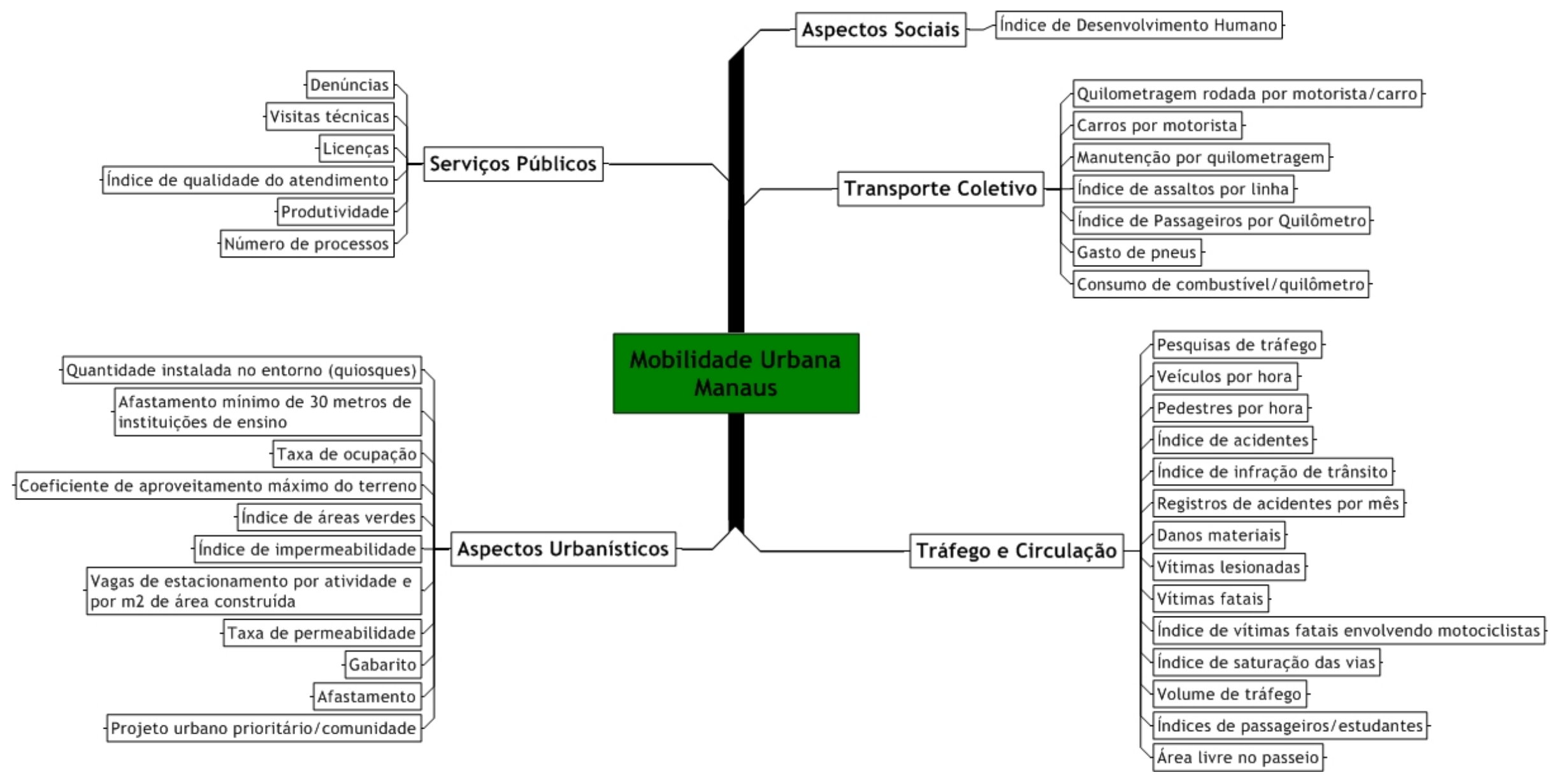

Figura 7.23: Árvore de Temas e Indicadores de Mobilidade para Manaus e municípios vizinhos. 


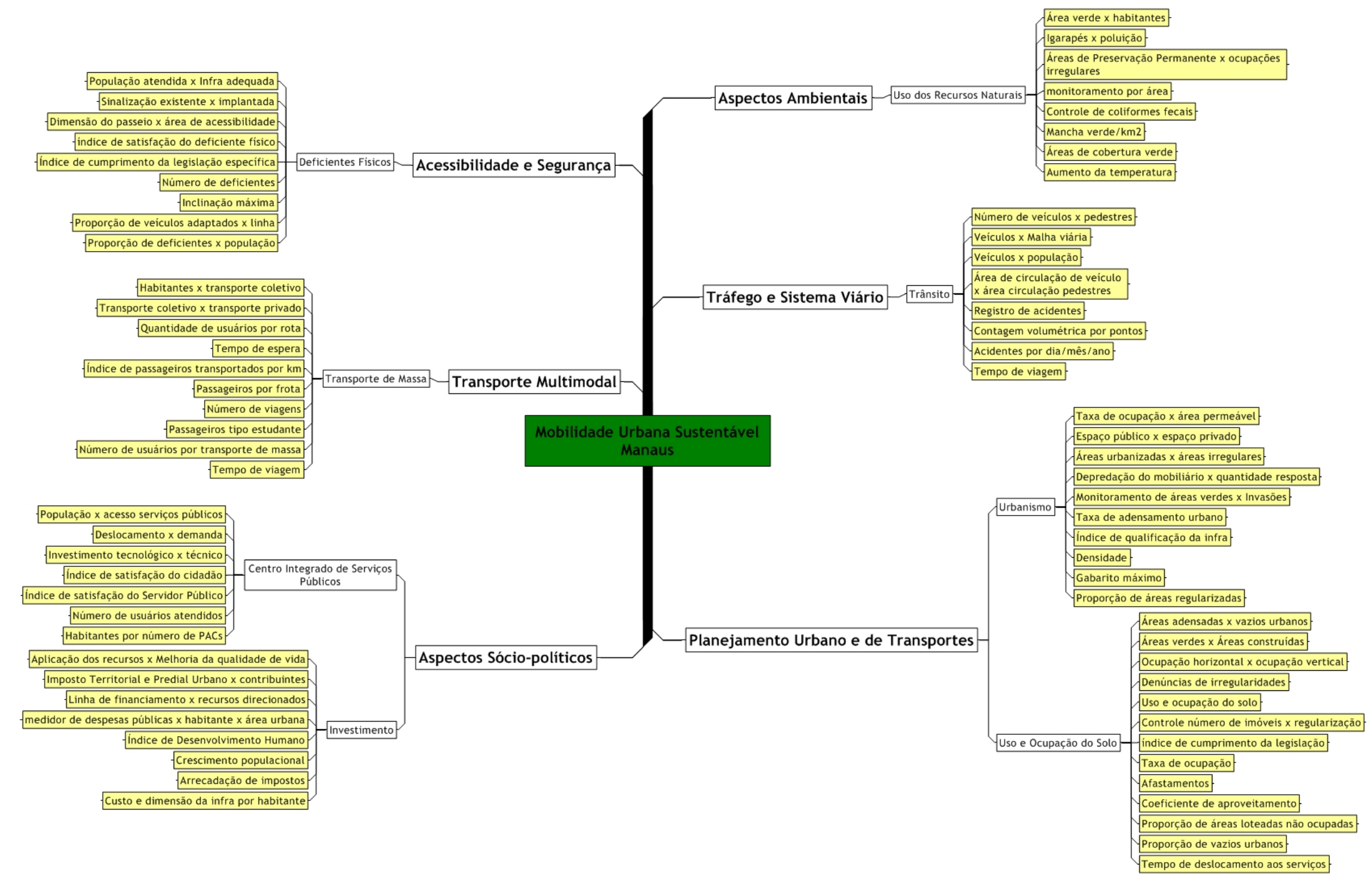

Figura 7.24: Árvore de Alternativas, PVFs e Indicadores de Mobilidade Sustentável para Manaus e municípios vizinhos. 


\subsection{Análise dos Resultados}

A análise dos resultados obtidos através dos workshops realizados nas onze cidades brasileiras é feita com base nas seguintes abordagens:

- A primeira, para cada cidade, com foco na identificação das diferenças existentes entre os conceitos obtidos nas duas etapas do exercício, relacionadas ao enfoque tradicional e ao novo paradigma de tratamento das questões de mobilidade urbana;

- A segunda, comparando as cinco regiões, visando destacar as diferenças existentes e consolidar os principais elementos que constituem o referencial de mobilidade urbana sustentável para as cidades pesquisadas.

\subsubsection{Análise dos Resultados por Região - Enfoque Tradicional x Novo Paradigama}

Nesta fase a análise dos resultados é feita por cidade, através da comparação entre a proporção de indicadores classificados nos temas identificados pelo Facilitador na primeira etapa do exercício de capacitação (representados nos gráficos "a" das figuras a seguir) e as Alternativas obtidas na etapa seguinte do exercício (representados nos gráficos "b" das figuras a seguir), que refletem as grandes áreas de preocupação expressas pelo conjunto de EPAs identificados para as cidades analisadas.

Os gráficos à esquerda agregam os elementos relacionados ao que se denomina neste trabalho de Enfoque Tradicional de tratamento das questões de mobilidade urbana, uma vez que se tratam dos indicadores usualmente utilizados no planejamento e gestão da mobilidade nas cidades brasileiras. Os gráficos à direita agregam os elementos relacionados ao denominado Novo Paradigma, uma vez que estão associados aos conceitos de sustentabilidade discutidos durante a atividade de capacitação. Refletem, portanto, um novo modelo de tratamento das questões de mobilidade urbana no país, o qual, conforme será observado neste trabalho, ainda encontra-se em consolidação.

\subsubsection{Região Sul}

\section{Porto Alegre - RS}

A Figura 7.25 (a) e (b) apresenta a proporção de indicadores classificados nos diferentes grupos para os enfoques Tradicional (primeira etapa do exercício) e Novo Paradigma (segunda etapa, conforme conjunto de Alternativas), para a cidade de Porto Alegre e Região Metropolitana. 
Enfoque Tradicional

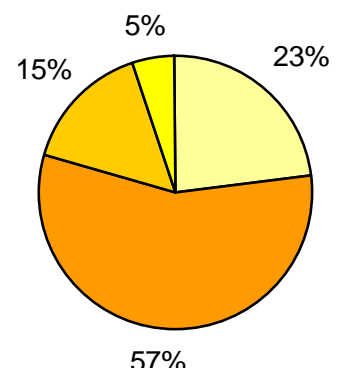

(a)

Tráfego e Circulação

Gerais

Transporte Não-motorizado e para pessoas com necessidades especiais

Transporte Coletivo
Novo Paradigma

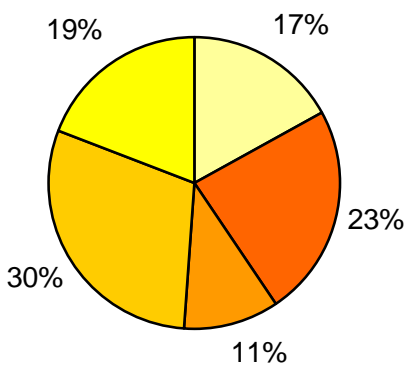

(b)

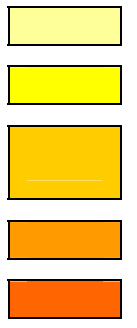

Meio Ambiente e Modos Não-motorizados

Planejamento

Transporte Público Urbano

Organização Espacial

Gestão e Organização dos Transportes

Figura 7.25: Enfoques dos indicadores de mobilidade urbana para Porto Alegre e Região

Metropolitana.

No conjunto de indicadores identificados na primeira fase do exercício observa-se o predomínio das questões relacionadas a Transporte Coletivo e Tráfego e Circulação que representaram, respectivamente, $57 \%$ e $23 \%$ do total de indicadores. Os indicadores sobre transporte coletivo revelaram preocupação especial com aspectos operacionais dos serviços de transporte, expressa através da inclusão de indicadores como índice de Passageiros por Quilômetro (IPK), índice de regularidade, percurso médio mensal, pontualidade, etc. Cabe destacar, conforme análise feita no Capítulo 3, que as questões de transporte coletivo e provisão de infra-estrutura para melhoria das condições de tráfego e circulação se constituíram no foco do planejamento de transportes no país, especialmente até o final da década de 80 do século passado.

Os demais indicadores relacionados nesta etapa dizem respeito ao Transporte Nãomotorizado e para Pessoas com Necessidades Especiais, e indicadores Gerais, relacionados a questões econômicas, comunicação e informação, que representaram respectivamente $15 \%$ e $5 \%$ dos indicadores identificados.

Já no decorrer das discussões referentes à caracterização do conceito de mobilidade urbana sustentável, ainda que a questão do transporte coletivo tenha permanecido como tema principal, expressa através da Alternativa Transporte Público Urbano, que agregou $30 \%$ dos indicadores relacionados nesta etapa, dois aspectos puderam ser observados: 
- O primeiro, relacionado ao amadurecimento no tratamento dado aos temas abordados na primeira fase do exercício, visível especialmente com relação às questões de transporte público, cujo enfoque na segunda etapa se concentrou em aspectos de integração dos serviços, e quanto aos modos não-motorizados de transporte, que na segunda etapa foram relacionados diretamente às questões ambientais;

- O segundo, a inclusão de novos temas antes desconsiderados tais como Planejamento, Organização Espacial e Gestão e Organização dos Transportes, incorporando temas recentemente enfatizados no processo de planejamento e gestão da mobilidade nas cidades brasileiras.

\section{Florianópolis - SC}

A Figura 7.26 (a) e (b) apresenta a proporção de indicadores classificados nos diferentes grupos para os enfoques Tradicional e Novo Paradigma, para a cidade de Florianópolis e Região Metropolitana.

Enfoque Tradicional

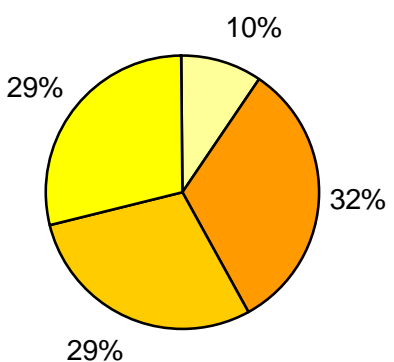

(a)
Novo Paradigma

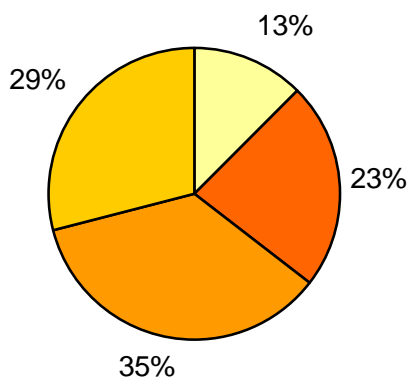

(b)
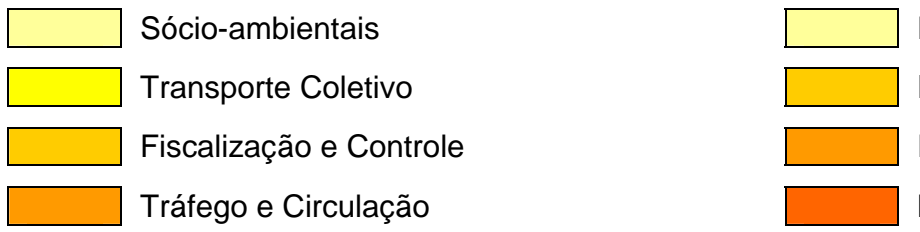

Planejamento e Controle

Ética, Participação e Políticas Públicas Infra-estrutura e Meio Ambiente Modos Não Motorizados

Figura 7.26: Enfoques dos indicadores de mobilidade urbana para Florianópolis e Região Metropolitana.

Para Florianópolis, os indicadores identificados na primeira etapa deram ênfase às questões de Tráfego e Circulação (32\%) e Fiscalização e Controle (29\%), ambas relacionadas à circulação de veículos em vias urbanas, e às questões de Transporte Coletivo (29\%), repetindo os temas destacados para a cidade de Porto Alegre e Região Metropolitana, e também tradicionalmente empregados no planejamento de transportes em cidades brasileiras. 
Outro tema foi incluído nesta etapa, representado pelas questões Sócio-ambientais. Enquanto que na primeira fase da atividade de capacitação as questões ambientais representaram somente $10 \%$ dos indicadores identificados, na segunda fase, associadas à infra-estrutura urbana (Alternativa Infra-estrutura e Meio Ambiente), representaram 35\% dos indicadores relacionados, a maior parcela de indicadores obtidos. Cabe destacar que este tema está diretamente associado às questões de sustentabilidade dos sistemas de transportes, tendo sido incorporado nas primeiras iniciativas e debates sobre o assunto em nível internacional e mais recentemente em nível nacional.

Ainda na segunda etapa, os temas abordados na primeira fase foram colocados em segundo plano, dando espaço para novos temas como Planejamento e Controle (13\%), Ética, Participação e Políticas Públicas (29\%) e Modos Não-motorizados (23\%), também relacionados ao novo modelo de tratamento das questões de mobilidade urbana em consolidação no país.

\subsubsection{Região Sudeste}

\section{Vitória - ES}

A Figura 7.27 (a) e (b) apresenta a proporção de indicadores classificados nos diferentes grupos para os enfoques Tradicional e Novo Paradigma, para a cidade de Vitória e Região Metropolitana.

Enfoque Tradicional

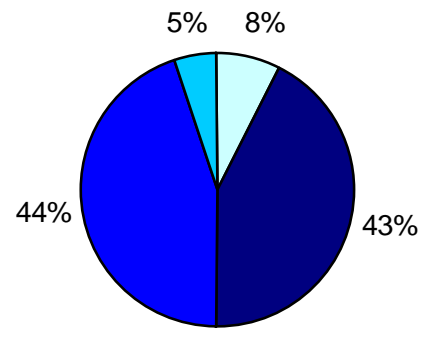

(a)

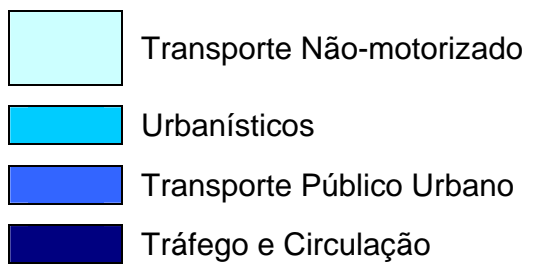

Novo Paradigma

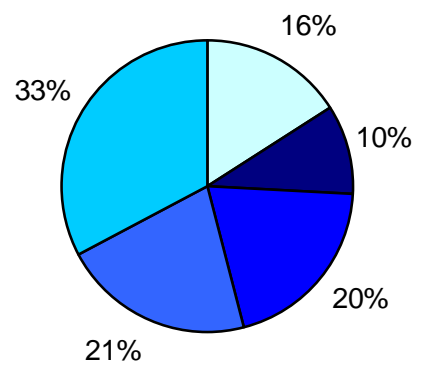

(b)

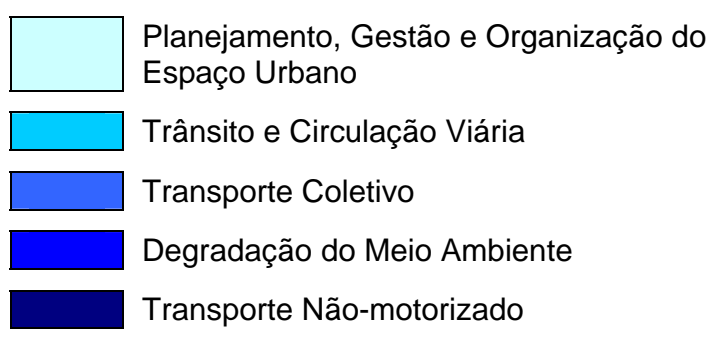

Figura 7.27: Enfoques dos indicadores de mobilidade urbana para Vitória e Região Metropolitana. 
Em Vitória, novamente as questões de Transporte Público Urbano e Tráfego e Circulação representaram a maioria dos indicadores identificados na primeira etapa, agregando respectivamente $44 \%$ e $43 \%$ dos mesmos. No tema Transporte Público Urbano foram incluídos, fundamentalmente, indicadores referentes a aspectos operacionais como Índice de Passageiros por Quilômetro (IPK), percurso médio mensal, custo por quilômetro, quilometragem percorrida, entre outros. Nesta fase ainda foram incorporados indicadores Urbanísticos e de Transporte Não-motorizado, que representaram apenas $5 \%$ e $8 \%$ dos indicadores.

As mesmas questões enfatizadas na primeira etapa se constituíram no foco da segunda etapa da atividade de capacitação, representadas através das Alternativas Trânsito e Circulação Viária (33\%) e Transporte Coletivo (21\%). No entanto, aos indicadores de tráfego, anteriormente limitados a medidas de nível de serviço do sistema viário urbano, foram acrescentados indicadores relacionados a acidentes e à acessibilidade universal. Já para os indicadores operacionais dos serviços de transporte, foram incorporadas medidas de acessibilidade ao sistema. As questões de acessibilidade são temas abordados especialmente nas iniciativas para o transporte urbano sustentável.

No que diz respeito ao tema Transporte Não-motorizado, este teve sua participação ligeiramente ampliada na segunda etapa, passando de $8 \%$ a $10 \%$ dos indicadores relacionados.

$\mathrm{Na}$ segunda etapa foram incorporados ainda os temas Planejamento, Gestão e Organização do Espaço Urbano (16\%) e Degradação do Meio Ambiente (20\%).

\section{Belo Horizonte - MG}

A Figura 7.28 (a) e (b) apresenta a proporção de indicadores classificados nos diferentes grupos para os enfoques Tradicional e Novo Paradigma, para a cidade de Belo Horizonte e Região Metropolitana.

Em Belo Horizonte, destacaram-se na primeira etapa da atividade de capacitação os temas Tráfego e Fiscalização (29\%) e Transporte Público (24\%), seguindo a tendência das demais cidades analisadas. Nesta fase, ainda foram considerados aspectos Econômicos (9\%), Institucionais e Serviços Públicos (19\%), Acidentes de Trânsito (9\%) e questões Ambientais, que representaram somente $4 \%$ dos indicadores obtidos nesta etapa.

$\mathrm{Na}$ etapa posterior do exercício as questões de Planejamento Urbano, Metropolitano e de Transportes Integrado foram enfatizadas, agregando 33\% dos indicadores. Cabe destacar 
que a integração entre o planejamento urbano e de transportes é uma questão-chave para a sustentabilidade dos sistemas de mobilidade.

Enfoque Tradicional

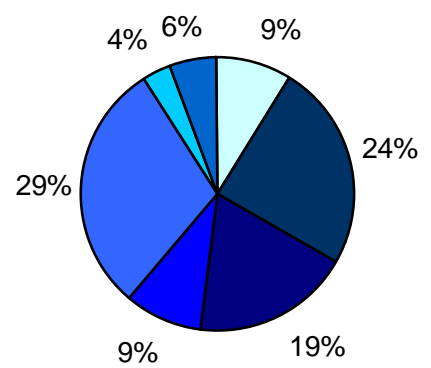

(a)
Novo Paradigma

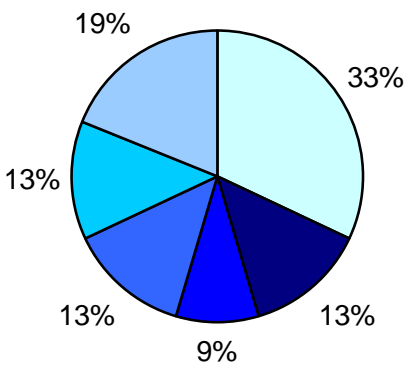

(b)

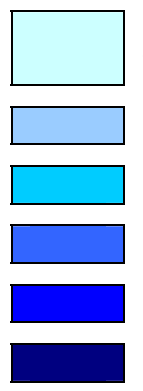

Planejamento Urbano, Metropolitano e de Transportes Integrado

Sistemas de Transporte Urbano

Financiamento

Educação, Cidadania e Fiscalização

Sistemas de Tráfego e Circulação

Aspectos Ambientais

Figura 7.28: Enfoques dos indicadores de mobilidade urbana para Belo Horizonte e Região Metropolitana.

A segunda Alternativa a concentrar maior proporção de indicadores está relacionada aos Sistemas de Transporte Urbano (19\%), que incluiu indicadores para modos coletivos e não-motorizados de transporte. Na primeira etapa, ao serem abordados aspectos referentes aos sistemas de transporte (através do tema Transporte Público), os indicadores se concentraram somente em aspectos operacionais do serviço de transporte público. Já na segunda etapa, trataram dos sistemas de transporte de forma mais global, considerando os diferentes modos existentes.

No que diz respeito aos Aspectos Ambientais, estes foram novamente considerados na análise. No entanto, apresentaram uma maior participação no conjunto de indicadores observados, passando de $4 \%$ para $13 \%$ do total. O mesmo aconteceu com o tema Educação e Cidadania que, ao incorporar a questão da fiscalização (Educação, Cidadania e Fiscalização), passou de $9 \%$ para $13 \%$ dos indicadores identificados. Já as questões relacionadas aos Sistemas de Tráfego e Circulação, anteriormente incluídas no tema Tráfego e Fiscalização e representando $29 \%$ dos indicadores, apresentaram uma sensível redução, passando a agregar somente $9 \%$ dos indicadores relacionados nesta etapa. 
Além destes temas foi incorporada também a Alternativa Financiamento, representando $13 \%$ do conjunto.

\subsubsection{Região Centro-oeste}

\section{Goiânia - GO}

A Figura 7.29 (a) e (b) apresenta a proporção de indicadores classificados nos diferentes grupos para os enfoques Tradicional e Novo Paradigma, para a cidade de Goiânia e Região Metropolitana.

Enfoque Tradicional

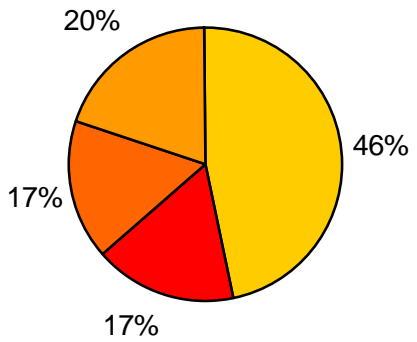

(a)

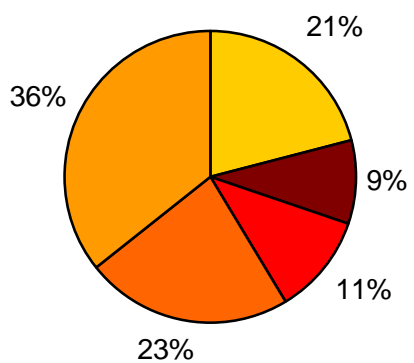

(b)

Modos Motorizados

Planejamento Integrado

Aspectos Socioeconômicos

Modos Não-motorizados

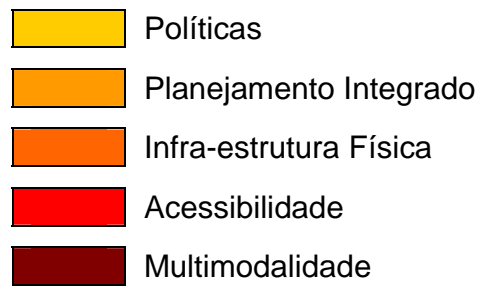

Figura 7.29: Enfoques dos indicadores de mobilidade urbana para Goiânia e Região Metropolitana.

Para Goiânia, foram destacados na primeira etapa da atividade de capacitação indicadores relacionados aos Modos Motorizados de Transporte (46\%), seguidos por indicadores de Planejamento Integrado (20\%), tema comumente relacionado na segunda etapa do exercício nas demais cidades pesquisadas. Ainda nesta fase foram incorporados Aspectos Socioeconômicos (17\%) e Modos Não-motorizados de Transporte (17\%).

As questões de Planejamento Integrado (36\%) representaram a principal preocupação na cidade na segunda etapa do exercício, porém, dividiram sua importância com Alternativas como Infra-estrutura Física (23\%), Políticas (21\%), Acessibilidade (11\%) e Multimodalidade (9\%). Enquanto que na primeira fase incluíram indicadores diversos como pesquisas de transportes, parcelamentos urbanos, infra-estrutura, modos de locomoção, demanda e pólos geradores de viagem, na segunda fase as questões de Planejamento 
Integrado incluíram aspectos associados mais diretamente ao planejamento territorial e de transportes integrado, expressos através de indicadores como densidade populacional, distâncias médias de deslocamento, grau de congestionamento, distribuição de atividades, etc.

\subsubsection{Região Nordeste}

\section{Recife - PE}

A Figura 7.30 (a) e (b) apresenta a proporção de indicadores classificados nos diferentes grupos para os enfoques Tradicional e Novo Paradigma, para a cidade de Recife e Região Metropolitana.

\section{Enfoque Tradicional}

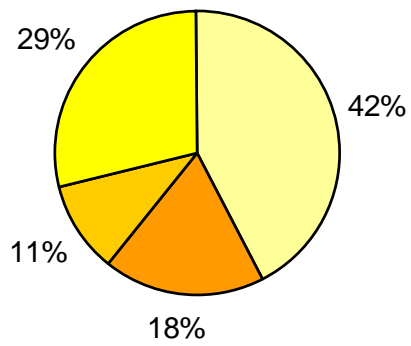

(a)
Novo Paradigma

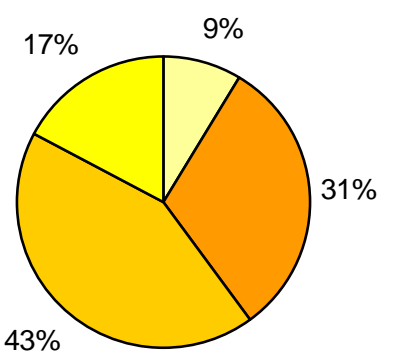

(b)

\section{Modos Motorizados}

Sócio-ambiental

Planejamento Integrado

Modos Não-motorizados

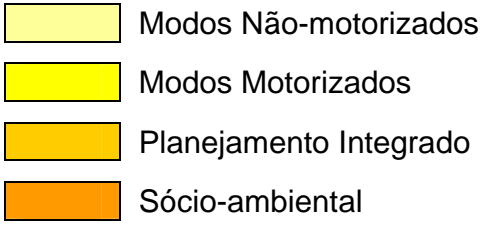

Figura 7.30: Enfoques dos indicadores de mobilidade urbana para Recife e Região Metropolitana.

Devido a semelhança entre os tópicos relacionados nas duas fase da atividade piloto realizada na cidade, foram considerados os mesmos agrupamentos para a classificação dos tópicos identificados no exercício. Desta forma, a comparação entre o Enfoque Tradicional e Novo Paradigma se dá através da análise das diferentes proporções obtidas para os temas considerados. Para construção do gráfico que representa o Novo Paradigma, foram consideradas as Idéias-chave classificadas em cada uma das Estratégias (Alternativas) identificadas no workshop. 
Para Recife e Região Metropolitana os Modos Motorizados tiveram destaque na primeira etapa, representando $42 \%$ dos indicadores do conjunto, seguidos pelos temas Sócioambiental (29\%), Modos Não-motorizados (18\%) e Planejamento Integrado (11\%).

Na segunda etapa a Alternativa Planejamento Integrado passou do aspecto com menor representatividade para o de maior representatividade, ampliando sua participação de 11\% para 43\%. A questão Sócio-Ambiental passou a incorporar 31\% dos indicadores, mantendo-se na segunda posição em relação aos temas considerados. O tema Modos Motorizados (17\%) passou da primeira para a terceira colocação, ao mesmo tempo em que o tema Modos Não-motorizados (9\%) passou da terceira para a quarta colocação.

\section{Aracaju - SE}

A Figura 7.31 (a) e (b) apresenta a proporção de indicadores classificados nos diferentes grupos para os enfoques Tradicional e Novo Paradigma, para a cidade de Aracaju e Região Metropolitana.

Enfoque Tradicional

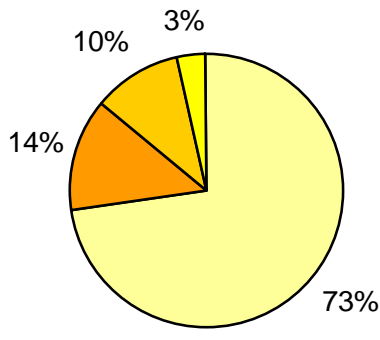

(a)

Modos Motorizados

Transporte de Carga

Características Demográficas e Socioeconômicas

Modos Não-motorizados
Novo Paradigma

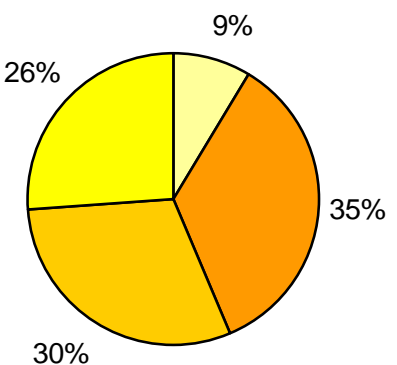

(b)

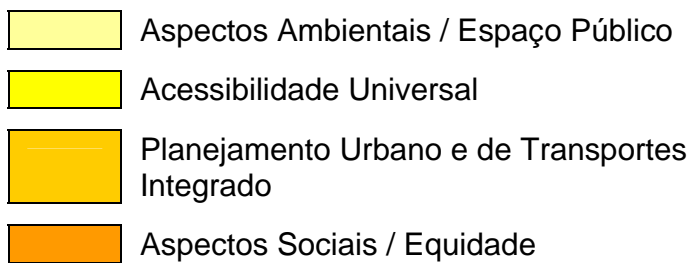

Figura 7.31: Enfoques dos indicadores de mobilidade urbana para Aracaju e Região Metropolitana.

$\mathrm{Na}$ primeira etapa da atividade de capacitação os Modos Motorizados de Transporte acabaram por agregar a grande maioria dos indicadores identificados, representando $73 \%$ do total. Os demais temas considerados dizem respeito a Modos Não-motorizados (14\%), Características Demográficas e Sócio-Econômicas (10\%) e Transporte de Carga (3\%). 
Já na segunda etapa maior ênfase foi dada aos Aspectos Sociais I Eqüidade, que agregaram 35\% dos indicadores. As questões de Planejamento Urbano e de Transportes Integrado (30\%) ficaram na segunda posição, seguidas pelas Alternativas Acessibilidade Universal e Aspectos Ambientais / Espaço Público (9\%).

\section{Maceió - AL}

A Figura 7.32 (a) e (b) apresenta a proporção de indicadores classificados nos diferentes grupos para os enfoques Tradicional e Novo Paradigma, para a cidade de Maceió e Região Metropolitana.

Enfoque Tradicional

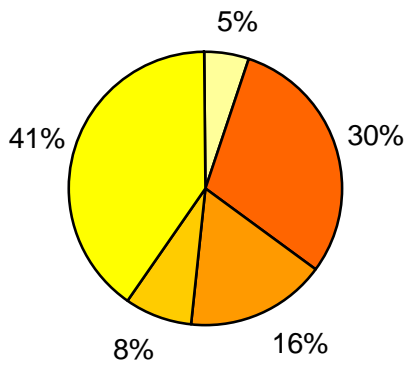

(a)
Novo Paradigma

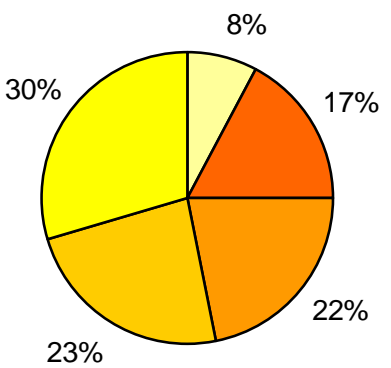

(b)

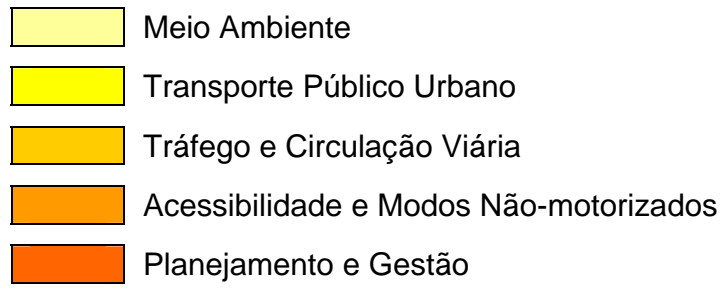

Figura 7.32: Enfoques dos indicadores de mobilidade urbana para Maceió e Região Metropolitana.

Para Maceió os aspectos principais considerados na primeira fase da atividade de capacitação foram Transporte Coletivo (41\%) e Tráfego e Circulação (30\%), assim como as cidades de Porto Alegre, Florianópolis, Vitória e Belo Horizonte. Os outros temas considerados foram Transporte Não-motorizado e para Pessoas com Necessidades Especiais (16\%), Socioeconômicos (8\%) e Ambientais (5\%).

$\mathrm{Na}$ segunda etapa os sistemas de transporte se mantiveram como foco, expressos através da Alternativa Transporte Público Urbano, que concentrou 30\% dos indicadores da etapa. Nesta no entanto, a ênfase dada aos indicadores operacionais foi substituída pela ênfase dada à integração modal e à priorização do transporte público. Tráfego e Circulação Viária se manteve na segunda posição, representando $23 \%$ do conjunto. Diferentemente da 
primeira etapa, onde foram considerados somente indicadores de tráfego, na segunda etapa foram adicionados os indicadores acidentes de trânsito, ampliação da rede viária e taxa de ocupação de veículos. Outras Alternativas consideradas foram Acessibilidade e Modos Não-motorizados (22\%) e Planejamento e Gestão (17\%). As questões ambientais (Meio Ambiente) continuaram a agregar o menor número de indicadores (8\%).

\section{Fortaleza - CE}

A Figura 7.33 (a) e (b) apresenta a proporção de indicadores classificados nos diferentes grupos para os enfoques Tradicional e Novo Paradigma, para a cidade de Fortaleza e Região Metropolitana.

Enfoque Tradicional

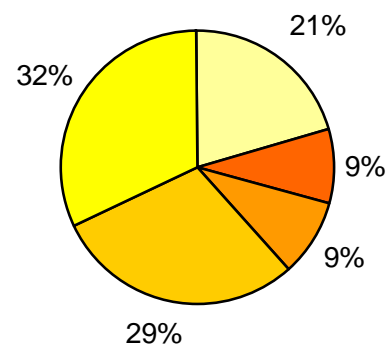

(a)

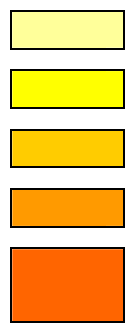

Planejamento Urbano e de Transportes Tráfego e Circulação

Transporte Público Urbano Infra-estrutura Urbana

Modos não-motorizados e pessoas com necessidades especiais
Novo Paradigma

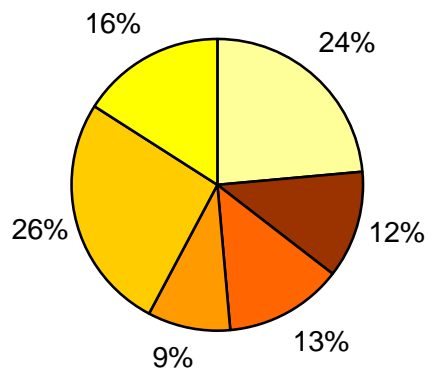

(b)

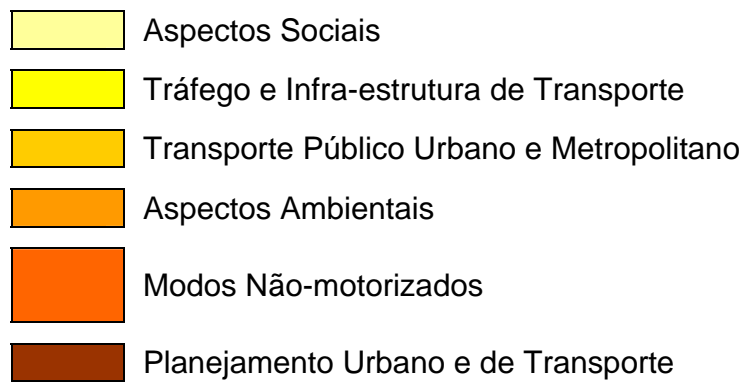

Figura 7.33: Enfoques dos indicadores de mobilidade urbana para Fortaleza e Região Metropolitana.

Para Fortaleza e Região Metropolitana novamente os temas Tráfego e Circulação e Transporte Público Urbano se sobressaíram, representando, respectivamente, 32\% e 29\% dos indicadores relacionados na primeira etapa. Nesta fase foram consideradas ainda questões de Planejamento Urbano e de Transportes (21\%), Infra-estrutura Urbana (9\%) e Modos Não-motorizados e Pessoas com Necessidades Especiais (9\%).

Na segunda etapa o tema Transporte Público Urbano incorporou também a dimensão metropolitana (Transporte Público Urbano e Metropolitano), agregando a maior parte dos indicadores, ou 26\%. Os Aspectos Sociais representaram a segunda principal 
preocupação, representando $24 \%$ dos indicadores. Outras Alternativas consideradas foram Tráfego e Infra-estruura de Transportes (16\%) e Modos Não-motorizados (13\%), que aumentou sua participação, em relação à primeira etapa. Ainda, Planejamento Urbano e de Transportes (12\%) reduziu sensivelmente sua participação e Aspectos Ambientais apresentou 9\% dos indicadores identificados.

\subsubsection{Região Norte}

Palmas - TO

A Figura 7.34 (a) e (b) apresenta a proporção de indicadores classificados nos diferentes grupos para os enfoques Tradicional e Novo Paradigma, para a cidade de Palmas e municípios vizinhos.

Enfoque Tradicional

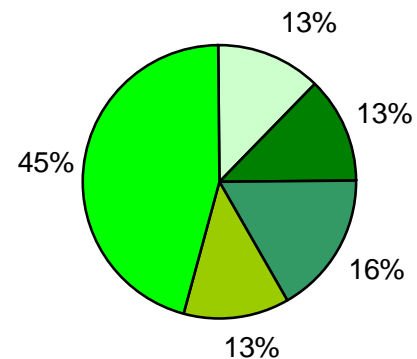

(a)
Novo Paradigma

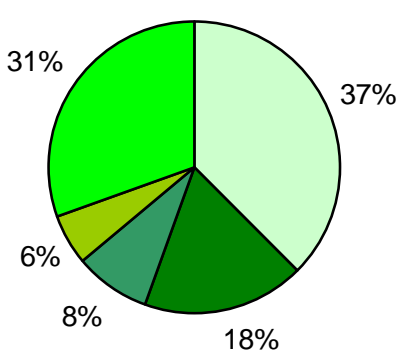

(b)

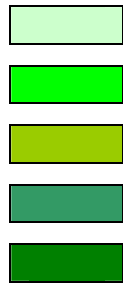

Transporte Coletivo

Trânsito e Segurança Viária

Aspectos Ambientais

Aspectos Demográficos

Aspectos Urbanísticos

Figura 7.34: Enfoques dos indicadores de mobilidade urbana para Palmas e municípios vizinhos.

Em Palmas, o tema Trânsito e Segurança Viária representou a grande maioria dos indicadores relacionados (45\%). Os demais temas considerados dizem respeito a Aspectos Demográficos (16\%), Aspectos Ambientais (13\%), Aspectos Urbanísticos (13\%) e Transporte Coletivo (13\%).

Já na segunda etapa, a Alternativa que agregou maior número de indicadores foi Planejamento Integrado (37\%), repetindo uma tendência observada em grande parte das cidades pesquisadas. A segunda Alternativa a agregar maior número de indicadores foi Aspectos Sociais, representando 31\% do total. Os aspectos associados ao Trânsito caíram 
da primeira para a terceira posição, agregando $18 \%$ dos indicadores. As demais Alternativas consideradas foram Infra-estrutura Urbana (6\%) e Aspectos Ambientais (8\%), que teve sua participação reduzida.

\section{Manaus - AM}

A Figura 7.35 (a) e (b) apresenta a proporção de indicadores classificados nos diferentes grupos para os enfoques Tradicional e Novo Paradigma, para a cidade de Manaus e municípios vizinhos.

Enfoque Tradicional

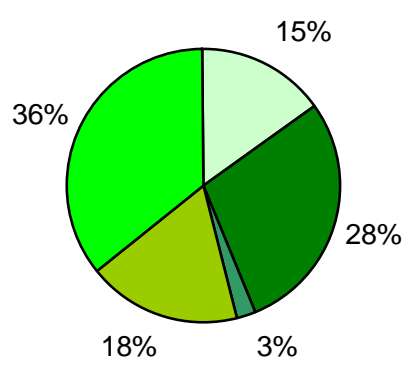

(a)

Serviços Públicos

Tráfego e Circulação

Transporte Coletivo

Aspectos Sociais

Aspectos Urbanísticos
Novo Paradigma

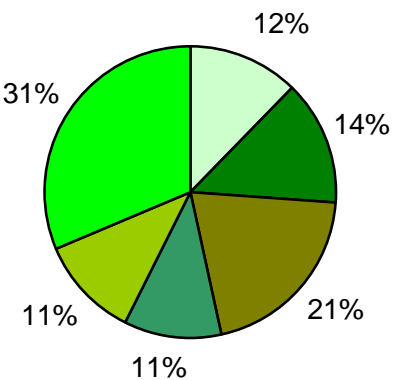

(b)

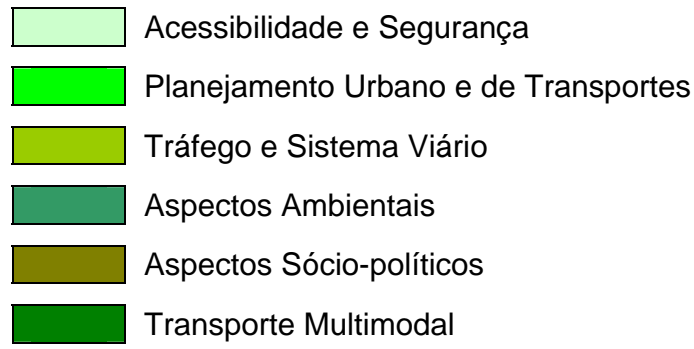

Figura 7.35: Enfoques dos indicadores de mobilidade urbana para Manaus e municípios vizinhos.

Em Manaus, o tema Tráfego e Circulação incorporou 36\% dos indicadores identificados na primeira etapa do workshop, seguido por Aspectos Urbanísticos (28\%), Transporte Coletivo (18\%), Serviços Públicos (15\%), e Aspectos Sociais (3\%).

Na segunda etapa, ênfase foi dada ao Planejamento Urbano e de Transportes, que agregou a maior parte dos indicadores (31\%). A segunda Alternativa enfatizada diz respeito a Aspectos Sócio-políticos (21\%). As demais Alternativas são constituídas por Transporte Multimodal (14\%), Acessibilidade e Segurança (12\%), Tráfego e Sistema Viário (11\%) e Aspectos Ambientais (11\%), revelando tópicos bastante diferentes dos identificados na primeira etapa do exercício de capacitação. 


\subsection{2. $\quad$ Análise dos Resultados para as Regiões Brasileiras}

Para a análise comparativa dos resultados para as regiões do país, os dados obtidos nas cidades foram agrupados e apresentados por meio de árvores ou hierarquia de critérios. $\mathrm{O}$ primeiro nível da hierarquia corresponde as Alternativas identificadas. O segundo nível representa os PVFs associados a cada uma das Alternativas. As Alternativas, assim como os PDFs de mesmo nome e significados semelhantes foram apresentadas uma única vez na hierarquia. Devido ao grande número de indicadores identificados e por os mesmos estarem associados diretamente aos PVFs, estes elementos não foram incluídos nas hierarquias que agregam os critérios obtidos por região.

As Figuras 7.36 a 7.40 apresentam as hierarquias de critérios por região do país.

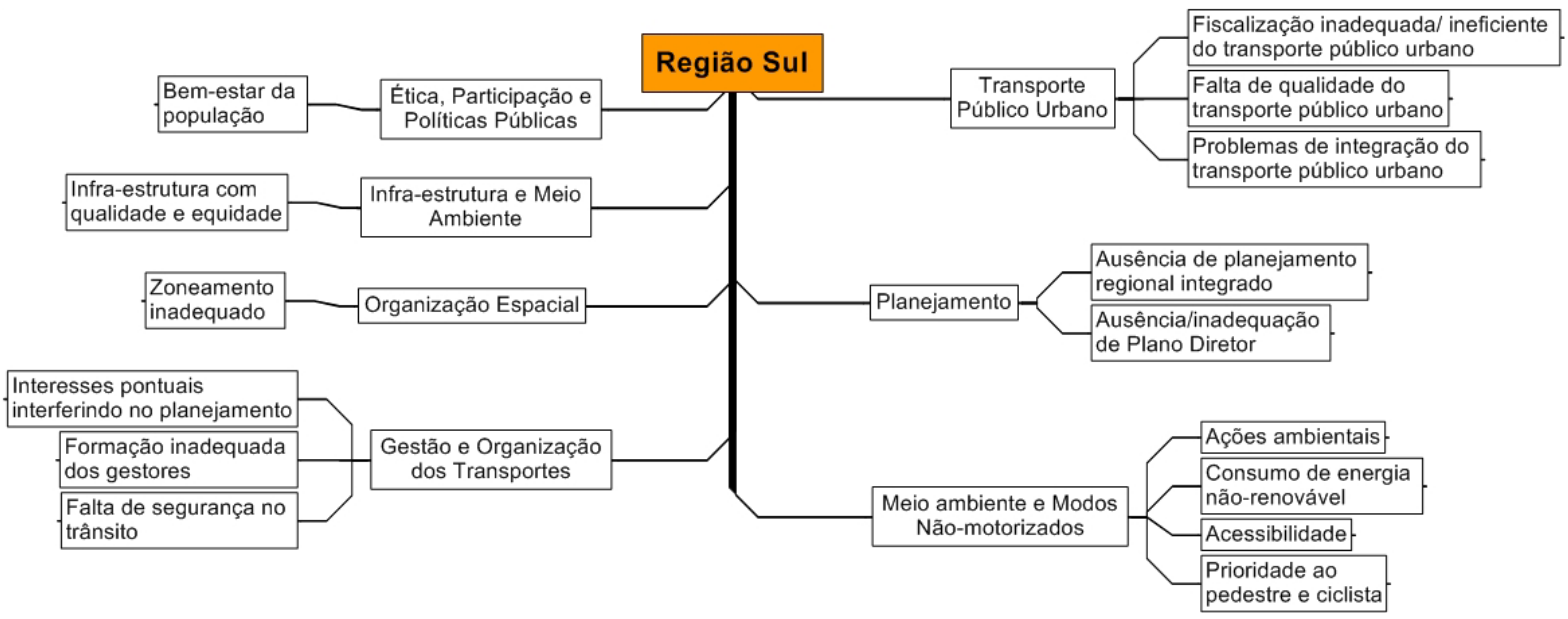

Figura 7.36: Árvore de Alternativas e PVFs para a Região Sul.

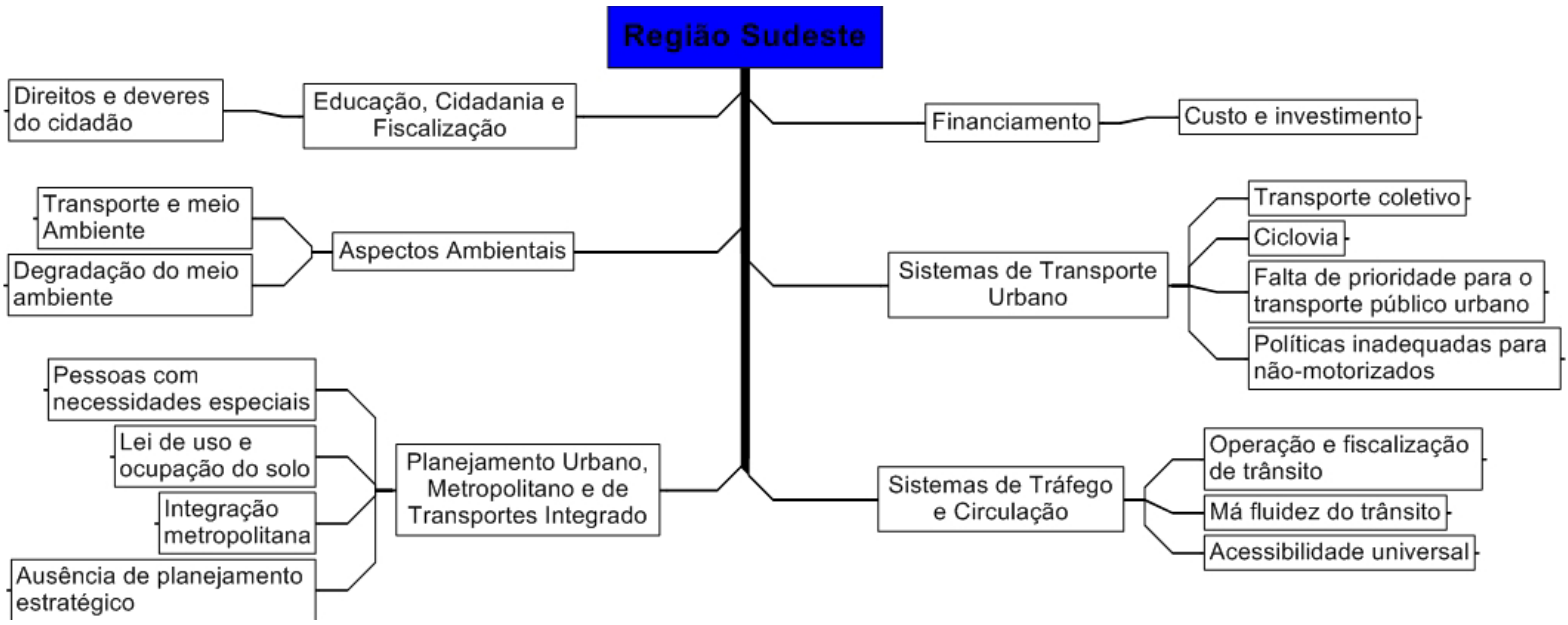

Figura 7.37: Árvore de Alternativas e PVFs para a Região Sudeste. 


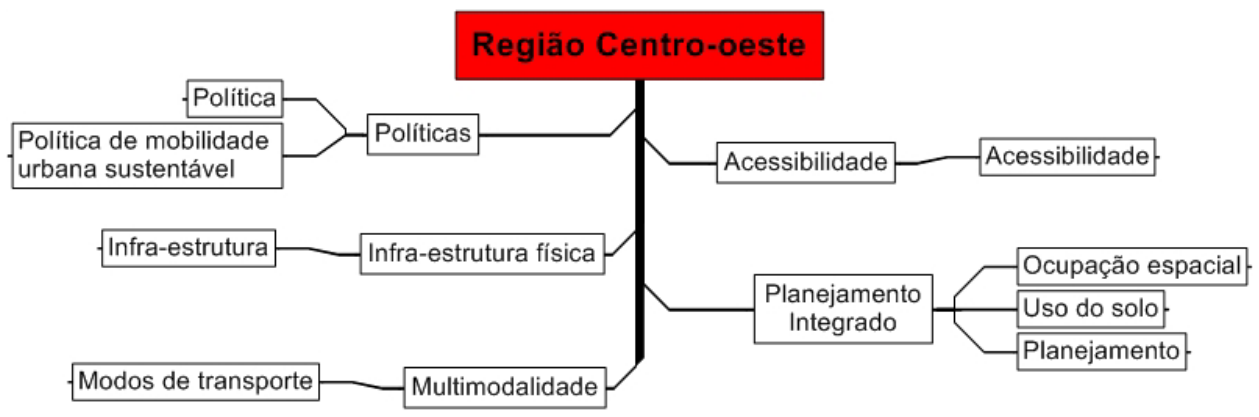

Figura 7.38: Árvore de Alternativas e PVFs para a Região Centro-oeste.

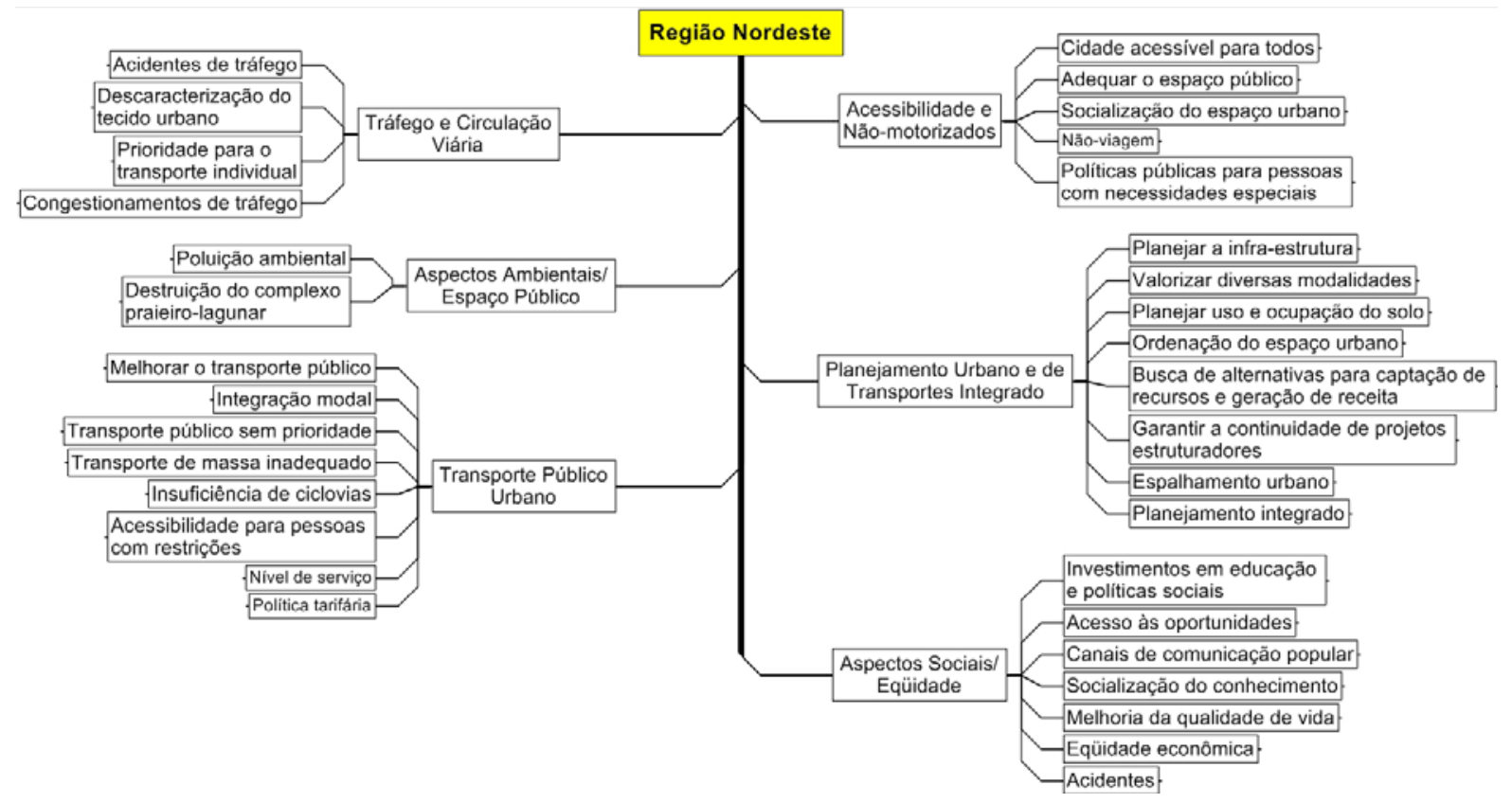

Figura 7.39: Árvore de Alternativas e PVFs para a Região Nordeste.

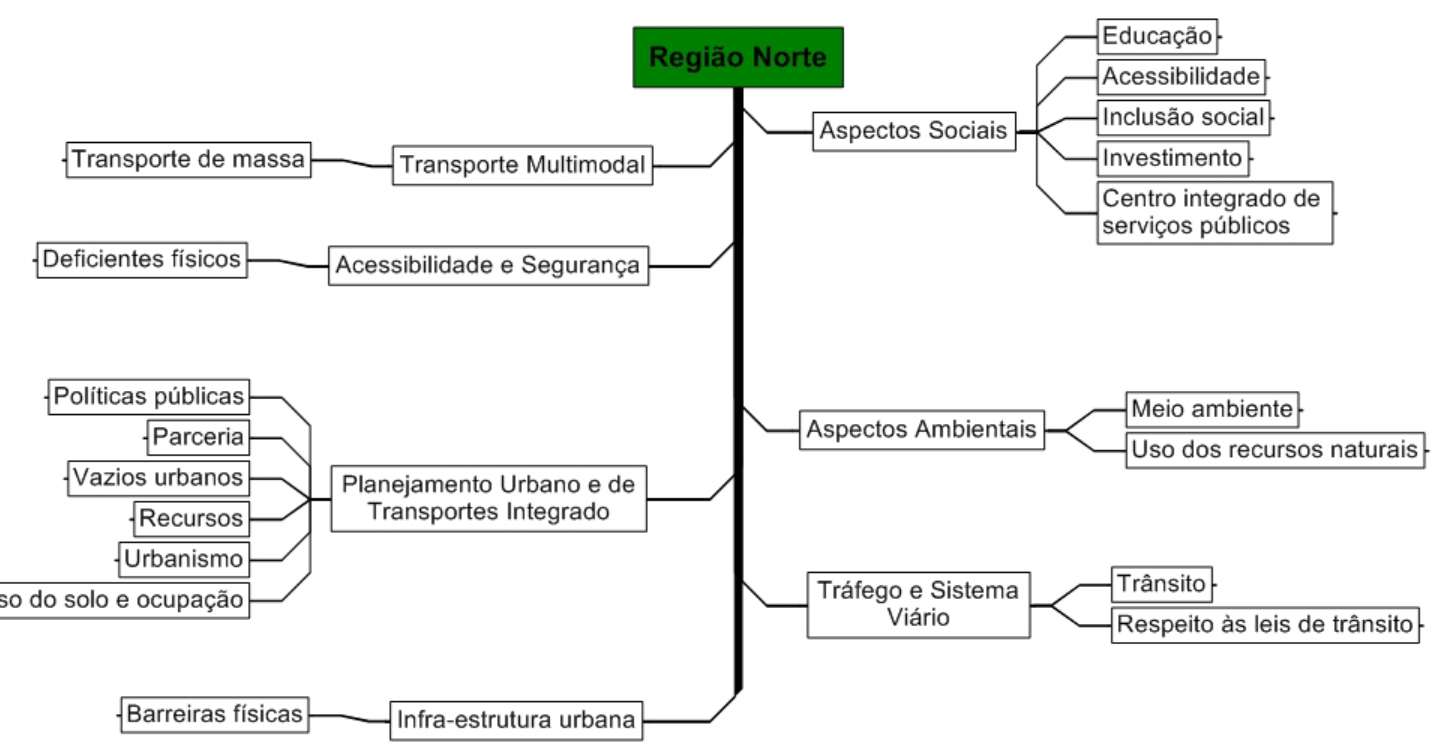

Figura 7.40: Árvore de Alternativas e PVFs para a Região Norte. 
Os resultados obtidos são analisados sob dois enfoques principais:

- Com relação às dimensões fundamentais que estruturam o conceito de sustentabilidade urbana: social, econômica e ambiental, buscando identificar a importância relativa ou peso atribuído a cada dimensão nas diferentes regiões brasileiras, por meio da análise das Alternativas identificadas em cada contexto;

- Com relação aos temas abordados, expressos por meio dos PVFs, de modo a verificar os enfoques específicos para as questões de ordem social, econômica e ambiental em cada região.

Antes da análise dos resultados obtidos é necessário, no entanto, apresentar algumas características básicas que diferenciam as cinco regiões brasileiras, as quais podem estar relacionadas às diferentes dimensões e temas destacados para cada contexto. Estas características são sintetizadas na Tabela 7.1.

Tabela 7.1: Características das regiões brasileiras.

\begin{tabular}{lccccc}
\hline \multicolumn{1}{c}{ Características } & Sul & Sudeste & $\begin{array}{c}\text { Centro- } \\
\text { oeste }\end{array}$ & Nordeste & Norte \\
\hline População $^{1}$ & 25.107 .616 & 72.412 .411 & 11.636 .728 & 12.900 .704 & 47.741 .711 \\
\hline Área $^{1}\left(\mathrm{~km}^{2}\right)$ & 576.409 & 924.511 & 1.606 .371 & 3.853 .327 & 1.554 .257 \\
\hline Território (\%) $^{\text {Densidade demográfica }}$ & 6,77 & 10,86 & 18,87 & 45,25 & 18,25 \\
(hab/km $^{2}$ ) & 43,55 & 78,32 & 7,24 & 3,34 & 30,71 \\
\hline Urbanização $^{2}(\%)$ & 82 & 92,1 & 86,3 & 73,5 & 71,5 \\
\hline IDH Médio $^{3}$ & 0,807 & 0,791 & 0,792 & 0,725 & 0,683 \\
\hline Renda per-capita $^{3}(\mathrm{R} \$)$ & 342,62 & 355,69 & 366,72 & 196,22 & 152,16 \\
\hline Alfabetização $^{3}(\%)$ & 92,5 & 90,77 & 89,71 & 73,5 & 71,5 \\
\hline
\end{tabular}

Fontes: ${ }^{1}$ IBGE (2000); ${ }^{2}$ IBGE (2004a); ${ }^{3}$ PNDU (2000).

A análise dos resultados para as cinco regiões levou em consideração, ainda que de forma preliminar, suas principais características sociais, econômicas e ambientais, além das diferentes abordagens para as dimensões e temas relacionados ao conceito de mobilidade urbana sustentável. Estas análises são sintetizadas a seguir.

\subsubsection{Análise das Dimensões da Sustentabilidade - Alternativas}

Para a análise relativa das dimensões da sustentabilidade urbana no contexto de cada região foi feita, em um primeiro momento, a classificação das Alternativas expressas nas três diferentes dimensões que compõem o conceito.

Para reduzir a subjetividade desta classificação foi estabelecida uma relação de temas que representam cada uma das dimensões. Esta relação foi desenvolvida com base em um conjunto de indicadores de sustentabilidade urbana analisados no trabalho de Costa (2003). A partir do grupo de dezesseis sistemas avaliados nesse estudo, os quais incluíam 
indicadores sociais, econômicos e ambientais, foram extraídos os principais temas relacionados às dimensões da sustentabilidade, totalizando um conjunto de aproximadamente cento e setenta palavras-chave ou expressões, que constituiu o referencial teórico para a classificação das Alternativas. Esta estrutura é apresentada na Tabela 7.2.

Tabela 7.2: Referencial para classificação das Alternativas nas Dimensões da Sustentabilidade.

\begin{tabular}{|c|c|}
\hline \multicolumn{2}{|c|}{ Social } \\
\hline Acessibilidade & Integração metropolitana \\
\hline Acesso aos serviços & Intermodalidade \\
\hline Acidentes & Lazer \\
\hline Áreas de recreação & Médias salariais \\
\hline Assentamentos formais/informais & Migração \\
\hline Bem-estar & Moradia \\
\hline Benefícios sociais & Mortalidade \\
\hline Cidadania & Nível de serviço do transporte público \\
\hline Cobertura do transporte coletivo & Oportunidades \\
\hline Comportamento & Participação \\
\hline Comunicação & Participação política \\
\hline Conhecimento & Pessoas com necessidades especiais \\
\hline Conscientização & Planejamento integrado \\
\hline Continuidade & Pobreza \\
\hline Crescimento populacional & Política \\
\hline Criminalidade & População \\
\hline Cultura & População urbana \\
\hline Custos sociais & Propriedade \\
\hline Demanda por transportes & Qualidade de vida \\
\hline Densidade populacional & Qualidade do transporte público \\
\hline Desemprego & Reclamações \\
\hline Desenvolvimento humano & Satisfação \\
\hline Desigualdade & Saúde \\
\hline Direitos e deveres & Segregação social \\
\hline Distância média ao trabalho & Segurança \\
\hline Divisão modal & Segurança no trânsito \\
\hline Educação & Solicitações \\
\hline Engajamento & Tempo de viagem \\
\hline Envolvimento comunitário & Transparência \\
\hline Eqüidade & Transporte de passageiros \\
\hline Fiscalização & Viagens/dia \\
\hline Formação & Violência \\
\hline Inclusão & Vitalidade \\
\hline \multicolumn{2}{|l|}{ Integração } \\
\hline \multicolumn{2}{|c|}{ Econômica } \\
\hline Balança comercial & Indústria \\
\hline Bens e consumo & Investimento \\
\hline Capital & Motorização \\
\hline Captação & Padrões de consumo \\
\hline Comércio & Parcerias público-privadas \\
\hline Concentração/distribuição de renda & PIB \\
\hline Custo de vida & Planejamento estratégico \\
\hline
\end{tabular}




\begin{tabular}{|c|c|}
\hline Custos de transporte & Preços \\
\hline Débitos & Produção \\
\hline Déficit & Produtividade \\
\hline Despesas públicas & Receita \\
\hline Empresas & Recursos \\
\hline Endividamento & Rendimentos \\
\hline Exportações & Subsídios \\
\hline Financiamento & Tarifa \\
\hline Fundos & Taxas \\
\hline Gastos & Transporte de carga \\
\hline Importações & Turismo \\
\hline Impostos & Veículos em circulação \\
\hline \multicolumn{2}{|c|}{ Ambiental } \\
\hline Ambiente construído & Monitoração ambiental \\
\hline Áreas impermeáveis & Não-motorizados \\
\hline Áreas livres & Ocupações irregulares/subnormais \\
\hline Áreas protegidas & Organização espacial \\
\hline Aspectos físicos & Pavimentação \\
\hline Barreiras físicas & Pesquisa e desenvolvimento \\
\hline Ciclovias & Planejamento urbano \\
\hline Combustíveis & Plano Diretor de Desenvolvimento Urbano \\
\hline Combustíveis fósseis & Planos ambientais \\
\hline Conforto térmico & Poluição \\
\hline Consumo de energia & Poluição sonora \\
\hline Contaminação & População em áreas protegidas \\
\hline Degradação & Qualidade ambiental \\
\hline Descentralização/concentração & Reciclagem \\
\hline Desenho urbano & Recursos hídricos \\
\hline Desenvolvimento periférico & Recursos não-renováveis \\
\hline Desmatamento & Recursos naturais \\
\hline Drenagem & Reservas minerais \\
\hline Ecossistemas & Resíduos \\
\hline Educação ambiental & Ruído \\
\hline Eficiência energética & Saneamento \\
\hline Emissões & Segregação espacial \\
\hline Energia & Sistema viário \\
\hline Esgoto & Tecnologias limpas \\
\hline Espaço público & Temperatura \\
\hline Espaço urbano & Uso do solo \\
\hline Espalhamento urbano & Utilização de veículos \\
\hline Espécies & Vazios urbanos \\
\hline Estacionamento & Vegetação \\
\hline Impactos ambientais & Vias adequadas \\
\hline Infra-estrutura & Vias para pedestres \\
\hline Intensidade do tráfego & Zoneamento \\
\hline Lei de uso do solo & \\
\hline Lixo & \\
\hline
\end{tabular}


Assim, cada Alternativa foi relacionada à uma dimensão, de acordo com a questão que enfocava e com base nas informações contidas nesta relação preliminar. Agrupadas, as Alternativas permitiram revelar a ênfase ou a importância relativa de cada dimensão para as cinco regiões brasileiras, conforme mostra a Figura 7.41.

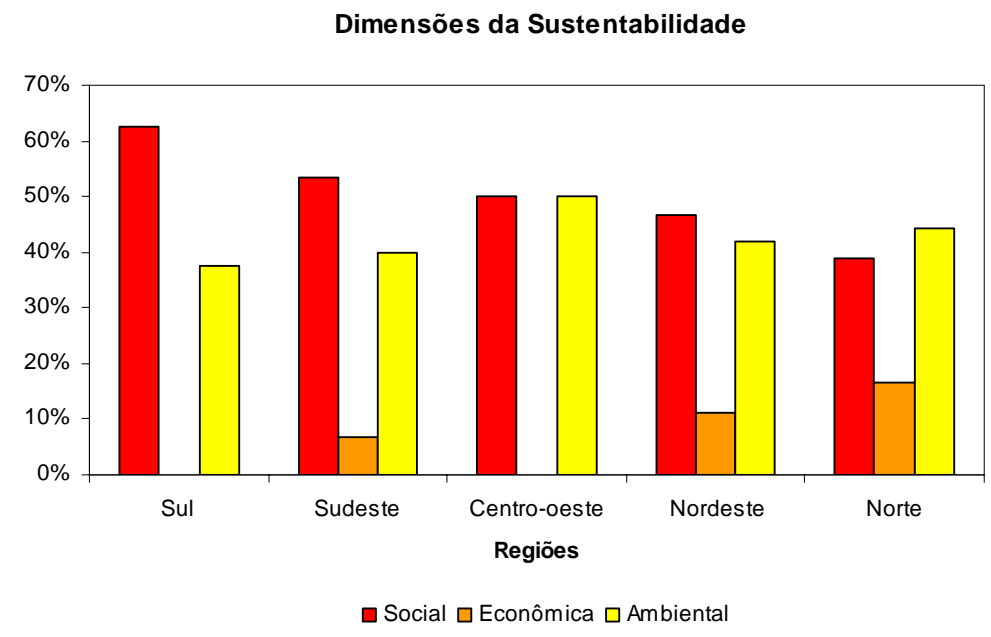

Figura 7.41: Importância relativa das dimensões da sustentabilidade nas regiões brasileiras.

Para a Região Sul, a dimensão social representou $62 \%$ do total de Alternativas identificadas. Já a dimensão ambiental, representou cerca de 38\% do conjunto. Na Região Sudeste a dimensão social correspondeu a 53\%, ambiental 40\% e econômica 7\%. Na Região Centrooeste as dimensões social e ambiental representaram $50 \%$ cada uma do total de Alternativas. Na Região Norte as dimensões social, econômica e ambiental representaram, respectivamente, $39 \%, 17 \%$ e $44 \%$, e Nordeste, $47 \%, 11 \%$ e $42 \%$.

Desta forma, em três das cinco regiões a dimensão social foi a mais enfatizada (Sul, Sudeste e Nordeste), ficando a dimensão ambiental em segundo lugar nestas mesmas localidades. Na região Centro-oeste as dimensões social e ambiental foram equivalentes. Já na região Norte, a dimensão ambiental foi a mais enfatizada, concentrando o maior número de conceitos relacionados ao tema.

As questões econômicas acabaram por não ser contempladas em duas regiões: Centrooeste e Sul. Cabe lembrar que estas regiões apresentam índices econômicos relativamente elevados se comparadas as demais regiões brasileiras, incluindo renda per capita, correspondendo ao primeiro e ao terceiro maiores valores do país. Em função de apresentar em melhores indicadores econômicos conforme mostra a Tabela 7.1, a dimensão não é, portanto, um fator crítico nestas regiões, justificando o fato da mesma não ter sido citada nestes contextos. Nas três regiões onde as questões econômicas foram incorporadas, estas acabaram por apresentar valores diferenciados, sendo estes mais significativos nas regiões 
Norte e Nordeste. Estas regiões apresentam justamente os piores indicadores econômicos do Brasil, além de profundos problemas sociais, como grande desigualdade na distribuição de renda, baixa expectativa de vida ao nascer, baixos índices de escolaridade, entre outros.

Para a Região Norte, a ênfase dada à dimensão ambiental pode ser justificada pelas especificidades de seu ecossistema e pela dificuldade em se manter o equilíbrio entre as atividades humanas (em especial as atividades relacionadas à urbanização e à mobilidade de pessoas e bens) e o meio ambiente, além da preocupação com a manutenção da qualidade ambiental das cidades numa região carente de recursos e infra-estrutura. Se comparada às demais regiões, a Região Norte apresentou ainda um maior equilíbrio na consideração das três dimensões da sustentabilidade, indicativo das carências apresentadas pela mesma em todas as esferas de desenvolvimento.

Ainda que a dimensão ambiental tenha recebido maior destaque na Região Norte, vale destacar que a mesma teve representação significativa em todas as regiões, o que pode indicar a recente incorporação das questões ambientais no planejamento da mobilidade urbana no Brasil.

\subsubsection{Análise de Temas Específicos - PVFs}

Ainda que a dimensão social tenha recebido o maior destaque na maioria das regiões brasileiras, conforme indicou a análise baseada na classificação das Alternativas nos três campos que estruturam o conceito de sustentabilidade urbana, variações de enfoque puderam ser observadas em sua abordagem em cada contexto. E o mesmo foi observado para as dimensões econômica e ambiental, para as quais também foram destacados aspectos distintos nas diferentes regiões.

Estas diferenças foram percebidas através da análise dos PVFs associados às Alternativas. Estes revelaram os enfoques específicos no tratamento das questões de caráter social, econômico e ambiental. Do mesmo modo, revelaram as principais limitações e potencialidades das localidades abrangidas pelo estudo no sentido de implementar políticas de mobilidade urbana sustentável. Os PVFs identificados para cada região, classificados nas três dimensões da sustentabilidade são mostrados na Tabela 7.3. 
Tabela 7.3: Classificação dos PVFs nas Dimensões da Sustentabilidade.

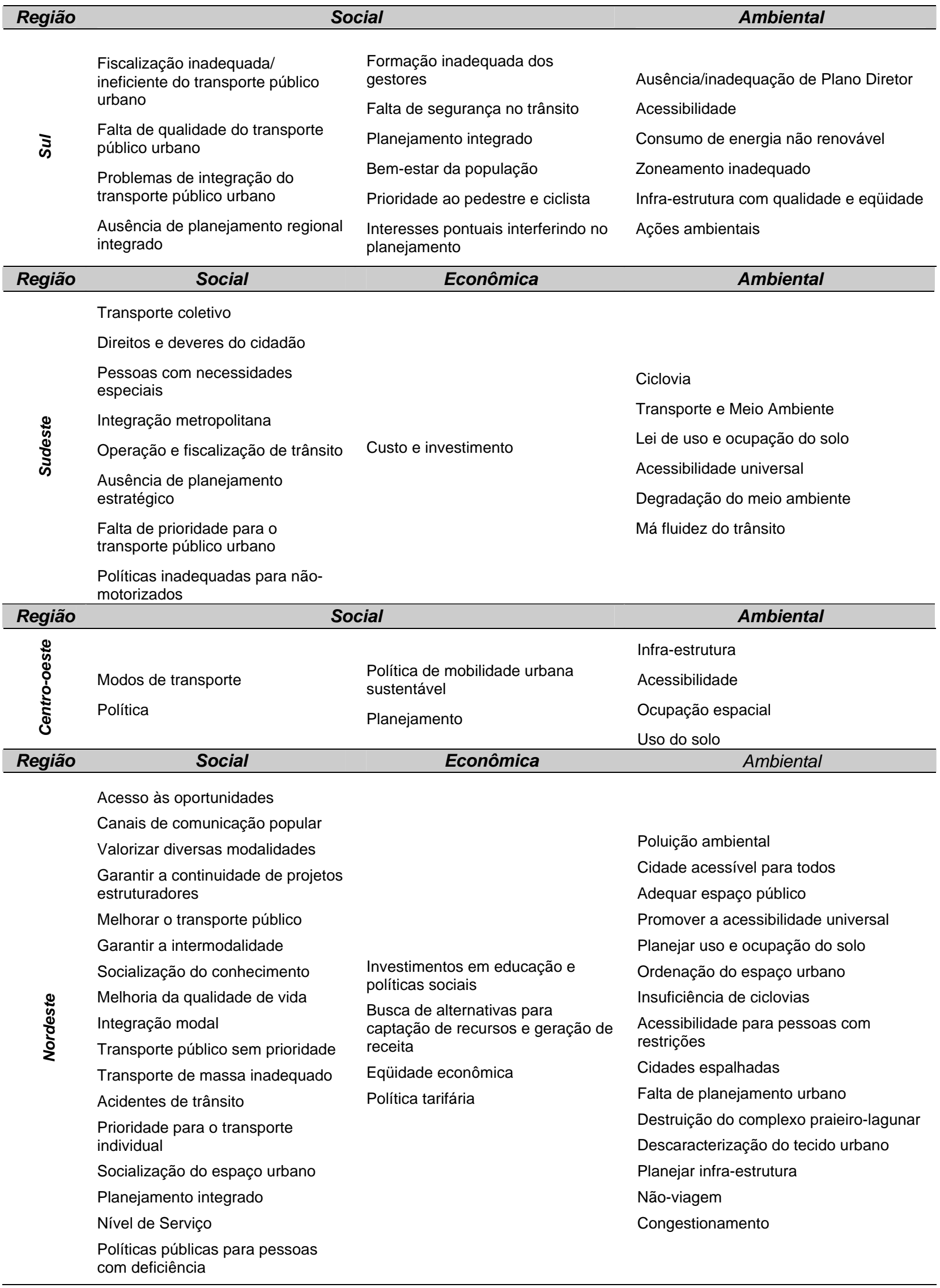




\begin{tabular}{llll}
\hline Reg. & \multicolumn{1}{c}{ Social } & Econômica & Ambiental \\
& Educação & & Meio Ambiente \\
& Inclusão Social & & Acessibilidade \\
& Respeito as leis de trânsito & Parceria & Barreiras físicas \\
& Políticas públicas & Recursos & Vazios urbanos \\
& Transporte de massa & Unvestimento dos recursos naturais \\
& Cúblicos & & Urbanismo \\
& Deficientes físicos & & Uso e ocupação do solo \\
\end{tabular}

Para a Região Sul do país, na dimensão social foram enfocados aspectos relacionados à provisão, qualidade e integração dos sistemas de transporte público urbano, considerado como fator fundamental no campo social para o progresso em direção à mobilidade urbana sustentável. Outros temas dizem respeito a questões de planejamento urbano e metropolitano integrado, bem como preocupações com segurança e prioridade para pedestres e ciclistas. No campo ambiental, as preocupações se concentraram nas questões de planejamento territorial, incluindo o desenvolvimento de Planos Diretores de Desenvolvimento Urbano adequados, bem como no zoneamento das atividades urbanas. Além disso foram considerados o consumo de energia não renovável, qualidade da infraestrutura e ações ambientais para concretização do conceito na região.

Na Região Sudeste, os temas destacados na dimensão social também incluem transporte coletivo, integração metropolitana e preocupação com os modos não-motorizados de transporte. Além destes, respeito aos direitos e deveres dos cidadãos e pessoas com necessidades especiais compõem o rol de temas enfocados neste campo. Para a questão econômica, a preocupação se restringiu aos custos e investimentos nos sistemas de mobilidade. Já a dimensão ambiental destacou a provisão de infra-estrutura para ciclistas, o equilíbrio entre transporte e meio ambiente, acessibilidade universal e má fluidez do trânsito.

Na Região Centro-oeste, na dimensão social foi dado destaque à formulação de políticas públicas, em especial, políticas de mobilidade urbana sustentável. As questões do planejamento e modos de transportes também foram consideradas. No que diz respeito à dimensão ambiental as questões de infra-estrutura, acessibilidade e ocupação determinaram seu enfoque na região.

A Região Nordeste destacou, na dimensão social, o acesso às oportunidades, participação popular, diversidade e integração entre modos de transporte, socialização do conhecimento e do espaço urbano e os problemas de falta de incentivo ao transporte público e valorização do transporte individual. O campo econômico abordou questões relacionadas a investimentos em educação e políticas sociais, alternativas para a geração e captação de 
recursos e eqüidade econômica. Já o campo ambiental destacou o problema da poluição ambiental, acessibilidade através da adequação do espaço público e melhoria da infraestrutura urbana, planejamento e ordenação do uso do solo e especificamente o problema de destruição do complexo praieiro-lagunar, problema comum nas cidades litorâneas do nordeste brasileiro e que implica em impactos diretos sobre a qualidade ambiental destas cidades.

Na Região Norte a dimensão social incluiu, além de aspectos como políticas públicas, transporte de massa e pessoas com necessidades especiais, também enfocados nas outras regiões, aspectos como educação, inclusão social e integração de serviços públicos. A dimensão econômica deu destaque às parcerias público-privadas para a obtenção de recursos e investimentos nos sistemas de mobilidade. Já na dimensão ambiental foram destacados aspectos relacionados à acessibilidade urbana e eliminação de barreiras físicas, a questão do uso e ocupação do solo e a utilização de recursos naturais.

Em todas as regiões cabe destacar que as questões relacionadas ao planejamento urbano e de transportes integrado se fizeram presentes na dimensão social.

\subsubsection{Síntese do Referencial de Mobilidade Urbana Sustentável em Cidades Brasileiras}

Os resultados obtidos por meio das Alternativas e PVFs identificados na fase final da atividade de capacitação referem-se aos elementos associados ao conceito de mobilidade urbana sustentável identificados a partir das reflexões e opiniões dos técnicos que participaram do exercício. Deste modo, refletem seu conhecimento da realidade local, bem como suas expectativas e desejos com relação ao tema abordado.

De forma a evidenciar as principais questões incorporadas neste processo, foi observado o rol de temáticas consideradas durante a construção do referencial de mobilidade sustentável nas cidades pesquisadas. Esta análise se deu com base nas Alternativas identificadas em cada local, as quais foram agrupadas por similaridade, constituindo o que foi denominado neste trabalho de Domínios. Estes representam, portanto, os enfoques mais abrangentes em relação ao conceito de mobilidade sustentável, extraídos a partir da experiência de capacitação realizada em onze cidades brasileiras. A Figura 7.42 apresenta os Domínios identificados, bem como sua ocorrência nas cidades pesquisadas. 


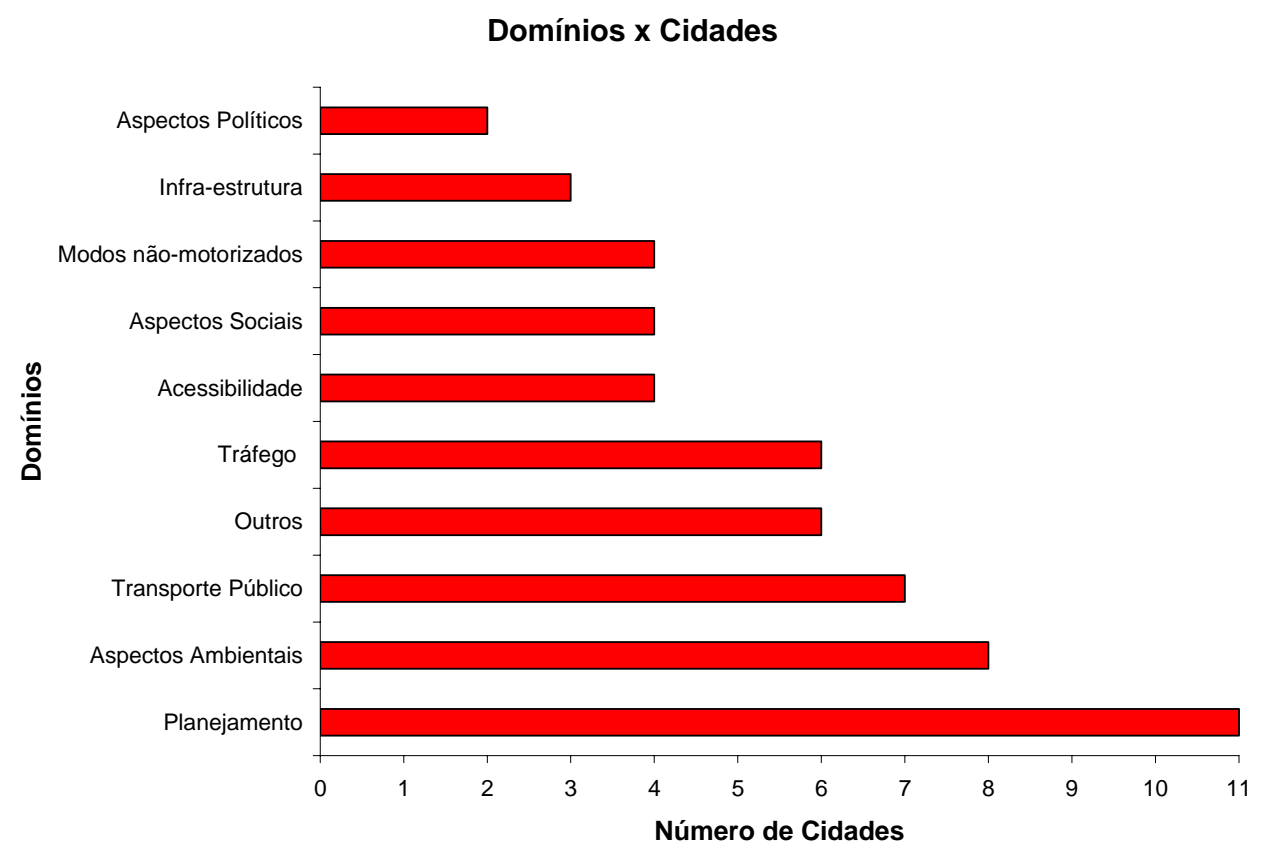

Figura 7.42: Ocorrência dos Domínios nas cidades pesquisadas.

Com base nos resultados obtidos nos workshops, observa-se que o conceito de sustentabilidade vem sendo incorporado de forma gradativa nas atividades de gestão e planejamento urbano no Brasil, especialmente no que se refere à mobilidade. Tal situação foi evidenciada, principalmente, através da ênfase dada às questões de Planejamento e Aspectos Ambientais, destacadas em 11e 8 cidades, respectivamente.

Cabe lembrar que historicamente estes temas foram colocados em segundo plano no tratamento das questões de mobilidade urbana no país. Sua inserção no processo de planejamento reflete, em parte, a assimilação dos novos conceitos e dimensões que norteiam as noções de sustentabilidade e de desenvolvimento sustentável, já difundidos internacionalmente e ainda em construção no Brasil.

Outras temáticas pouco enfatizadas no processo de planejamento e gestão da mobilidade urbana no país até o presente momento também foram citadas, cabendo destacar Aspectos Políticos, Aspectos Sociais, Acessibilidade e Modos Não-motorizados. As temáticas representadas por Infra-estrutura, Tráfego e Transporte Público, já consideradas no modelo tradicional de planejamento da mobilidade urbana, se mantiveram no rol de questões a serem consideradas visando a mobilidade sustentável. As demais temáticas, com menor representatividade no âmbito das onze cidades avaliadas, foram agrupadas no Domínio Outros, e incluíram questões tanto de enfoque tradicional como relacionadas ao novo paradigma de tratamento das questões de mobilidade. 
Ainda que os Domínios identificados estejam relacionados a um determinado contexto temporal e geográfico, limitado às onze cidades pesquisadas, pode-se dizer, no entanto, que em função de sua representatividade, representam questões-chave para efetivação do conceito de mobilidade urbana sustentável no país.

Desta forma, os elementos destacados nesta etapa se constituíram no ponto de partida para o desenvolvimento de uma ferramenta para monitorar a mobilidade, com enfoque na sustentabilidade dos sistemas de transporte. As etapas de construção desta ferramenta, bem como a estrutura final obtida são apresentadas no capítulo seguinte. 


\section{8. ÍNDICE DE MOBILIDADE URBANA SUSTENTÁVEL}

Neste capítulo são sintetizadas as principais etapas de construção do Índice de Mobilidade Urbana Sustentável (IMUS), apresentando a estrutura obtida para a ferramenta. Na parte final são analisados aspectos referentes a hierarquia de critérios, tipologias de indicadores e sistema de pesos obtido.

\subsection{Aspectos Gerais}

O Índice de Mobilidade Urbana Sustentável (IMUS) consiste em uma ferramenta desenvolvida para auxiliar na análise e monitoração da mobilidade urbana e na elaboração de políticas públicas visando a sustentabilidade dos sistemas de mobilidade e a melhoria da qualidade de vida. O índice tem como principais características:

- Apoiar-se em uma hierarquia de critérios construída a partir de conceitos e elementos identificados junto a técnicos e gestores em nível municipal e metropolitano, de onze das principais cidades brasileiras, nas quais decorreu a atividade de capacitação promovida pelo Ministério das Cidades;

- Estabelecer um sistema de pesos para os critérios, revelando sua importância relativa. Considera ainda, para cada tema avaliado, a importância das dimensões da sustentabilidade (Social, Econômica e Ambiental). Assim permite avaliar os impactos de ações setoriais sobre o sistema de mobilidade e segundo as três dimensões consideradas na sustentabilidade;

- Adotar um modelo de agregação dos critérios que permite sua compensação, ou seja, permite que um critério de qualidade baixa seja compensado por um conjunto de critérios de maior qualidade;

- Constituir uma ferramenta de fácil compreensão e simplicidade de aplicação, não exigindo a utilização de pacotes computacionais específicos, nem conhecimento de modelos matemáticos complexos para sua utilização. 
As etapas de construção do IMUS, conforme a metodologia apresentada no Capítulo 6, são sintetizadas a seguir.

\subsection{Hierarquia de Critérios}

A estrutura de critérios está organizada em diferentes níveis. No nível superior encontra-se o conjunto de Alternativas, que reflete grandes áreas de preocupação. No nível seguinte estão os PVFs, que refletem temas específicos associados às Alternativas. No nível inferior encontram-se os Indicadores, relacionados à monitoração dos aspectos discutidos nos workshops realizados. Todos os elementos foram analisados e agregados, a fim de reduzir o conjunto e estabelecer uma hierarquia de critérios comum a todas as cidades pesquisadas.

A hierarquia de critérios que estrutura o IMUS foi desenvolvida com base nos procedimentos apresentados no item 6.3 do Capítulo 6. O Anexo C - "Construção da Hierarquia de Critérios" mostra de forma detalhada cada etapa de construção desta hierarquia, apresentando os processos sucessivos de agregação dos critérios e os resultados obtidos.

Na primeira etapa, as cinqüenta e cinco Alternativas obtidas junto às cidades pesquisadas foram trabalhadas, de forma a constituir agrupamentos com conceitos semelhantes. As etapas de agregação das Alternativas compreenderam:

- Agrupamento das Alternativas com nomenclatura idêntica, reduzindo o conjunto de cinqüenta e cinco para quarenta e cinco elementos;

- Agrupamento das Alternativas com pelos menos um tópico em comum ou denominação semelhante, reduzindo o conjunto para quinze elementos;

- Identificação dos agrupamentos com menor número de Alternativas, verificação do nível dos PVFs para detalhamento do conceito expresso em cada Alternativa e realocação dos PVFs para agrupamentos maiores, quando verificada semelhança entre as idéias expressas, reduzindo o conjunto para nove elementos;

- Atribuição de nomes aos nove agrupamentos de forma que melhor descrevessem as idéias expressas nas Alternativas e PVFs agregados.

Em uma etapa final, o conjunto de Alternativas resultantes foi comparado com as grandes áreas temáticas identificadas a partir da análise do referencial de mobilidade sustentável apresentada no Capítulo 7 (Figura 7.42). Uma vez que os resultados obtidos nas duas fases foram compatíveis, foram consolidados os nove conceitos apresentados na Figura 8.1, constituindo, a partir de então, o nível hierárquico denominado de Domínio.

$\mathrm{Na}$ etapa posterior foi trabalhado o nível dos Pontos de Vista Fundamentais (PVFs) identificados nas cidades pesquisadas, conforme procedimentos apresentados no item 
6.3.1, visando construir o segundo nível da hierarquia de critérios. Com base nestes procedimentos o conjunto de noventa e seis PVFs inicialmente identificados foi reduzido para trinta e sete elementos, agrupados dentro dos nove Domínios previamente identificados. Em uma etapa final, os indicadores associados a cada PVF foram realocados junto aos mesmos e cada elemento recebeu uma nova denominação, de acordo com o conceito mais amplo que expressa. Nesta etapa, os elementos deste nível da hierarquia passaram a ser identificados como Temas, por tratarem de questões específicas associadas a cada Domínio.

A estrutura contendo os níveis dos Domínios (no total de nove) e Temas (no total de trinta e sete) identificados nesta etapa de construção do IMUS é mostrada na Figura 8.1. Implicitamente, é feita nesta etapa a associação das Dimensões da sustentabilidade (Social, Econômica e Ambiental) a cada um dos Temas, porém, as mesmas não são apresentadas nesta estrutura. Estas irão constar na estrutura final do índice apresentada no item 8.4, onde constarão os respectivos pesos que refletem a importância relativa de cada Tema para cada Dimensão.

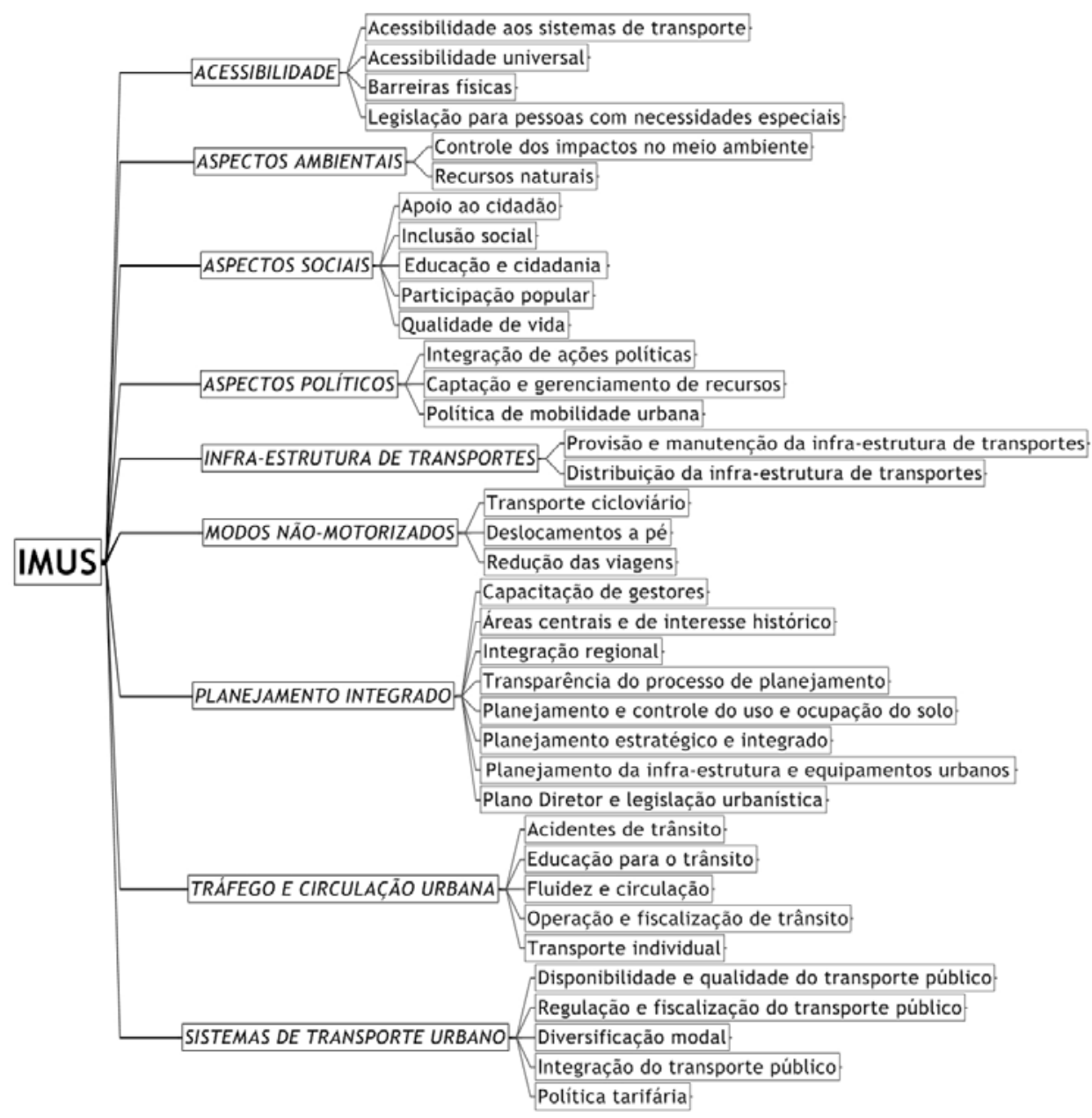

Figura 8.1: Hierarquia de Domínios e Temas do IMUS. 


\subsection{Seleção de Indicadores}

A etapa posterior de construção do IMUS compreendeu a identificação de Indicadores para cada um dos Temas que compõem a hierarquia.

A identificação de indicadores foi desenvolvida a partir de dois conjuntos de informação, conforme indicado no item 6.3.2: uma base de referência composta por aproximadamente 2900 indicadores urbanos oriundos de sistemas desenvolvidos no Brasil e no exterior; e o conjunto de 645 indicadores obtido nos workshops realizados nas cidades pesquisadas. Estes dois conjuntos, bem como todo o procedimento de classificação e seleção de indicadores de mobilidade constam, respectivamente, no Anexo D - "Sistemas de Indicadores Urbanos" e no Anexo C - "Construção da Hierarquia de Critérios".

A identificação dos sistemas que compõem o primeiro conjunto, seu respectivo número de indicadores e as fontes de referência são apresentados na Tabela 8.1. A lista completa de Referências consta no final deste documento. Alguns dos indicadores e sistemas contemplados nesta fase foram utilizados anteriormente por Costa (2003), para seleção de indicadores de mobilidade sustentável para cidades brasileiras e portuguesas. Estes sistemas foram atualizados ou complementados, e incorporados aos demais sistemas relacionados neste trabalho.

Ao conjunto inicial de aproximadamente 2900 indicadores identificados foram acrescentados, em uma etapa posterior, cerca de $\mathbf{3 0 0}$ indicadores de experiências nacionais mais recentes. Ainda que não tenham sido utilizados na fase de seleção dos indicadores, estas experiências foram incorporadas à base de dados, servindo de referência em outras etapas do trabalho, especialmente na fase de detalhamento dos indicadores selecionados. Estes sistemas constam na parte inferior da Tabela 8.1.

Tabela 8.1: Sistemas que compõem a base de referência para a busca de indicadores.

\begin{tabular}{lcl}
\hline \multicolumn{1}{c}{ Sistema } & $\mathbf{N}^{\mathbf{0}}$ Ind. & \multicolumn{1}{c}{ Fonte } \\
\hline Agenda 21 & 132 & UNCSD (2001) \\
\hline Baltic 21 & 25 & Gilbert e Tanguay (2000) \\
\hline Banister & 15 & Campos e Ramos (2005) \\
\hline Bossel & 247 & Bossel (1999) \\
\hline Campos e Ramos & 26 & Campos e Ramos (2005) \\
\hline Cardiff & 59 & Cardiff Council (2002) \\
\hline Indicators of Sustainable Development & 30 & $\begin{array}{l}\text { UK Government Sustainable Development } \\
(2000)\end{array}$ \\
\hline ECl & 10 & European Comission (2002) \\
\hline ECO XXI & 85 & ABAE (2006) \\
\hline Environment Canada & 8 & Gilbert e Tanguay (2000) \\
\hline Euskadi/Governo Basco & 87 & Gobierno Vasco (2007) \\
\hline Fife Council & 42 & $\begin{array}{l}\text { Scottish Executive Central Research Unit } \\
(2001)\end{array}$ \\
\hline
\end{tabular}




\begin{tabular}{|c|c|c|}
\hline Sistema & $\mathbf{N}^{\circ}$ Ind. & Fonte \\
\hline Hertfordshire (2005) & 25 & Hertfordshire County Council (2005) \\
\hline Hertfordshire (2003) & 82 & Wood (2003) \\
\hline Hertfordshire (1999) & 45 & Hertfordshire County Council (1999) \\
\hline IBGE & 59 & IBGE (2004b) \\
\hline IQVU/BH & 39 & $\begin{array}{l}\text { Prefeitura Municipal de Belo Horizonte } \\
(2004)\end{array}$ \\
\hline Library of Local Performance Indicators & 272 & Audit Comission e IDeA (2007) \\
\hline LITMUS & 36 & Lingayah e Sommer (2001) \\
\hline Mendes/QV & 54 & Mendes (1999) / Mendes (2004) \\
\hline Mendip Council & 44 & Mendip District Council (2006) \\
\hline New Zealand & 33 & Gilbert e Tanguay (2000) \\
\hline NRTEE & 8 & Gilbert e Tanguay (2000) \\
\hline OECD & 32 & OECD (1999) \\
\hline Ontario transportation & 21 & Gilbert e Tanguay (2000) \\
\hline PROPOLIS & 60 & Lautso et al. (2004) \\
\hline PROSPECTS (2001) & 26 & Minken; Samstad e Putz (2001) \\
\hline PROSPECTS (2002) & 44 & Minken et al. (2002) \\
\hline Qualidade de Vida/Porto & 72 & Santos e Martins (2002) \\
\hline Scottish Enterprise Tayside & 22 & Jackson e Roberts (2000) \\
\hline Seattle & 40 & Sustainable Seattle (1998) \\
\hline SIDS & 132 & Direcção Geral do Ambiente (2000) \\
\hline SNIU & 72 & SNIU (2002) \\
\hline SPARTACUS & 29 & União Européia (1998) \\
\hline STPI & 14 & Centre for Sustainable Transportation (2001) \\
\hline SUMMA & 60 & SUMMA (2004) \\
\hline Sustainable Measures & 319 & Sustainable Measures (2006) \\
\hline SUTRA & 39 & Caratti et al. (2001) \\
\hline TERM (2001-2003) & 61 & TERM (2001) / TERM (2002) / TERM (2003) \\
\hline TRANSPLUS & 49 & TRANSPLUS (2002) \\
\hline Sustainability Indicators & 11 & $\begin{array}{l}\text { UK Government Sustainable Development } \\
\text { (2004) }\end{array}$ \\
\hline UN/CSD & 63 & UNCSD (2001) \\
\hline UNCHS & 42 & UNCHS (2004) \\
\hline USDT & 120 & U.S. Department of Transportation (2002) \\
\hline STPI & 34 & Gilbert e Tanguay (2000) \\
\hline Victoria Institute & 40 & Litman (2007) \\
\hline Victoria Transport Policy & 19 & Gilbert e Tanguay (2000) \\
\hline WBCSD & 31 & WBCSD (2004) \\
\hline ANTP & 25 & ANTP (2006) \\
\hline Observatório Cidadão Nossa São Paulo & 118 & $\begin{array}{l}\text { Observatório Cidadão Nossa São Paulo } \\
(2008)\end{array}$ \\
\hline NTU & 16 & NTU (2006) \\
\hline São Paulo em Movimento & 154 & Prefeitura Municipal de São Paulo (2008) \\
\hline Total & 3228 & - \\
\hline
\end{tabular}

A etapa seguinte compreendeu o desenvolvimento de uma estrutura auxiliar para a busca dos indicadores nos dois conjuntos de informações. Esta estrutura foi constituída pelos Domínios, Temas e suas respectivas definições, Tópicos abordados em cada tema (com base nas informações iniciais obtidas nas cidades e sintetizadas através das hierarquias de critérios) e Palavras (ou partes de palavras) e Expressões que auxiliassem na identificação destes tópicos. Entre estes elementos encontravam-se também expressões em inglês e espanhol, uma vez que muitos dos sistemas que compõem a base de indicadores resultaram de referências encontradas em experiências internacionais detalhadas nestes 
idiomas. Para cada Tema foi associado um respectivo Identificador (ID). A estrutura utilizada neste trabalho é mostrada na Tabela 8.2.

Os indicadores do sistema de referência, assim como os indicadores obtidos nas cidades foram registrados em planilhas eletrônicas. Com o auxílio de ferramentas de busca, foi feita a procura pelas palavras e expressões constantes na Tabela 8.2. Para os indicadores que continham pelo menos uma das expressões relacionadas, foi feita a atribuição do ID referente ao Tema. Após a busca pelas palavras-chave, uma análise final ainda foi realizada, buscando identificar outros indicadores relacionados aos Tópicos listados que, eventualmente, não tivessem sido capturados através da busca por Palavras e Expressões.

Com base nestes procedimentos foram identificados 375 indicadores na base de referência, classificados de acordo com os Temas que compõem a hierarquia. O mesmo procedimento foi aplicado para o conjunto de indicadores das cidades pesquisadas, classificando 623 indicadores. Nesta base, vinte e dois indicadores não puderam ser classificados por conterem informações incompletas e imprecisas, impossibilitando a definição do seu respectivo Tema.

Os dois conjuntos classificados foram comparados tema a tema, destacando-se os indicadores mais representativos de cada área, conforme os Tópicos da estrutura de busca, e aqueles comuns a ambos os conjuntos. Assim, no final desta etapa, foi obtida uma lista de "candidatos" a indicadores, em quantidades variáveis para cada Tema, para a composição do IMUS.

A seleção final dos indicadores foi feita com base em uma triagem, analisando o enfoque específico de cada indicador, através das informações técnicas e metodológicas disponíveis em seus sistemas de origem, e verificando sua compatibilidade com a idéia expressa pelo Tema e Tópicos relacionados. Privilegiou-se assim, a seleção de indicadores para os quais encontravam-se disponíveis informações detalhadas sobre seu significado, metodologia e processo de cálculo. 


\section{Tabela 8.2: Estrutura de auxílio à busca de indicadores.}

\begin{tabular}{|c|c|c|c|c|c|c|}
\hline \multirow{2}{*}{ ID } & \multirow{2}{*}{ Dom. } & \multirow{2}{*}{ ID } & \multirow{2}{*}{ Tema } & \multirow{2}{*}{ Definição } & \multicolumn{2}{|c|}{ Auxílio à Busca } \\
\hline & & & & & Tópicos & Palavras_Expressões \\
\hline \multirow{10}{*}{1} & \multirow{10}{*}{ 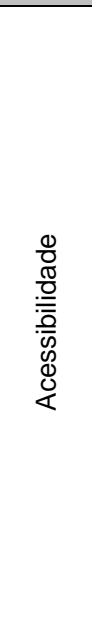 } & \multirow{3}{*}{1.1} & \multirow{3}{*}{$\begin{array}{l}\text { Acessibilidade aos sistemas de } \\
\text { transportes }\end{array}$} & \multirow{3}{*}{$\begin{array}{l}\text { Acesso aos sistemas de transporte englobando } \\
\text { acesso físico à rede e acesso econômico. }\end{array}$} & Acessibilidade econômica & \multirow{3}{*}{$\begin{array}{l}\text { acess (access), } \\
\text { tranif }^{I^{1}}\end{array}$} \\
\hline & & & & & Acessibilidade física & \\
\hline & & & & & $\begin{array}{l}\text { Transporte para pessoas com necessidades } \\
\text { especiais }\end{array}$ & \\
\hline & & \multirow{4}{*}{1.2} & \multirow{4}{*}{ Acessibilidade universal } & \multirow{4}{*}{$\begin{array}{l}\text { Acesso a espaços públicos e privados e às } \\
\text { atividades urbanas, incluindo pessoas com } \\
\text { necessidades especiais ou restrições de mobilidade. }\end{array}$} & Acessibilidade a edificações & \multirow{4}{*}{$\begin{array}{l}\text { acess (access), defici (disab), especia } \\
\text { (special), restri, idoso (elderly), criança } \\
\text { (child), espaço (spatial), servi }\end{array}$} \\
\hline & & & & & Acessibilidade aos espaços públicos/abertos & \\
\hline & & & & & Acessibilidade aos serviços essenciais & \\
\hline & & & & & $\begin{array}{l}\text { Adaptação da infra-estrutura para pessoas } \\
\text { com necessidades especiais }\end{array}$ & \\
\hline & & 1.3 & Barreiras físicas & $\begin{array}{l}\text { Obstáculos que dificultam ou impedem a } \\
\text { acessibilidade a determinadas áreas da cidade, } \\
\text { além de elementos naturais ou construídos que } \\
\text { contribuem para a segregação urbana. }\end{array}$ & Fragmentação/segregação urbana & barr, segreg, fragment, isola \\
\hline & & & Leqislacão para pessoas com & Dispositivos legais e institucionais para & Legislação e normas técnicas & lei (law), leg, institu, mobil, acess \\
\hline & & 1.4 & necessidades especiais & $\begin{array}{l}\text { acessibilidade/mobilidade de pessoas com } \\
\text { necessidades especiais. }\end{array}$ & $\begin{array}{l}\text { Ações para nelhoria da } \\
\text { acessibilidade/mobilidade }\end{array}$ & $\begin{array}{c}\text { (access), deficiente (disable), especial } \\
\text { (special) }\end{array}$ \\
\hline \multirow{5}{*}{2} & \multirow{5}{*}{ 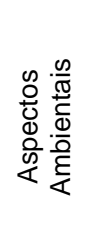 } & \multirow{3}{*}{2.1} & \multirow{3}{*}{$\begin{array}{l}\text { Controle dos impactos no meio } \\
\text { ambiente }\end{array}$} & \multirow{3}{*}{$\begin{array}{l}\text { Instrumentos de monitorização e controle dos } \\
\text { impactos oriundos dos sistemas de transporte no } \\
\text { meio ambiente. }\end{array}$} & Emissões de poluentes & \multirow{3}{*}{$\begin{array}{l}\text { control, polu (pollu), ambient } \\
\text { (environment), tecno (tech), mitiga, } \\
\text { emiss, impact, preven, resid (waste) }\end{array}$} \\
\hline & & & & & Medidas preventivas e mitigadoras & \\
\hline & & & & & Ruído de tráfego & \\
\hline & & \multirow{2}{*}{2.2} & \multirow{2}{*}{ Recursos naturais } & \multirow{2}{*}{$\begin{array}{l}\text { Utilização de recursos naturais pelos sistemas de } \\
\text { transporte e mobilidade. }\end{array}$} & Consumo de energia & \multirow{2}{*}{$\begin{array}{l}\text { recurso (resource), renov (renewable), } \\
\quad \text { alternativ, energ, combust (fuel) }\end{array}$} \\
\hline & & & & & Fontes de energia & \\
\hline \multirow[t]{4}{*}{3} & \multirow{4}{*}{ 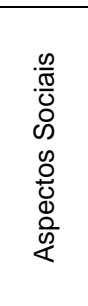 } & 3.1 & Apoio ao cidadão & $\begin{array}{l}\text { Atendimento, apoio e informação ao cidadão e } \\
\text { usuário de serviços públicos, especialmente } \\
\text { serviços de transporte. }\end{array}$ & Informação/apoio ao cidadão & $\begin{array}{l}\text { atend, cidadão (citizen), informa, apoio, } \\
\text { servi, usuário (user), supot (support) }\end{array}$ \\
\hline & & \multirow{2}{*}{3.2} & \multirow{2}{*}{ Inclusão social } & \multirow{2}{*}{$\begin{array}{l}\text { Acesso eqüitativo às oportunidades e benefícios das } \\
\text { cidades e redução da segregação sócio-espacial. }\end{array}$} & Inclusão social & \multirow{2}{*}{$\begin{array}{l}\text { inclus, social, eqüi (equity), oportun } \\
\text { (opportunity), benef }\end{array}$} \\
\hline & & & & & Eqüidade & \\
\hline & & 3.3 & Educação e cidadania & $\begin{array}{l}\text { Investimentos em educação e políticas sociais para } \\
\text { ampliar o acesso à informação e conscientização } \\
\text { sobre os direitos e deveres do cidadão. }\end{array}$ & Educação e conscientização & $\begin{array}{l}\text { educa, cidadania (citizenship), consci } \\
\text { (awareness), direito (right), dever (dut) }\end{array}$ \\
\hline
\end{tabular}

\footnotetext{
${ }^{1}$ Um exemplo de como as partes de palavra foram utilizadas nesta estrutura pode ser visto no caso da expressão "tarif", que representa as palavras tarifa em português e tariff em inglês.
} 


\begin{tabular}{|c|c|c|c|c|c|c|}
\hline \multirow{4}{*}{ ID } & \multirow{4}{*}{ Dom. } & \multirow{2}{*}{ ID } & \multirow{2}{*}{ Tema } & \multirow{2}{*}{ Definição } & \multicolumn{2}{|c|}{ Auxílio à Busca } \\
\hline & & & & & Tópicos & Palavras_Expressões \\
\hline & & 3.4 & Participação popular & $\begin{array}{l}\text { Participação e engajamento popular nos processos } \\
\text { de tomada de decisão em nível urbano. }\end{array}$ & Participação na tomada de decisão & $\begin{array}{l}\text { participa, engaja (commitment), decis, } \\
\text { popular, envolv (involvement) }\end{array}$ \\
\hline & & 3.5 & Qualidade de vida & $\begin{array}{l}\text { Medida do bem-estar da população e satisfação } \\
\text { com relação a aspectos sociais, econômicos e } \\
\text { ambientais da cidade. }\end{array}$ & Qualidade de vida/Bem-estar & quali, bem-estar (welfare), satisfa \\
\hline \multirow{5}{*}{4} & \multirow{5}{*}{ 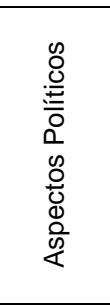 } & \multirow{2}{*}{4.1} & \multirow{2}{*}{ Integração de ações políticas } & \multirow{2}{*}{$\begin{array}{l}\text { Articulação e integração de ações políticas no } \\
\text { âmbito municipal, regional, estadual e federal e } \\
\text { parcerias público-privadas. }\end{array}$} & Integração entre níveis de governo & \multirow{2}{*}{$\begin{array}{l}\text { integra, parceira (partnership), public, } \\
\text { priva, politic }\end{array}$} \\
\hline & & & & & Intergração setor público e privado & \\
\hline & & \multirow[b]{2}{*}{4.2} & \multirow[b]{2}{*}{$\begin{array}{l}\text { Captação e gerenciamento de } \\
\text { recursos }\end{array}$} & \multirow{2}{*}{$\begin{array}{l}\text { Captação de recursos e geração de receitas para } \\
\text { projetos de transportes e mobilidade urbana e } \\
\text { monitoração dos recursos empregados por parte da } \\
\text { população. }\end{array}$} & Captação de recursos & \multirow{2}{*}{$\begin{array}{l}\text { financ, gerencia (management), } \\
\text { monitor, capta, inve, despesa } \\
\text { (expendit) }\end{array}$} \\
\hline & & & & & Investimentos/Distribuição dos recursos & \\
\hline & & 4.3 & Política de mobilidade urbana & $\begin{array}{l}\text { Criação e regulamentação de políticas públicas de } \\
\text { transportes e mobilidade urbana em nível municipal. }\end{array}$ & Política de mobilidade urbana & $\begin{array}{c}\text { mobil, politic, regula, sust, program, } \\
\text { proje }\end{array}$ \\
\hline \multirow{3}{*}{5} & \multirow{3}{*}{ 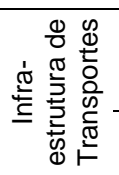 } & \multirow{2}{*}{5.1} & \multirow{2}{*}{$\begin{array}{l}\text { Provisão e manutenção da } \\
\text { infra-estrutura de transportes }\end{array}$} & \multirow{2}{*}{$\begin{array}{l}\text { Planejamento da provisão e manutenção da infra- } \\
\text { estrutura de transportes. }\end{array}$} & Provisão de infra-estrutura & \multirow{2}{*}{$\begin{array}{l}\text { infra, provi, manut (maint), gerencia } \\
\text { (management), via (street) }\end{array}$} \\
\hline & & & & & Manutenção da infra-estrutura & \\
\hline & & 5.2 & $\begin{array}{l}\text { Distribuição da infra-estrutura } \\
\text { de transportes }\end{array}$ & $\begin{array}{l}\text { Distribuição espacial e modal da infra-estrutura de } \\
\text { transportes. }\end{array}$ & $\begin{array}{l}\text { Distribuição da infra-estrutura entre os } \\
\text { modos de transporte }\end{array}$ & mod, infra, distribu \\
\hline \multirow{5}{*}{6} & \multirow{5}{*}{ 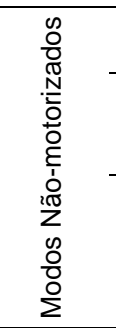 } & 6.1 & Transporte cicloviário & $\begin{array}{l}\text { Provisão e integração da infra-estrutura para o } \\
\text { transporte cicloviário. }\end{array}$ & Infra-estrutura para transporte cicloviário & bicicleta (bike), ciclo (cycl) \\
\hline & & 6.2 & Deslocamentos a pé & $\begin{array}{l}\text { Ações e estratégias para priorização e incentivo ao } \\
\text { uso de modos não-motorizados de transporte. }\end{array}$ & Infra-estrutura para modos não-motorizados & $\begin{array}{l}\text { não-motor (non-motorized), caminha } \\
\text { (walk), ciclo (cycl), bic, pedest }\end{array}$ \\
\hline & & \multirow{3}{*}{6.3} & \multirow{3}{*}{ Redução de viagens } & \multirow{3}{*}{$\begin{array}{l}\text { Ações para redução da necessidade por viagens, } \\
\text { extensão e tempo de viagem. }\end{array}$} & Características das viagens & \multirow{3}{*}{$\begin{array}{l}\text { redu, viag, viaj (travel/trip), tempo } \\
\text { (time/tiempo), exten (length), motor }\end{array}$} \\
\hline & & & & & Redução do tempo e extensão da viagem & \\
\hline & & & & & Redução das viagens motorizadas & \\
\hline \multirow[t]{8}{*}{7} & \multirow{8}{*}{ 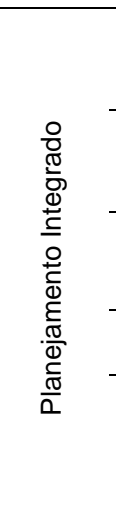 } & \multirow{2}{*}{7.1} & \multirow{2}{*}{ Capacitação de gestores } & \multirow{2}{*}{$\begin{array}{l}\text { Capacitação de técnicos e gestores municipais para } \\
\text { as atividades de planejamento urbano e de } \\
\text { transportes. }\end{array}$} & Nível técnico & capacita, gest, forma, qualifica, treina \\
\hline & & & & & Treinamento/capacitação de gestores & (training) \\
\hline & & 7.2 & $\begin{array}{l}\text { Áreas centrais e de interesse } \\
\text { histórico }\end{array}$ & $\begin{array}{l}\text { Preservação e valorização de áreas de interesse } \\
\text { histórico ou cultural. }\end{array}$ & Áreas centrais e de interesse histórico & centr (center), hist, cultur, preserv, valor \\
\hline & & 7.3 & Integração regional & $\begin{array}{l}\text { Integração entre órgãos e municípios no } \\
\text { planejamento e gestão da mobilidade em regiões } \\
\text { metropolitanas e aglomerações urbanas. }\end{array}$ & Integração regional e metropolitana & $\begin{array}{l}\text { integ, munic, metropol, aglomer } \\
\text { (agglomer), regi, institu, coop }\end{array}$ \\
\hline & & 7.4 & $\begin{array}{l}\text { Transparência do processo de } \\
\text { planejamento }\end{array}$ & $\begin{array}{l}\text { Informação e transparência no processo de } \\
\text { planejamento urbano e de transportes. }\end{array}$ & Transparência & transpar, informa \\
\hline & & & & & Uso do solo & \\
\hline & & 7.5 & $\begin{array}{l}\text { Planejamento e controle do } \\
\text { uso e ocupação do solo }\end{array}$ & $\begin{array}{l}\text { Planejamento e controle da ocupação espacial e } \\
\text { desenvolvimento urbano. }\end{array}$ & Crescimento urbano & espa (spatial), espalha (sprawl), densi, \\
\hline & & & & & Ocupações irregulares & \\
\hline
\end{tabular}




\begin{tabular}{|c|c|c|c|c|c|c|}
\hline \multirow{8}{*}{ ID } & \multirow{8}{*}{ Dom. } & \multirow{2}{*}{ ID } & \multirow{2}{*}{ Tema } & \multirow{2}{*}{ Definição } & \multicolumn{2}{|c|}{ Auxílio à Busca } \\
\hline & & & & & Tópicos & Palavras_Expressões \\
\hline & & \multirow{2}{*}{7.6} & \multirow{2}{*}{$\begin{array}{l}\text { Planejamento estratégico e } \\
\text { integrado }\end{array}$} & \multirow{2}{*}{$\begin{array}{l}\text { Integração e continuidade das ações de } \\
\text { planejamento urbano e de transportes e definição } \\
\text { de objetivos estratégicos para a mobilidade urbana. }\end{array}$} & Planejamento integrado & \multirow{2}{*}{ estrat (strat), planeja (plann), continu } \\
\hline & & & & & Continuidade do planejamento & \\
\hline & & \multirow{2}{*}{7.7} & \multirow{2}{*}{$\begin{array}{l}\text { Planejamento da infra- } \\
\text { estrutura e equipamentos } \\
\text { urbanos }\end{array}$} & \multirow{2}{*}{$\begin{array}{l}\text { Planejamento da infra-estrutura e equipamentos } \\
\text { urbanos. }\end{array}$} & Equipamentos urbanos & \multirow{2}{*}{$\begin{array}{l}\text { equipa (facilit), serv, infra, parque } \\
\text { (park), escola (school), hosp }\end{array}$} \\
\hline & & & & & Espaços verdes & \\
\hline & & \multirow{2}{*}{7.8} & \multirow{2}{*}{$\begin{array}{l}\text { Plano Diretor e legislação } \\
\text { urbanística }\end{array}$} & \multirow{2}{*}{$\begin{array}{l}\text { Desenvolvimento, revisão e atualização de Planos } \\
\text { Diretores de Desenvolvimento Urbano e legislação } \\
\text { urbanística. }\end{array}$} & Plano Diretor & \multirow{2}{*}{$\begin{array}{c}\text { Plano Diretor (Master Plan), lei (law), } \\
\text { leg }\end{array}$} \\
\hline & & & & & Legislação urbanística & \\
\hline \multirow{6}{*}{8} & \multirow{6}{*}{ 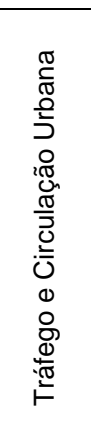 } & \multirow{2}{*}{8.1} & \multirow{2}{*}{ Acidentes de trânsito } & \multirow{2}{*}{$\begin{array}{l}\text { Monitoração e medidas para prevenção e redução } \\
\text { de acidentes de trânsito e ampliação da segurança } \\
\text { viária. }\end{array}$} & Acidentes de trânsito & \multirow{2}{*}{$\begin{array}{l}\text { acidente (accident), segur (security, } \\
\text { safety), preven, ferido (injur), mort } \\
\text { (fatalit), traffic calming }\end{array}$} \\
\hline & & & & & Segurança viária & \\
\hline & & 8.2 & Educação para o trânsito & $\begin{array}{l}\text { Educação e campanhas de conscientização para } \\
\text { humanização do trânsito. }\end{array}$ & Educação para o trânsito & $\begin{array}{l}\text { educa, trânsito (traffic), conscientiza } \\
\text { (awarenes) }\end{array}$ \\
\hline & & 8.3 & Fluidez e circulação & $\begin{array}{l}\text { Condições de trânsito e circulação e ações para } \\
\text { melhoria da fluidez do tráfego. }\end{array}$ & Condições de circulação & $\begin{array}{l}\text { trânsito (traffic), congest, circula, } \\
\text { velocidade (speed) }\end{array}$ \\
\hline & & 8.4 & $\begin{array}{l}\text { Operação e fiscalização de } \\
\text { trânsito }\end{array}$ & Gestão do trânsito e circulação em nível urbano. & Operação e fiscalização de trânsito & $\begin{array}{l}\text { gest, gerencia (management), opera, } \\
\text { fiscaliza, trânsito (traffic) }\end{array}$ \\
\hline & & 8.5 & Transporte individual & $\begin{array}{l}\text { Monitorização e controle do transporte individual e } \\
\text { circulação em áreas críticas e incentivo aos modos } \\
\text { coletivos de transporte. }\end{array}$ & Transporte individual motorizado & $\begin{array}{l}\text { auto, indiv, car, restri, control, veículo } \\
\text { (vehicle), limit, priva, estaciona (park) }\end{array}$ \\
\hline \multirow{10}{*}{9} & \multirow{10}{*}{ 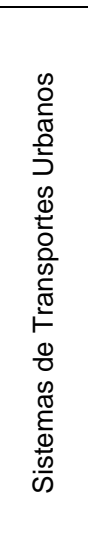 } & \multirow{2}{*}{9.1} & \multirow{2}{*}{$\begin{array}{l}\text { Disponibilidade e qualidade do } \\
\text { transporte público }\end{array}$} & \multirow{2}{*}{$\begin{array}{l}\text { Cobertura, disponibilidade e qualidade dos serviços } \\
\text { de transporte público urbano e metropolitano. }\end{array}$} & Disponibilidade de transpote público & \multirow{2}{*}{$\begin{array}{l}\text { transport, public, transit, servi, quali, } \\
\text { cobertura, abrang (cover), satisf, efic } \\
\text { (effic), coletiv (colectiv), desempenho } \\
\text { (performance) }\end{array}$} \\
\hline & & & & & Qualidade do transporte público & \\
\hline & & \multirow{2}{*}{9.2} & \multirow{2}{*}{ Diversificação modal } & \multirow{2}{*}{$\begin{array}{l}\text { Modos de transporte disponíveis, utilização e } \\
\text { investimentos por modo. }\end{array}$} & Modos de transporte & \multirow{2}{*}{ mod, divers, intermodal } \\
\hline & & & & & Divisão modal & \\
\hline & & & & & Regulação do transporte público & \\
\hline & & 9.3 & $\begin{array}{l}\text { Regulação e fiscalização do } \\
\text { transporte público }\end{array}$ & $\begin{array}{l}\text { Regulação e estrutura de controle e fiscalização do } \\
\text { servico de transporte público urbano. }\end{array}$ & Fiscalização do transporte público & fiscal, regula \\
\hline & & & & & Integração física & \\
\hline & & 9.4 & $\begin{array}{l}\text { Integração do transporte } \\
\text { público }\end{array}$ & $\begin{array}{l}\text { Integração física, tarifária e temporal do sistema de } \\
\text { transporte público urbano e metropolitano. }\end{array}$ & Integração tarifária & $\begin{array}{c}\text { integra, fisic (physic), tarif, sistema } \\
\text { (system) }\end{array}$ \\
\hline & & 95 & Poĺtica tarifária & Definição e implantação de política tarifária visando & Subsídios & tarif, tax, preço (price), remunera, \\
\hline & & 9.0 & PUitued Lamalia & tarifas acessíveis aos usuários. & Preços e tarifas & \\
\hline
\end{tabular}


Com base nestes procedimentos foram selecionados oitenta e sete indicadores, agregados nos trinta e sete Temas que compõem a hierarquia de critérios do IMUS. Aos Temas que não foi possível associar indicadores originados do sistema de referência, foram incorporados, com algumas adaptações, os próprios indicadores integrantes do sistema obtido nas cidades pesquisadas. A relação de Indicadores por Tema, bem como as referências preliminares associadas nesta etapa do trabalho são mostradas na Tabela 8.3.

$\mathrm{Na}$ fase de detalhamento da metodologia e cálculo dos indicadores, conforme será visto no item 8.7, outras referências foram pesquisadas, de forma a facilitar o desenvolvimento dos indicadores e permitir sua adequação aos critérios que constituem a hierarquia. Da mesma forma, alguns indicadores sofreram pequenas adaptações, tanto na sua definição como abrangência, visando atender aos mesmos objetivos expressos anteriormente.

\subsection{Pesos para os Critérios}

Os pesos para os critérios que compõem o IMUS foram obtidos através de um painel de especialistas nas áreas de planejamento urbano, transportes, mobilidade e sustentabilidade, do Brasil e de outros países como Portugal, Alemanha, Estados Unidos e Austrália. A seleção dos especialistas foi feita com base em sua experiência prévia e trabalhos desenvolvidos nas áreas relacionadas. A intenção foi envolver pesquisadores com conhecimento em diferentes campos, permitindo uma análise comparativa dos critérios que compõem o índice e a determinação de sua importância relativa para a sustentabilidade urbana, com base nas experiências anteriores e nos resultados obtidos em suas pesquisas e trabalhos sobre o tema. Neste sentido, foram convidados a participar especialistas que têm desenvolvido trabalhos relevantes nas seguintes áreas, tais como: desenvolvimento de índices de mobilidade, ferramentas de auxílio às atividades de planejamento, aplicação de métodos de análise multicritério para tomada de decisão em nível urbano, etc.

A consulta foi desenvolvida via Internet. Para cada um dos avaliadores convidados a participar no painel foi enviado um Localizador Uniforme de Recursos (URL, em sua sigla em inglês) para acesso às informações sobre a pesquisa, o qual ficou disponível durante trinta dias para a avaliação. No Anexo F - "Painel de Especialistas" constam os modelos de planilhas disponibilizadas via Internet, incluindo as informações gerais fornecidas e tabelas de avaliação de Temas e Dimensões. 
Tabela 8.3: Indicadores selecionados para compor o IMUS.

\begin{tabular}{|c|c|c|c|c|}
\hline ID & Tema & Indicador & Unidade de medida & Referências \\
\hline \multirow{3}{*}{1.1} & \multirow{3}{*}{$\begin{array}{l}\text { Acessibilidade aos sistemas de } \\
\text { transportes }\end{array}$} & Acessibilidade ao transporte público & ר & $\begin{array}{l}\text { Minken; Samstad e Putz (2001), Campos e Ramos (2005), } \\
\text { Litman, T. (2007) }\end{array}$ \\
\hline & & $\begin{array}{l}\text { Transporte público para pessoas com necessidades } \\
\text { especiais }\end{array}$ & $\begin{array}{l}\text { \% ou existência de serviço } \\
\text { especial }\end{array}$ & Campos e Ramos (2005) \\
\hline & & Despesas com transporte & 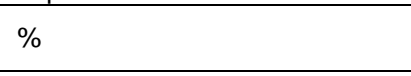 & $\begin{array}{l}\text { WBCSD (2004), TRANSPLUS (2002), Campos e Ramos } \\
\text { (2005) }\end{array}$ \\
\hline \multirow{5}{*}{1.2} & \multirow{5}{*}{ Acessibilidade universal } & $\begin{array}{l}\text { Travessias adaptadas a pessoas com necessidades } \\
\text { especiais }\end{array}$ & $\%$ & Hertfordshire (1999), Hertfordshire (2003) \\
\hline & & Acessibilidade a espaços abertos & $\%$ & Campos e Ramos (2005) \\
\hline & & $\begin{array}{l}\begin{array}{l}\text { Vagas de estacionamento para } \\
\text { necessidades especiais }\end{array} \\
\end{array}$ & Número & Audit Comission e IDeA (2007) \\
\hline & & Acessibilidade a edifícios públicos & $\%$ & Lingayah, S. e Sommer, F. (2001) \\
\hline & & Acessibilidade aos serviços essenciais & $\%$ & Audit Comission e IDeA (2007) \\
\hline 1.3 & Barreiras físicas & Fragmentação urbana & Número & SUMMA (2004), LAUTSO, K. ET AL. (2004), TERM \\
\hline 1.4 & $\begin{array}{l}\text { Legislação para pessoas com } \\
\text { necessidades especiais }\end{array}$ & Ações para acessibilidade universal & Tipos de medidas & Audit Comission e IDeA (2007), ECO XXI \\
\hline \multirow{4}{*}{2.1} & \multirow{4}{*}{$\begin{array}{l}\text { Controle dos impactos no meio } \\
\text { ambiente }\end{array}$} & Emissões de CO & $\%$ & OECD (1999) \\
\hline & & Emissões de $\mathrm{CO}^{2}$ & $\%$ & TERM, (2001) OECD (1999) \\
\hline & & População exposta ao ruído de tráfego & $\%$ & $\begin{array}{l}\text { Minken, et al. (2001), SUMMA (2004), Gilbert e Tanguay } \\
(2000)\end{array}$ \\
\hline & & Estudos de impacto ambiental & Sim/Não, Tipo & TERM (2002), UNCSD (2001) \\
\hline \multirow{2}{*}{2.2} & \multirow{2}{*}{ Recursos naturais } & Consumo de combustível & L/hab/ano & Sustainable Measures (2006), UNCSD (2001) \\
\hline & & Uso de energia limpa e combustíveis alternativos & $\%$ & Sustainable Measures (2006), TERM (2002) \\
\hline 3.1 & Apoio ao cidadão & Informação disponível ao cidadão & Tipos de informação & $\begin{array}{l}\text { ABAE (2006), Hertfordshire (1999), Audit Comission e } \\
\text { IDeA (2007) }\end{array}$ \\
\hline 3.2 & Inclusão social & Eqüidade vertical (renda) & Número & SUMMA (2004) \\
\hline 3.3 & Educação e cidadania & Educação para o desenvolvimento sustentável & Tipos de ações & ABAE (2006), Cardiff (2002) \\
\hline 3.4 & Participação popular & Participação na tomada de decisão & Grau de participação & $\begin{array}{l}\text { Audit Comission e IDeA (2007), UNCHS (2004), Gilbert e } \\
\text { Tanguay (2000) }\end{array}$ \\
\hline 3.5 & Qualidade de vida & Qualidade de vida & $\%$ & $\begin{array}{l}\text { Cardiff (2002), Indicators of SD, Sustainable Seattle } \\
(1998)\end{array}$ \\
\hline \multirow{2}{*}{4.1} & \multirow{2}{*}{ Integração de ações políticas } & Integração entre níveis de governo & Freqüência, grau de integração & - \\
\hline & & Parcerias público/privadas & Sim/Não & ABAE (2006) \\
\hline \multirow{4}{*}{4.2} & \multirow{4}{*}{$\begin{array}{l}\text { Captação e gerenciamento de } \\
\text { recursos }\end{array}$} & Captação de recursos & $\%$ & SUMMA (2004), Lautso, K. et al. (2004) \\
\hline & & Investimentos em sistemas de transportes & Áreas, tipos de investimentos & $\begin{array}{l}\text { UNCSD (2001), Centre for Sustainable Transportation } \\
(2001)\end{array}$ \\
\hline & & $\begin{array}{lllll}\begin{array}{l}\text { Distribuição dos recursos } \\
\text { transporte privado) }\end{array} & \text { (transporte } & \text { público } & \mathrm{x} \\
\end{array}$ & Número & Sustainable Measures (2006) \\
\hline & & $\begin{array}{l}\text { Distribuição dos recursos (modos motorizados } \mathrm{x} \\
\text { modos não-motorizados) }\end{array}$ & Númeo & - \\
\hline 4.3 & Política de mobilidade urbana & Política de mobilidade urbana & $\begin{array}{l}\text { Sim/Não, estágio de } \\
\text { implantação }\end{array}$ & Litman (2007) \\
\hline
\end{tabular}




\begin{tabular}{|c|c|c|c|c|}
\hline ID & Tema & Indicador & Unidade de medida & Referências \\
\hline \multirow{4}{*}{5.1} & \multirow{4}{*}{$\begin{array}{l}\text { Provisão e manutenção da infra- } \\
\text { estrutura de transportes }\end{array}$} & Densidade da rede viária & $\mathrm{km} / \mathrm{km}^{2}$, grau de conectividade & $\begin{array}{l}\text { Mendes (1999), Mendes (2004), Sustainable Measures } \\
(2006)\end{array}$ \\
\hline & & Vias pavimentadas & $\%$ & Prefeitura Municipal de Belo Horizonte (2004) \\
\hline & & $\begin{array}{l}\text { Despesas com manutenção da infra-estrutura de } \\
\text { transportes }\end{array}$ & Tipos de despesas & SUMMA (2004) \\
\hline & & Sinalização viária & Parcela da população & - \\
\hline 5.2 & $\begin{array}{l}\text { Distribuição da infra-estrutura de } \\
\text { transportes }\end{array}$ & Vias para transporte coletivo & $\%$ & Sustainable Measures (2006) \\
\hline \multirow{3}{*}{6.1} & \multirow{3}{*}{ Transporte cicloviário } & Extensão de ciclovias & $\%$, grau de conectividade & Campos e Ramos (2005), Sustainable Measures (2006) \\
\hline & & Frota de bicicletas & bicicletas/100 habitantes & - \\
\hline & & Estacionamento para bicicletas & $\%$ & Hertfordshire (1999) \\
\hline \multirow[t]{2}{*}{6.2} & \multirow[t]{2}{*}{ Deslocamentos a pé } & Vias para pedestres & $\%$, conectividade & $\begin{array}{l}\text { ABAE (2006), Sustainable Sustainable Seattle (1998), } \\
\text { SUMMA (2004) }\end{array}$ \\
\hline & & Vias com calçadas & $\%$ & Campos e Ramos (2005) \\
\hline \multirow{4}{*}{6.3} & \multirow{4}{*}{ Redução de viagens } & Distância de viagem & $\mathrm{km}$ & Gilbert e Tanguay (2000) \\
\hline & & Tempo de viagem & $\min$ & UNCHS (2004), Lautso, K. et al. (2004) \\
\hline & & Número de viagens & viagens/habitante/dia & - \\
\hline & & Ações para redução do tráfego motorizado & Sim/Não, tipo & ABAE (2006), TRANSPLUS (2002), OECD (1999) \\
\hline \multirow{2}{*}{7.1} & \multirow{2}{*}{ Capacitação de gestores } & Nível de formação de técnicos e gestores & $\%$ & Santos e Martins (2002) \\
\hline & & Capacitação de técnicos e gestores & horas/funcionário/ano & Audit Comission e IDeA (2007) \\
\hline 7.2 & $\begin{array}{l}\text { Áreas centrais e de interesse } \\
\text { histórico }\end{array}$ & Vitalidade do centro & Número & SPARTACUS, LAUTSO, K. ET AL. (2004) \\
\hline 7.3 & Integração regional & Consórcios intermunicipais & Sim/Não, Tipo & SNIU (2002) \\
\hline 7.4 & $\begin{array}{l}\text { Transparência do processo de } \\
\text { planejamento }\end{array}$ & Transparência e responsabilidade & Sim/Não & UNCHS (2004) \\
\hline \multirow{5}{*}{7.5} & \multirow{5}{*}{$\begin{array}{l}\text { Planejamento e controle do uso e } \\
\text { ocupação do solo }\end{array}$} & Vazios urbanos & $\%$ & - \\
\hline & & Crescimento urbano & Número & $\begin{array}{l}\text { Tayside, Fife Council, Audit Comission e IDeA (2007), } \\
\text { TRANSPLUS (2002) }\end{array}$ \\
\hline & & Densidade populacional urbana & habitantes $/ \mathrm{km}^{2}$ & Scottish Executive Central Research Unit (2001) \\
\hline & & Índice de uso misto & $\%$ & Caratti et al. (2001) \\
\hline & & Ocupações irregulares & $\%$ & UNCSD (2001), UN/CSD (2001) \\
\hline \multirow[t]{2}{*}{7.6} & \multirow{2}{*}{$\begin{array}{l}\text { Planejamento } \\
\text { integrado }\end{array}$} & $\begin{array}{l}\text { Planejamento urbano, ambiental e de transportes } \\
\text { integrado }\end{array}$ & Sin/Não, Grau de cooperação & TERM (2002) \\
\hline & & Efetivação e continuidade das ações & Programas/Projetos & Bossel (1999) \\
\hline \multirow{3}{*}{7.7} & \multirow{3}{*}{$\begin{array}{l}\text { Planejamento da infra-estrutura e } \\
\text { equipamentos urbanos }\end{array}$} & Parques e áreas verdes & $\mathrm{m}^{2} /$ habitante & $\begin{array}{l}\text { Sustainable Measures (2006), Audit Comission e IDeA } \\
\text { (2007), Cardiff (2002) }\end{array}$ \\
\hline & & Equipamentos urbanos (escolas) & escolas/1000 habitantes & - \\
\hline & & Equipamentos urbanos (hospitais) & $\begin{array}{l}\text { postos de saúde/100.000 } \\
\text { habitantes }\end{array}$ & $\begin{array}{l}\text { Mendes (1999), Mendes (2004), Direcção Geral do } \\
\text { Ambiente (2000) }\end{array}$ \\
\hline \multirow{3}{*}{7.8} & \multirow{3}{*}{$\begin{array}{l}\text { Plano Diretor e legislação } \\
\text { urbanística }\end{array}$} & Plano Diretor & Sim/Não, atualização & SNIU (2002) \\
\hline & & Legislação urbanística & Sim/Não & SNIU (2002) \\
\hline & & Cumprimento da legislação urbanística & Sim/Não, Tipo & - \\
\hline 8.1 & Acidentes de trânsito & Acidentes de trânsito & mortos/100.000 habitantes/ano & SNIU (2002), Santos e Martins (2002), Gilbert e Tangua) \\
\hline
\end{tabular}




\begin{tabular}{|c|c|c|c|c|}
\hline ID & Tema & Indicador & Unidade de medida & Referências \\
\hline & & & & $\begin{array}{l}\text { (2006), TERM (2001-2003), SUMMA (2004), Centre for } \\
\text { Sustainable Transportation (2001) }\end{array}$ \\
\hline & & Acidentes com pedestres e ciclistas & $\%$ & - \\
\hline & & Prevenção de acidentes & $\%$ & Campos e Ramos (2005), SUMMA (2004) \\
\hline 8.2 & Educação para o trânsito & Educação para o trânsito & $\%$ & Audit Comission e IDeA (2007) \\
\hline \multirow{2}{*}{8.3} & \multirow{2}{*}{ Fluidez e circulação } & Congestionamento & horas/dia & Campos e Ramos (2005) \\
\hline & & Velocidade média de tráfego & $\mathrm{km} / \mathrm{h}$ & Santos e Martins (2002) \\
\hline 8.4 & $\begin{array}{l}\begin{array}{l}\text { Operação } \\
\text { trânsito }\end{array} \\
\end{array}$ & Violação das leis de trânsito & $\%$ & SUMMA (2004) \\
\hline \multirow[t]{2}{*}{8.5} & \multirow[t]{2}{*}{ Transporte individual } & Índice de motorização & autos/1000 habitantes & $\begin{array}{l}\text { Santos e Martins (2002), Mendes (1999), Mendes (2004), } \\
\text { TRANSPLUS (2002), Gobierno Vasco (2007) }\end{array}$ \\
\hline & & Taxa de ocupação dos veículos & passageiros/auto & TERM (2002), Gobierno Vasco (2007), Caratti et al. (2001) \\
\hline \multirow{8}{*}{9.1} & \multirow{8}{*}{$\begin{array}{l}\text { Disponibilidade e qualidade do } \\
\text { transporte público }\end{array}$} & Extensão da rede de transporte público & $\%$ & $\begin{array}{l}\text { Baltic 21, Gilbert e Tanguay (2000), Gobierno Vasco } \\
\text { (2007), Sustainable Measures (2006) }\end{array}$ \\
\hline & & Freqüência de atendimento do transporte público & $\min$ & Campos e Ramos (2005) \\
\hline & & Pontualidade & $\%$ & $\begin{array}{l}\text { Hertfordshire (2003), Hertfordshire (1999), UK } \\
\text { Government Sustainable Development (2004) }\end{array}$ \\
\hline & & Velocidade média do transporte público & $\mathrm{km} / \mathrm{h}$ & Campos e Ramos (2005) \\
\hline & & Idade média da frota de transporte público & anos & - \\
\hline & & Índice de passageiros por quilômetro & passgeiros/km & - \\
\hline & & Passageiros transportados anualmente & Número & $\begin{array}{l}\text { Sustainable Measures (2006), Hertfordshire (1999), } \\
\text { Gobierno Vasco (2007) }\end{array}$ \\
\hline & & $\begin{array}{l}\text { Satisfação do usuário com o serviço de transporte } \\
\text { público }\end{array}$ & $\%$ & Hertfordshire (2003) \\
\hline \multirow[b]{3}{*}{9.2} & \multirow[b]{3}{*}{ Diversificação modal } & Diversidade de modos de transporte & Número & Bossel (1999), Litman (2007) \\
\hline & & Transporte público $\mathrm{x}$ transporte privado & Número & Sustainable Measures (2006) \\
\hline & & Modos motorizados x modos não-motorizados & Número & $\begin{array}{l}\text { Litman (2007), Hertfordshire (1999) - UK Government } \\
\text { Sustainable Development (2004), Gilbert e Tanguay } \\
\text { (2000) }\end{array}$ \\
\hline \multirow{2}{*}{9.3} & \multirow{2}{*}{$\begin{array}{l}\text { Regulação e fiscalização do } \\
\text { transporte público }\end{array}$} & Contratos e licitações & $\%$ & - \\
\hline & & Transporte clandestino & Participação, tipo & - \\
\hline \multirow{2}{*}{9.4} & \multirow{2}{*}{ Integração do transporte público } & Terminais intermodais & $\%$ & SUMMA (2004) \\
\hline & & Linhas integradas & Grau, Tipo & - \\
\hline \multirow{3}{*}{9.5} & \multirow{3}{*}{ Política tarifária } & Descontos e gratuidades & $\%$ & Audit Comission e IDeA (2007) \\
\hline & & Tarifas de transportes & Variação \% & $\begin{array}{l}\text { SUMMA (2004), Direcção Geral do Ambiente (2000), } \\
\text { TERM (2002) }\end{array}$ \\
\hline & & Subsídios públicos & Sim/Não, tipo & SUMMA (2004), Gilbert e Tanguay (2000) \\
\hline
\end{tabular}


Todas as informações foram disponibilizadas em dois idiomas (inglês e português). Buscouse organizar o processo de avaliação de forma que os especialistas não precisassem digitar nenhum valor, tornando mais simples e rápido o processo de avaliação. No entanto, no final de cada etapa foi disponibilizado um espaço para comentários, dúvidas e sugestões, que poderiam ser inseridos pelos participantes do painel, caso desejassem.

Os resultados das avaliações de cada especialista foram registrados automaticamente em um banco de dados. Posteriormente estes foram normalizados de modo a obter pesos para cada um dos critérios, por avaliador. O peso final para cada critério corresponde à média aritmética de todas as avaliações efetuadas para esse critério.

Na primeira parte da avaliação foi solicitado aos especialistas que avaliassem a importância relativa dos Temas que integram cada um dos nove Domínios pré-definidos. Esta avaliação foi feita atribuindo-se uma pontuação variável de 1 a 5 , variando de Insignificante a Extremamente Importante, conforme mostrado a Figura 8.2.

Insignficante

\begin{tabular}{|l|l|l|l|l|}
\hline 1 & 2 & 3 & 4 & 5 \\
\hline
\end{tabular}

Extremamente Importante

Figura 8.2: Escala de avaliação dos critérios do IMUS.

Os Temas foram dispostos em tabelas, divididas por Domínio. Para cada Tema foi apresentada uma breve definição, de forma a auxiliar o especialista na determinação de sua importância relativa. Um exemplo de tabela de avaliação para o Domínio Acessibilidade é mostrado na Figura 8.3.

\begin{tabular}{|c|c|c|c|c|c|}
\hline \multicolumn{6}{|c|}{$\begin{array}{l}\text { Qual a importância dos Temas abaixo para o } \\
\text { Dominio: Acessibilidade? }\end{array}$} \\
\hline \multirow{2}{*}{ } & \multicolumn{5}{|c|}{ Nivel de Importância } \\
\hline & 1 & 2 & 3 & 4 & 5 \\
\hline $\begin{array}{l}\text { Acessiblidade aos sistemas de transportes } \\
\text { Acesso aos sistemas de transporte engiobando acesso físico à rede e acesso } \\
\text { econômico. }\end{array}$ & 0 & 0 & 0 & 0 & $\mathrm{O}$ \\
\hline $\begin{array}{l}\text { Acessibilidade universal } \\
\text { Acesso a espaços públicos e privados e às atividades urbanas, inciuindo pessoas com } \\
\text { necessidades especiais ou restriçōes de mobilidade. }\end{array}$ & 0 & 0 & 0 & $\mathrm{O}$ & $\mathrm{O}$ \\
\hline $\begin{array}{l}\text { Barreiras fisicas } \\
\text { Obstáculos que dificuitam ou impedem a acessibilidade a determinadas áreas da cidade, } \\
\text { além de elementos naturais ou construidos que contribuem para a segregaçäo urbana. }\end{array}$ & 0 & 0 & 0 & 0 & $\mathrm{O}$ \\
\hline $\begin{array}{c}\text { Legislação para pessoas com necessidas especiais } \\
\text { Dispositivos legais e institucionais para acessibilidade/mobilidade de pessoas com } \\
\text { necessidades especiais. }\end{array}$ & 0 & 0 & 0 & $\mathrm{O}$ & 0 \\
\hline
\end{tabular}

Figura 8.3: Exemplo de tabela de avaliação dos Temas do IMUS.

Avaliados os Temas, a etapa seguinte contemplou a avaliação da importância relativa dos mesmos (ainda classificados por Domínio), para cada uma das Dimensões da 
sustentabilidade: Social, Econômica e Ambiental. Para tal, foi utilizada a mesma escala de avaliação já mostrada na Figura 8.2.

Ao final de cada etapa de inserção dos valores era feita uma verificação automática da consistência no preenchimento das avaliações, alertando ao especialista se o mesmo havia esquecido de preencher algum valor. Finalizada a avaliação, o especialista efetuava a submissão dos dados, os quais eram armazenados automaticamente em um banco de dados.

No total, quatorze especialistas participaram do processo de avaliação. Apenas um não concluiu a avaliação, fazendo com que os resultados da primeira etapa de sua avaliação (análise da importância relativa dos Temas) fosses descartados. Os resultados das avaliações por especialista, assim como os pesos obtidos para cada critério constam no Anexo G - "Sistemas de Pesos para os Critérios".

Os pesos para os Temas foram obtidos diretamente dos resultados do painel de especialistas. Foi obtida primeiramente a média aritmética dos valores definidos por todos os participantes, expressos na escala de 1 a 5 . Posteriormente estes valores foram normalizados para o intervalo entre 0,00 e 1,00, obtendo-se o peso final para cada Tema. Desta forma, os pesos dos Temas por Domínio, se somados, resultam no valor igual a 1,00.

Os pesos dos Temas para cada Dimensão foram obtidos de forma semelhante. Neste caso, se somados para as Dimensões Social, Econômica e Ambiental, também resultam em 1,00. Os pesos dos Domínios foram obtidos através da razão entre a média aritmética do peso de seus respectivos Temas e o somatório das médias obtidas para o conjunto de Domínios. Agregam, portanto, as tendências dos seus respectivos Temas em relação aos pesos associados às Dimensões da sustentabilidade.

No que diz respeito aos Indicadores, foram atribuídos pesos iquais para os indicadores integrantes de cada Tema, normalizados para o intervalo entre 0,00 e 1,00. Do mesmo modo, a soma dos pesos por Tema é igual a 1,00. Uma vez que os Indicadores apresentam pesos iguais, é possível substituir indicadores ou inserir novos indicadores para avaliação do IMUS, sem a necessidade de se proceder a um novo painel de especialistas para a definição dos pesos. Neste caso, é feita somente uma redistribuição dos pesos de forma que seu somatório seja igual a 1,00. No entanto, em situações especiais, pesos diferenciados podem ser identificados para os indicadores, seja por painel de especialistas, ou outra forma de avaliação. 
Os resultados obtidos a partir do painel de especialistas realizado neste trabalho, bem como o cálculo dos pesos obtidos para os critérios que compõem o IMUS constam no Anexo G "Sistemas de Pesos para os Critérios" deste documento.

A Tabela 8.4 apresenta a estrutura completa do IMUS com seus Domínios, Temas e Indicadores, bem como os respectivos pesos. Para cada Tema são apresentados ainda os pesos que refletem sua importância relativa para as Dimensões da sustentabilidade. 
Tabela 8.4: Estrutura Hierárquica de Critérios do IMUS e respectivos Pesos.

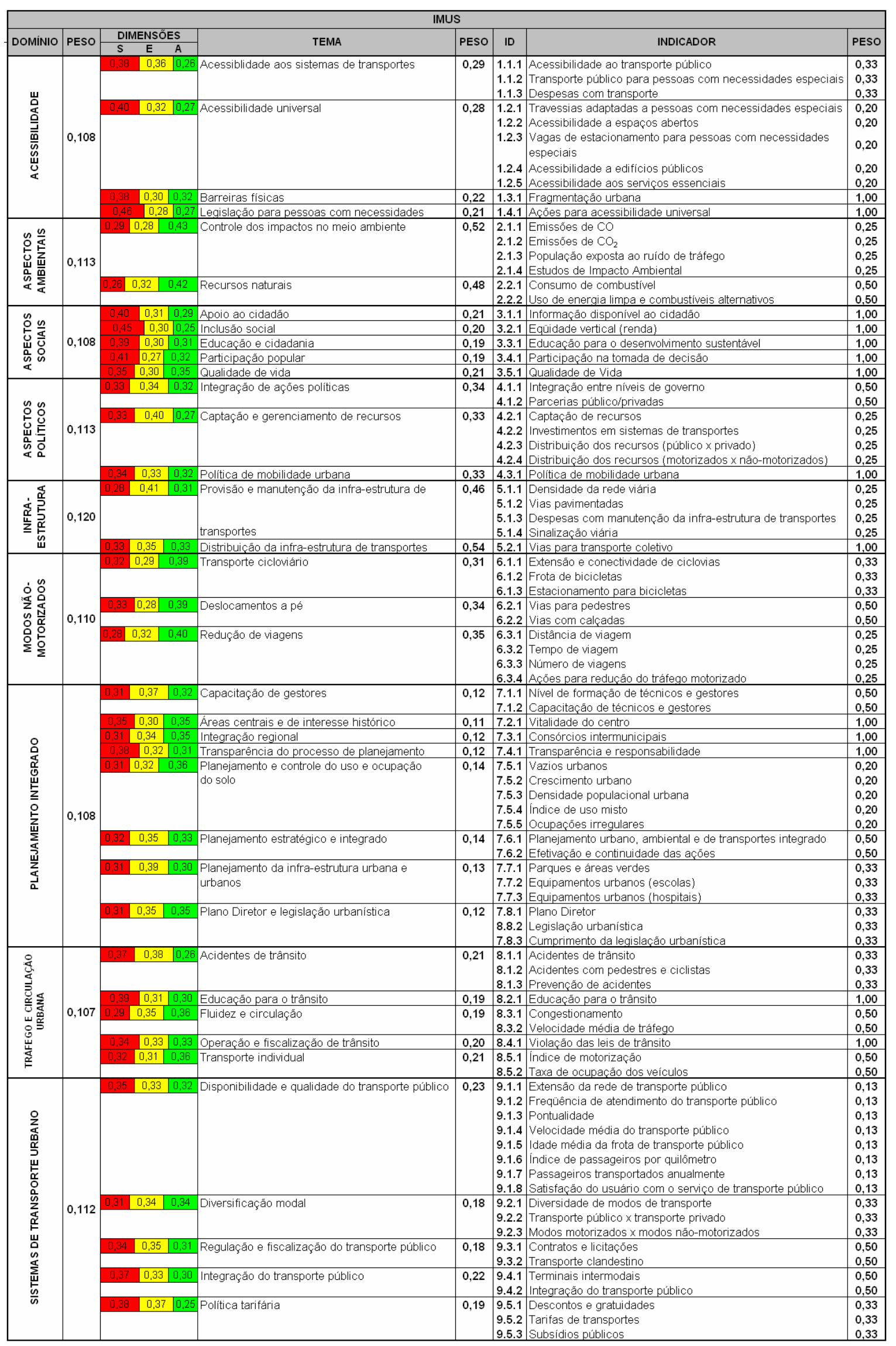




\subsection{Normalização dos Critérios}

Uma vez consolidada a hierarquia de critérios do IMUS e definidos seus respectivos pesos, a etapa posterior consistiu na definição do processo de normalização dos scores para os indicadores, de forma a torná-los comparáveis e possíveis de serem agregados através de um modelo matemático ou regra de decisão.

Conforme definido no item 6.3.4, o processo de normalização consiste no cálculo de um score normalizado entre os valores mínimo e máximo correspondentes a 0,00 e 1,00, uma vez que se optou por este intervalo. Para isso é determinada uma Escala de Avaliação para cada indicador, onde são associados, aos valores mínimo e máximo, valores de referência para o score do indicador. As Escalas de Avaliação para todos os indicadores que compõem o IMUS são apresentadas no Anexo E - "Guia de Elaboração dos Indicadores do IMUS" deste documento.

A Escala de Avaliação é definida conforme a tipologia do indicador. A estrutura do IMUS integra três tipos de indicadores, identificados como Quantitativos, Qualitativos e Mistos.

Os Indicadores Quantitativos tratam de medidas calculadas a partir de dados quantitativos oriundos de base de dados e levantamentos de campo, entre outras fontes. Incluem os seguintes subgrupos de indicadores:

- Subgrupo 1 - Indicadores Quantitativos Tradicionais, obtidos a partir de formulações matemáticas, razões e proporções. Neste subgrupo podem ser distinguidos ainda indicadores cujos parâmetros de controle para sua avaliação são fixos (ver, por exemplo, Indicador 1.1.2 na Tabela 8.5 e no Anexo E) e aqueles cujos parâmetros devem ser calculados antecipadamente, segundo padrões pré-estabelecidos ou legislação específica, entre outros, de forma a permitir a avaliação do indicador (ver, por exemplo, Indicador 1.2.3 na Tabela 8.6 e no Anexo E);

- Subgrupo 2 - Indicadores Quantitativos Espaciais, que referem-se a localização geográfica, distribuição espacial, extensão ou abrangência de um determinado fenômeno. São obtidos com auxílio de ferramentas de desenho (manual ou assistido por computador) ou sistemas de informações geográficas (ver, por exemplo, Indicador 1.1.1 apresentado na Tabela 8.7 e no Anexo E).

Para os Indicadores Quantitativos são definidas Escalas de Avaliação baseadas, em sua maioria, em funções lineares. Assim, a normalização do score obtido para o indicador é feita através da verificação do valor correspondente diretamente na escala, ou no caso de valores intermediários daqueles disponíveis na escala, através de interpolação. 
Nos casos em que o indicador apresenta uma contribuição negativa para a mobilidade sustentável, ou seja, quanto maior o seu valor, menor seu score, a escala de avaliação foi adequada de forma a refletir esta característica do indicador. Além disso, em situações onde são definidos limites inferior ou superior, a partir dos quais o indicador passa a contribuir de forma negativa para mobilidade sustentável, estes foram indicados nas Escalas de Avaliação (ver, por exemplo, indicador 7.5.3 na Tabela 8.8 e no Anexo E).

Exemplos de Escalas de Avaliação para os Indicadores Quantitativos são mostrados nas Tabelas a 8.5 a 8.8 .

Tabela 8.5: Escala de Avaliação para o Indicador 1.1.2 - Transporte público para pessoas com necessidades especiais.

\begin{tabular}{ll}
\hline Score & $\begin{array}{l}\text { Valores de Referência } \\
\text { Porcentagem da frota municipal de ônibus urbano adaptada para pessoas } \\
\text { com necessidades especiais ou restrições de mobilidade }\end{array}$ \\
\hline 1,00 & $\begin{array}{l}100 \% \text { (ou há serviços especiais para transporte de pessoas com } \\
\text { necessidades especiais) }\end{array}$ \\
\hline 0,75 & $75 \%$ \\
\hline 0,50 & $50 \%$ \\
\hline 0,25 & $25 \%$ \\
\hline 0,00 & $\begin{array}{l}0 \text { (ou não há serviços especiais para transporte de pessoas com } \\
\text { necessidades especiais) }\end{array}$ \\
\hline
\end{tabular}

Tabela 8.6: Escala de Avaliação para o Indicador 1.2.3 - Vagas de estacionamento para pessoas com necessidades especiais.

\begin{tabular}{ll}
\hline Score & Valores de Referência \\
1,00 & $\begin{array}{l}\text { Há disponibilidade de vagas para pessoas com necessidades especiais em } \\
\text { número superior aos valores estabelecidos por lei específica (ou indicados } \\
\text { na NBR 9050) e estas encontram-se devidamente sinalizadas e } \\
\text { dimensionadas }\end{array}$ \\
\hline $\begin{array}{l}\text { Há disponibilidade de vagas para pessoas com necessidades especiais em } \\
\text { número superior aos valores estabelecidos por lei específica (ou indicados } \\
\text { na NBR 9050), porém as vagas estão mal sinalizadas ou não apresentam } \\
\text { as dimensões adequadas }\end{array}$ \\
\hline $\begin{array}{l}\text { Há disponibilidade de vagas para pessoas com necessidades especiais em } \\
\text { número igual aos valores estabelecidos por lei específica (ou indicados na }\end{array}$ \\
$\begin{array}{l}\text { NBR 9050) e estas encontram-se devidamente sinalizadas e } \\
\text { dimensionadas }\end{array}$ \\
$\begin{array}{l}\text { Há disponibilidade de vagas para pessoas com necessidades especiais em } \\
\text { número igual aos valores estabelecidos por lei específica (ou indicados na }\end{array}$ \\
$\begin{array}{l}\text { NBR 9050), porém as vagas estão mal sinalizadas ou não apresentam as } \\
\text { dimensões adequadas }\end{array}$ \\
\hline $\begin{array}{l}\text { Há disponibilidade de vagas para pessoas com necessidades especiais em } \\
\text { número inferior aos valores estabelecidos por lei específica (ou indicados } \\
\text { na NBR 9050) }\end{array}$ \\
\hline $\begin{array}{l}\text { Não há disponibilidade de vagas para pessoas com necessidades especiais } \\
\text { em estacionamentos públicos }\end{array}$ \\
\hline
\end{tabular}


Tabela 8.7: Escala de Avaliação para o Indicador 1.1.1 - Acessibilidade ao transporte público.

\begin{tabular}{ll}
\hline Score & $\begin{array}{l}\text { Valores de Referência } \\
\text { Porcentagem da população urbana residente na área de cobertura de } \\
\text { pontos de acesso ao transporte público }\end{array}$ \\
\hline 1,00 & $100 \%$ \\
\hline 0,75 & $77,5 \%$ \\
\hline 0,50 & $55 \%$ \\
\hline 0,25 & $32,5 \%$ \\
\hline 0,00 & Até $10 \%$ \\
\hline
\end{tabular}

Tabela 8.8: Escala de Avaliação para o Indicador 7.5.3 - Densidade populacional urbana.

\begin{tabular}{ll}
\hline Score & $\begin{array}{l}\text { Valores de Referência } \\
\text { Densidade populacional urbana }\end{array}$ \\
\hline 1,00 & 45.000 habitantes $/ \mathrm{km}^{2}$ ou 450 habitantes $/ \mathrm{ha}$ \\
\hline 0,75 & 35.000 habitantes $/ \mathrm{km}^{2}$ ou 350 habitantes $/$ ha \\
\hline 0,50 & 25.000 habitantes $/ \mathrm{km}^{2}$ ou 250 habitantes $/$ ha \\
\hline 0,25 & 15.000 habitantes $/ \mathrm{km}^{2}$ ou 150 habitantes $/$ ha \\
\hline 0,00 & $\begin{array}{l}\text { Até } 5.000 \text { habitantes } / \mathrm{km}^{2} \text { ou } 50 \text { habitantes } / \text { ha ou superior a } \\
\text { 45.00 habitantes } / \mathrm{km}^{2} \text { ou } 450 \text { habitantes } / \mathrm{ha}\end{array}$ \\
\hline
\end{tabular}

Os Indicadores Qualitativos são obtidos com base na avaliação de critérios qualitativos relacionados a um determinado fenômeno. Neste caso, em função da dificuldade em se mensurar determinados indicadores através de dados Quantitativos, decorrentes da inexistência, indisponibilidade ou forma de agregação dos dados, foram definidas Escalas de Avaliação com base em critérios qualitativos para indicadores de natureza quantitativa. Incluem os seguintes subgrupos de indicadores:

- Subgrupo 1 - Indicadores Qualitativos Tradicionais, cujas Escalas de Avaliação apresentam diferentes níveis qualitativos relacionados a um determinado fenômeno (ver, por exemplo, Indicador no Anexo E). Em algumas situações, representam estágios de desenvolvimento de uma ação ou fenômeno (ver por exemplo, Indicador 4.1.1 na Tabela 8.9 e no Anexo E).

- Subgrupo 2 - Indicadores de Presença/Ausência, medidos em função da presença ou ausência de determinados fatores relacionados ao fenômeno em questão (ver, por exemplo, Indicador 1.4.1 na Tabela 8.10 e no Anexo E).

No caso dos Indicadores Qualitativos, a normalização é feita associando-se diretamente os resultados da avaliação qualitativa do indicador ao respectivo score normalizado.

Exemplos de Escalas de Avaliação para os Indicadores Qualitativos são mostrados nas Tabelas 8.9 a 8.10. 
Tabela 8.9: Escala de Avaliação para o Indicador 4.1.1 - Integração entre níveis de governo.

\begin{tabular}{ll}
\hline Score & $\begin{array}{l}\text { Valores de Referência } \\
\text { As ações integradas são }\end{array}$ \\
\hline 1,00 & Muito freqüentes, envolvendo os governos municipal, estadual e federal \\
\hline 0,75 & Freqüentes, envolvendo os governos municipal, estadual e federal \\
\hline 0,50 & Pouco freqüentes, envolvendo os governos municipal, estadual e federal \\
\hline 0,25 & Pouco freqüentes, envolvendo somente os governos municipal e estadual \\
\hline 0,00 & $\begin{array}{l}\text { As ações integradas entre os governos municipal, estadual e federal são } \\
\text { raras no município }\end{array}$ \\
\hline
\end{tabular}

Tabela 8.10: Escala de Avaliação para o Indicador 1.4.1 - Ações para acessibilidade universal.

\begin{tabular}{ll}
\hline Score & Valores de Referência \\
\hline 1,00 & $\begin{array}{l}\text { O município dispõe de legislação específica, normas técnicas, } \\
\text { recomendações, programas de iniciativa pública e campanhas de educação e } \\
\text { sensibilização para acessibilidade universal }\end{array}$ \\
\hline 0,75 & $\begin{array}{l}\text { O município dispõe de legislação específica, normas técnicas, } \\
\text { recomendações e ações ou programas de iniciativa pública para } \\
\text { acessibilidade universal }\end{array}$ \\
\hline 0,50 & $\begin{array}{l}\text { O município dispõe de legislação específica, normas técnicas e } \\
\text { recomendações para acessibilidade universal }\end{array}$ \\
\hline 0,25 & O município dispõe de legislação específica sobre acessibilidade universal \\
\hline 0,00 & $\begin{array}{l}\text { O município não dispõe de qualquer ação ou instrumento para acessibilidade } \\
\text { universal }\end{array}$ \\
\hline
\end{tabular}

Os Indicadores Mistos são avaliados combinando a análise de critérios quantitativos e qualitativos. A Tabela 8.11 apresenta um exemplo de Escala de Avaliação para um indicador Misto.

Para a avaliação dos indicadores Mistos é necessário o cálculo de um valor numérico baseado em dados provenientes de levantamentos ou pesquisas específicas, além da avaliação de um critério qualitativo a ele associado. De posse destes dois fatores, é associado o respectivo score normalizado ao indicador, indicado na Escala de Avaliação.

Tabela 8.11: Escala de Avaliação para o Indicador 6.1.1 - Extensão e conectividade da rede viária.

\begin{tabular}{ll}
\hline Score & Valores de Referência \\
\hline 1,00 & $\begin{array}{l}\text { Mais de 25\% do sistema viário urbano apresenta ciclovias ou ciclofaixas e a } \\
\text { rede apresenta alta conectividade }\end{array}$ \\
\hline 0,75 & $\begin{array}{l}\text { Mais de 25\% do sistema viário urbano apresenta ciclovias ou ciclofaixas, } \\
\text { porém, a rede apresenta baixa conectividade }\end{array}$ \\
\hline 0,50 & $\begin{array}{l}\text { Até } 25 \% \text { do sistema viário urbano apresenta ciclovias ou ciclofaixas e a } \\
\text { rede apresenta alta conectividade }\end{array}$ \\
\hline 0,25 & $\begin{array}{l}\text { Até } 25 \% \text { do sistema viário urbano apresenta ciclovias ou ciclofaixas, porém, } \\
\text { a rede apresenta baixa conectividade }\end{array}$ \\
\hline 0,00 & Não há no município nenhum trecho de ciclovias ou ciclofaixa \\
\hline
\end{tabular}

Alguns aspectos fundamentais devem ser destacados em relação às Escalas de Avaliação propostas neste trabalho. Em primeiro lugar, estas foram definidas para estabelecer um 
parâmetro de referência para os indicadores, proporcionando uma primeira avaliação a respeito da situação medida pelo mesmo. Além disso, estabelecem um referencial para análise comparativa de cidades ou regiões, permitindo obter valores médios, desvios padrão, entre outras medidas, em relação aos parâmetros pré-estabelecidos para os indicadores. No entanto, não é obrigatória sua adoção para cálculo do IMUS em qualquer município ou Região Metropolitana que deseja utilizá-lo como ferramenta de monitoração da mobilidade urbana, sendo sugerida sua aplicação para aqueles que ainda não tenham definido metas ou parâmetros de referência específicos.

Os valores sugeridos aqui foram propostos com base na revisão da literatura, em padrões nacionais e internacionais, em experiências já difundidas no desenvolvimento de índices e indicadores urbanos ou a partir da observação de valores médios para as onze cidades brasileiras pesquisadas. No entanto, o ideal é que estes valores sejam definidos pelos próprios municípios, com base em metas e objetivos definidos na ocasião da formulação de planos de desenvolvimento urbano ou estratégias para a mobilidade sustentável, ou com base em normas ou legislação específica. Desta forma, os valores sugeridos podem ser adaptados a realidade local, aos recursos disponíveis e às características do sistema de mobilidade da cidade analisada.

Além da normalização dos scores obtidos para os indicadores, a Escala de Avaliação pode também ser utilizada para a análise expedita dos indicadores. Em situações de inexistência ou indisponibilidade de dados, que impeçam o cálculo preciso do indicador, o score poderá ser obtido por meio de avaliação expedita, feita por profissional ou gestor com amplo conhecimento do sistema de mobilidade urbana.

Neste caso, devem ser apresentados ao especialista (ou especialistas) responsáveis pela avaliação, as definições de cada indicador, bem como suas respectivas Escalas de Avaliação. Ao ser questionado a respeito do indicador, um especialista poderá indicar, com base em sua experiência e conhecimento, o respectivo score para o mesmo. Neste sentido, ele poderá optar tanto pelos valores já normalizados apresentados na escala (entre 0,00 e $1,00)$ ou informar os valores que representam a avaliação do indicador expressos em sua unidade de medida. Estes valores, no entanto, deverão ser normalizados posteriormente para cálculo dos valores global e setorial do IMUS. 


\subsection{Agregação dos Critérios e Planilha de Cálculo do IMUS}

Uma vez normalizados para valores entre 0,00 e 1,00, a etapa seguinte consiste na agregação dos indicadores de forma a obter os valores para o índice global e setoriais do IMUS.

Conforme descrito no item 6.3.5, o método de agregação do IMUS consiste em uma combinação linear ponderada, onde os critérios são combinados através de uma média ponderada, permitindo a compensação entre os mesmos. Esta combinação é feita através das Equações 6.1 e 6.2, onde a primeira é aplicada para se obter o valor global do IMUS (considerando o peso do Indicador e do Domínio e Tema a que pertence) e a segunda, aplicada para se obter os valores setoriais do IMUS (considerando o peso do Indicador e do Domínio e Tema a que pertence, e de cada uma das Dimensões da sustentabilidade).

Para facilitar o processo de cálculo, foi desenvolvida uma planilha eletrônica contendo a estrutura hierárquica do IMUS, o sistema de pesos para os critérios, formulações para a normalização dos scores dos indicadores segundo as Escalas de Avaliação e formulações para obtenção dos resultados global e setoriais do índice, segundo as Equações 6.1 e 6.2. A planilha permite ainda a visualização dos resultados por meio de gráficos gerados automaticamente.

A Figura 8.4 mostra a estrutura da planilha de cálculo do IMUS. A planilha eletrônica consta no Anexo H - "Planilha de Cálculo do IMUS" deste documento. Nas linhas 3 a 89 da planilha encontram-se os 87 Indicadores que compõem o IMUS, agregados nos Domínios e Temas. O conteúdo de cada coluna, bem como a descrição das operações realizadas é feita a seguir:

- Coluna A - Domínios que compõem a estrutura hierárquica do IMUS;

- Coluna B - Peso dos Domínios, calculados segundo procedimentos apresentados nos itens 6.3 .3 e 8.4;

- Coluna C - Temas que compõem a estrutura hierárquica do IMUS;

- Coluna D - Coluna onde é indicada a "Execução" do Tema para cálculo do IMUS, através dos valores 0 e 1 preenchidos automaticamente. A "Execução" do Tema está associada ao cálculo de quaisquer um dos Indicadores que o compõem. Ou seja, caso pelo menos um dos indicadores que compõem o respectivo Tema possa ser calculado, nesta coluna aparecerá automaticamente o valor 1, implicando assim na consideração do peso do Tema para cálculo dos valores global e setoriais IMUS. Caso nenhum indicador possa ser calculado, aparecerá o valor 0 para o Tema, implicando na 
desconsideração do seu respectivo peso. No final desta coluna é possível verificar o total de Temas considerados para cálculo do IMUS para a cidade analisada;

- Coluna E - Esta coluna está associada à Coluna D. Uma vez possível a "Execução" do Tema conforme critérios mencionados acima, implicando automaticamente na atribuição do valor 1 na células associadas ao mesmo, na Coluna $E$ aparecerá automaticamente o peso atribuído ao Tema, conforme resultados obtidos a partir do Painel de Especialistas (Tabela 8.4). Caso o Tema não possa ser executado, nesta coluna aparecerá novamente o valor 0 para o peso do Tema;

- Coluna F - Nesta coluna é feita automaticamente a redistribuição dos pesos dos Temas, em situações onde não será possível a "Execução" de pelo menos um dos Temas que compõem o Domínio considerado. Neste caso o cálculo é feito de forma que o somatório dos pesos dos Temas por Domínio mantenha-se igual a 1, e que sejam mantidas as proporções dos pesos verificadas a partir dos resultados do Painel de Especialistas. Caso todos os Temas possam ser considerados, nesta coluna irão se repetir os pesos obtidos através do painel;

- Coluna G - Identificador (ID) dos Indicadores que compõem o IMUS;

- Coluna H - Descrição dos Indicadores que compõem o IMUS;

- Coluna I - Coluna onde é indicada a "Execução" do Indicador para cálculo do IMUS, através dos valores 0 e 1, preenchidos automaticamente. A "Execução" do Indicador está associada à obtenção de um score para o mesmo, seja através do método de cálculo tradicional ou através da análise expedita. Uma vez inserido o valor do score na Coluna K, a respectiva célula da Coluna I é preenchida automaticamente com o valor 1. Caso não seja inserido nenhum valor na Coluna $\mathrm{K}$, automaticamente a célula é preenchida com o valor 0 . No final desta coluna é possível verificar o total de Indicadores considerados para Cálculo do IMUS para a cidade analisada;

- Coluna J - Pesos dos Indicadores obtidos automaticamente, assim que inserido o seu respectivo score na Coluna K. O cálculo destes pesos é feito de modo que a soma por Tema seja igual a 1. Neste caso, se não for atribuído nenhum score para o Indicador, seu peso será igual a 0,00;

- Coluna K - Esta é a única coluna que deve ser preenchida na Planilha de Cálculo do IMUS, uma vez que as demais são preenchidas automaticamente. Nela são inseridos os valores dos scores dos indicadores, substituindo a indicação "Vazio" constante na célula, conforme a unidade de medida indicada no Anexo E - "Guia de Indicadores do IMUS" e na Coluna L. A correta inserção dos valores nesta coluna permite o desenvolvimento adequado de todo o processo de cálculo do IMUS;

- Coluna L - Indicação das unidades de medidas dos Indicadores que compõem o IMUS; 
- Coluna M - Nesta coluna é feita automaticamente a Normalização dos scores dos indicadores, para valores entre 0,00 e 1,00. Para isso foram inseridas fórmulas baseadas nos valores e funções que representam a Escala de Avaliação proposta para cada indicador. Nos casos onde é definido um limite para o indicador, a partir do qual este passa a contribuir de forma negativa para a mobilidade sustentável, a planilha também permite a normalização de seu score, levando em consideração esta variação no comportamento do indicador. No caso de variação dos valores de referência destas escalas, será necessária a adaptação desta coluna de forma a permitir a correta normalização dos scores dos indicadores. Caso tenha sido inserido na Coluna K um score incompatível com a unidade de medida do Indicador, ou valores fora dos limites mínimo e máximo indicados como valores de referência na Escala de Avaliação, nesta coluna irá aparecer a mensagem "ERRO". Isso implica na revisão do valor inserido, uma vez que não é possível obter os resultados global e setoriais do IMUS se qualquer uma das células estiver apresentando esta mensagem;

- Coluna N - Coluna auxiliar para cálculo do índice que mostra o score normalizado máximo que pode ser obtido para o Indicador (neste caso, igual a 1);

- Coluna O - Pesos dos Temas para a Dimensão Social da sustentabilidade, obtidos a partir do Painel de Especialistas;

- Coluna P - Nesta coluna é obtido o resultado do Indicador para a Dimensão Social, a partir do produto de seus pesos (Domínio, Tema e Indicador e peso da Dimensão) e score normalizado. No final da mesma é obtido o somatório dos valores, que representa o valor absoluto do IMUS para a respectiva Dimensão (IMUSs $S_{S}$ ), conforme Equação 6.2;

- Coluna Q - Pesos dos Temas para a Dimensão Econômica da sustentabilidade, obtidos a partir do Painel de Especialistas; 


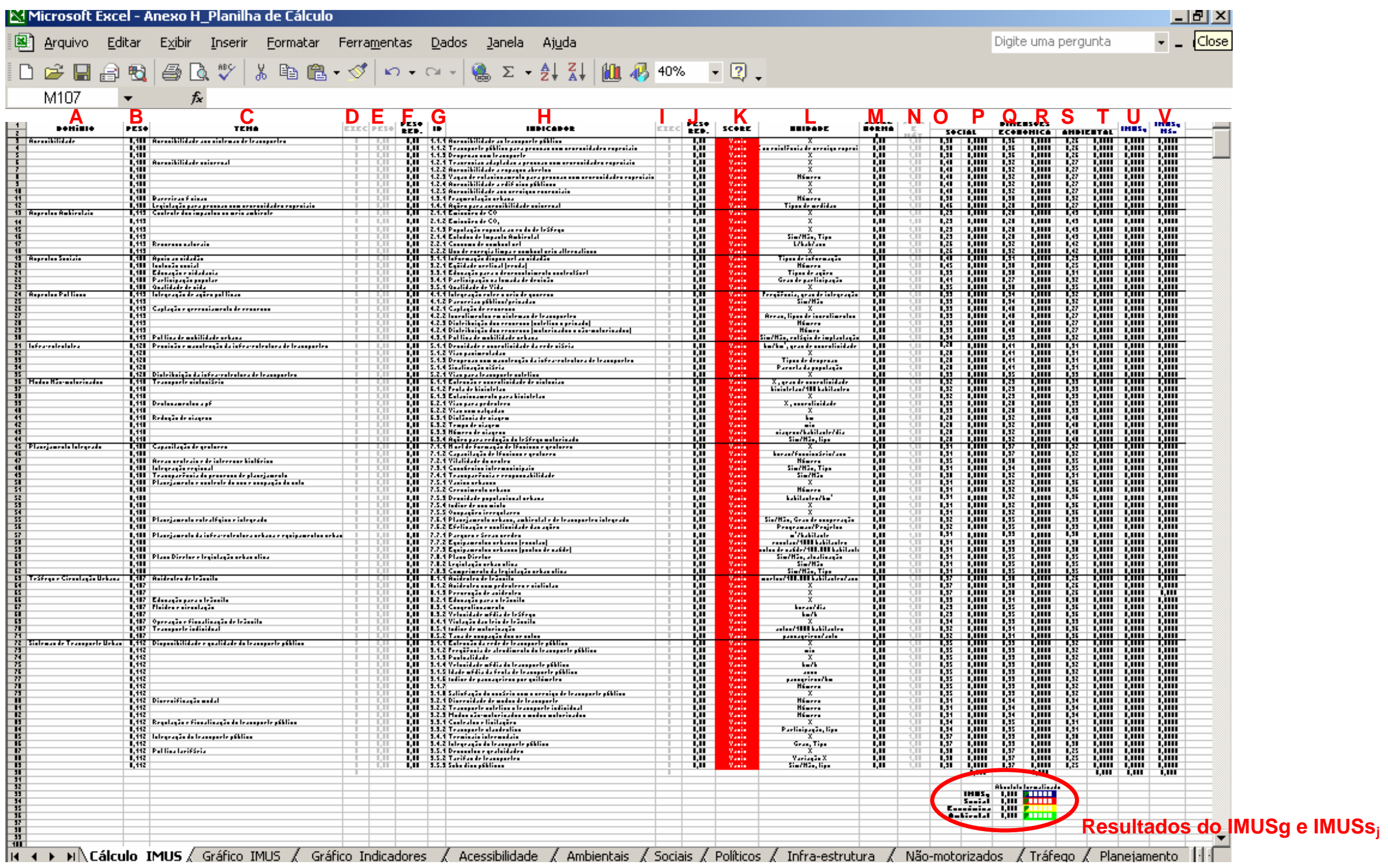

Figura 8.4: Estrutura da Planilha de Cálculo do IMUS. 
- Coluna R - Nesta coluna é obtido o resultado do Indicador para a Dimensão Econômica, a partir do produto de seus pesos (Domínio, Tema e Indicador e peso da Dimensão) e score normalizado. No final da mesma é obtido o somatório dos valores, que representa o valor absoluto do IMUS para a respectiva Dimensão $\left(\mathrm{IMUSS}_{\mathrm{E}}\right)$, conforme Equação 6.2;

- Coluna S - Pesos dos Temas para a Dimensão Ambiental da sustentabilidade, obtidos a partir do Painel de Especialistas;

- Coluna T - Nesta coluna é obtido o resultado do Indicador para a Dimensão Ambiental, a partir do produto de seus pesos (Domínio, Tema e Indicador e peso da Dimensão) e score normalizado. No final da mesma é obtido o somatório dos valores, que representa o valor absoluto do IMUS para a respectiva Dimensão (IMUSS $\mathrm{A}_{\mathrm{A}}$ ), conforme Equação 6.2;

- Coluna U - Resultado do IMUS para o Indicador, ou seja, parcela que o mesmo representa para o valor global do Índice. No final desta coluna é obtido o somatório dos valores, que representa o valor absoluto global do IMUS (IMUSg), conforme Equação 6.1;

- Coluna V - Coluna que apresenta o valor absoluto máximo que pode ser atingido pelo Indicador para a avaliação do IMUS, considerando seu peso, os pesos do Domínio e Tema a que pertence (já redistribuídos, caso algum Indicador ou Tema não tenha sido avaliado) e o score máximo que pode ser obtido (para todos os casos, igual a 1,00). No final da coluna é obtido o valor máximo que o índice poderia alcançar, em função do número de Indicadores avaliados. Este valor é utilizado para se obter o valor normalizado do IMUSg e IMUSs.

$\mathrm{Na}$ parte inferior da planilha são apresentados os valores absoluto e corrigido para o IMUSg e IMUSsj. Os valores corrigidos para o IMUSsj representam a parcela que cada Dimensão contribui para o valor global do índice. Com base nos valores corrigidos é gerado automaticamente um gráfico que mostra o valor global do IMUS e a parcela referente a cada Dimensão. O segundo gráfico gerado automaticamente apresenta os scores normalizados obtidos para todos os indicadores calculados. Os demais gráficos mostram os resultados globais para os indicadores, classificados por Domínio.

\subsection{Guia de Indicadores de Mobilidade}

A fim de orientar o cálculo do IMUS, foi elaborado um guia com informações para a elaboração dos oitenta e sete indicadores que o compõem, bem como todos os procedimentos de normalização dos critérios, incluindo as Escalas de Avaliação. As 
informações para cada um dos indicadores apresentam-se organizadas conforme a estrutura apresentada a seguir:

\section{DOMÍNIO Domínio, conforme estrutura do IMUS}

TEMA Tema, conforme estrutura do IMUS

INDICADOR (ID) Identificação do Indicador

\section{A. Definição}

Descrição do indicador.

\section{B. Unidade de Medida}

Unidade de apresentação do indicador.

\section{Referências}

Sistemas nacionais e internacionais de referência para desenvolvimento do indicador, fontes de informação complementares e exemplos de aplicação.

\section{Relevância}

Contextualização e importância do indicador para a avaliação da Mobilidade Urbana Sustentável.

\section{E. Contribuição}

A contribuição do indicador para a avaliação da Mobilidade Urbana Sustentável é identificada conforme as seguintes possibilidades:

- Maior/Melhor - (+)

- Sim/Melhor - (+)

- Menor/Melhor - (-)

- Não/Melhor - (-)

\section{F. Pesos}

Pesos para os critérios obtidos segundo a avaliação do Painel de Especialistas. Estes pesos são combinados de forma a evidenciar a contribuição (Global e Setorial) do indicador para o resultado do IMUS. Os pesos para cada Indicador, seu respectivo Tema e Domínio são apresentados conforme a Tabela 8.12. 
Tabela 8.12: Exemplo de apresentação dos pesos para um dos critérios do IMUS.

\begin{tabular}{|c|c|c|c|c|c|c|c|c|c|}
\hline \multirow{2}{*}{ DOMÍNIO } & \multirow{2}{*}{ PESO } & DIN & ENSÕE & & \multirow{2}{*}{ TEMA } & \multirow{2}{*}{ PESO } & \multirow{2}{*}{ ID } & \multirow{2}{*}{ INDICADOR } & \multirow{2}{*}{ PESO } \\
\hline & & $\mathrm{s}$ & $E$ & A & & & & & \\
\hline ACESSIBILIDADE & 0,108 & 0,38 & 0,36 & 0,26 & Acessiblidade aos sistemas de transportes & 0,29 & 1.1.1 & Acessibilidade ao transporte público & 0,33 \\
\hline
\end{tabular}

Os pesos Global e Setorial são assim calculados:

- Peso Global - Agregação do peso do Indicador, do peso do Tema e do peso do Domínio;

- Peso Setorial da Dimensão Social - Agregação do peso do Indicador, do peso do Tema, do peso para a Dimensão Social e do peso do Domínio;

- Peso Dimensão Econômica - Agregação do peso do Indicador, do peso do Tema, do peso para a Dimensão Econômica e do peso do Domínio;

- Peso Setorial da Dimensão Ambiental - Agregação do peso do Indicador, do peso do Tema, do peso para a Dimensão Ambiental e do peso do Domínio.

\section{G. Dados de Base}

Dados e informações necessárias para cálculo do indicador e suas respectivas definições e unidades de medida.

\section{H. Fontes de Dados}

Indicação de prováveis fontes de dados necessárias para desenvolvimento do indicador. Identificação de sistemas nacionais, estaduais e municipais, agências, instituições, órgãos de pesquisa, entre outros, responsáveis pela coleta e divulgação de dados estatísticos e demais informações utilizadas na construção do indicador.

\section{Método de Cálculo}

Instruções para desenvolvimento do indicador, incluindo fórmulas matemáticas, ferramentas de apoio, e instruções para o tratamento dos dados, sempre que necessário. Incluem procedimentos para avaliação qualitativa, conforme tipologia do indicador.

\section{J. Normalização e Avaliação}

Neste item é apresentada a Escala de Avaliação para o Indicador, com os respectivos valores de referência.

No caso de avaliação expedita, sem que seja feito o cálculo efetivo do Indicador, a avaliação, com base na escala proposta, deve ser feita por técnico ou gestor com conhecimento sobre o sistema de mobilidade da cidade analisada. Deve refletir, com a 
maior fidelidade possível, as características do sistema e dos elementos analisados. Os resultados obtidos através da avaliação substituem, portanto, os valores dos indicadores que não puderam ser obtidos pelo método principal (definido no item I).

No caso do indicador ter sido calculado com base em dados numéricos e necessitar ser normalizado para valores entre 0,00 e 1,00, a Escala de Avaliação deve ser usada como referência para definição dos valores mínimo e máximo necessários para obtenção do score normalizado, ou mesmo para a associação direta do score obtido para o indicador, procedimento que estará indicado no Método de Cálculo.

\subsection{Análise da Estrutura do IMUS}

A análise da hierarquia de critérios do IMUS deve considerar, primeiramente, aspectos relacionados à obtenção dos dados sobre os quais se baseou a estrutura proposta e o processo de filtragem e agregação dos mesmos.

A estrutura hierárquica proposta para o índice buscou refletir as questões fundamentais para a promoção do conceito de mobilidade sustentável no país, uma vez que foi obtida com base em pesquisa realizada com técnicos e gestores municipais, que conhecem e vivenciam os problemas de planejamento e gestão da mobilidade urbana de algumas das principais cidades brasileiras. Assim, a hierarquia de critérios representa as preocupações específicas de capitais de estado, bem como suas características espaciais, econômicas e sociais, além das características de seus sistemas de mobilidade. Deve-se, portanto, avaliar sua aplicabilidade para municípios de menor porte, com estrutura institucional e sistemas de mobilidade distintos, propondo eventualmente adaptações para melhor adequá-lo a estas situações. Além disso, os dados obtidos estão relacionados a um contexto temporal específico, podendo ser reavaliados em situações futuras, em função de mudanças de ordem econômica, social ou ambiental ou do sistema de mobilidade urbana.

Já o processo de agregação dos dados procurou estabelecer uma estrutura que contemplasse todos os elementos fundamentais identificados nas cidades pesquisadas. Assim, destacaram-se deste processo nove principais Domínios que devem ser considerados na avaliação da mobilidade urbana em cidades brasileiras, os quais se constituíram na base para o desenvolvimento da estrutura hierárquica do IMUS.

Uma vez que critérios semelhantes receberam denominações distintas em cada região, o processo de agregação buscou identificar e detalhar os conceitos que originaram cada critério, tanto para o nível dos Domínios como para o nível dos Temas, e assim identificar aqueles que expressavam idéias semelhantes, de forma a não se repetirem. Ainda que este 
processo tenha sido desenvolvido de forma sistemática e que todas as suas etapas tenham sido documentadas detalhadamente (ver ANEXO C - "Construção da Hierarquia de Critérios"), este é um processo dependente da forma como a pesquisadora compreende a questão.

Neste sentido, durante o processo de agregação dos dados, a pesquisadora se valeu de suas percepções e registros feitos durante a pesquisa empreendida nas onze cidades brasileiras para a construção de uma hierarquia, visando refletir com maior fidelidade os aspectos discutidos. Isso pode implicar em hierarquias de critérios com feições distintas e elementos que as compõem identificados de forma diferente, dependendo da forma como os dados são trabalhados por cada indivíduo. No entanto, cuidado especial foi dado para a manutenção das idéias-chave expressas na coleta de dados, relacionadas ao modo como os vários elementos são percebidos pelos técnicos e especialistas das cidades investigadas.

Cabe destacar ainda que, os mesmos cuidados tomados no desenvolvimento da hierarquia de Domínios e Temas que compõem o índice foram tomados na seleção de Indicadores. Ainda que experiências nacionais e internacionais tenham sido observadas para a seleção, as medidas que compõem o índice refletem sobretudo o enfoque dado aos diferentes temas abordados nas onze cidades onde a atividade de capacitação foi desenvolvida.

\subsection{Análise dos Indicadores do IMUS}

A análise dos Indicadores que compõem o IMUS é feita através da análise das diferentes tipologias identificadas, as quais foram descritas no item 8.5. A Tabela 8.13 apresenta os indicadores classificados nas tipologias identificadas no item 8.5 e a Figura 8.5 apresenta a proporção de indicadores classificados em cada tipologia. 
Tabela 8.13: Indicadores do IMUS conforme tipologia.

\section{Indicadores Quantitativos}

\begin{tabular}{|c|c|c|}
\hline & & Indicadores Quantitativos \\
\hline \multirow{48}{*}{ Subgrupo 1} & 1.1 .2 & Transporte público para pessoas com necessidades especiais \\
\hline & 1.1 .3 & Despesas com transporte \\
\hline & 1.2 .1 & Travessias adaptadas a pessoas com necessidades especiais \\
\hline & 1.2 .3 & Vagas de estacionamento para pessoas com necessidades especiais \\
\hline & 1.2 .4 & Acessibilidade a edifícios públicos \\
\hline & 2.1 .1 & Emissões de CO \\
\hline & 2.2 .1 & Consumo de combustível \\
\hline & 2.2 .1 & Uso de energia limpa e combustíveis alternativos \\
\hline & 2.2 .2 & Emissões de CO2 \\
\hline & 3.2 .1 & Eqüidade vertical (renda) \\
\hline & 3.5 .1 & Qualidade de Vida \\
\hline & 4.2.1 & Captação de recursos \\
\hline & 4.2 .3 & Distribuição dos recursos (público x privado) \\
\hline & 4.2 .4 & Distribuição dos recursos (motorizados x não-motorizados) \\
\hline & 5.1 .4 & Sinalização viária \\
\hline & 6.1 .2 & Frota de bicicletas \\
\hline & 6.1 .3 & Estacionamento para bicicletas \\
\hline & 6.2 .2 & Vias com calçadas \\
\hline & 6.3 .2 & Tempo de viagem \\
\hline & 6.3 .3 & Número de viagens \\
\hline & 7.1 .1 & Nível de formação de técnicos e gestores \\
\hline & 7.1 .2 & Capacitação de técnicos e gestores \\
\hline & 7.2 .1 & Vitalidade do centro \\
\hline & 7.5 .4 & Índice de uso misto \\
\hline & 7.5 .5 & Ocupações irregulares \\
\hline & 7.7 .2 & Equipamentos urbanos (escolas) \\
\hline & 7.7 .3 & Equipamentos urbanos (hospitais) \\
\hline & 8.1 .1 & Acidentes de trânsito \\
\hline & 8.1 .2 & Acidentes com pedestres e ciclistas \\
\hline & 8.1 .3 & Prevenção de acidentes \\
\hline & 8.2 .1 & Educação para o trânsito \\
\hline & 8.3 .1 & Congestionamento \\
\hline & 8.3 .2 & Velocidade média de tráfego \\
\hline & 8.4 .1 & Violação das leis de trânsito \\
\hline & 8.5 .1 & Índice de motorização \\
\hline & 8.5 .2 & Taxa de ocupação dos veículos \\
\hline & 9.1 .2 & Freqüência de atendimento do transporte público \\
\hline & 9.1 .3 & Pontualidade \\
\hline & 9.1 .4 & Velocidade média do transporte público \\
\hline & 9.1 .5 & Idade média da frota de transporte público \\
\hline & 9.1 .6 & Índice de passageiros por quilômetro \\
\hline & 9.1 .8 & Satisfação do usuário com o serviço de transporte público \\
\hline & 9.2 .1 & Diversidade de modos de transporte \\
\hline & 9.2.2. & Transporte público $\mathrm{x}$ transporte privado \\
\hline & 9.2 .3 & Modos motorizados x modos não-motorizados \\
\hline & 9.3 .1 & Contratos e licitações \\
\hline & 9.4 .1 & Terminais intermodais \\
\hline & 9.5 .1 & Descontos e gratuidades \\
\hline \multirow[t]{5}{*}{ Subgrupo 2} & 1.1 .1 & Acessibilidade ao transporte público \\
\hline & 1.2 .2 & Acessibilidade a espaços abertos \\
\hline & 1.2 .5 & Acessibilidade aos serviços essenciais \\
\hline & 1.3 .1 & Fragmentação urbana \\
\hline & 2.1 .3 & População exposta ao ruído de tráfego \\
\hline
\end{tabular}




\begin{tabular}{|c|c|c|}
\hline & 5.1 .1 & Densidade e conectividade da rede viária \\
\hline & 5.1 .2 & Vias pavimentadas \\
\hline & 5.2 .1 & Vias para transporte coletivo \\
\hline & 6.3 .1 & Distância de viagem \\
\hline & 7.5 .1 & Vazios urbanos \\
\hline & 7.5 .2 & Crescimento urbano \\
\hline & 7.5 .3 & Densidade populacional urbana \\
\hline & 7.7 .1 & Parques e áreas verdes \\
\hline & 9.1 .1 & Extensão da rede de transporte público \\
\hline & & Indicadores Qualitativos \\
\hline \multirow{13}{*}{ Subgrupo 1} & 2.1 .4 & Estudos de Impacto Ambiental \\
\hline & 3.4 .1 & Participação na tomada de decisão \\
\hline & 4.1 .1 & Integração entre níveis de governo \\
\hline & 5.1 .3 & Despesas com manutenção da infra-estrutura de transportes \\
\hline & 7.3 .1 & Consórcios intermunicipais \\
\hline & 7.6 .1 & Planejamento urbano, ambiental e de transportes integrado \\
\hline & 7.6 .2 & Efetivação e continuidade das ações \\
\hline & 7.8 .1 & Plano Diretor \\
\hline & 7.8 .3 & Cumprimento da legislação urbanística \\
\hline & 8.8 .2 & Legislação urbanística \\
\hline & 9.3 .2 & Transporte clandestino \\
\hline & 9.4 .2 & Integração do transporte público \\
\hline & 9.5 .3 & Subsídios públicos \\
\hline \multirow{8}{*}{ Subgrupo 2} & 1.4 .1 & Ações para acessibilidade universal \\
\hline & 3.1 .1 & Informação disponível ao cidadão \\
\hline & 3.3 .1 & Educação para o desenvolvimento sustentável \\
\hline & 4.1 .2 & Parcerias público/privadas \\
\hline & 4.2 .2 & Investimentos em sistemas de transportes \\
\hline & 4.3 .1 & Política de mobilidade urbana \\
\hline & 6.3 .4 & Ações para redução do tráfego motorizado \\
\hline & 7.4 .1 & Transparência e responsabilidade \\
\hline \multirow{5}{*}{-} & \multicolumn{2}{|r|}{ Indicadores Mistos } \\
\hline & 6.1 .1 & Extensão e conectividade de ciclovias \\
\hline & 6.2 .1 & Vias para pedestres \\
\hline & 9.1 .7 & Passageiros transportados anualmente \\
\hline & 9.5 .2 & Tarifas de transportes \\
\hline
\end{tabular}

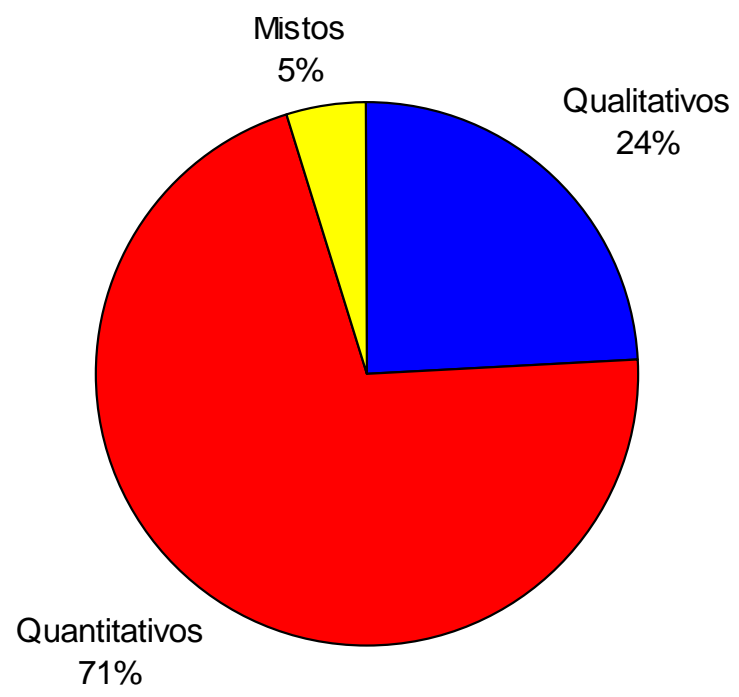

Figura 8.5: Indicadores do IMUS conforme tipologia. 
Com base na Figura 8.5 verifica-se o predomínio dos Indicadores Quantitativos na estrutura do IMUS, que representam $71 \%$ do conjunto total de indicadores. Estes indicadores exigem, para seu desenvolvimento, o levantamento de dados quantitativos através de bases de dados ou outras fontes de informação, além do desenvolvimento de procedimentos de cálculo para obtenção de seu score. Os demais indicadores dos tipos Qualitativos e Mistos representaram, respectivamente, $24 \%$ e $5 \%$ do conjunto total.

A Figura 8.6 apresenta a proporção de indicadores Quantitativos e Qualitativos classificados em cada subgrupo.

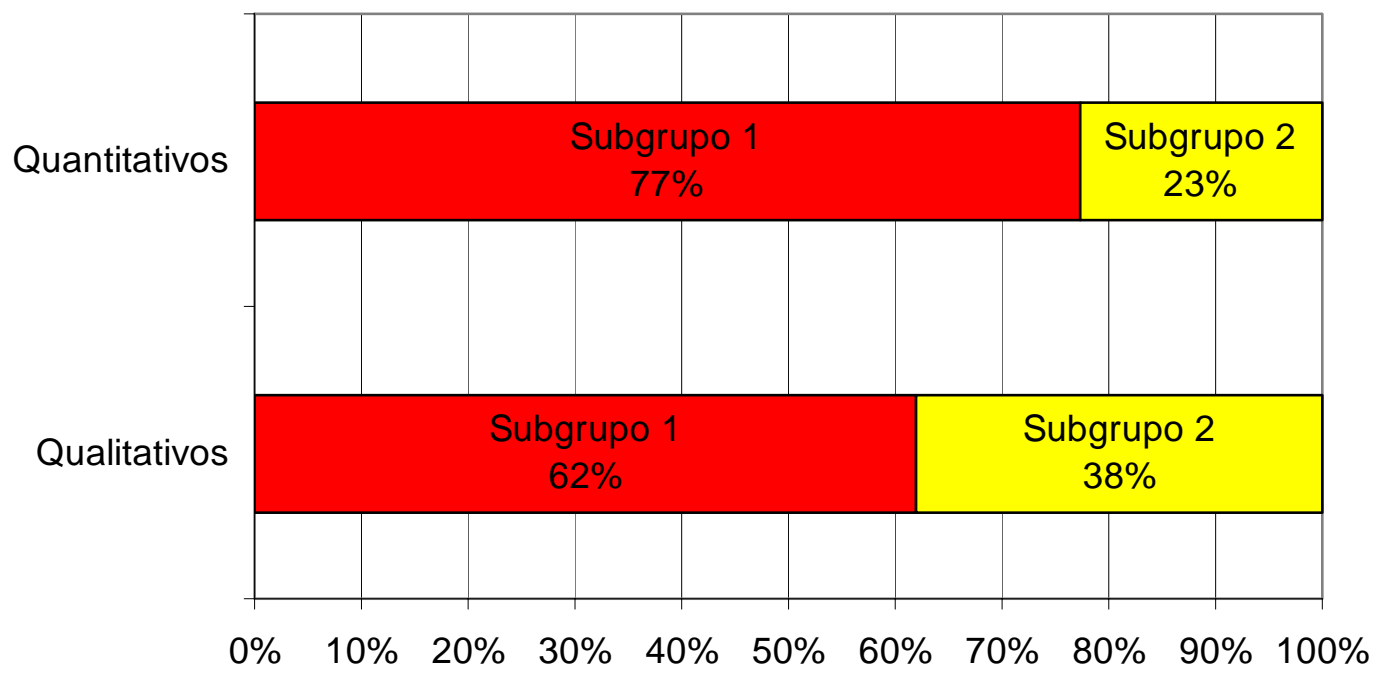

Figura 8.6: Indicadores Quantitativos e Qualitativos conforme subgrupo.

Para os Indicadores Quantitativos, observa-se o predomínio dos classificados no Subgrupo 1 (Quantitativos Tradicionais), que representam $77 \%$ dos indicadores desta tipologia. Os demais 23\% são constituídos por indicadores do Subgrupo 2 (Quantitativos Espaciais), relacionados à distribuição espacial, abrangência ou extensão de um determinado fenômeno.

Para os Indicadores Qualitativos, a proporção de indicadores classificados no Subgrupo 1 (Qualitativos Tradicionais) é de 62\%. Estes indicadores são avaliados segundo escalas de critérios qualitativos. O Subgrupo 2 (Qualitativos de Presença/Ausência) agrega 38\% dos indicadores desta tipologia, incluindo indicadores cujos scores são obtidos através da avaliação da ausência ou da presença de determinados elementos.

\subsection{Análise do Sistema de Pesos para os Critérios}

Com relação ao sistema de pesos, três aspectos devem ser considerados: as características do grupo de avaliadores que participaram do painel de especialistas; o método de obtenção 
dos pesos para os critérios e os pesos propriamente ditos, que refletem a importância relativa dos critérios que compõem o IMUS.

Ao contrário da composição da hierarquia de critérios, feita com base em dados obtidos através de consulta a profissionais brasileiros vinculados às cidades em estudo, a avaliação dos critérios buscou a opinião de profissionais e especialistas de diferentes países, que possuem extensa experiência e conhecimento nos temas abrangidos pelo índice, ou seja, planejamento urbano e de transportes, mobilidade e sustentabilidade urbana. Buscou-se assim uma avaliação desvinculada do contexto específico das cidades pesquisadas, mas relacionada ao conceito de mobilidade urbana sustentável, propriamente dito. O sistema de pesos deve permitir assim, identificar os aspectos de maior importância para a promoção da mobilidade urbana sustentável, coerente com o referencial de sustentabilidade já amplamente difundido internacionalmente.

No que se refere aos procedimentos para a obtenção dos pesos, o método baseado na escala de pontos consiste em um método de avaliação direta e de fácil compreensão, sendo facilmente implementado em planilhas eletrônicas ou através da Internet (com o registro dos resultados em um banco de dados), simplificando assim o processo e garantindo maior retorno das respostas pela sua praticidade. No entanto, a aplicação de uma escala de cinco níveis, como a utilizada neste estudo, e o posterior processo de normalização implicou em uma pequena diferenciação dos pesos obtidos (como será visto mais adiante) e resultou, portanto, em um conjunto com baixo Desvio Padrão. Acredita-se que o alargamento da escala a um maior número de níveis (sete ou nove níveis), ou a utilização de um processo de maior complexidade como o método de comparação par a par (Ramos, 2000; Silva et al. 2004; Saaty, 1980), pode resultar num conjunto de pesos mais diferenciado (com maior amplitude) e que mostre mais claramente a importância relativa dos critérios.

Em relação aos pesos propriamente ditos, são analisados aqui os pesos dos Domínios, Temas e Indicadores que compõem o IMUS.

A Figura 8.7 mostra a relação de pesos para os Domínios que compõem o IMUS. Apesar de não ter havido grande diferenciação entre os pesos obtidos para estes critérios, em função dos aspectos já discutidos, o Domínio Infra-estrutura de Transportes apresentou uma maior importância relativa, seguido por Aspectos Ambientais e Aspectos Políticos. O Domínio Tráfego e Circulação Urbana, de grande destaque no planejamento de transportes no país principalmente nos anos de 1980 e 1990, apresentou o menor peso entre todos os Domínios avaliados. 


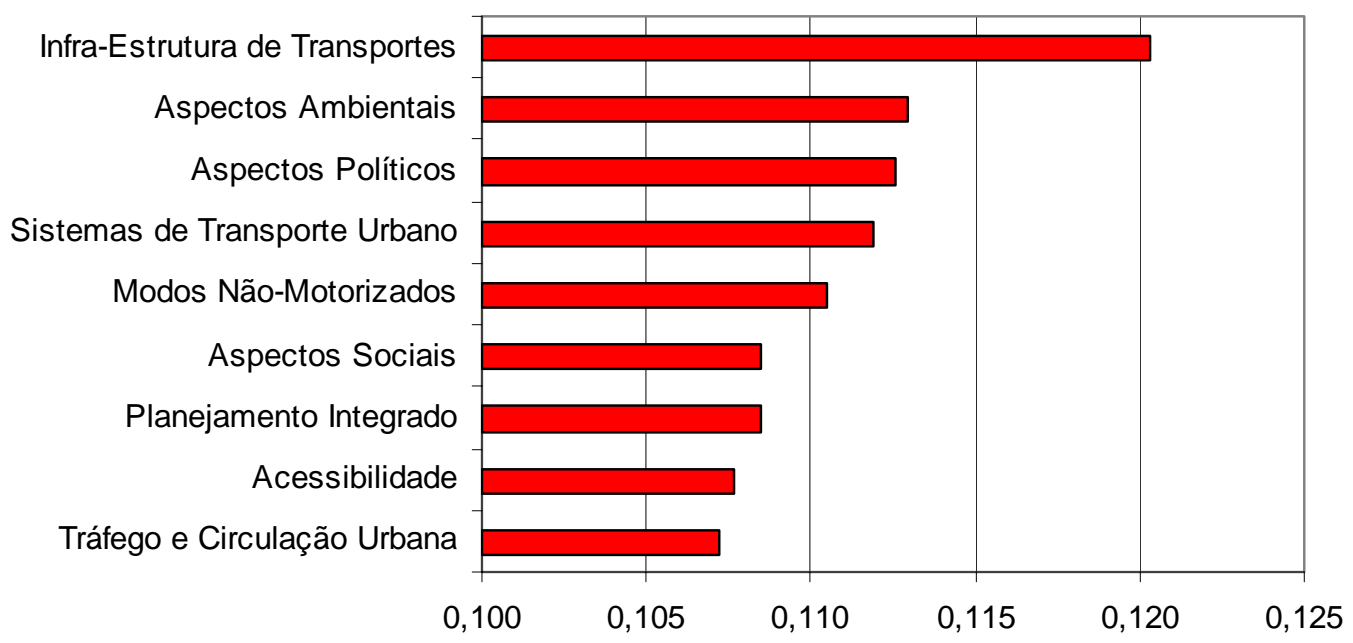

Figura 8.7: Pesos para os Domínios do IMUS.

No que diz respeito aos pesos absolutos obtidos para os Temas, a Tabela 8.14 apresenta os Temas classificados por Domínio, dispostos em ordem decrescente em relação aos seus respectivos pesos. Para o Domínio Acessibilidade, o tema de maior importância relativa é Acessibilidade aos Sistemas de Transportes; para o Domínio Aspectos Ambientais, Controle dos Impactos no Meio Ambiente; para o Domínio Aspectos Sociais, Qualidade de Vida; para o Domínio Aspectos Políticos, Integração de Ações Políticas; para o Domínio Infra-estrutura de Transportes, Distribuição da Infra-estrutura de Transportes; para o Domínio Modos Nãomotorizados, Redução das Viagens; para o Domínio Planejamento Integrado, Planejamento e Controle do Uso e Ocupação do Solo; para o Domínio Tráfego e Circulação Urbana, Transporte Individual e para o Domínio Sistemas de Transporte Urbano, Disponibilidade e Qualidade do Transporte Público.

Com relação às Dimensões da sustentabilidade, foram obtidos pesos que representam a importância de cada um dos Temas avaliados para as três Dimensões. O objetivo desta abordagem é permitir aos planejadores e gestores avaliarem os impactos de investimentos e ações em cada Tema (e seus respectivos Indicadores) para as esferas da sustentabilidade. Estes pesos foram apresentados na Tabela 8.4 e constam também no Anexo G - Sistema de Pesos para os Critérios. A Dimensão que representa maior peso para um determinado Tema é, portanto, a Dimensão que receberá os maiores benefícios (ou maiores perdas) em função de mudanças nos scores dos Indicadores associados a este Tema. 
Tabela 8.14: Pesos para os Temas que compõem o IMUS.

\begin{tabular}{|c|c|c|}
\hline Domínio & Tema & Peso \\
\hline \multirow{4}{*}{ Acessibilidade } & Acessibilidade aos sistemas de transportes & 0,29 \\
\hline & Acessibilidade universal & 0,28 \\
\hline & Barreiras físicas & 0,22 \\
\hline & Legislação para pessoas com necessidades especiais & 0,21 \\
\hline \multirow{2}{*}{ Aspectos Ambientais } & Controle dos impactos no meio ambiente & 0,52 \\
\hline & Recursos naturais & 0,48 \\
\hline \multirow{5}{*}{ Aspectos Sociais } & Qualidade de vida & 0,21 \\
\hline & Apoio ao cidadão & 0,21 \\
\hline & Inclusão social & 0,20 \\
\hline & Participação popular & 0,19 \\
\hline & Educação e cidadania & 0,19 \\
\hline \multirow{3}{*}{ Aspectos Políticos } & Integração de ações políticas & 0,34 \\
\hline & Política de mobilidade urbana & 0,34 \\
\hline & Captação e gerenciamento de recursos & 0,33 \\
\hline \multirow{2}{*}{$\begin{array}{l}\text { Infra-estrutura de } \\
\text { Transportes }\end{array}$} & Distribuição da infra-estrutura de transportes & 0,54 \\
\hline & Provisão e manutenção da infra-estrutura de transportes & 0,46 \\
\hline \multirow{3}{*}{$\begin{array}{l}\text { Modos } \\
\text { Não-motorizados }\end{array}$} & Redução de viagens & 0,35 \\
\hline & Deslocamentos a pé & 0,34 \\
\hline & Transporte cicloviário & 0,31 \\
\hline \multirow{8}{*}{$\begin{array}{l}\text { Planejamento } \\
\text { Integrado }\end{array}$} & Planejamento e controle do uso e ocupação do solo & 0,14 \\
\hline & Planejamento estratégico e integrado & 0,14 \\
\hline & Planejamento da infra-estrutura urbana e equipamentos urbanos & 0,13 \\
\hline & Capacitação de gestores & 0,12 \\
\hline & Plano Diretor e legislação urbanística & 0,12 \\
\hline & Integração regional & 0,12 \\
\hline & Transparência do processo de planejamento & 0,12 \\
\hline & Áreas centrais e de interesse histórico & 0,11 \\
\hline \multirow{5}{*}{$\begin{array}{l}\text { Tráfego e Circulação } \\
\text { Urbana }\end{array}$} & Transporte individual & 0,21 \\
\hline & Acidentes de trânsito & 0,21 \\
\hline & Operação e fiscalização de trânsito & 0,20 \\
\hline & Fluidez e circulação & 0,19 \\
\hline & Educação para o trânsito & 0,19 \\
\hline \multirow{5}{*}{$\begin{array}{l}\text { Sistemas de } \\
\text { Transporte Urbano }\end{array}$} & Disponibilidade e qualidade do transporte público & 0,23 \\
\hline & Integração do transporte público & 0,22 \\
\hline & Política tarifária & 0,19 \\
\hline & Diversificação modal & 0,18 \\
\hline & Regulação e fiscalização do transporte público & 0,18 \\
\hline
\end{tabular}


A avaliação dos pesos obtidos para os Domínios e Temas foi seguida da avaliação dos pesos para cada Indicador, com o objetivo de identificar sua contribuição para os resultados global e setorial do IMUS.

Para tal, procedeu-se a uma avaliação setorial, relacionada a cada uma das Dimensões da sustentabilidade e uma avaliação global, considerando os vários pesos que afetam cada um dos Indicadores, ou seja, o somatório nas três dimensões, conforme mostram as Equações 8.1 e 8.2 .

$$
\mathrm{P}^{s_{j}}=\mathrm{P}_{i} \cdot \mathrm{PT}_{i} \cdot \mathrm{PT}^{s_{j}} \cdot \mathrm{PD}_{i} \text {, com } s_{j}=\text { Dimensão Social ou Econômica ou Ambiental }
$$

em que: $\mathrm{P}_{\mathrm{i}}^{\mathrm{sj}}$ : peso do Indicador $\mathrm{i}$ na Dimensão sj (peso setorial por Dimensão de sustentabilidade);

$\mathrm{P}_{\mathrm{i}}$ : peso do Indicador $\mathrm{i}$;

$\mathrm{PT}_{\mathrm{i}}$ : peso do Tema a que pertence o Indicador $\mathrm{i}$;

$\mathrm{PT}_{\mathrm{i}}^{\mathrm{sj}}$ : peso da Dimensão de sustentabilidade sj no Tema a que pertence o Indicador i;

$P D_{i}$ : peso do Domínio a que pertence o Indicador i.

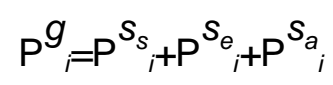

em que: $\quad \mathrm{P}_{\mathrm{i}}^{\mathrm{g}}$ : peso global do Indicador i para o índice IMUS;

$\mathrm{P}_{\mathrm{i}}^{\mathrm{Ss}}$ : peso do Indicador i na Dimensão Social;

$\mathrm{P}_{\mathrm{i}}^{\mathrm{Se}}$ : peso do Indicador i na Dimensão Econômica;

$\mathrm{P}_{\mathrm{i}}^{\mathrm{Sa}}$ : peso do Indicador i na Dimensão Ambiental.

Os pesos globais e setoriais foram calculados para todos os indicadores a partir dos pesos mostrados na Tabela 8.4. A Tabela 8.15 mostra os resultados obtidos. Ao lado do peso global e para cada Dimensão, há uma coluna chamada "Ordem", onde consta a posição ou ranking de cada Indicador. Os dez melhores Indicadores, ou seja, aqueles com maiores pesos para cada situação, encontram-se em destaque na tabela. 
Tabela 8.15: Pesos globais e setoriais para os Indicadores que compõem o IMUS.

\begin{tabular}{|c|c|c|c|c|c|c|c|c|}
\hline & & & & & ombinaç & âo de Pesos & & \\
\hline ID & Indicador & & & & & Setor & & \\
\hline & & Global & Ordem & Social & Ordem & Econômica & Ordem & Ambiental \\
\hline 1.1.1 & Acessibilidade ao transporte público & 0,0104 & 36 & 0,0039 & 29 & 0,0037 & 30 & 0,0027 \\
\hline 1.1 .2 & Transporte público para pessoas com necessidades especiais & 0,0104 & 37 & 0,0039 & 27 & 0,0037 & 31 & 0,0027 \\
\hline 1.1 .3 & Despesas com transporte & 0,0104 & 38 & 0,0039 & 28 & 0,0037 & 32 & 0,0027 \\
\hline 1.2 .1 & Travessias adaptadas a pessoas com necessidades especiais & 0,0060 & 64 & 0,0024 & 58 & 0,0019 & 64 & 0,0016 \\
\hline 1.2 .2 & Acessibilidade a espaços abertos & 0,0060 & 65 & 0,0024 & 60 & 0,0019 & 65 & 0,0016 \\
\hline 1.2 .3 & Vagas de estacionamento para pessoas com necessidades especiais & 0,0060 & 66 & 0,0024 & 57 & 0,0019 & 66 & 0,0016 \\
\hline 1.2 .4 & Acessibilidade a edifícios públicos & 0,0060 & 67 & 0,0024 & 61 & 0,0019 & 67 & 0,0016 \\
\hline 1.2 .5 & Acessibilidade aos serviços essenciais & 0,0060 & 68 & 0,0024 & 59 & 0,0019 & 68 & 0,0016 \\
\hline 1.3.1 & Fragmentaçăo urbana & 0,0237 & 5 & 0,0090 & 6 & 0,0072 & 5 & 0,0076 \\
\hline 1.4 .1 & Açő́es para acessibilidade universal & 0,0227 & 7 & 0,0104 & 3 & 0,0063 & 12 & 0,0061 \\
\hline 2.1.1 & Emissốes de CO & 0,0148 & 18 & 0,0043 & 25 & 0,0041 & 23 & 0,0064 \\
\hline 2.1 .2 & Emissões de $\mathrm{CO}^{2}$ & 0,0148 & 19 & 0,0043 & 24 & 0,0041 & 24 & 0,0064 \\
\hline 2.1 .3 & População exposta ao ruído de tráfego & 0,0148 & 20 & 0,0043 & 22 & 0,0041 & 25 & 0,0064 \\
\hline 2.1.4 & Estudos de Impacto Ambiental & 0,0148 & 21 & 0,0043 & 23 & 0,0041 & 26 & 0,0064 \\
\hline 2.2 .1 & Consumo de combustivel & 0,0269 & 3 & 0,0070 & 13 & 0,0086 & 3 & 0,0113 \\
\hline 2.2 .2 & Uso de energia limpa e combustiveis alternativos & 0,0269 & 4 & 0,0070 & 12 & 0,0086 & 4 & 0,0113 \\
\hline 3.1.1 & Informaçăo disponivel ao cidadẫo & 0,0224 & 8 & 0,0091 & 5 & 0,0069 & 7 & 0,0064 \\
\hline 3.2 .1 & Eqüidade vertical (renda) & 0,0220 & 9 & 0,0099 & 4 & 0,0066 & 9 & 0,0054 \\
\hline 3.3.1 & Educação para o desenvolvimento sustentável & 0,0203 & 12 & 0,0079 & 9 & 0,0060 & 14 & 0,0064 \\
\hline 3.4.1 & Participação na tomada de decisão & 0,0207 & 11 & 0,0085 & 7 & 0,0055 & 19 & 0,0066 \\
\hline 3.5 .1 & Qualidade de Vida & 0,0232 & 6 & 0,0081 & 8 & 0,0069 & 8 & 0,0082 \\
\hline 4.1.1 & Integraçäo entre niveis de governo & 0,0190 & 16 & 0,0063 & 15 & 0,0065 & 10 & 0,0062 \\
\hline 4.1 .2 & Parcerias público/privadas & 0,0190 & 17 & 0,0063 & 14 & 0,0065 & 11 & 0,0062 \\
\hline 4.2 .1 & Captaçăo de recursos & 0,0091 & 47 & 0,0030 & 44 & 0,0036 & 33 & 0,0025 \\
\hline 4.2 .2 & Investimentos em sistemas de transportes & 0,0091 & 48 & 0,0030 & 41 & 0,0036 & 34 & 0,0025 \\
\hline 4.2 .3 & Distribuiçăo dos recursos (transporte público $x$ transporte privado) & 0,0091 & 49 & 0,0030 & 42 & 0,0036 & 35 & 0,0025 \\
\hline 4.2 .4 & Distribuiçăo dos recursos (modos motorizados x modos năo-motorizados) & 0,0091 & 50 & 0,0030 & 43 & 0,0036 & 36 & 0,0025 \\
\hline 4.3.1 & Política de mobilidade urbana & 0,0380 & 2 & 0,0131 & 2 & 0,0126 & 2 & 0,0123 \\
\hline 5.1.1 & Densidade da rede viária & 0,0140 & 22 & 0,0039 & 33 & 0,0058 & 15 & 0,0043 \\
\hline 5.1 .2 & Vias pavimentadas & 0,0140 & 23 & 0,0039 & 30 & 0,0058 & 16 & 0,0043 \\
\hline 5.1 .3 & Despesas com manutenção da infra-estrutura de transportes & 0,0140 & 24 & 0,0039 & 32 & 0,0058 & 17 & 0,0043 \\
\hline 5.1 .4 & Sinalizaçẫo viária & 0,0140 & 25 & 0,0039 & 31 & 0,0058 & 18 & 0,0043 \\
\hline 5.2 .1 & Vias para transporte coletivo & 0,0644 & 1 & 0,0210 & 1 & 0,0224 & 1 & 0,0210 \\
\hline 6.1.1 & Extensäo de ciclovias & 0,0113 & 33 & 0,0036 & 37 & 0,0033 & 44 & 0,0044 \\
\hline 6.1 .2 & Frota de bicicletas & 0,0113 & 34 & 0,0036 & 36 & 0,0033 & 45 & 0,0044 \\
\hline 6.1 .3 & Estacionamento para bicicletas & 0,0113 & 35 & 0,0036 & 38 & 0,0033 & 46 & 0,0044 \\
\hline 6.2 .1 & Vias para pedestres & 0,0190 & 14 & 0,0062 & 16 & 0,0052 & 20 & 0,0075 \\
\hline 6.2 .2 & Vias com calçadas & 0,0190 & 15 & 0,0062 & 17 & 0,0052 & 21 & 0,0075 \\
\hline 6.3.1 & Distância de viagem & 0,0097 & 43 & 0,0027 & 55 & 0,0031 & 47 & 0,0039 \\
\hline 6.3 .2 & Tempo de viagem & 0,0097 & 44 & 0,0027 & 53 & 0,0031 & 48 & 0,0039 \\
\hline 6.3 .3 & Número de viagens & 0,0097 & 45 & 0,0027 & 54 & 0,0031 & 49 & 0,0039 \\
\hline 6.3 .4 & Açőes para reduçăo do tráfego motorizado & 0,0097 & 46 & 0,0027 & 56 & 0,0031 & 50 & 0,0039 \\
\hline 7.1.1 & Nivel de formaçăo de técnicos e gestores & 0,0067 & 62 & 0,0021 & 67 & 0,0025 & 59 & 0,0022 \\
\hline 7.1 .2 & Capacitação de técnicos e gestores & 0,0067 & 63 & 0,0021 & 68 & 0,0025 & 60 & 0,0022 \\
\hline 7.2 .1 & Vitalidade do centro & 0,0121 & 28 & 0,0043 & 21 & 0,0036 & 39 & 0,0043 \\
\hline 7.3 .1 & Consórcios intermunicipais & 0,0129 & 26 & 0,0040 & 26 & 0,0043 & 22 & 0,0045 \\
\hline 7.4 .1 & Transparência e responsabilidade & 0,0129 & 27 & 0,0049 & 18 & 0,0041 & 27 & 0,0040 \\
\hline 7.5 .1 & Vazios urbanos & 0,0030 & 83 & 0,0009 & 83 & 0,0010 & 83 & 0,0011 \\
\hline 7.5 .2 & Crescimento urbano & 0,0030 & 84 & 0,0009 & 87 & 0,0010 & 84 & 0,0011 \\
\hline 7.5 .3 & Densidade populacional urbana & 0,0030 & 85 & 0,0009 & 86 & 0,0010 & 85 & 0,0011 \\
\hline 7.5 .4 & Índice de uso misto & 0,0030 & 86 & 0,0009 & 85 & 0,0010 & 86 & 0,0011 \\
\hline 7.5 .5 & Ocupaçőes irregulares & 0,0030 & 87 & 0,0009 & 84 & 0,0010 & 87 & 0,0011 \\
\hline 7.6 .1 & Planejamento urbano, ambiental e de transportes integrado & 0,0074 & 54 & 0,0024 & 62 & 0,0026 & 57 & 0,0025 \\
\hline 7.6 .2 & Efetivaçăo e continuidade das açőes & 0,0074 & 55 & 0,0024 & 63 & 0,0026 & 58 & 0,0025 \\
\hline 7.7 .1 & Parques e áreas verdes & 0,0047 & 69 & 0,0015 & 69 & 0,0018 & 69 & 0,0014 \\
\hline 7.7 .2 & Equipamentos urbanos (escolas) & 0,0047 & 70 & 0,0015 & 71 & 0,0018 & 70 & 0,0014 \\
\hline 7.7 .3 & Equipamentos urbanos (hospitais) & 0,0047 & 71 & 0,0015 & 70 & 0,0018 & 71 & 0,0014 \\
\hline 7.8 .1 & Plano Diretor & 0,0044 & 72 & 0,0014 & 72 & 0,0015 & 72 & 0,0015 \\
\hline 8.8 .2 & Legislação urbanística & 0,0044 & 73 & 0,0014 & 73 & 0,0015 & 73 & 0,0015 \\
\hline 7.8 .3 & Cumprimento da legislação urbanística & 0,0044 & 74 & 0,0014 & 74 & 0,0015 & 74 & 0,0015 \\
\hline 8.1 .1 & Acidentes de trânsito & 0,0075 & 51 & 0,0027 & 48 & 0,0028 & 51 & 0,0019 \\
\hline 8.1 .2 & Acidentes com pedestres e ciclistas & 0,0075 & 52 & 0,0027 & 49 & 0,0028 & 52 & 0,0019 \\
\hline 8.1 .3 & Prevençăo de acidentes & 0,0075 & 53 & 0,0027 & 47 & 0,0028 & 53 & 0,0019 \\
\hline 8.2 .1 & Educaçăo para o trânsito & 0,0198 & 13 & 0,0077 & 10 & 0,0062 & 13 & 0,0060 \\
\hline 8.3 .1 & Congestionamento & 0,0103 & 39 & 0,0030 & 46 & 0,0036 & 37 & 0,0037 \\
\hline 8.3 .2 & Velocidade média de tráfego & 0,0103 & 40 & 0,0030 & 45 & 0,0036 & 38 & 0,0037 \\
\hline 8.4 .1 & Violação das leis de trânsito & 0,0215 & 10 & 0,0073 & 11 & 0,0071 & 6 & 0,0071 \\
\hline 8.5 .1 & Índice de motorizaçăo & 0,0114 & 31 & 0,0037 & 35 & 0,0035 & 40 & 0,0042 \\
\hline 8.5 .2 & Taxa de ocupação dos veículos & 0,0114 & 32 & 0,0037 & 34 & 0,0035 & 41 & 0,0042 \\
\hline 9.1 .1 & Extensấo da rede de transporte público & 0,0033 & 75 & 0,0011 & 82 & 0,0011 & 75 & 0,0010 \\
\hline 9.1 .2 & Frequência de atendimento do transporte público & 0,0033 & 76 & 0,0011 & 81 & 0,0011 & 76 & 0,0010 \\
\hline 9.1 .3 & Pontualidade & 0,0033 & 77 & 0,0011 & 77 & 0,0011 & 77 & 0,0010 \\
\hline 9.1 .4 & Velocidade média do transporte público & 0,0033 & 78 & 0,0011 & 75 & 0,0011 & 78 & 0,0010 \\
\hline 9.1 .5 & Idade média da frota de transporte público & 0,0033 & 79 & 0,0011 & 80 & 0,0011 & 79 & 0,0010 \\
\hline 9.1 .6 & Índice de passageiros por kilômetro & 0,0033 & 80 & 0,0011 & 79 & 0,0011 & 80 & 0,0010 \\
\hline 9.1 .7 & Passageiros transportados anualmente & 0,0033 & 81 & 0,0011 & 78 & 0,0011 & 81 & 0,0010 \\
\hline 9.1 .8 & Satisfaçẫo do usuário com o serviço de transporte público & 0,0033 & 82 & 0,0011 & 76 & 0,0011 & 82 & 0,0010 \\
\hline 9.2 .1 & Diversidade de modos de transporte & 0,0068 & 59 & 0,0021 & 66 & 0,0023 & 61 & 0,0023 \\
\hline 9.2 .2 & Transporte público $\times$ transporte privado & 0,0068 & 60 & 0,0021 & 64 & 0,0023 & 62 & 0,0023 \\
\hline 9.2 .3 & Modos motorizados $x$ modos nằo-motorizados & 0,0068 & 61 & 0,0021 & 65 & 0,0023 & 63 & 0,0023 \\
\hline 9.3 .1 & Contratos e licitações & 0,0099 & 41 & 0,0034 & 40 & 0,0035 & 42 & 0,0031 \\
\hline 9.3 .2 & Transporte clandestino & 0,0099 & 42 & 0,0034 & 39 & 0,0035 & 43 & 0,0031 \\
\hline 9.4 .1 & Terminais intermodais & 0,0120 & 29 & 0,0044 & 19 & 0,0040 & 28 & 0,0036 \\
\hline 9.4 .2 & Linhas integradas & 0,0120 & 30 & 0,0044 & 20 & 0,0040 & 29 & 0,0036 \\
\hline 9.5 .1 & Descontos e gratuidades & 0,0072 & 56 & 0,0027 & 52 & 0,0026 & 54 & 0,0018 \\
\hline 9.5 .2 & Preços dos transportes & 0,0072 & 57 & 0,0027 & 51 & 0,0026 & 55 & 0,0018 \\
\hline 9.5 .3 & Subsidios públicos & 0,0072 & 58 & 0,0027 & 50 & 0,0026 & 56 & 0,0018 \\
\hline
\end{tabular}


A análise da Tabela 8.15 permite estabelecer alguns direcionamentos para a melhoria dos valores obtidos para o IMUS. Ou seja, se o objetivo for melhorar o resultado global do índice, devem ser empreendidas ações para a melhoria dos scores dos indicadores mais importantes segundo a avaliação global, identificados em azul. Se o objetivo for melhorar o desempenho de uma Dimensão, especificamente, recomenda-se que sejam empreendidas ações para a melhoria dos scores dos indicadores mais importantes para a respectiva Dimensão. Como, por exemplo, se o desejo é promover a Dimensão Social, as ações devem começar, fundamentalmente, pela melhoria dos indicadores grifados em vermelho na Tabela 8.15.

Com base na Tabela 8.15 verifica-se ainda que os mesmos indicadores apresentaram os maiores pesos global e para as três Dimensões da sustentabilidade, representados por Vias para Transporte Coletivo e Política de Mobilidade Urbana. Estes Indicadores deverão, portanto, ser os principais aspectos observados por uma cidade que utilize a ferramenta para avaliação da mobilidade urbana, como referencial para a proposição de políticas públicas visando a sustentabilidade. Os demais Indicadores destacados na Tabela 8.15 apresentaram posições diferentes para as avaliações global e setoriais. Desta forma, em cada situação e para cada Dimensão deverão ser promovidos indicadores específicos para melhoria dos resultados global e setoriais do IMUS, observando o ranking obtido.

A Tabela 8.15 permite também observar que nenhum indicador dos Domínios Modos NãoMotorizados (identificados com ID iniciando em 6) e Tráfego e Circulação Urbana (identificados com ID iniciando em 8) figuraram entre os dez indicadores mais bem posicionados com base na análise global e setorial. No entanto, a medida que vão sendo promovidos os indicadores melhor posicionados na tabela, e atingidas as metas e objetivos pré-definidos para os mesmos, os demais indicadores devem ser considerados na seqüência das ações, a fim de aumentar os valores do IMUS e atingir o score máximo que pode ser obtido, igual a 1.

Assim, com a observação da ordem de classificação dos indicadores podem ser definidas prioridades para investimentos, planos e ações para a mobilidade sustentável, visando melhorar os resultados encontrados para os indicadores de maior importância relativa. A possibilidade de se identificar as áreas primordiais para ação, através da identificação dos aspectos mais relevantes para cada Dimensão e para a mobilidade como um todo é, portanto, a principal característica do IMUS.

A Tabela 8.16 apresenta os dez indicadores com maiores pesos para o resultado global e para cada Dimensão da sustentabilidade. 
Tabela 8.16: Dez indicadores com maiores pesos para os resultados global e por Dimensões.

\begin{tabular}{|c|c|c|}
\hline Posição & ID & Global \\
\hline 1 & 5.2 .1 & Vias para transporte coletivo \\
\hline 2 & 4.3 .1 & Política de mobilidade urbana \\
\hline 3 & 2.2 .1 & Consumo de combustível \\
\hline 4 & 2.2 .2 & Uso de energia limpa e combustíveis alternativos \\
\hline 5 & 1.3 .1 & Fragmentação urbana \\
\hline 6 & 3.5 .1 & Qualidade de Vida \\
\hline 7 & 1.4 .1 & Ações para acessibilidade universal \\
\hline 8 & 3.1 .1 & Informação disponível ao cidadão \\
\hline 9 & 3.2 .1 & Eqüidade vertical (renda) \\
\hline 10 & 8.4 .1 & Violação das leis de trânsito \\
\hline Posição & ID & Social \\
\hline 1 & 5.2 .1 & Vias para transporte coletivo \\
\hline 2 & 4.3 .1 & Política de mobilidade urbana \\
\hline 3 & 1.4 .1 & Ações para acessibilidade universal \\
\hline 4 & 3.2 .1 & Eqüidade vertical (renda) \\
\hline 5 & 3.1 .1 & Informação disponível ao cidadão \\
\hline 6 & 1.3 .1 & Fragmentação urbana \\
\hline 7 & 3.4 .1 & Participação na tomada de decisão \\
\hline 8 & 3.5 .1 & Qualidade de Vida \\
\hline 9 & 3.3 .1 & Educação para o desenvolvimento sustentável \\
\hline 10 & 8.2 .1 & Educação para o trânsito \\
\hline Posição & ID & Econômica \\
\hline 1 & 5.2 .1 & Vias para transporte coletivo \\
\hline 2 & 4.3 .1 & Política de mobilidade urbana \\
\hline 3 & 2.2 .1 & Consumo de combustível \\
\hline 4 & 2.2 .2 & Uso de energia limpa e combustíveis alternativos \\
\hline 5 & 1.3 .1 & Fragmentação urbana \\
\hline 6 & 8.4 .1 & Violação das leis de trânsito \\
\hline 7 & 3.1 .1 & Informação disponível ao cidadão \\
\hline 8 & 3.5 .1 & Qualidade de Vida \\
\hline 9 & 3.2 .1 & Eqüidade vertical (renda) \\
\hline 10 & 4.1 .1 & Integração entre níveis de governo \\
\hline Posição & ID & Ambiental \\
\hline 1 & 5.2 .1 & Vias para transporte coletivo \\
\hline 2 & 4.3 .1 & Política de mobilidade urbana \\
\hline 3 & 2.2 .1 & Consumo de combustível \\
\hline 4 & 2.2 .2 & Uso de energia limpa e combustíveis alternativos \\
\hline 5 & 3.5 .1 & Qualidade de Vida \\
\hline 6 & 1.3 .1 & Fragmentação urbana \\
\hline 7 & 6.2 .1 & Vias para pedestres \\
\hline 8 & 6.2 .2 & Vias com calçadas \\
\hline 9 & 8.4 .1 & Violação das leis de trânsito \\
\hline 10 & 3.4 .1 & Participação na tomada de decisão \\
\hline
\end{tabular}




\section{APLICAÇÃO DO IMUS NA CIDADE DE SÃO CARLOS}

Neste capítulo é apresentada a aplicação do IMUS para São Carlos, cidade do interior do estado de São Paulo. Primeiramente são apresentadas algumas características da cidade, bem como a justificativa de sua escolha para avaliação do índice. Posteriormente são discutidas as etapas de coleta e avaliação da qualidade dos dados para cálculo do IMUS. Na etapa seguinte é feito o cálculo dos indicadores que compõem o índice e obtidos os resultados global e setorial para o mesmo. Estes resultados são avaliados em termos das dimensões da sustentabilidade, além de aspectos específicos relacionados aos indicadores. Na etapa final, os resultados obtidos através do processo de cálculo e de uma avaliação expedita dos indicadores são comparados.

\subsection{A cidade de São Carlos - SP}

Localizada no centro do estado de São Paulo e conhecida como importante pólo científico e tecnológico do Brasil, a cidade de São Carlos abriga importantes centros de ensino e pesquisa, além de inúmeras empresas de alta tecnologia. Assim como muitos outros centros de porte médio brasileiros, a cidade experimentou nas últimas décadas um intenso crescimento. Com população aproximada de 213 mil habitantes (IBGE, 2008), São Carlos apresenta hoje uma grande pressão por infra-estrutura de diferentes naturezas, dentre elas o transporte.

A Figura 9.1 mostra a localização da cidade de São Carlos. A Tabela 9.1 apresenta dados demográficos e socioeconômicos do município, bem como sua participação em relação ao estado de São Paulo. 


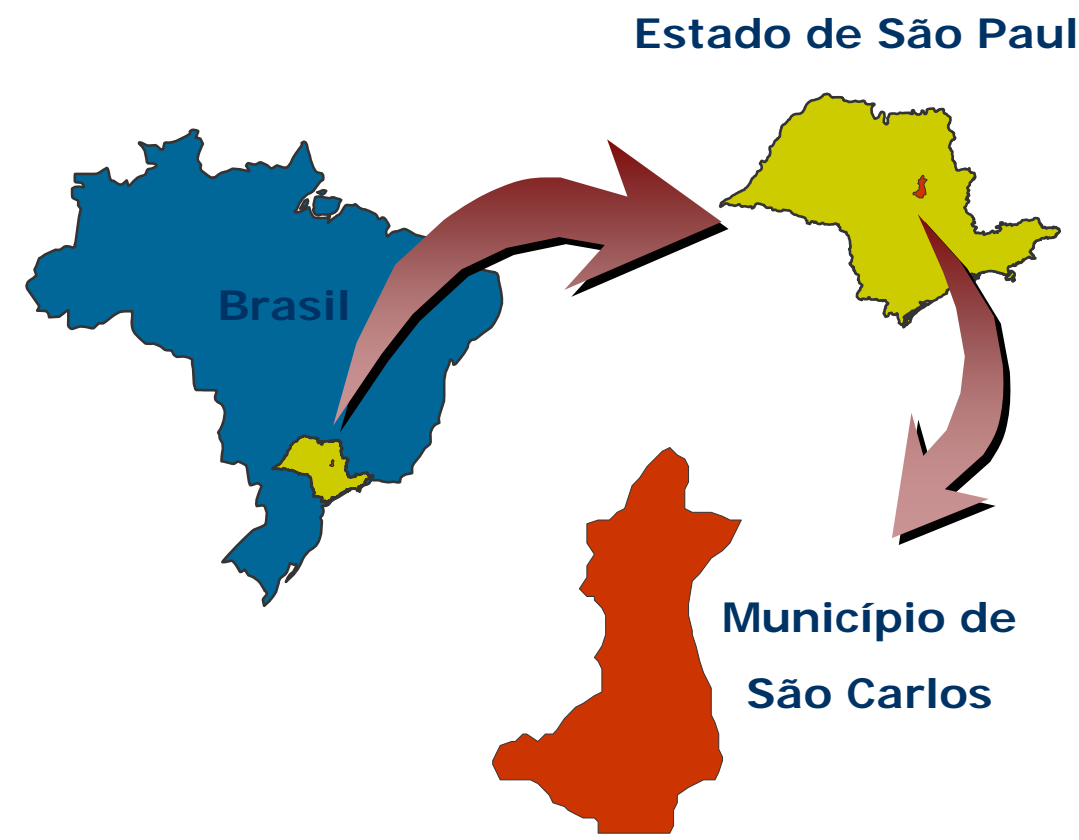

Figura 9.1: Localização do município de São Carlos - SP.

Tabela 9.1: Dados demográficos e socioeconômicos do município de São Carlos.

\begin{tabular}{|c|c|c|}
\hline Dados & São Carlos & $\%$ SP \\
\hline Estimativa da população 2007 (habitantes) & 212.956 & 0,53 \\
\hline Área $\left(\mathrm{km}^{2}\right)^{\mathrm{A}}$ & 1.141 & 0,46 \\
\hline Densidade demográfica (hab/km²) & 187 & \\
\hline PIB 2005 (mil Reais) $^{A}$ & 2.949 .858 & 0,41 \\
\hline $\mathrm{IDH}-\mathrm{M} 2000^{\mathrm{B}}$ & 0,841 & - \\
\hline
\end{tabular}

Fonte: ${ }^{A}$ IBGE (2008).

${ }^{B}$ PNDU (2000).

Recentemente, em função da necessidade de se adequar às diretrizes estabelecidas pelo Estatuto das Cidades (Lei N 10.257 de julho de 2001, que estabelece a obrigatoriedade de revisão e elaboração de Planos Diretores Municipais para cidades com mais de 20 mil habitantes no prazo de cinco anos), a cidade de São Carlos promoveu a revisão de seus instrumentos de planejamento urbano. Este processo gerou uma série de diagnósticos e levantamentos a respeito das condições urbanas e de mobilidade, e culminou com a aprovação do projeto de Lei do Plano Diretor (Lei Municipal Nº 13.691 de 2005). Ao mesmo tempo, foi dado início à Pesquisa de Origem e Destino, que se constitui em uma completa e importante fonte de informações para o planejamento urbano e de transportes da cidade.

Em conseqüência dos estudos efetuados para atualização do Plano Diretor e do desenvolvimento da Pesquisa Origem e Destino, um grande número de dados e informações foram coletados ou atualizados para a cidade. Assim, em função da existência de grande volume de dados para cálculo dos indicadores e da maior facilidade de acesso 
aos mesmos devido à localização geográfica e à disponibilidade da Prefeitura Municipal de São Carlos em fornecer informações para o estudo, a cidade de São Carlos foi escolhida para validação do IMUS.

Nas etapas seguintes é descrito o processo de obtenção dos dados, bem como a análise qualitativa dos mesmos, seguido do cálculo do índice para a cidade e a análise dos resultados obtidos.

\subsection{Coleta e Avaliação da Qualidade dos Dados para Cálculo do IMUS}

O processo de cálculo do IMUS foi precedido por uma coleta de dados envolvendo: levantamentos de campo; entrevistas com técnicos de órgãos e secretarias da Prefeitura Municipal, juntamente com a recolha de documentação relacionada aos indicadores; consultas à base de dados de institutos de pesquisa e estatística nacionais e estaduais, além de estudos desenvolvidos em âmbito acadêmico para a cidade e estado de São Paulo.

Na Prefeitura Municipal de São Carlos foram consultadas as secretarias municipais de Transporte, Trânsito e Vias Públicas; Habitação e Desenvolvimento Urbano e Desenvolvimento Sustentável, Ciência e Tecnologia, as quais são responsáveis por áreas contempladas pelos indicadores do IMUS, além de base de dados de legislação e outras informações disponíveis no endereço oficial da Câmara de Vereadores e Prefeitura Municipal de São Carlos na Internet.

Informações em formato de desenhos, bases georreferenciadas, relatórios e banco de dados foram fornecidos pelas secretarias mencionadas. Quando os dados não se encontravam disponíveis ou não podiam ser fornecidos por razões de origem diversa, o score do indicador era obtido diretamente junto a técnicos de cada secretaria.

A relação de dados solicitados às secretarias, bem como aqueles pesquisados em outras fontes diretas e indiretas observou as informações contidas no Anexo E - "Guia para Elaboração dos Indicadores do IMUS". Em função de não haver uma coleta periódica ou atualização mais recente dos dados necessários para cálculo de alguns indicadores, foram relacionados dados para o período entre 2000 a 2007. Apesar de não se constituir em uma situação ideal, esta possibilidade foi considerada de forma a permitir a avaliação de um número maior de indicadores, visando proporcionar uma visão mas ampla da mobilidade urbana em São Carlos. Além disso, considera-se que os dados produzidos para o período apresentam razoável atualização, não comprometendo os resultados finais do índice. 
A informação coletada foi posteriormente organizada, permitindo avaliar a possibilidade de cálculo de cada indicador, conforme procedimentos descritos no item 6.4 do Método. Com base nesta abordagem, a viabilidade de aplicação do IMUS para a cidade foi avaliada de acordo com a disponibilidade e qualidade dos dados de base para cálculo dos indicadores. Estes aspectos são analisados segundo a escala apresentada na Tabela 6.1, que qualifica a disponibilidade de dados em curto, médio e longo prazo e a qualidade dos mesmos nos níveis alta, média e baixa. A combinação da avaliação referente à disponibilidade e qualidade dos dados indica, portanto, a mensurabilidade do indicador.

Neste estudo, mesmo os indicadores com qualidade média e baixa foram calculados mantendo-se, no entanto, ressalvas em relação aos resultados obtidos. Os indicadores cujos dados não encontravam-se disponíveis e não havia perspectivas de sua obtenção em curto ou médio prazo, não puderam ser incorporados à análise do IMUS. Para estes, conseqüentemente, não foi possível avaliar sua qualidade.

A Tabela 9.2 apresenta a síntese da coleta e avaliação dos dados de base para os indicadores que compõem o IMUS. No final da tabela encontram-se todas as notas de rodapé referentes a observações a respeito dos resultados obtidos. São relacionados, para cada indicador, seus respectivos dados, as fontes consultadas e a avaliação conforme disponibilidade e qualidade. Na coluna à direita é apresentada a avaliação final do indicador, a partir da combinação dos dois critérios. A disponibilidade e qualidade são representadas através dos seguintes códigos:

- Disponibilidade:

- C - Curto prazo;

- M - Médio Prazo;

- L - Longo Prazo;

- Qualidade:

- A - Alta;

- M - Média;

- B - Baixa.

Uma vez que esta avaliação permitiu verificar que grande parte dos indicadores do IMUS poderiam ser calculados e ainda, na sua maioria, com qualidade alta ou média (ver detalhes no item 9.5.1), deu-se início ao processo de cálculo do índice para a cidade de São Carlos, conforme descrito a seguir. 
Tabela 9.2: Síntese da avaliação de qualidade e disponibilidade de dados para os indicadores do IMUS.

\begin{tabular}{|c|c|c|c|c|c|c|c|}
\hline DOM. & TEMA & INDICADOR & DADOS DE BASE & FONTES & DISP. & QUAL. & RESULT. \\
\hline \multirow{25}{*}{ 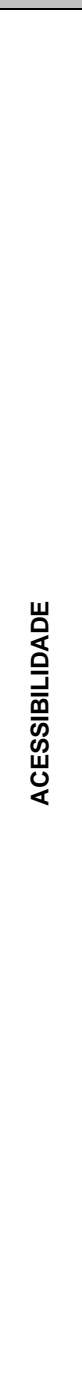 } & \multirow{7}{*}{$\begin{array}{l}\text { Acessibilidade aos sistemas } \\
\text { de transportes }\end{array}$} & \multirow{3}{*}{$\begin{array}{l}\text { Acessibilidade ao transporte } \\
\text { público }\end{array}$} & Base georreferenciada de pontos de ônibus & $\begin{array}{l}\text { Empresa operadora de transporte público de São } \\
\text { Carlos (2007) }\end{array}$ & c & A & \multirow{3}{*}{$\mathrm{CA}$} \\
\hline & & & Base georreferenciada do município & $\begin{array}{l}\text { Serviço Autônomo de Água e Esgoto - SAAE } \\
(2006)\end{array}$ & c & A & \\
\hline & & & $\begin{array}{l}\text { Base georreferenciada de Setores } \\
\text { Censitários }\end{array}$ & $\begin{array}{l}\text { Instituto Brasileiro de Geografia e Estatística - } \\
\text { IBGE (2000) }\end{array}$ & c & A & \\
\hline & & \multirow{2}{*}{$\begin{array}{l}\text { Transporte público para pessoas } \\
\text { com necessidades especiais }\end{array}$} & Frota operacional de transporte coletivo & $\begin{array}{l}\text { Secretaria Municipal de Transporte, Trânsito e } \\
\text { Vias Públicas (2008) }\end{array}$ & c & A & \multirow{2}{*}{$\mathrm{CA}$} \\
\hline & & & $\begin{array}{l}\text { Veículos/serviços para pessoas com } \\
\text { necessidades especiais }\end{array}$ & $\begin{array}{l}\text { Secretaria Municipal de Transporte, Trânsito e } \\
\text { Vias Públicas (2008) }\end{array}$ & c & A & \\
\hline & & \multirow[b]{2}{*}{ Despesas com transporte } & Rendimento médio mensal pessoal & Pesquisa Origem e Destino de São Carlos (2007) & $\mathrm{C}$ & $\mathrm{M}^{1}$ & \multirow[b]{2}{*}{$\mathrm{CM}$} \\
\hline & & & Tarifa básica de transporte coletivo & $\begin{array}{l}\text { Secretaria Municipal de Transporte, Trânsito e } \\
\text { Vias Públicas (2008) }\end{array}$ & c & A & \\
\hline & \multirow{15}{*}{ Acessibilidade universal } & \multirow{3}{*}{$\begin{array}{l}\text { Travessias adaptadas a pessoas } \\
\text { com necessidades especiais }\end{array}$} & Base georreferenciada do município & $\begin{array}{l}\text { Serviço Autônomo de Água e Esgoto - SAAE } \\
(2006)\end{array}$ & c & A & \multirow{3}{*}{$\mathrm{CA}$} \\
\hline & & & Hierarquização Viária & $\begin{array}{l}\text { Levantamentos do Plano Diretor Municipal (2001- } \\
\text { 2002) }\end{array}$ & c & A & \\
\hline & & & $\begin{array}{l}\text { Travessias adaptadas para pessoas com } \\
\text { necessidades especiais }\end{array}$ & Levantamento de campo (2008) & c & A & \\
\hline & & \multirow{3}{*}{ Acessibilidade a espaços abertos } & Base georreferenciada do município & $\begin{array}{l}\text { Serviço Autônomo de Água e Esgoto - SAAE } \\
\text { (2006) }\end{array}$ & c & A & \multirow{3}{*}{$\mathrm{CA}$} \\
\hline & & & $\begin{array}{l}\text { Base georreferenciada de Setores } \\
\text { Censitários }\end{array}$ & $\begin{array}{l}\text { Instituto Brasileiro de Geografia e Estatística - } \\
\text { IBGE (2000) }\end{array}$ & c & A & \\
\hline & & & $\begin{array}{l}\text { Croquis do Censo } 2000 \text { contendo as áreas } \\
\text { verdes do município }\end{array}$ & $\begin{array}{l}\text { Instituto Brasileiro de Geografia e Estatística - } \\
\text { IBGE (2000) }\end{array}$ & c & A & \\
\hline & & \multirow{3}{*}{$\begin{array}{l}\text { Vagas de estacionamento para } \\
\text { pessoas com necessidades } \\
\text { especiais }\end{array}$} & Vagas em estacionamentos públicos rotativos & $\begin{array}{l}\text { Secretaria Municipal de Transporte, Trânsito e } \\
\text { Vias Públicas (2008) }\end{array}$ & c & A & \multirow{3}{*}{$\mathrm{CA}$} \\
\hline & & & $\begin{array}{l}\text { Vagas em estacionamentos públicos rotativos } \\
\text { para pessoas com necessidades especiais }\end{array}$ & $\begin{array}{l}\text { Secretaria Municipal de Transporte, Trânsito e } \\
\text { Vias Públicas (2008) }\end{array}$ & c & A & \\
\hline & & & $\begin{array}{l}\text { Delimitação e sinalização das vagas para } \\
\text { pessoas com necessidades especiais }\end{array}$ & $\begin{array}{l}\text { Secretaria Municipal de Transporte, Trânsito e } \\
\text { Vias Públicas (2008) }\end{array}$ & c & A & \\
\hline & & \multirow{2}{*}{$\begin{array}{l}\text { Acessibilidade a edifícios } \\
\text { públicos }\end{array}$} & Edifícios públicos & - & $\mathrm{L}^{2}$ & - & \multirow[b]{2}{*}{$\mathrm{L}$} \\
\hline & & & $\begin{array}{l}\text { Edifícios públicos adaptados para pessoas } \\
\text { com necessidades especiais }\end{array}$ & - & $\mathrm{L}^{2}$ & - & \\
\hline & & \multirow{4}{*}{$\begin{array}{l}\text { Acessibilidade aos serviços } \\
\text { essenciais }\end{array}$} & Base georreferenciada do município & $\begin{array}{l}\text { Serviço Autônomo de Água e Esgoto - SAAE } \\
\text { (2006) }\end{array}$ & c & A & \multirow{4}{*}{$\mathrm{CA}$} \\
\hline & & & $\begin{array}{l}\text { Base georreferenciada de Setores } \\
\text { Censitários }\end{array}$ & $\begin{array}{l}\text { Instituto Brasileiro de Geografia e Estatística - } \\
\text { IBGE (2000) }\end{array}$ & c & A & \\
\hline & & & $\begin{array}{l}\text { Base georreferenciada de equipamentos de } \\
\text { saúde }\end{array}$ & $\begin{array}{l}\text { Secretaria Municipal da Habitação e } \\
\text { Desenvolvimento Urbano (2008) }\end{array}$ & c & A & \\
\hline & & & $\begin{array}{l}\text { Base georreferenciada de equipamentos de } \\
\text { educação }\end{array}$ & $\begin{array}{l}\text { Secretaria Municipal da Habitação e } \\
\text { Desenvolvimento Urbano (2008) }\end{array}$ & c & A & \\
\hline & Barreiras físicas & Fragmentação urbana & Base georreferenciada do município & $\begin{array}{l}\text { Serviço Autônomo de Água e Esgoto - SAAE } \\
(2006)\end{array}$ & c & A & CA \\
\hline & \multirow{2}{*}{$\begin{array}{l}\text { Legislação para pessoas } \\
\text { com necessidades especiais }\end{array}$} & \multirow{2}{*}{$\begin{array}{l}\text { Ações para acessibilidade } \\
\text { universal }\end{array}$} & \multirow{2}{*}{$\begin{array}{l}\text { Ações, medidas, programas e instrumentos } \\
\text { voltados à promoção da acessibilidade } \\
\text { universal }\end{array}$} & $\begin{array}{l}\text { Secretaria Municipal de Transporte, Trânsito e } \\
\text { Vias Públicas (2008) }\end{array}$ & c & A & \multirow{2}{*}{$\mathrm{CA}$} \\
\hline & & & & $\begin{array}{l}\text { Secretaria Municipal da Habitação e } \\
\text { Desenvolvimento Urbano (2008) }\end{array}$ & c & A & \\
\hline
\end{tabular}




\begin{tabular}{|c|c|c|c|c|c|c|c|}
\hline DOM. & TEMA & INDICADOR & DADOS DE BASE & FONTES & DISP. & QUAL. & RESULT \\
\hline \multirow{21}{*}{ 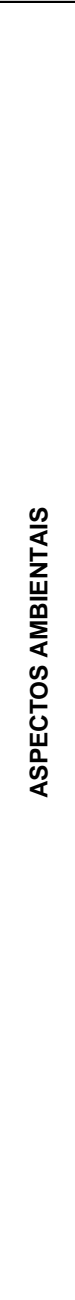 } & \multirow{15}{*}{$\begin{array}{l}\text { Controle dos impactos no } \\
\text { meio ambiente }\end{array}$} & \multirow{5}{*}{ Emissões de CO } & Frota Municipal & Departamento Nacional de Trânsito (2007) & C & A & \multirow{5}{*}{$\mathrm{CM}$} \\
\hline & & & $\begin{array}{l}\text { Frota de veículos por ano de fabricação para } \\
\text { o interior do estado de São Paulo }\end{array}$ & $\begin{array}{l}\text { Departamento Estadual de Trânsito de São Paulo } \\
\text { (2008) }\end{array}$ & c & $\mathrm{M}^{3}$ & \\
\hline & & & $\begin{array}{l}\text { Participação percentual nas vendas de } \\
\text { veículos leves no mercado interno por } \\
\text { combustível e ano modelo }\end{array}$ & $\begin{array}{l}\text { Mendes, F. E. (2004). Avaliação de Programas de } \\
\text { Controle de Poluição Atmosférica por Veículos } \\
\text { Leves no Brasil }\end{array}$ & c & $\mathrm{M}^{4}$ & \\
\hline & & & $\begin{array}{l}\text { Fatores de Emissão do poluente CO para } \\
\text { veículos segundo ano de fabricação e } \\
\text { combustível }\end{array}$ & $\begin{array}{l}\text { Companhia de Saneamento Ambiental do Estado } \\
\text { de São Paulo (2008) }\end{array}$ & c & A & \\
\hline & & & $\begin{array}{l}\text { Quilometragem anual percorrida pela frota } \\
\text { municipal }\end{array}$ & $\begin{array}{l}\text { Landmann. M. C. (2004). Estimativa das } \\
\text { Emissões de Poluentes dos Automóveis da RMSP } \\
\text { Considerando as Rotas de Tráfego }\end{array}$ & c & $M^{5}$ & \\
\hline & & \multirow{5}{*}{ Emissões de $\mathrm{CO}_{2}$} & Frota Municipal & Departamento Nacional de Trânsito (2007) & $\mathrm{C}$ & A & \multirow{5}{*}{$\mathrm{CM}$} \\
\hline & & & $\begin{array}{l}\text { Frota de veículos por ano de fabricação para } \\
\text { o interior do estado de São Paulo }\end{array}$ & $\begin{array}{l}\text { Departamento Estadual de Trânsito de São Paulo } \\
\text { (2008) }\end{array}$ & c & $\mathrm{M}^{2}$ & \\
\hline & & & $\begin{array}{l}\text { Participação percentual nas vendas de } \\
\text { veículos leves no mercado interno por } \\
\text { combustível e ano modelo }\end{array}$ & $\begin{array}{l}\text { Mendes, F. E. (2004). Avaliação de Programas de } \\
\text { Controle de Poluição Atmosférica por Veículos } \\
\text { Leves no Brasil }\end{array}$ & c & $\mathrm{M}^{3}$ & \\
\hline & & & $\begin{array}{l}\text { Fatores de Emissão do poluente } \mathrm{CO}_{2} \text { para } \\
\text { veículos segundo ano de fabricação e } \\
\text { combustível }\end{array}$ & $\begin{array}{l}\text { Companhia de Saneamento Ambiental do Estado } \\
\text { de São Paulo (2008) }\end{array}$ & c & A & \\
\hline & & & $\begin{array}{l}\text { Quilometragem anual percorrida pela frota } \\
\text { municipal }\end{array}$ & $\begin{array}{l}\text { Landmann. M. C. (2004). Estimativa das } \\
\text { Emissões de Poluentes dos Automóveis da RMSP } \\
\text { Considerando as Rotas de Tráfego }\end{array}$ & c & $\mathrm{M}^{4}$ & \\
\hline & & \multirow{2}{*}{$\begin{array}{l}\text { População exposta ao ruído de } \\
\text { tráfego }\end{array}$} & Base georreferenciada do município & $\begin{array}{l}\text { Serviço Autônomo de Água e Esgoto - SAAE } \\
\text { (2006) }\end{array}$ & c & A & \multirow[t]{2}{*}{ CA } \\
\hline & & & Níveis de ruído em vias urbanas & Levantamento de campo (2008) & C & A & \\
\hline & & \multirow{3}{*}{ Estudos de Impacto Ambiental } & & $\begin{array}{l}\text { Secretaria Municipal da Habitação e } \\
\text { Desenvolvimento Urbano (2008) }\end{array}$ & c & A & \multirow{3}{*}{ CA } \\
\hline & & & $\begin{array}{l}\text { Estudos de impacto ambiental e de } \\
\text { vizinhança e medidas mitigadoras }\end{array}$ & $\begin{array}{l}\text { Secretaria Municipal de Desenvolvimento } \\
\text { Sustentável, Ciência e Tecnologia (2008) }\end{array}$ & c & A & \\
\hline & & & & Plano Diretor Municipal (2005) & C & A & \\
\hline & \multirow{6}{*}{ Recursos naturais } & \multirow{4}{*}{ Consumo de combustível } & Frota Municipal & Departamento Nacional de Trânsito (2007) & C & A & \multirow{4}{*}{$\mathrm{CM}$} \\
\hline & & & $\begin{array}{l}\text { Participação percentual nas vendas de } \\
\text { veículos leves no mercado interno por } \\
\text { combustível e ano modelo }\end{array}$ & $\begin{array}{l}\text { Mendes, F. E. (2004). Avaliação de Programas de } \\
\text { Controle de Poluição Atmosférica por Veículos } \\
\text { Leves no Brasil }\end{array}$ & c & $M^{3}$ & \\
\hline & & & $\begin{array}{l}\text { Quilometragem anual percorrida pela frota } \\
\text { municipal }\end{array}$ & $\begin{array}{l}\text { Landmann. M. C. (2004). Estimativa das } \\
\text { Emissões de Poluentes dos Automóveis da RMSP } \\
\text { Considerando as Rotas de Tráfego }\end{array}$ & c & $\mathrm{M}^{4}$ & \\
\hline & & & Estimativa da população & $\begin{array}{l}\text { Instituto Brasileiro de Geografia e Estatística - } \\
\text { IBGE (2008) }\end{array}$ & c & A & \\
\hline & & \multirow{2}{*}{$\begin{array}{l}\text { Uso de energia limpa e } \\
\text { combustíveis alternativos }\end{array}$} & Frota operacional de transporte coletivo & $\begin{array}{l}\text { Secretaria Municipal de Transporte, Trânsito e } \\
\text { Vias Públicas (2008) }\end{array}$ & c & A & \multirow{2}{*}{$\mathrm{CA}$} \\
\hline & & & $\begin{array}{l}\text { Frota operacional de veículos usando } \\
\text { combustíveis alternativos }\end{array}$ & $\begin{array}{l}\text { Secretaria Municipal de Transporte, Trânsito e } \\
\text { Vias Públicas (2008) }\end{array}$ & c & A & \\
\hline
\end{tabular}




\begin{tabular}{|c|c|c|c|c|c|c|c|}
\hline DOM. & TEMA & INDICADOR & DADOS DE BASE & FONTES & DISP. & QUAL. & RESULT. \\
\hline \multirow{12}{*}{ 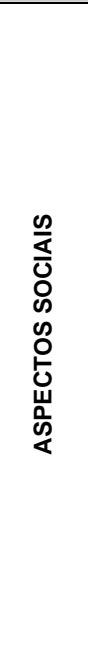 } & \multirow{3}{*}{ Apoio ao cidadão } & \multirow{3}{*}{ Informação disponível ao cidadão } & Informação sobre serviços de transporte & \multirow{3}{*}{$\begin{array}{l}\text { Endereço Oficial da Prefeitura Municipal de São } \\
\text { Carlos na Internet (2008) }\end{array}$} & C & A & \multirow{3}{*}{ CA } \\
\hline & & & $\begin{array}{l}\text { Canais de comunicação para denúncias e } \\
\text { reclamações sobre serviços de transporte }\end{array}$ & & c & A & \\
\hline & & & $\begin{array}{l}\text { Informações sobre planos e projetos de } \\
\text { transporte e mobilidade urbana }\end{array}$ & & c & A & \\
\hline & \multirow{2}{*}{ Inclusão social } & \multirow{2}{*}{ Eqüidade vertical (renda) } & Rendimento médio mensal pessoal & Pesquisa Origem e Destino de São Carlos (2007) & $\mathrm{C}$ & $M^{1}$ & \multirow{2}{*}{ CM } \\
\hline & & & Número médio de viagens em dia útil & Pesquisa Origem e Destino de São Carlos (2007) & $\mathrm{C}$ & $\mathrm{M}^{1}$ & \\
\hline & \multirow{3}{*}{ Educação e cidadania } & \multirow{3}{*}{$\begin{array}{l}\text { Educação para o } \\
\text { desenvolvimento sustentável }\end{array}$} & $\begin{array}{l}\text { Equipamentos destinados à educação } \\
\text { ambiental e educação para o DS }\end{array}$ & \multirow{3}{*}{$\begin{array}{l}\text { Secretaria Municipal de Desenvolvimento } \\
\text { Sustentável, Ciência e Tecnologia (2008) }\end{array}$} & c & A & \multirow{3}{*}{ CA } \\
\hline & & & $\begin{array}{l}\text { Ações continuadas de formação em matéria } \\
\text { de desenvolvimento sustentável }\end{array}$ & & c & A & \\
\hline & & & $\begin{array}{l}\text { Ações de sensibilização em matéria de } \\
\text { desenvolvimento sustentável }\end{array}$ & & C & A & \\
\hline & Participação popular & $\begin{array}{l}\text { Participação na tomada de } \\
\text { decisão }\end{array}$ & $\begin{array}{l}\text { Participação popular nos processos de } \\
\text { elaboração, implementação e monitoramento } \\
\text { das políticas, ações e projetos de transporte e } \\
\text { mobilidade urbana }\end{array}$ & $\begin{array}{l}\text { Endereço Oficial da Prefeitura Municipal de São } \\
\text { Carlos na Internet (2008) }\end{array}$ & c & A & CA \\
\hline & \multirow{3}{*}{ Qualidade de vida } & \multirow{3}{*}{ Qualidade de Vida } & \multirow{2}{*}{$\begin{array}{l}\text { Pesquisa de Opinião sobre Qualidade de } \\
\text { Vida Urbana }\end{array}$} & $\begin{array}{l}\text { Secretaria Municipal de Transporte, Trânsito e } \\
\text { Vias Públicas (2008) }\end{array}$ & $\mathrm{L}^{2}$ & - & \multirow{3}{*}{$\mathrm{L}$} \\
\hline & & & & $\begin{array}{l}\text { Secretaria Municipal da Habitação e } \\
\text { Desenvolvimento Urbano (2008) }\end{array}$ & $\mathrm{L}^{2}$ & - & \\
\hline & & & $\begin{array}{l}\text { População satisfeita com a cidade como local } \\
\text { para viver }\end{array}$ & $\begin{array}{l}\text { Secretaria Municipal de Desenvolvimento } \\
\text { Sustentável, Ciência e Tecnologia (2008) }\end{array}$ & $\mathrm{L}^{2}$ & - & \\
\hline \multirow{10}{*}{ 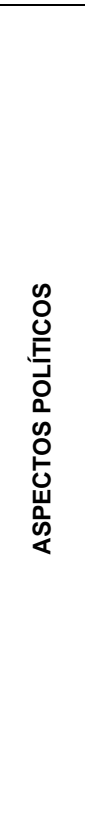 } & \multirow[t]{2}{*}{ Integração de ações políticas } & $\begin{array}{l}\text { Integração entre níveis de } \\
\text { governo }\end{array}$ & $\begin{array}{l}\text { Ações, planos e projetos de transportes e } \\
\text { mobilidade urbana desenvolvidos pelo } \\
\text { município no ano de referência, em parceria } \\
\text { ou com recursos do governo estadual e/ou } \\
\text { governo federal }\end{array}$ & $\begin{array}{l}\text { Secretaria Municipal de Transporte, Trânsito e } \\
\text { Vias Públicas (2008) }\end{array}$ & C & A & CA \\
\hline & & Parcerias público/privadas & $\begin{array}{l}\text { Ações, projetos, serviços ou infra-estrutura de } \\
\text { transporte urbano viabilizados por meio de } \\
\text { parcerias entre o governo municipal e } \\
\text { entidades privadas }\end{array}$ & $\begin{array}{l}\text { Secretaria Municipal de Transporte, Trânsito e } \\
\text { Vias Públicas (2008) }\end{array}$ & C & A & CA \\
\hline & \multirow{7}{*}{$\begin{array}{l}\text { Captação e gerenciamento } \\
\text { de recursos }\end{array}$} & \multirow[t]{2}{*}{ Captação de recursos } & $\begin{array}{l}\text { Recursos públicos aplicados em transportes e } \\
\text { mobilidade urbana }\end{array}$ & - & $\mathrm{L}^{2}$ & - & \multirow[t]{2}{*}{ L } \\
\hline & & & Recursos oriundos de multas e taxações & - & $L^{2}$ & - & \\
\hline & & $\begin{array}{l}\text { Investimentos em sistemas de } \\
\text { transportes }\end{array}$ & $\begin{array}{l}\text { Tipos de investimentos feitos em sistemas de } \\
\text { transportes e mobilidade pelo município }\end{array}$ & $\begin{array}{l}\text { Secretaria Municipal de Transporte, Trânsito e } \\
\text { Vias Públicas (2008) }\end{array}$ & c & A & CA \\
\hline & & \multirow{2}{*}{$\begin{array}{l}\text { Distribuição dos recursos } \\
\text { (público x privado) }\end{array}$} & $\begin{array}{l}\text { Investimentos em provisão, ampliação, } \\
\text { melhoria e manutenção da infra-estrutura } \\
\text { para o transporte coletivo }\end{array}$ & $\begin{array}{l}\text { Secretaria Municipal de Transporte, Trânsito e } \\
\text { Vias Públicas (2008) }\end{array}$ & C & $B^{6}$ & \multirow{2}{*}{$\mathrm{CB}$} \\
\hline & & & $\begin{array}{l}\text { Investimentos em provisão, ampliação, } \\
\text { melhoria e manutenção da infra-estrutura } \\
\text { para o transporte privado }\end{array}$ & $\begin{array}{l}\text { Secretaria Municipal de Transporte, Trânsito e } \\
\text { Vias Públicas (2008) }\end{array}$ & c & $B^{6}$ & \\
\hline & & \multirow{2}{*}{$\begin{array}{l}\text { Distribuição dos recursos } \\
\text { (motorizados } \times \text { não-motorizados) }\end{array}$} & $\begin{array}{l}\text { Investimentos em provisão, ampliação, } \\
\text { melhoria e manutenção da infra-estrutura } \\
\text { para modos não-motorizados }\end{array}$ & $\begin{array}{l}\text { Secretaria Municipal de Transporte, Trânsito e } \\
\text { Vias Públicas (2008) }\end{array}$ & c & $\mathrm{B}^{6}$ & \multirow[b]{2}{*}{ CB } \\
\hline & & & $\begin{array}{l}\text { Investimentos relacionados à provisão, } \\
\text { ampliação, melhoria e manutenção da infra- } \\
\text { estrutura para modos de transportes } \\
\text { motorizados (coletivos ou privados) }\end{array}$ & $\begin{array}{l}\text { Secretaria Municipal de Transporte, Trânsito e } \\
\text { Vias Públicas (2008) }\end{array}$ & C & $B^{6}$ & \\
\hline & $\begin{array}{l}\text { Política de mobilidade } \\
\text { urbana }\end{array}$ & Política de mobilidade urbana & $\begin{array}{l}\text { Política de transportes e mobilidade urbana } \\
\text { em nível local }\end{array}$ & $\begin{array}{l}\text { Secretaria Municipal de Transporte, Trânsito e } \\
\text { Vias Públicas (2008) }\end{array}$ & c & A & CA \\
\hline
\end{tabular}




\begin{tabular}{|c|c|c|c|c|c|c|c|}
\hline DOM. & TEMA & INDICADOR & DADOS DE BASE & FONTES & DISP. & QUAL. & RESULT. \\
\hline \multirow{8}{*}{ 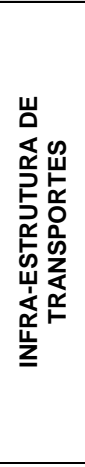 } & \multirow{6}{*}{$\begin{array}{l}\text { Provisão e manutenção da } \\
\text { infra-estrutura de transportes }\end{array}$} & Densidade da rede viária & Base georreferenciada do município & $\begin{array}{l}\text { Serviço Autônomo de Água e Esgoto - SAAE } \\
\text { (2006) }\end{array}$ & c & A & $\mathrm{CA}$ \\
\hline & & \multirow{2}{*}{ Vias pavimentadas } & Base georreferenciada do município & $\begin{array}{l}\text { Serviço Autônomo de Água e Esgoto - SAAE } \\
\text { (2006) }\end{array}$ & c & A & \multirow{2}{*}{$\mathrm{CM}$} \\
\hline & & & $\begin{array}{l}\text { Base georreferenciada de vias a serem } \\
\text { pavimentadas }\end{array}$ & $\begin{array}{l}\text { Secretaria Municipal de Transporte, Trânsito e } \\
\text { Vias Públicas (2007) }\end{array}$ & C & $M^{7}$ & \\
\hline & & $\begin{array}{l}\text { Despesas com manutenção da } \\
\text { infra-estrutura de transportes }\end{array}$ & $\begin{array}{l}\text { Investimentos em manutenção e conservação } \\
\text { de infra-estrutura de transportes }\end{array}$ & $\begin{array}{l}\text { Secretaria Municipal de Transporte, Trânsito e } \\
\text { Vias Públicas (2008) }\end{array}$ & c & $\mathrm{B}^{6}$ & CB \\
\hline & & \multirow{2}{*}{ Sinalização viária } & $\begin{array}{l}\text { Pesquisa de Opinião sobre qualidade da } \\
\text { sinalização urbana }\end{array}$ & $\begin{array}{l}\text { Secretaria Municipal de Transporte, Trânsito e } \\
\text { Vias Públicas (2008) }\end{array}$ & $\mathrm{L}^{2}$ & - & \multirow{2}{*}{$\mathrm{L}$} \\
\hline & & & $\begin{array}{l}\text { Avaliação por parte da população em relação } \\
\text { à qualidade da sinalização }\end{array}$ & $\begin{array}{l}\text { Secretaria Municipal de Transporte, Trânsito e } \\
\text { Vias Públicas (2008) }\end{array}$ & $\mathrm{L}^{2}$ & - & \\
\hline & \multirow{2}{*}{$\begin{array}{l}\text { Distribuição da infra- } \\
\text { estrutura de transportes }\end{array}$} & \multirow{2}{*}{ Vias para transporte coletivo } & Base georreferenciada do município & $\begin{array}{l}\text { Serviço Autônomo de Água e Esgoto - SAAE } \\
\text { (2006) }\end{array}$ & C & A & \multirow{2}{*}{ CA } \\
\hline & & & $\begin{array}{l}\text { Base georreferenciada de linhas de ônibus } \\
\text { urbanas }\end{array}$ & $\begin{array}{l}\text { Secretaria Municipal de Transporte, Trânsito e } \\
\text { Vias Públicas (2008) }\end{array}$ & C & A & \\
\hline \multirow{15}{*}{ 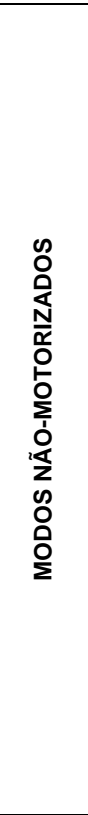 } & \multirow{6}{*}{ Transporte cicloviário } & \multirow{2}{*}{ Extensão de ciclovias } & Base georreferenciada do município & $\begin{array}{l}\text { Serviço Autônomo de Água e Esgoto - SAAE } \\
(2006)\end{array}$ & c & A & \multirow{2}{*}{ CA } \\
\hline & & & Base georreferenciada de ciclovias & $\begin{array}{l}\text { Secretaria Municipal de Transporte, Trânsito e } \\
\text { Vias Públicas (2007) }\end{array}$ & C & A & \\
\hline & & \multirow[b]{2}{*}{ Frota de bicicletas } & Frota de bicicletas para transporte & - & $L^{2}$ & - & \multirow[b]{2}{*}{$\mathrm{L}$} \\
\hline & & & Estimativa da população & $\begin{array}{l}\text { Instituto Brasileiro de Geografia e Estatística - } \\
\text { IBGE (2007) }\end{array}$ & c & A & \\
\hline & & \multirow{2}{*}{ Estacionamento para bicicletas } & Terminais urbanos de transporte coletivo & $\begin{array}{l}\text { Secretaria Municipal de Transporte, Trânsito e } \\
\text { Vias Públicas (2008) }\end{array}$ & C & A & \multirow{2}{*}{ CA } \\
\hline & & & $\begin{array}{l}\text { Terminais urbanos de transporte coletivo com } \\
\text { estacionamento para bicicletas }\end{array}$ & $\begin{array}{l}\text { Secretaria Municipal de Transporte, Trânsito e } \\
\text { Vias Públicas (2008) }\end{array}$ & C & A & \\
\hline & \multirow{4}{*}{ Deslocamentos a pé } & \multirow{2}{*}{ Vias para pedestres } & Base georreferenciada do município & $\begin{array}{l}\text { Serviço Autônomo de Água e Esgoto - SAAE } \\
\text { (2006) }\end{array}$ & c & A & \multirow{2}{*}{ CA } \\
\hline & & & $\begin{array}{l}\text { Base georreferenciada de vias e passarelas } \\
\text { de pedestres }\end{array}$ & $\begin{array}{l}\text { Secretaria Municipal de Transporte, Trânsito e } \\
\text { Vias Públicas (2008) }\end{array}$ & c & A & \\
\hline & & \multirow{2}{*}{ Vias com calçadas } & Base georreferenciada do município & $\begin{array}{l}\text { Serviço Autônomo de Água e Esgoto - SAAE } \\
(2006)\end{array}$ & C & A & \multirow{2}{*}{ CA } \\
\hline & & & $\begin{array}{l}\text { Base georreferenciada com vias e passarelas } \\
\text { de pedestres }\end{array}$ & $\begin{array}{l}\text { Secretaria Municipal de Transporte, Trânsito e } \\
\text { Vias Públicas (2008) }\end{array}$ & C & A & \\
\hline & \multirow{5}{*}{ Redução de viagens } & Distância de viagem & $\begin{array}{l}\text { Distância média de viagem para cada modo } \\
\text { de transporte }\end{array}$ & Pesquisa Origem e Destino de São Carlos (2007) & c & $M^{1}$ & $\mathrm{CM}$ \\
\hline & & \multirow{2}{*}{ Tempo de viagem } & $\begin{array}{l}\text { Distância média de viagem para cada modo } \\
\text { de transporte }\end{array}$ & Pesquisa Origem e Destino de São Carlos (2007) & c & $M^{1}$ & \multirow{2}{*}{$\mathrm{CM}$} \\
\hline & & & $\begin{array}{l}\text { Velocidade média de deslocamento para } \\
\text { cada modo de transporte }\end{array}$ & $\begin{array}{l}\text { Ministério das Cidades (2007b) e Ferraz e Torres } \\
\text { (2001) }\end{array}$ & C & A & \\
\hline & & Número de viagens & Viagens em dia útil na área urbana & Pesquisa Origem e Destino de São Carlos (2007) & C & $M^{1}$ & $\mathrm{CM}$ \\
\hline & & $\begin{array}{l}\text { Ações para redução do tráfego } \\
\text { motorizado }\end{array}$ & $\begin{array}{l}\text { Políticas, estratégias e ações visando a } \\
\text { redução do tráfego motorizado }\end{array}$ & $\begin{array}{l}\text { Secretaria Municipal de Transporte, Trânsito e } \\
\text { Vias Públicas (2008) }\end{array}$ & c & A & CA \\
\hline
\end{tabular}




\begin{tabular}{|c|c|c|c|c|c|c|c|}
\hline DOM. & TEMA & INDICADOR & DADOS DE BASE & FONTES & DISP. & QUAL. & RESULT. \\
\hline \multirow{21}{*}{ 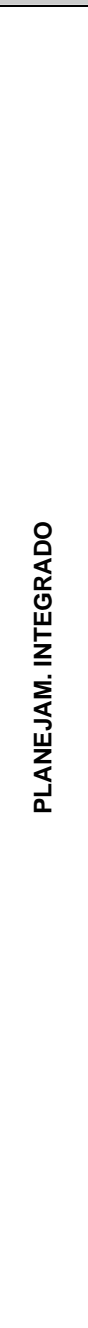 } & \multirow{4}{*}{ Capacitação de gestores } & \multirow[t]{2}{*}{$\begin{array}{l}\text { Nível de formação de técnicos e } \\
\text { gestores }\end{array}$} & $\begin{array}{l}\text { Funcionários da administração municipal, em } \\
\text { nível técnico e gerencial, em órgãos ligados } \\
\text { ao planejamento urbano, transportes e } \\
\text { mobilidade }\end{array}$ & $\begin{array}{l}\text { Secretaria Municipal de Transporte, Trânsito e } \\
\text { Vias Públicas (2008) }\end{array}$ & C & $\mathrm{B}^{8}$ & \multirow[t]{2}{*}{$\mathrm{CB}$} \\
\hline & & & Funcionários com qualificação superior & $\begin{array}{l}\text { Secretaria Municipal de Transporte, Trânsito e } \\
\text { Vias Públicas (2008) }\end{array}$ & C & $B^{8}$ & \\
\hline & & \multirow{2}{*}{$\begin{array}{l}\text { Capacitação de técnicos e } \\
\text { gestores }\end{array}$} & $\begin{array}{l}\text { Funcionários da administração municipal, em } \\
\text { nível técnico e gerencial, em órgãos ligados } \\
\text { ao planejamento urbano, transportes e } \\
\text { mobilidade }\end{array}$ & $\begin{array}{l}\text { Secretaria Municipal de Transporte, Trânsito e } \\
\text { Vias Públicas (2008) }\end{array}$ & C & $B^{8}$ & \multirow[t]{2}{*}{$\mathrm{CB}$} \\
\hline & & & $\begin{array}{l}\text { Horas de cursos e programas de treinamento } \\
\text { e capacitação }\end{array}$ & $\begin{array}{l}\text { Secretaria Municipal de Transporte, Trânsito e } \\
\text { Vias Públicas (2008) }\end{array}$ & C & $B^{8}$ & \\
\hline & \multirow{2}{*}{$\begin{array}{l}\text { Áreas centrais e de interesse } \\
\text { histórico }\end{array}$} & \multirow{2}{*}{ Vitalidade do centro } & Base georreferenciada do município & $\begin{array}{l}\text { Serviço Autônomo de Água e Esgoto - SAAE } \\
\text { (2006) }\end{array}$ & C & A & \multirow{2}{*}{ CA } \\
\hline & & & $\begin{array}{l}\text { Base georreferenciada dos tipos de uso do } \\
\text { solo }\end{array}$ & $\begin{array}{l}\text { Secretaria Municipal da Habitação e } \\
\text { Desenvolvimento Urbano (2002 e 2007) }\end{array}$ & c & A & \\
\hline & Integração regional & Consórcios intermunicipais & $\begin{array}{l}\text { Consórcios públicos intermunicipais para a } \\
\text { provisão de infra-estrutura e serviços de } \\
\text { transporte }\end{array}$ & $\begin{array}{l}\text { Secretaria Municipal de Transporte, Trânsito e } \\
\text { Vias Públicas (2008) }\end{array}$ & C & A & CA \\
\hline & $\begin{array}{l}\text { Transparência do processo } \\
\text { de planejamento }\end{array}$ & $\begin{array}{l}\text { Transparência e } \\
\text { responsabilidade }\end{array}$ & $\begin{array}{l}\text { Publicação formal e periódica sobre assuntos } \\
\text { relacionados à infra-estrutura, serviços, } \\
\text { planos e projetos de transportes e mobilidade } \\
\text { urbana }\end{array}$ & $\begin{array}{l}\text { Endereço Oficial da Prefeitura Municipal de São } \\
\text { Carlos na Internet (2008) }\end{array}$ & c & A & CA \\
\hline & \multirow{9}{*}{$\begin{array}{l}\text { Planejamento e controle do } \\
\text { uso e ocupação do solo }\end{array}$} & Vazios urbanos & Áreas (lotes e glebas) vazios na área urbana & Levantamentos do Plano Diretor Municipal (2001-2002) & $\mathrm{C}$ & A & CA \\
\hline & & \multirow{3}{*}{ Crescimento urbano } & Parcelamentos aprovados e registrados & Plano Diretor Municipal (2005) & $\mathrm{C}$ & A & \multirow{3}{*}{ CA } \\
\hline & & & Base georreferenciada do município & $\begin{array}{l}\text { Serviço Autônomo de Água e Esgoto - SAAE } \\
\text { (2006) }\end{array}$ & c & A & \\
\hline & & & $\begin{array}{l}\text { Base georreferenciada de linhas de ônibus } \\
\text { urbanas }\end{array}$ & $\begin{array}{l}\text { Secretaria Municipal de Transporte, Trânsito e } \\
\text { Vias Públicas (2008) }\end{array}$ & c & A & \\
\hline & & \multirow{2}{*}{ Densidade populacional urbana } & Base georreferenciada do município & $\begin{array}{l}\text { Serviço Autônomo de Água e Esgoto - SAAE } \\
(2006)\end{array}$ & c & A & \multirow{2}{*}{ CA } \\
\hline & & & $\begin{array}{l}\text { Base georreferenciada de Setores } \\
\text { Censitários }\end{array}$ & $\begin{array}{l}\text { Instituto Brasileiro de Geografia e Estatística - } \\
\text { IBGE (2000) }\end{array}$ & C & A & \\
\hline & & \multirow[b]{2}{*}{ Índice de uso misto } & Zoneamento do município & Plano Diretor Municipal (2005) & C & A & \multirow[b]{2}{*}{ CA } \\
\hline & & & Base vetorizada de ruas do município & $\begin{array}{l}\text { Secretaria Municipal da Habitação e } \\
\text { Desenvolvimento Urbano (2007) }\end{array}$ & c & A & \\
\hline & & Ocupações irregulares & $\begin{array}{l}\text { Loteamentos irregulares } \\
\text { Assentamentos subnormais }\end{array}$ & $\begin{array}{l}\text { Secretaria Municipal da Habitação e } \\
\text { Desenvolvimento Urbano (2007) }\end{array}$ & $\begin{array}{l}\mathrm{C} \\
\mathrm{C}\end{array}$ & $\frac{M^{9}}{M^{9}}$ & $\mathrm{CM}$ \\
\hline & \multirow{4}{*}{$\begin{array}{l}\text { Planejamento estratégico e } \\
\text { integrado }\end{array}$} & $\begin{array}{l}\text { Planejamento urbano, ambiental } \\
\text { e de transportes integrado }\end{array}$ & $\begin{array}{l}\text { Cooperação entre os órgãos responsáveis } \\
\text { pelo planejamento e gestão de transportes, } \\
\text { planejamento urbano e meio ambiente }\end{array}$ & $\begin{array}{l}\text { Secretaria Municipal da Habitação e } \\
\text { Desenvolvimento Urbano (2007) }\end{array}$ & $\mathrm{C}$ & A & CA \\
\hline & & \multirow{3}{*}{$\begin{array}{l}\text { Efetivação e continuidade das } \\
\text { açôes }\end{array}$} & $\begin{array}{l}\text { Ações, planos e programas de transporte } \mathrm{e} \\
\text { mobilidade previstos }\end{array}$ & - & $\mathrm{L}^{2}$ & - & \multirow{3}{*}{ L } \\
\hline & & & $\begin{array}{l}\text { Ações, planos e programas de transporte e } \\
\text { mobilidade efetivados }\end{array}$ & - & $\mathrm{L}^{2}$ & - & \\
\hline & & & Continuidade das ações, planos e programas & - & $\mathrm{L}^{2}$ & - & \\
\hline
\end{tabular}




\begin{tabular}{|c|c|c|c|c|c|c|c|}
\hline DOM. & TEMA & INDICADOR & DADOS DE BASE & FONTES & DISP. & QUAL. & RESULT. \\
\hline \multirow{12}{*}{ 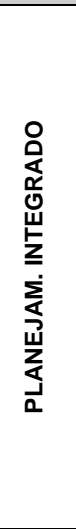 } & \multirow{7}{*}{$\begin{array}{l}\text { Planejamento da infra- } \\
\text { estrutura urbana e } \\
\text { equipamentos urbanos }\end{array}$} & \multirow{3}{*}{ Parques e áreas verdes } & Base georreferenciada do município & Serviço Autônomo de Água e Esgoto - SAAE (2006) & $\mathrm{C}$ & $\mathrm{A}$ & \multirow{3}{*}{ CA } \\
\hline & & & $\begin{array}{l}\text { Base georreferenciada de Setores } \\
\text { Censitários }\end{array}$ & $\begin{array}{l}\text { Instituto Brasileiro de Geografia e Estatística - } \\
\text { IBGE (2000) }\end{array}$ & c & A & \\
\hline & & & $\begin{array}{l}\text { Croquis do Censo } 2000 \text { contendo as áreas } \\
\text { verdes do município }\end{array}$ & $\begin{array}{l}\text { Instituto Brasileiro de Geografia e Estatística - } \\
\text { IBGE (2000) }\end{array}$ & C & A & \\
\hline & & \multirow[t]{2}{*}{ Equipamentos urbanos (escolas) } & $\begin{array}{l}\text { Base georreferenciada de equipamentos de } \\
\text { educação }\end{array}$ & $\begin{array}{l}\text { Secretaria Municipal da Habitação e } \\
\text { Desenvolvimento Urbano (2008) }\end{array}$ & C & A & \multirow[t]{2}{*}{ CA } \\
\hline & & & Estimativa da população & Instituto Brasileiro de Geografia e Estatística - IBGE (2007) & C & A & \\
\hline & & \multirow{2}{*}{$\begin{array}{l}\text { Equipamentos urbanos (postos } \\
\text { de saúde) }\end{array}$} & $\begin{array}{l}\text { Base georreferenciada de equipamentos de } \\
\text { saúde }\end{array}$ & $\begin{array}{l}\text { Secretaria Municipal da Habitação e } \\
\text { Desenvolvimento Urbano (2008) }\end{array}$ & c & A & \multirow[t]{2}{*}{ CA } \\
\hline & & & Estimativa da população & Instituto Brasileiro de Geografia e Estatística - IBGE (2007) & $\mathrm{C}$ & A & \\
\hline & \multirow{5}{*}{$\begin{array}{l}\text { Plano Diretor e legislação } \\
\text { urbanística }\end{array}$} & Plano Diretor & Plano Diretor Municipal & Legislação municipal (2008) & $\mathrm{C}$ & A & $\mathrm{CA}$ \\
\hline & & Legislação urbanística & Legislação urbana & 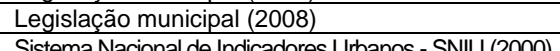 & $\frac{C}{C}$ & A & $\mathrm{CA}$ \\
\hline & & \multirow{3}{*}{$\begin{array}{l}\text { Cumprimento da legislação } \\
\text { urbanística }\end{array}$} & Operações de fiscalização, notificação, & \multirow{3}{*}{$\begin{array}{l}\text { Secretaria Municipal da Habitação e } \\
\text { Desenvolvimento Urbano (2008) }\end{array}$} & $\mathrm{C}$ & A & \multirow{3}{*}{ CA } \\
\hline & & & $\begin{array}{l}\text { autuação e penalização de projetos, obras e } \\
\text { empreendimentos }\end{array}$ & & c & A & \\
\hline & & & Penalidades aplicadas & & C & A & \\
\hline \multirow{17}{*}{ 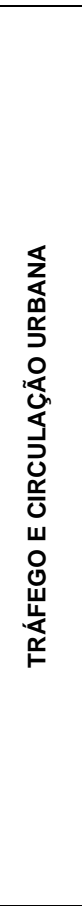 } & \multirow{6}{*}{ Acidentes de trânsito } & \multirow{2}{*}{ Acidentes de trânsito } & $\begin{array}{l}\text { Acidentes de trânsito em vias urbanas } \\
\text { Mortos em acidentes de trânsito em vias urbanas }\end{array}$ & $\begin{array}{l}\text { Secretaria Municipal de Transporte, Trânsito e } \\
\text { Vias Públicas (2005) }\end{array}$ & C & A & \multirow{2}{*}{$\mathrm{CA}$} \\
\hline & & & Estimativa da população & $\begin{array}{l}\text { Instituto Brasileiro de Geografia e Estatística - } \\
\text { IBGE (2005) }\end{array}$ & C & A & \\
\hline & & \multirow{3}{*}{$\begin{array}{l}\text { Acidentes com pedestres e } \\
\text { ciclistas }\end{array}$} & Acidentes de trânsito em vias urbanas & \multirow{3}{*}{$\begin{array}{l}\text { Secretaria Municipal de Transporte, Trânsito e } \\
\text { Vias Públicas (2005) }\end{array}$} & $\mathrm{C}$ & A & \multirow{3}{*}{$\mathrm{CM}$} \\
\hline & & & $\begin{array}{l}\text { Acidentes de trânsito em vias urbanas } \\
\text { envolvendo pedestres }\end{array}$ & & c & A & \\
\hline & & & $\begin{array}{l}\text { Acidentes de trânsito em vias urbanas } \\
\text { envolvendo ciclistas }\end{array}$ & & $\mathrm{M}^{10}$ & M & \\
\hline & & Prevenção de acidentes & $\begin{array}{l}\text { Base georreferenciada do município } \\
\text { Disnositives de traffic calming }\end{array}$ & - & $\frac{\mathrm{L}^{2}}{\mathrm{~d}^{2}}$ & - & $\mathrm{L}$ \\
\hline & \multirow{2}{*}{ Educação para o trânsito } & \multirow{2}{*}{ Educação para o trânsito } & $\begin{array}{l}\text { Dispositivos de traffic calming } \\
\text { Escolas públicas (municipais, estaduais e } \\
\text { federais) e particulares de ensino pré-escolar, } \\
\text { fundamental e médio }\end{array}$ & \multirow{2}{*}{$\begin{array}{l}\text { Secretaria Municipal de Transporte, Trânsito e } \\
\text { Vias Públicas (2005) }\end{array}$} & c & A & \multirow{2}{*}{$\mathrm{CA}$} \\
\hline & & & $\begin{array}{l}\text { Escolas que têm implantado disciplinas } \\
\text { regulares ou têm promovido campanhas de } \\
\text { educação e sensibilização para o trânsito }\end{array}$ & & c & A & \\
\hline & \multirow{3}{*}{ Fluidez e circulação } & Congestionamento & $\begin{array}{l}\text { Média de horas diárias de congestionamento } \\
\text { em vias urbanas }\end{array}$ & $\begin{array}{l}\text { Secretaria Municipal de Transporte, Trânsito e } \\
\text { Vias Públicas (2008) }\end{array}$ & c & $\mathrm{B}^{11}$ & $\mathrm{CB}$ \\
\hline & & \multirow{2}{*}{ Velocidade média de tráfego } & Base georreferenciada do município & $\begin{array}{l}\text { Serviço Autônomo de Água e Esgoto - SAAE } \\
\text { (2006) }\end{array}$ & c & A & \multirow{2}{*}{$\mathrm{CA}$} \\
\hline & & & $\begin{array}{l}\text { Medição da velocidade média de } \\
\text { deslocamento em vias urbanas }\end{array}$ & Levantamento de campo (2008) & C & A & \\
\hline & & & Estimativa da população entre 18 e 65 anos & Instituto Brasileiro de Geografia e Estatística - IBGE (2007) & $\mathrm{C}$ & $\mathrm{M}^{12}$ & \\
\hline & $\begin{array}{l}\text { Uperaçao e riscallzaçao de } \\
\text { trânsito }\end{array}$ & Violação das leis de trânsito & Posse de Carteira Nacional de Habilitação & Pesquisa Origem e Destino de São Carlos (2007) & $\mathrm{C}$ & $\mathrm{M}^{1}$ & $\mathrm{CM}$ \\
\hline & & & CNHs notificadas no município & Departamento Estadual de Trânsito de São Paulo (2008) & $\mathrm{C}$ & $\mathrm{M}^{13}$ & \\
\hline & & & Frota Municipal & Departamento Nacional de Trânsito (2007) & C & A & \\
\hline & Transporte individual & Índice de motorização & Estimativa da população & $\begin{array}{l}\text { Instituto Brasileiro de Geografia e Estatística - } \\
\text { IBGE (2007) }\end{array}$ & c & A & CA \\
\hline & & Taxa de ocupação dos veículos & $\begin{array}{l}\text { Número médio de ocupantes em veículos } \\
\text { motorizados individuais }\end{array}$ & $\begin{array}{l}\text { Pesquisa Origem e Destino de São Carlos - } \\
\text { Screen Line (2007) }\end{array}$ & C & $M^{1}$ & $\mathrm{CM}$ \\
\hline
\end{tabular}




\begin{tabular}{|c|c|c|c|c|c|c|c|}
\hline DOM. & TEMA & INDICADOR & DADOS DE BASE & FONTES & DISP. & QUAL. & RESULT. \\
\hline \multirow{22}{*}{ 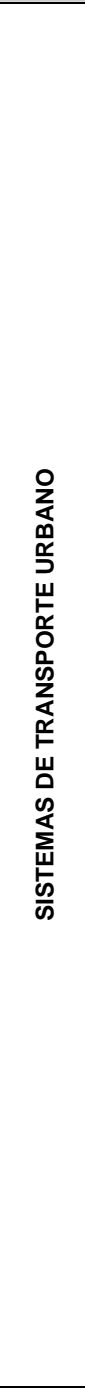 } & \multirow{9}{*}{$\begin{array}{l}\text { Disponibilidade e qualidade } \\
\text { do transporte público }\end{array}$} & \multirow{2}{*}{$\begin{array}{l}\text { Extensão da rede de transporte } \\
\text { público }\end{array}$} & Base georreferenciada do município & $\begin{array}{l}\text { Serviço Autônomo de Água e Esgoto - SAAE } \\
(2006)\end{array}$ & c & A & \multirow{2}{*}{ CA } \\
\hline & & & $\begin{array}{l}\text { Base georreferenciada de linhas de ônibus } \\
\text { urbanas }\end{array}$ & $\begin{array}{l}\text { Secretaria Municipal de Transporte, Trânsito e } \\
\text { Vias Públicas (2008) }\end{array}$ & C & A & \\
\hline & & $\begin{array}{l}\text { Freqüência de atendimento do } \\
\text { transporte público }\end{array}$ & $\begin{array}{l}\text { Planilhas horárias de linhas de transporte } \\
\text { coletivo }\end{array}$ & $\begin{array}{l}\text { Empresa operadora de transporte público de São } \\
\text { Carlos (2007) }\end{array}$ & C & A & $\mathrm{CA}$ \\
\hline & & Pontualidade & $\begin{array}{l}\text { Viagens em veículos de transporte coletivo } \\
\text { cumprindo a programação horária }\end{array}$ & $\begin{array}{l}\text { Secretaria Municipal de Transporte, Trânsito e } \\
\text { Vias Públicas (2008) }\end{array}$ & C & A & CA \\
\hline & & $\begin{array}{l}\text { Velocidade média do transporte } \\
\text { público }\end{array}$ & $\begin{array}{l}\text { Velocidade comercial do serviço de } \\
\text { transporte coletivo }\end{array}$ & $\begin{array}{l}\text { Secretaria Municipal de Transporte, Trânsito e } \\
\text { Vias Públicas (2008) }\end{array}$ & C & A & $\mathrm{CA}$ \\
\hline & & $\begin{array}{l}\text { Idade média da frota de } \\
\text { transporte público }\end{array}$ & Idade média da frota de transporte coletivo & $\begin{array}{l}\text { Secretaria Municipal de Transporte, Trânsito e } \\
\text { Vias Públicas (2008) }\end{array}$ & c & A & CA \\
\hline & & $\begin{array}{l}\text { Índice de passageiros por } \\
\text { quilômetro }\end{array}$ & Índice médio de passageiros por km & $\begin{array}{l}\text { Secretaria Municipal de Transporte, Trânsito e } \\
\text { Vias Públicas (2008) }\end{array}$ & C & A & $\mathrm{CA}$ \\
\hline & & $\begin{array}{l}\text { Passageiros transportados } \\
\text { anualmente }\end{array}$ & $\begin{array}{l}\text { Número de passageiros transportados } \\
\text { anualmente }\end{array}$ & $\begin{array}{l}\text { Secretaria Municipal de Transporte, Trânsito e } \\
\text { Vias Públicas (2006-2007) }\end{array}$ & c & A & $\mathrm{CA}$ \\
\hline & & $\begin{array}{l}\text { Satisfação do usuário com o } \\
\text { serviço de transporte público }\end{array}$ & $\begin{array}{l}\text { Pesquisa de opinião sobre satisfação com o } \\
\text { serviço de transporte coletivo }\end{array}$ & $\begin{array}{l}\text { Pesquisa Avaliação dos Transportes Urbanos da } \\
\text { Cidade de São Carlos - SP/ } 2007\end{array}$ & C & A & CA \\
\hline & \multirow{3}{*}{ Diversificação modal } & $\begin{array}{l}\text { Diversidade de modos de } \\
\text { transporte }\end{array}$ & Modos de transporte do município & Levantamento de campo (2008) & c & A & CA \\
\hline & & $\begin{array}{l}\text { Transporte coletivo } \mathrm{x} \text { transporte } \\
\text { individual }\end{array}$ & $\begin{array}{l}\text { Viagens urbanas, em dia útil, por modos } \\
\text { coletivos de transporte } \\
\text { Viagens urbanas, em dia útil, por modos } \\
\text { individuais de transporte }\end{array}$ & Pesquisa Origem e Destino de São Carlos (2007) & $\mathrm{C}$ & $M^{1}$ & $\mathrm{CM}$ \\
\hline & & $\begin{array}{l}\text { Modos motorizados } \mathrm{x} \text { modos } \\
\text { não-motorizados }\end{array}$ & $\begin{array}{l}\text { Viagens urbanas, em dia útil, por modos } \\
\text { motorizados de transporte } \\
\text { Viagens urbanas, em dia útil, por modos não- } \\
\text { motorizados de transporte }\end{array}$ & Pesquisa Origem e Destino de São Carlos (2007) & c & $M^{1}$ & $\mathrm{CM}$ \\
\hline & \multirow{3}{*}{$\begin{array}{l}\text { Regulação e fiscalização do } \\
\text { transporte público }\end{array}$} & \multirow[b]{2}{*}{ Contratos e licitações } & $\begin{array}{l}\text { Contratos de prestação de serviço de } \\
\text { transporte coletivo }\end{array}$ & $\begin{array}{l}\text { Secretaria Municipal de Transporte, Trânsito e } \\
\text { Vias Públicas (2008) }\end{array}$ & c & A & \multirow[b]{2}{*}{ CA } \\
\hline & & & $\begin{array}{l}\text { Situação dos contratos de prestação de } \\
\text { serviço de transporte coletivo }\end{array}$ & $\begin{array}{l}\text { Rodrigues, M. O. (2006) Avaliação da Qualidade } \\
\text { do Transporte Coletivo na Cidade de São Carlos - } \\
\text { SP }\end{array}$ & C & A & \\
\hline & & Transporte clandestino & $\begin{array}{l}\text { Existência e participação do transporte } \\
\text { clandestino no município }\end{array}$ & $\begin{array}{l}\text { Secretaria Municipal de Transporte, Trânsito e } \\
\text { Vias Públicas (2008) }\end{array}$ & C & A & CA \\
\hline & \multirow{3}{*}{$\begin{array}{l}\text { Integração do transporte } \\
\text { público }\end{array}$} & \multirow[b]{2}{*}{ Terminais intermodais } & Terminais urbanos de transporte coletivo & \multirow{2}{*}{$\begin{array}{l}\text { Secretaria Municipal de Transporte, Trânsito e } \\
\text { Vias Públicas (2008) }\end{array}$} & $\mathrm{C}$ & A & \multirow[b]{2}{*}{ CA } \\
\hline & & & $\begin{array}{l}\text { Terminais urbanos de transporte coletivo com } \\
\text { integração intermodal }\end{array}$ & & c & A & \\
\hline & & Integração do transporte público & $\begin{array}{l}\text { Tipos de integração física e tarifária do } \\
\text { sistema de transporte coletivo urbano }\end{array}$ & $\begin{array}{l}\text { Secretaria Municipal de Transporte, Trânsito e } \\
\text { Vias Públicas (2008) }\end{array}$ & c & A & CA \\
\hline & \multirow{4}{*}{ Política tarifária } & Descontos e gratuidades & $\begin{array}{l}\text { Porcentagem de passageiros por categoria } \\
\text { de desconto/gratuidade }\end{array}$ & $\begin{array}{l}\text { Secretaria Municipal de Transporte, Trânsito e } \\
\text { Vias Públicas (2008) }\end{array}$ & C & A & CA \\
\hline & & \multirow{2}{*}{ Tarifas de transportes } & Tarifa básica de transporte coletivo & $\begin{array}{l}\text { Secretaria Municipal de Transporte, Trânsito e } \\
\text { Vias Públicas (2004-2008) }\end{array}$ & C & A & \multirow{2}{*}{ CA } \\
\hline & & & Índices inflacionários & $\begin{array}{l}\text { Instituto Brasileiro de Geografia e Estatística - } \\
\text { IBGE (2007) }\end{array}$ & C & A & \\
\hline & & Subsídios públicos & $\begin{array}{l}\text { Subsídios aos operadores de serviços de } \\
\text { transporte }\end{array}$ & $\begin{array}{l}\text { Secretaria Municipal de Transporte, Trânsito e } \\
\text { Vias Públicas (2008) }\end{array}$ & C & A & CA \\
\hline
\end{tabular}


1. Na ocasião deste levantamento, os resultados da Pesquisa Origem e Destino ainda não haviam sido totalmente tabulados e expandidos.

2. Não há dados disponíveis para cálculo do indicador.

3. Os dados são agregados para o interior do estado de São Paulo, não havendo dados discriminados especificamente para o Município de São Carlos.

4. Resultados de simulações desenvolvidas no âmbito do estudo de Mendes (2004). Os dados referem-se a RMSP.

5. Obtida com base em norma americana e através de pesquisa com motoristas brasileiros. Não foram considerados dados específicos para o município de São Carlos.

6. Valores obtidos a partir da avaliação da Secretaria de Transportes, Trânsito e Vias Públicas, sem o levantamento detalhado dos investimentos em cada área.

7. Pode não contemplar todas as vias não pavimentadas no município, uma vez que relaciona somente os trechos de vias previstos para intervenção imediata.

8. Levantamento feito somente para a Secretaria de Transportes, Trânsito e Vias Públicas, sem acesso à documentação específica.

9. Levantamento com base em documentos encaminhados para regularização dos loteamentos e estimativa de áreas em assentamentos subnormais feitos pela Secretaria de Habitação e Desenvolvimento Urbano.

10. O banco de dados com registro dos acidentes envolvendo ciclistas ainda não foi consolidado

11.Estimativa da Secretaria de Transportes, Trânsito e Vias Públicas. Não existem, no entanto, estudos e levantamentos específicos.

12. A Pesquisa Contagem da População 2007 contempla uma estimativa de população para o município de São Carlos, não fazendo a discriminação por idade, sexo ou tipo de domicílio

13. Apesar de haver dados sobre o número de CNHs notificadas no município, estas podem pertencer a cidadãos que residem atualmente em outro município. 


\subsection{Processo de Cálculo do IMUS}

Para cálculo dos indicadores do IMUS foram utilizados programa de computador, como planilhas eletrônicas, Sistemas de Informações Geográficas (SIG), Desenho Assistido por Computador (CAD), entre outros, permitindo manipular com maior facilidade os dados coletados. Dados estatísticos e outras informações de órgãos e instituições de ensino, pesquisa e estatísticas em nível municipal, estadual e federal foram obtidos através da Prefeitura Municipal e via Internet.

Para cada indicador foi elaborada uma síntese do processo de levantamento dos dados e cálculo. Esta síntese constitui, juntamente com a Planilha de Cálculo do índice para o município, o Anexo I - "Cálculo do IMUS para São Carlos - SP". Neste anexo, as informações para cada um dos indicadores apresentam-se organizadas conforme a estrutura a seguir, que consiste em um resumo dos tópicos apresentados no Guia de Indicadores, conforme mostrado no item 8.7.

\begin{tabular}{|ll|}
\hline DOMÍNIO & Domínio, conforme estrutura do IMUS \\
\hline TEMA & Tema, conforme estrutura do IMUS \\
\hline INDICADOR (ID) & Identificação do Indicador \\
\hline
\end{tabular}

\section{A. Fontes de Dados}

Bases e fontes dos dados utilizados para cálculo do indicador.

\section{B. Ferramentas}

Ferramentas utilizadas para cálculo do indicador.

\section{Método de Cálculo}

Síntese do método de cálculo, conforme etapas contidas no Guia de Indicadores de Mobilidade.

\section{Score}

Resultado obtido para o indicador, não normalizado.

Todos os procedimentos para tratamento dos dados, estimativas e asserções feitas para cálculo dos indicadores foram registradas no Anexo I. Assim, é possível verificar as adaptações da metodologia de cálculo constante no Anexo E - "Guia para Elaboração dos 
Indicadores do IMUS", realizadas em função do formato e desagregação dos dados obtidos e ferramentas de análise disponíveis.

Os scores resultantes para cada indicador foram posteriormente inseridos na Planilha de Cálculo (coluna K, conforme Figura 8.4). Para os indicadores que não foram calculados, a planilha possibilitou a redistribuição automática dos seus respectivos pesos. Do mesmo modo, os scores dos indicadores foram sendo automaticamente normalizados para intervalo entre 0,00 e 1,00, a medida que iam sendo inseridos na planilha Para cada indicador, foi calculado seu score, resultado da combinação de seu peso com o peso de seu respectivos Domínio e Tema, para análise global, e peso de cada Dimensão, em âmbito setorial. O somatório dos score globais e setoriais para os indicadores resultou nos valores do IMUSg e IMUSs $s$

A Figura 9.2 apresenta a Planilha de cálculo do IMUS com os scores dos indicadores avaliados e resultados obtidos.

\subsection{Análise dos Resultados}

Oitenta indicadores que compõem o IMUS ou 92\% do conjunto total puderam ser avaliados para a cidade de São Carlos. Dentre os Temas que compõem o índice, somente "Qualidade de Vida" não pode ser avaliado, uma vez que não havia dados disponíveis que possibilitassem a avaliação de seu único indicador.

A Tabela 9.3 apresenta a estrutura final do IMUS para a cidade de São Carlos, considerando os indicadores avaliados e os respectivos pesos redistribuídos.

\subsubsection{Disponibilidade e Qualidade dos Dados}

A Tabela 9.4 e a Figura 9.3 (a) a (j) apresentam os resultados obtidos, no que diz respeito à combinação dos critérios disponibilidade e qualidade de dados total (para o conjunto de indicadores) e por Domínio do IMUS. 
Arquivo Éditar Exibir Innserir Formatar Ferramentas Dados jెanela Ajuda

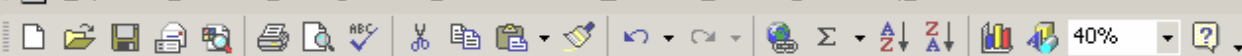

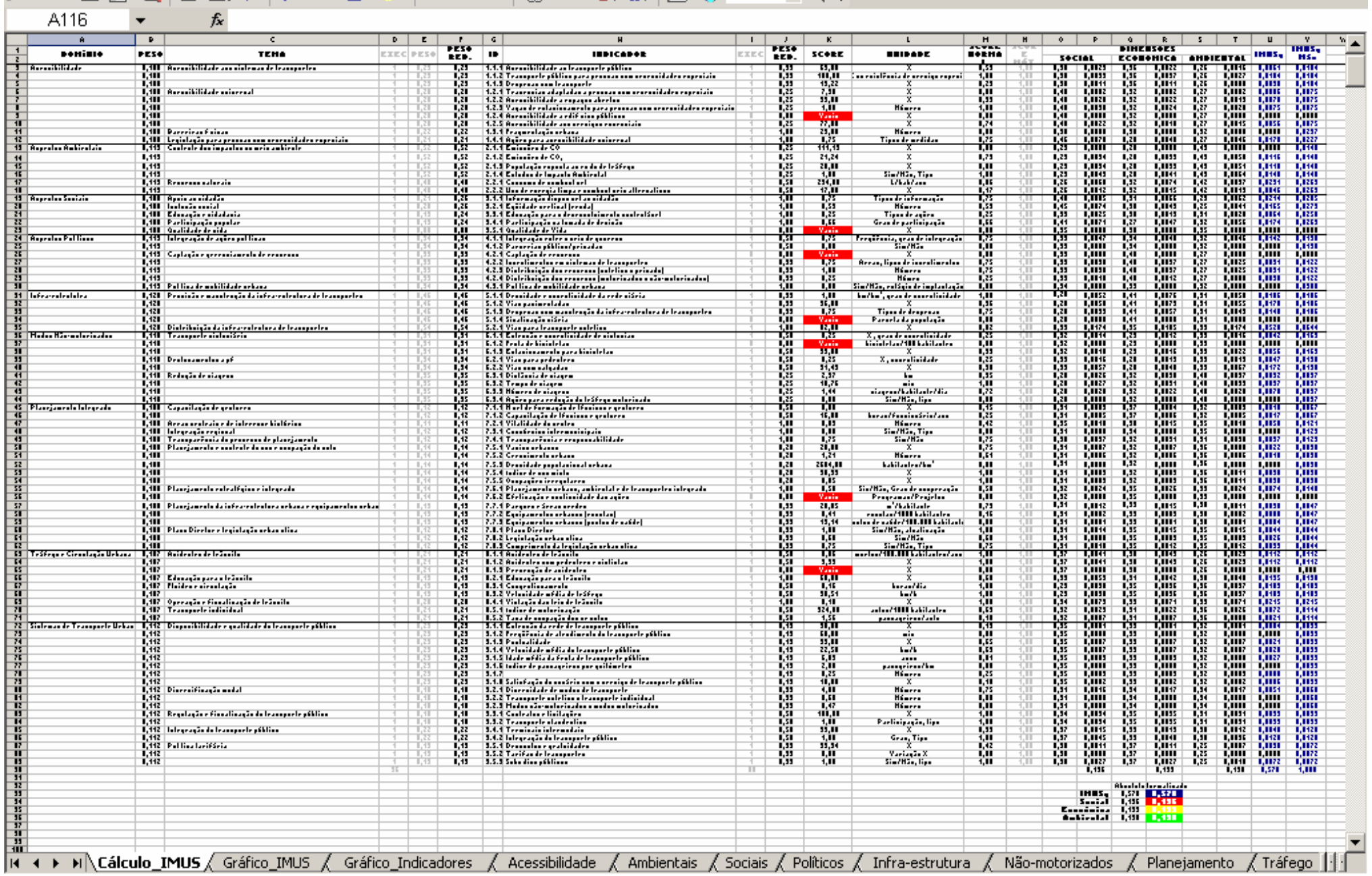

Figura 9.2: Planilha de Cálculo do IMUS para a cidade de São Carlos (processo de cálculo) 
Tabela 9.3: Estrutura do IMUS para a cidade de São Carlos.

\begin{tabular}{|c|c|c|c|c|c|c|c|}
\hline & & & IMU & & & & \\
\hline DOMiNIO & PESO & DIMENSÕES & TEMA & PESO & ID & INDICADOR & PESO \\
\hline & & \begin{tabular}{|l|l|l|}
0,36 & 0,26 \\
\end{tabular} & Acessiblidade aos sistemas de transportes & 0,29 & 1.1.1 & Acessibilidade ao transporte público & 0,33 \\
\hline & & & & & 1.1 .2 & Transporte público para pessoas com necessidades especiais & 0,33 \\
\hline 究 & & & & & 1.1 .3 & Despesas com transporte & 0,33 \\
\hline$\cong$ & & \begin{tabular}{l|l|l}
0,32 & 0,27 \\
\end{tabular} & Acessibilidade universal & 0,28 & 1.2 .1 & Travessias adaptadas a pessoas com necessidades especiais & 0,25 \\
\hline $\overrightarrow{\bar{m}}$ & 0.108 & & & & 1.2 .2 & Acessibilidade a espaços abertos & 0,25 \\
\hline 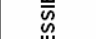 & 10,100 & & & & 1.2 .3 & Vagas de estacionamento para pessoas com necessidades & 0,25 \\
\hline$\underset{\widetilde{u}}{\stackrel{u}{u}}$ & & & & & \begin{tabular}{|l|}
1.2 .4 \\
1.2 .5
\end{tabular} & Acessibilidade a edificios públicos & $\begin{array}{l}0,00 \\
0,25\end{array}$ \\
\hline & & \begin{tabular}{|l|l|}
0,30 & 0,32
\end{tabular} & Barreiras físicas & 0,22 & 1.3 .1 & Fragmentaçäo urbana & 1,00 \\
\hline & & \begin{tabular}{|l|l|l|}
0,28 & 0,27 \\
\end{tabular} & Legislação para pessoas com necessidades & 0.21 & 1.4.1 & Aç̋es para acessibilidade universal & 1,00 \\
\hline & & \begin{tabular}{l|l|l|l}
0,29 & 0,28 & 0,43 \\
\end{tabular} & Controle dos impactos no meio ambiente & 0,52 & 2.1 .1 & Emissões de CO & 0,25 \\
\hline 总言 & & & & & 2.1 .2 & Emissőes de $\mathrm{CO}_{2}$ & 0,25 \\
\hline 总 & 0,113 & & & & 2.1.3 & $\begin{array}{l}\text { Populaçăo exposta ao ruído de tráfego } \\
\text { Estudos de Impacto Ambiental }\end{array}$ & $\begin{array}{l}0,25 \\
0,25\end{array}$ \\
\hline & & 0,42 & Recursos naturais & 0,48 & 2.2 .1 & Consumo de combustivel & 0,50 \\
\hline & & & & & 2.2 .2 & Uso de energia limpa e combustiveis alternativos & 0,50 \\
\hline & & \begin{tabular}{l|l|l}
0,31 & 0,29 \\
\end{tabular} & Apoio ao cidadăo & 0,26 & 3.1 .1 & Informação disponivel ao cidadão & 1,00 \\
\hline$\frac{0}{5}$ & & \begin{tabular}{|l|l|l|l|l|}
0,30 & 0,25 \\
\end{tabular} & Inclusão social & 0,26 & 3.2 .1 & Eqüidade vertical (renda) & 1,00 \\
\hline 岂 & 0,108 & \begin{tabular}{|l|l|l|}
0,30 & 0,31 \\
\end{tabular} & Educaçẫo e cidadania & 0,24 & 3.3 .1 & Educação para o desenvolvimento sustentável & 1,00 \\
\hline की in & & \begin{tabular}{|l|l|}
0,27 & 0,32 \\
\end{tabular} & Participaçäo popular & 0,24 & 3.4 .1 & Participaçăo na tomada de decisăo & 1,00 \\
\hline & & 0,30 & Qualidade de vida & 0,00 & 3.5 .1 & Qualidade de Vida & 0.00 \\
\hline & & \begin{tabular}{l|l}
0,34 & 0,32 \\
\end{tabular} & Integraçăo de açôes políticas & 0,34 & 4.1 .1 & Integração entre niveis de governo & 0,50 \\
\hline & & & & & 4.1 .2 & Parcerias público/privadas & 0,50 \\
\hline 0 & & \begin{tabular}{l|l|l}
0,40 & 0,27 \\
\end{tabular} & Captaçăo e gerenciamento de recursos & 0,33 & 4.2 .1 & Captaçắo de recursos & 0,00 \\
\hline 总: & 0,113 & & & & 4.2.2 & Investimentos em sistemas de transportes & 0,33 \\
\hline 荝 & & & & & 4.2.3 & Distribuição dos recursos (público x privado) & 0,33 \\
\hline & & & & & 4.2.4 & Distribuiçăo dos recursos (motorizados $x$ năo-motorizados) & 0,33 \\
\hline & & 0,33 & Política de mobilidade urbana & 0,33 & 4.3.1 & Política de mobilidade urbana & 1,00 \\
\hline 災 & & \begin{tabular}{l|l|l}
0,41 & 0,31 \\
\end{tabular} & Provisão e manutenção da infra-estrutura de & 0,46 & 5.1 .1 & Densidade da rede viária & 0,33 \\
\hline 我岁 & & & & & 5.1.2 & Vias pavimentadas & 0,33 \\
\hline 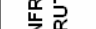 & 0,120 & & & & 5.1 .3 & Despesas com manutençẫo da infra-estrutura de transportes & 0,33 \\
\hline 点 & & & transportes & & 5.1 .4 & Sinalizaçăo viária & 0,00 \\
\hline 岀 & & 0,35 & Distribuicão da infra-estrutura de transportes & 0,54 & 5.2.1 & Vias para transporte coletivo & 1,00 \\
\hline & & 0,29 & Transporte cicloviário & 0,31 & 6.1 .1 & Extensão e conectividade de ciclovias & 0,50 \\
\hline & & & & & 6.1 .2 & Frota de bicicletas & 0,00 \\
\hline & & & & & 6.1 .3 & Estacionamento para bicicletas & 0,50 \\
\hline$\sum \frac{\mathbb{N}}{N}$ & & \begin{tabular}{|l|l|}
0,28 & 0,39 \\
\end{tabular} & Deslocamentos a pé & 0,34 & 6.2 .1 & Vias para pedestres & 0,50 \\
\hline 告 & 0,110 & & & & 6.2 .2 & Vias com calçadas & 0,50 \\
\hline 흥은 & & 0,40 & Reduçäo de viagens & 0,35 & 6.3 .1 & Distância de viagem & 0,25 \\
\hline$\Sigma \frac{0}{2}$ & & & & & 6.3 .2 & Tempo de viagem & 0,25 \\
\hline & & & & & 6.3.3 & Número de viagens & 0,25 \\
\hline & & & & & 6.3 .4 & Açôes para reduçâo do tráfego motorizado & 0,25 \\
\hline & & \begin{tabular}{l|l}
0,37 & 0,32 \\
\end{tabular} & Capacitaçẫo de gestores & 0,12 & 7.1 .1 & Nivel de formação de técnicos e gestores & 0,50 \\
\hline & & & & & 7.1 .2 & Capacitaçäo de técnicos e gestores & 0,50 \\
\hline & & 0,30 & Áreas centrais e de interesse histórico & 0,11 & 7.2 .1 & Vitalidade do centro & 1,00 \\
\hline & & 0,35 & Integração regional & 0,12 & 7.3 .1 & Consórcios intermunicipais & 1,00 \\
\hline 品 & & \begin{tabular}{l|l|l|}
0,32 & 0,31 \\
\end{tabular} & Transparência do processo de planejamento & 0,12 & 7.4 .1 & Transparência e responsabilidade & 1,00 \\
\hline$\frac{\alpha}{0}$ & & \begin{tabular}{|l|l|l}
0,31 & 0,32 & 0,36 \\
\end{tabular} & Planejamento e controle do uso e ocupaçẫo do & 0,14 & 7.5 .1 & Vazios urbanos & 0,20 \\
\hline$\underset{⺊}{\rightleftarrows}$ & & & & & 7.5 .2 & Crescimento urbano & 0,20 \\
\hline$\underline{z}$ & & & & & 7.5.3 & Densidade populacional urbana & 0,20 \\
\hline 온 & 0,108 & & & & 7.5 .4 & Índice de uso misto & 0,20 \\
\hline $\mathrm{z}_{\mathrm{u}}$ & 0,100 & & solo & & 7.5 .5 & Ocupaçôes irregulares & 0,20 \\
\hline$\sum_{<}^{\omega}$ & & 0,35 & Planejamento estratégico e integrado & 0,14 & 7.6 .1 & Planejamento urbano, ambiental e de transportes integrado & 1,00 \\
\hline แैं & & & & & 7.6 .2 & Efetivaçầo e continuidade das açôes & 0,00 \\
\hline$\underset{\mathbf{z}}{\mathbf{z}}$ & & 0,39 & Planejamento da infra-estrutura urbana $e$ & 0,13 & 7.7 .1 & Parques e áreas verdes & 0,33 \\
\hline & & & urbanos & & 7.7 .2 & Equipamentos urbanos (escolas) & 0,33 \\
\hline & & & & & 7.7 .3 & Equipamentos urbanos (hospitais) & 0,33 \\
\hline & & 0,35 & Plano Diretor e legislaçẫo urbanística & 0,12 & 7.8 .1 & Plano Diretor & 0,33 \\
\hline & & & & & 8.8 .2 & Legislaçẫo urbanística & 0,33 \\
\hline & & & & & 7.8 .3 & Cumprimento da legislaçăo urbanística & 0,33 \\
\hline$\stackrel{8}{4}$ & & $0,38 \quad 0,26$ & Acidentes de trânsito & 0,21 & 8.1.1 & Acidentes de trânsito & 0,50 \\
\hline$\stackrel{3}{\Xi}$ & & & & & 8.1.2 & Acidentes com pedestres e ciclistas & 0,50 \\
\hline $\bar{z}_{\varangle}$ & & & & & 8.1 .3 & Prevençấo de acidentes & 0,00 \\
\hline 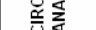 & & \begin{tabular}{|l|l|l|l}
0,31 & 0,30 \\
\end{tabular} & Educaçăo para o trânsito & 0,19 & 8.2 .1 & Educação para o trânsito & 1,00 \\
\hline 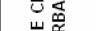 & 0,107 & \begin{tabular}{l|l}
0,35 & 0,36 \\
\end{tabular} & Fluidez e circulaçẫo & 0,19 & 8.3 .1 & Congestionamento & 0,50 \\
\hline 过 & & & & & 8.3.2 & Velocidade média de tráfego & 0,50 \\
\hline 峞 & & \begin{tabular}{|l|l|l|l|l|l|l|}
0,33 & 0,33 \\
\end{tabular} & Operaçăo e fiscalizaçăo de trânsito & 0,20 & 8.4.1 & Violaçẵo das leis de trânsito & 1,00 \\
\hline$\frac{w}{\Phi}$ & & \begin{tabular}{l|l}
0,31 & 0,36 \\
\end{tabular} & Transporte individual & 0,21 & 8.5 .1 & Iíndice de motorizaçăo & 0,50 \\
\hline & & & & & 8.5.2 & Taxa de ocupaçẫo dos veículos & 0,50 \\
\hline & & \begin{tabular}{|l|l|l|}
0,33 & 0,32 \\
\end{tabular} & Disponibilidade e qualidade do transporte público & 0,23 & 9.1 .1 & Extensăo da rede de transporte público & 0,13 \\
\hline & & & & & 9.1 .2 & Freqüência de atendimento do transporte público & 0,13 \\
\hline $\mathrm{z}$ & & & & & 9.1 .3 & Pontualidade & 0,13 \\
\hline 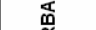 & & & & & 9.1 .4 & Velocidade média do transporte público & 0,13 \\
\hline$\underline{\underline{y}}$ & & & & & 9.1 .5 & Idade média da frota de transporte público & 0,13 \\
\hline щ & & & & & 9.1 .6 & Índice de passageiros por quilômetro & 0,13 \\
\hline 㸓 & & & & & 9.1.7 & Passageiros transportados anualmente & 0,13 \\
\hline 8 & & & & & 9.1 .8 & Satisfação do usuário com o serviço de transporte público & 0,13 \\
\hline$\sum$ & 0,112 & 0,34 & Diversificaçấo modal & 0,18 & 9.2 .1 & Diversidade de modos de transporte & 0,33 \\
\hline$\underset{\underline{q}}{\overleftarrow{Q}}$ & & & & & 9.2 .2 & Transporte público $x$ transporte privado & 0,33 \\
\hline$\vdash$ & & & & & 9.2 .3 & Modos motorizados $x$ modos năo-motorizados & 0,33 \\
\hline 㟔 & & \begin{tabular}{l|l|l}
0,35 & 0,31 \\
\end{tabular} & Regulaçẩo e fiscalizaçăo do transporte público & 0,18 & 9.3 .1 & Contratos e licitaçőes & 0,50 \\
\hline$\stackrel{\omega}{\infty}$ & & & & & 9.3 .2 & Transporte clandestino & 0,50 \\
\hline$\sum_{u}^{i}$ & & \begin{tabular}{l|l|l|l}
0,37 & 0,33 & 0,30 \\
\end{tabular} & Integraçäo do transporte público & 0,22 & 9.4 .1 & Terminais intermodais & 0,50 \\
\hline$\underline{E}$ & & & & & 9.4 .2 & Integraçăo do transporte público & 0,50 \\
\hline $\bar{\omega}$ & & \begin{tabular}{l|l|l|l}
0,38 & 0,37 & 0,25 \\
\end{tabular} & Política tarifária & 0,19 & 9.5 .1 & Descontos e gratuidades & 0,33 \\
\hline & & & & & 9.5 .2 & Tarifas de transportes & 0,33 \\
\hline & & & & & 9.5 .3 & Subsídios públicos & 0,33 \\
\hline
\end{tabular}


Tabela 9.4: Resultados do IMUS quanto à disponibilidade e qualidade dos dados.

\begin{tabular}{ccccc}
\hline Domínio & CA & CM & CB & $\mathbf{L}$ \\
\hline Acessibilidade & $80 \%$ & $10 \%$ & $0 \%$ & $10 \%$ \\
\hline Aspectos Ambientais & $50 \%$ & $50 \%$ & $0 \%$ & $0 \%$ \\
\hline Aspectos Sociais & $60 \%$ & $20 \%$ & $0 \%$ & $20 \%$ \\
\hline Aspectos Políticos & $57 \%$ & $0 \%$ & $29 \%$ & $14 \%$ \\
\hline Infra-estrutura de Transportes & $40 \%$ & $20 \%$ & $20 \%$ & $20 \%$ \\
\hline Modos Não-Motorizados & $56 \%$ & $33 \%$ & $0 \%$ & $11 \%$ \\
\hline Planejamento Integrado & $77 \%$ & $6 \%$ & $11 \%$ & $6 \%$ \\
\hline Tráfego e Circulação Urbana & $45 \%$ & $33 \%$ & $11 \%$ & $11 \%$ \\
\hline Sistemas de Transporte Urbano & $89 \%$ & $11 \%$ & $0 \%$ & $0 \%$ \\
\hline Total & $\mathbf{6 8 \%}$ & $\mathbf{1 7 \%}$ & $\mathbf{7 \%}$ & $\mathbf{8 \%}$ \\
\hline
\end{tabular}

Com base nos resultados obtidos é possível observar que grande parte dos indicadores que compõem o IMUS podem ser calculados em curto prazo para a cidade de São Carlos. Deste grupo, cinqüenta e nove indicadores (ou 68\% do conjunto) apresentam dados com alta qualidade, ou seja, apresentam razoável atualização e foram obtidos através de metodologia e fontes confiáveis.

Os demais indicadores deste grupo apresentam dados com qualidade média (quinze indicadores ou $17 \%$ conjunto) e baixa (seis indicadores ou $7 \%$ do conjunto). Desta forma, ainda que possam ser desenvolvidos em curto prazo, necessitam de atualização dos dados disponíveis e adequação da metodologia para sua obtenção, de forma a elevar sua qualidade e confiabilidade.

No que diz respeito aos indicadores com disponibilidade de dados em longo prazo, foram identificados sete indicadores (ou $8 \%$ do conjunto), os quais não foram incorporados na avaliação do IMUS. Para obtenção destes dados são necessários levantamentos de campo, pesquisas de opinião, além de sistematização de dados existentes por parte da Prefeitura Municipal, uma vez que não há um controle e acompanhamento específico destas informações. Assim, acredita-se que os mesmos só poderão ser disponibilizados em um horizonte de longo prazo, em função do tempo e esforços necessários para sua obtenção.

A análise da disponibilidade e qualidade dos dados por Domínio do IMUS é feita nos itens a seguir. 


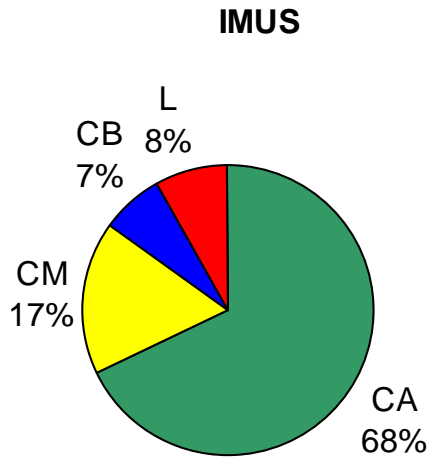

(a)

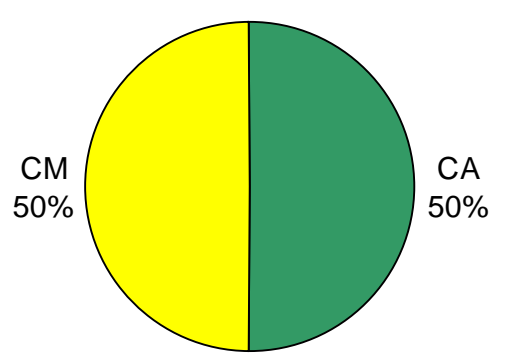

(c)

\section{ASPECTOS POLÍTICOS}

$\mathrm{L}$

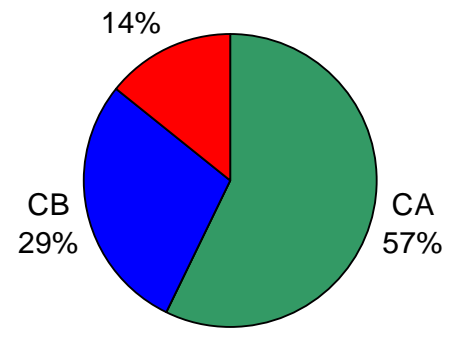

(e)

Curto Prazo, Qualidade Alta

Curto Prazo, Qualidade Média
ACESSIBILIDADE

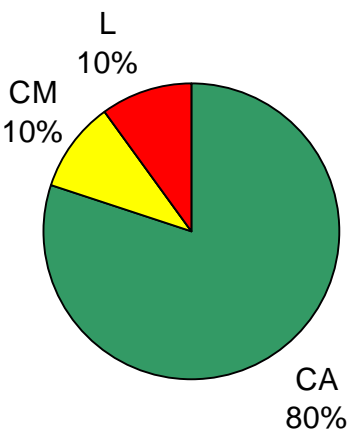

(b)

ASPECTOS SOCIAIS

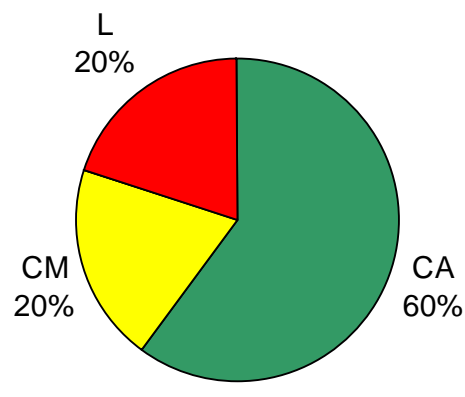

(d)

INFRA-ESTRUTURA DE TRANSPORTES

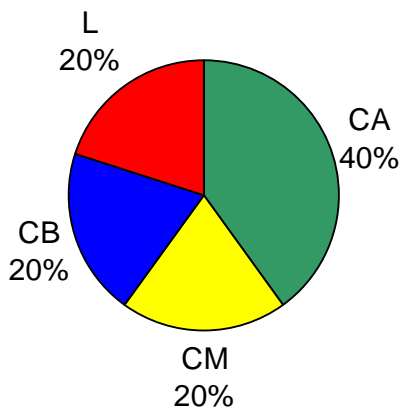

(f)

Curto Prazo, Qualidade Baixa Longo Prazo 
MODOS NÃO-MOTORIZADOS

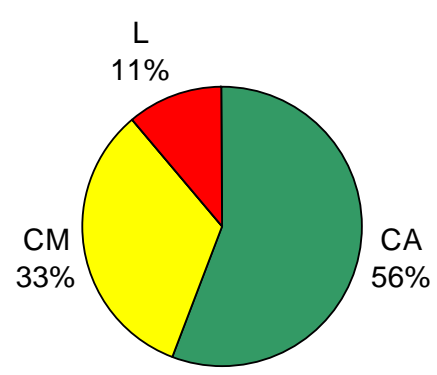

(g)

TRÁFEGO E CIRCULAÇÃO URBANA

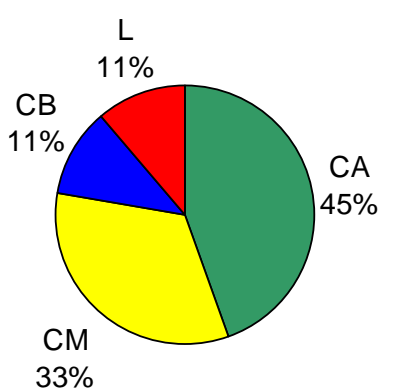

(i)

Curto Prazo, Qualidade Alta

Curto Prazo, Qualidade Média

\section{PLANEJAMENTO INTEGRADO}

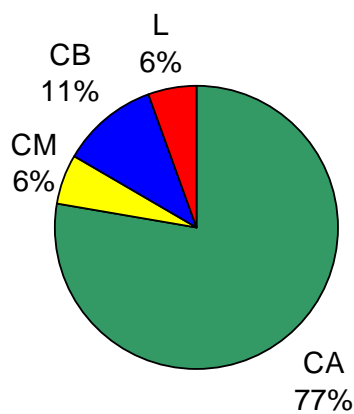

(h)

SISTEMAS DE TRANSPORTE URBANO

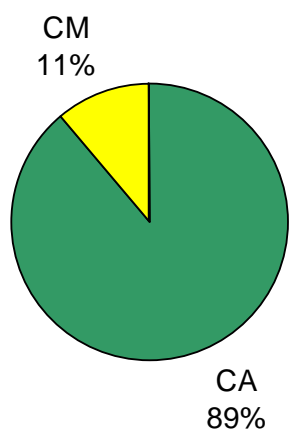

(j)

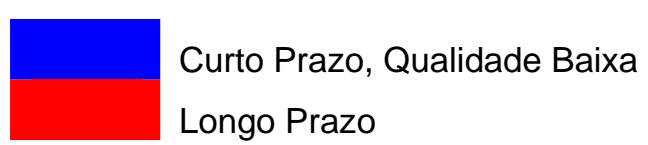

Figura 9.3: Análise da disponibilidade e qualidade dos dados para cálculo do IMUS.

\subsubsection{Domínio Acessibilidade}

Para o Domínio Acessibilidade, os indicadores que podem ser executados em curto prazo representam a maioria dos indicadores analisados (nove indicadores ou $90 \%$ do conjunto). Ao mesmo tempo, grande parte destes (oito indicadores ou $80 \%$ do conjunto) apresentam alta qualidade dos dados de base, conforme mostrado na Tabela 9.4 e na Figura 9.3 (b).

No que diz respeito aos indicadores passíveis de serem executados em curto prazo com qualidade média dos dados, foi identificado apenas o indicador: "Despesas com transportes". Ainda que os dados de base para este indicador sejam obtidos através da Pesquisa Origem e Destino (conforme mostra a Tabela 9.2), que representa uma rica fonte de informações socioeconômicas e de mobilidade da cidade, deve-se destacar que foram utilizados dados parciais da referente pesquisa, uma vez que a mesma ainda não foi 
totalmente tabulada. Desta forma, a qualidade dos dados foi considerada média, uma vez que a pesquisa não foi totalmente digitada, tabulada e seus resultados devidamente expandidos, o que deve acontecer ainda no ano de 2008.

Indicadores mensuráveis em curto prazo e com baixa qualidade dos dados não foram verificados neste Domínio.

Quanto aos indicadores que poderão ser executados somente em longo prazo devido a inexistência ou indisponibilidade de dados, foi verificado apenas um indicador: "Acessibilidade a edifícios públicos". Isto se dá em função da inexistência de um cadastro atualizado da Prefeitura Municipal, ou levantamentos de campo recentes que permitam verificar as edificações de uso público adaptadas para acesso de pessoas com necessidades especiais e restrições de mobilidade. No caso dos edifícios públicos de uso da Administração Municipal, muitos dos imóveis ocupados hoje por secretarias e órgãos municipais são edificações de interesse histórico, cuja modificação e adaptação é limitada em função das características físicas e restrições impostas pela legislação sobre patrimônio histórico. Desta forma, este indicador só poderá ser obtido após um levantamento de campo detalhado, possível de ser executado somente em longo prazo, em função do tempo que demanda.

\subsubsection{Aspectos Ambientais}

Para o Domínio Aspectos Ambientais, os indicadores que podem ser executados em curto prazo representam $100 \%$ dos indicadores do conjunto. No entanto, a qualidade dos dados de base é variável. Metade dos indicadores do grupo apresentam qualidade alta dos dados, enquanto a outra metade apresenta qualidade média dos dados, conforme mostrado na Tabela 9.4 e na Figura 9.3(c).

Os indicadores cujos dados de base apresentam média qualidade são: "Emissões de CO"; "Emissões de $\mathrm{CO}_{2}$ " e "Consumo de Combustível". Tanto para os indicadores de emissões, quanto de consumo, isso deve a ausência de parâmetros específicos para o município, principalmente no que diz respeito às características da frota veicular, quanto ao ano de fabricação dos veículos em circulação e tipo de combustível utilizado. Ao mesmo tempo, a inexistência de estudos específicos em relação à distância total percorrida pela frota anualmente se constitui em outro fator que impede o cálculo preciso dos indicadores. Mesmo diante destas dificuldades, estudos e pesquisas desenvolvidos no nível do estado de São Paulo, além de parâmetros definidos por órgãos ambientais estaduais, os quais foram adotados neste estudo, permitem o cálculo dos indicadores com razoável qualidade, permitindo assim incorporar seus resultados ao cálculo do IMUS. 
Neste Domínio não foram identificados indicadores mensuráveis em curto prazo com qualidade baixa dos dados, tampouco indicadores mensuráveis somente em longo prazo.

\subsubsection{Aspectos Sociais}

No Domínio Aspectos Sociais, quatro indicadores do conjunto (ou 80\%) podem ser mensurados em curto prazo, com qualidade dos dados de base variando entre alta e média, conforme mostrado na Tabela 9.4 e na Figura 9.3(d).

O indicador "Eqüidade vertical (renda)" é o indicador do conjunto que apresenta dados de base de qualidade média. Isto se deve ao fato de terem sido obtidos com base na Pesquisa Origem e Destino de São Carlos, a qual, conforme já destacado anteriormente, apresenta-se em fase de conclusão, com resultados ainda não totalmente consolidados.

Neste Domínio, foi identificado somente um indicador mensurável em longo prazo: "Qualidade de Vida". Isso se deve a inexistência de pesquisa de opinião sobre a qualidade de vida no município, a qual, para ser executada, deverá exigir planejamento e desenvolvimento de metodologia adequada, demandando assim considerável parcela de tempo para obtenção dos dados necessários para cálculo deste indicador.

\subsubsection{Aspectos Políticos}

Para o Domínio Aspectos Políticos, 86\% dos indicadores do conjunto podem ser mensurados em curto prazo. No entanto, $57 \%$ destes apresentam qualidade alta dos dados de base, e $29 \%$ baixa qualidade dos dados de base, conforme mostrado na Tabela 9.4 e na Figura 9.3(e).

Os indicadores que apresentam dados de base com baixa qualidade referem-se à distribuição de recursos nos sistemas de transporte, representados por: "Distribuição dos recursos (público x privado)" e "Distribuição dos recursos (motorizados x não-motorizados)". Isto se deve, em primeiro lugar, pela dificuldade em se distinguir os investimentos em modos públicos e privados de transporte, uma vez que no caso da infra-estrutura viária, por exemplo, a mesma pode ser utilizada por ambos os modos. Outra questão diz respeito à indisponibilidade de dados referentes à discriminação dos investimentos feitos pela Prefeitura Municipal nestas áreas, o que implicou que o indicador fosse avaliado somente através de algumas observações e dados informados pela Secretaria de Trânsito, Transportes e Vias Públicas, sem disponibilização de documentação a respeito dos mesmos. Em relação aos investimentos em modos não-motorizados e motorizados, a 
diferenciação é um pouco mais fácil. Mesmo assim, documentos ou dados formalizados para o indicador não foram disponibilizados pela Prefeitura Municipal.

Neste Domínio, apenas o indicador "Captação de recursos" não pôde ser mensurado, em função da indisponibilidade de dados por parte da Prefeitura Municipal.

\subsubsection{Infra-estrutura de Transportes}

Para o Domínio Infra-estrutura de Transportes, quatro indicadores (ou 80\%) podem ser mensurados em curto prazo, com qualidade dos dados de base alta (dois indicadores ou $40 \%$ ), média (um indicador ou $20 \%$ ) e baixa (um indicador ou 20\%), conforme mostrado na Tabela 9.4 e na Figura 9.3(f).

O indicador "Vias pavimentadas" apresenta qualidade dos dados de base média, uma vez que se trata de informação fornecida pela Prefeitura Municipal, referente às vias com previsão de pavimentação no ano de 2008. Portanto, pode não incluir todas as vias sem pavimentação do município, o que impede o cálculo do indicador com elevada precisão.

O indicador "Despesas com manutenção da infra-estrutura de transportes" foi calculado a partir de uma avaliação global por parte da Secretaria Municipal de Trânsito, Transportes e Vias Públicas, sem documentação específica ou discriminação dos valores investidos. Foi calculado, portanto, a partir de dados com baixa qualidade, uma vez que não houve nenhum detalhamento da informação fornecida.

Neste Domínio, apenas um indicador foi identificado como mensurável em longo prazo: "Sinalização Viária". Semelhante ao indicador "Qualidade de vida", integrante do Domínio Aspectos Sociais, não há para este indicador uma pesquisa específica que avalie a opinião dos cidadãos a respeito da qualidade da sinalização viária no município. Do mesmo modo, a organização e execução de uma pesquisa desta natureza demandaria considerável período de tempo, impedindo assim a incorporação deste indicador para cálculo do IMUS neste momento.

\subsubsection{Modos Não-motorizados}

No Domínio Modos Não-motorizados oito indicadores (ou $89 \%$ do conjunto) podem ser avaliados em curto prazo, apresentando dados de base de alta e média qualidade, conforme mostrado na Tabela 9.4 e na Figura 9.3(g).

Entre os indicadores que apresentam dados de média qualidade, encontram-se aqueles dependentes dos resultados da Pesquisa Origem e Destino: "Distância de viagem"; Tempo 
de viagem" e "Número de viagens". Assim, estima-se que após a consolidação dos resultados desta pesquisa, estes indicadores possam ser revistos, aumentado sua qualidade e precisão.

No Domínio Modos Não-motorizados, somente um indicador foi identificado como mensurável em longo prazo: "Frota de bicicletas". Isso se deve a inexistência de uma pesquisa específica para o município (a Pesquisa Origem e Destino, por exemplo, não contemplou a posse de bicicleta em seu questionário) e a indisponibilidade de dados sobre venda do bem nos últimos anos na cidade (conforme método de cálculo detalhado no Anexo E), o que permitiria estimar a frota de bicicletas no município. Dados para este indicador foram obtidos somente em nível federal (Ministério das Cidades, 2007b) ou agregados para cidades com mais de 100 mil habitantes (NTU, 2006), o que dificulta, no entanto, qualquer estimativa específica para a cidade de São Carlos.

\subsubsection{Planejamento Integrado}

Para o Domínio Planejamento Integrado, 94\% dos indicadores podem ser mensurados em curto prazo, com dados de base apresentando qualidade alta (77\%), média (6\%) e baixa (11\%), conforme mostrado na Tabela 9.4 e na Figura 9.3(h).

O indicador "Ocupações irregulares" apresenta dados de base de média qualidade, uma vez que foi obtido, em parte, com base em informação documental e, em parte, por estimativas feitas pela Secretaria de Habitação e Desenvolvimento Urbano, o que implica que os resultados obtidos não sejam totalmente confiáveis.

Já os indicadores que apresentam dados de base de baixa qualidade referem-se a: "Nível de formação de técnicos e gestores" e "Capacitação de Técnicos e Gestores". Para obtenção destes indicadores foram consideradas informações não documentais da Secretaria Municipal de Trânsito, Transportes e Vias Públicas, baseadas em estimativas do número de funcionários com graduação superior e número total de horas de cursos disponibilizadas, já que um levantamento preciso destes é dificultado pela diversidade de atividades oferecidas, em todos os níveis gerenciais e operacionais da secretaria.

Neste Domínio, apenas o indicador "Efetivação e continuidade das ações" não pôde ser mensurado, em função da indisponibilidade de dados e de uma avaliação realizada por parte da Prefeitura Municipal. 


\subsubsection{Tráfego e Circulação Urbana}

No Domínio Tráfego e Circulação Urbana, 89\% dos indicadores podem ser mensurados em curto prazo, com qualidade dos dados de base variando entre alta (45\%), média (33\%) e baixa (11\%), conforme mostrado na Tabela 9.4 e na Figura 9.3(i).

No que se refere aos indicadores com dados de base de média qualidade, estes incluem: "Acidentes com pedestres e ciclistas"; "Violação das leis de trânsito" e "Taxa de ocupação dos veículos".

A qualidade média dos dados de base do indicador "Acidentes com pedestres e ciclistas" está relacionada à indisponibilidade de dados referentes aos eventos envolvendo bicicletas. A Prefeitura Municipal tem desenvolvido um intenso trabalho de monitoração e registro dos acidentes de trânsito, especialmente nos últimos 8 anos. No entanto, o banco de dados completo, o qual inclui os acidentes envolvendo ciclistas, ainda não foi consolidado. Assim, o indicador foi calculado somente com dados referentes aos eventos ocorridos com pedestres. Tão logo estes dados estejam disponíveis, o indicador poderá ser calculado com elevada precisão, englobando informações para os dois tipos de usuários.

No que diz respeito ao indicador "Violação das leis de trânsito" a imprecisão dos dados reside especialmente na estimativa do número de cidadãos habilitados no município, uma vez que não há um banco de dados ou informações precisas a respeito deste aspecto, já que as Carteiras Nacionais de Habilitação são vinculadas ao município onde foram emitidas, o que não significa obrigatoriamente o local de residência atual do cidadão. Assim, estimativas para este dado foram feitas com base nos resultados parciais da Pesquisa Origem e Destino (posse de $\mathrm{CNH}$ ) e na proporção de pessoas residentes do sexo feminino e masculino no município, conforme pode ser visto no ANEXO I - "Cálculo do IMUS para São Carlos - SP". A mesma dificuldade é observada no que diz respeito ao número de CHNs notificadas no município.

Quanto ao indicador "Taxa de ocupação dos veículos", os dados apresentam média qualidade, uma vez que são oriundos dos resultados parciais da Pesquisa Origem e Destino.

Com relação aos indicadores com dados de base de baixa qualidade, somente uma medida foi identificada: "Congestionamento". Isso se deve a inexistência de estudos ou medições específicas, fundamentados em metodologias já difundidas sobre o tema. Assim o indicador foi obtido com base em informações de técnicos da Secretaria Municipal de Trânsito, Transporte e Vias Públicas, a partir de observações feitas em vias urbanas do município. 
No Domínio Tráfego e Circulação Urbana, somente um indicador pode ser mensurado em longo prazo: "Prevenção de acidentes". A impossibilidade de cálculo do indicador está associada a inexistência de um cadastro ou levantamento específico sobre os dispositivos de traffic calming em vias locais do município, e do tempo necessário para desenvolvimento de estudos desta natureza, uma vez que estas vias representam grande parcela do sistema viário urbano.

\subsubsection{Sistemas de Transporte Urbano}

Para o Domínio Sistemas de Transporte Urbano, 100\% dos indicadores podem ser mensurados em curto prazo, com qualidade alta (89\%) e média (11\%), conforme mostrado na Tabela 9.4 e na Figura 9.3(j).

Dois indicadores apresentam dados de base de média qualidade: "Transporte coletivo $x$ transporte individual" e "Modos motorizados x modos não-motorizados". Novamente a dificuldade está relacionada à conclusão da Pesquisa Origem e Destino, de forma a disponibilizar dados com maior precisão para cálculo dos indicadores relacionados.

\subsubsection{Análise dos Resultados do IMUS}

Os resultados global e por dimensões para o IMUS, obtidos através do processo de cálculo dos indicadores, são apresentados na Tabela 9.5. Os resultados corrigidos são obtidos em função do número de indicadores calculados e da redistribuição dos pesos nos casos em que não foi possível a avaliação de algum Indicador ou Tema. Uma vez que foi possível calcular grande parte dos indicadores que compõem o IMUS, os valores corrigidos são iguais aos valores absolutos obtidos para os índices global e setorial.

Tabela 9.5: Resultados obtidos para o IMUS global e setorial, a partir do processo de cálculo.

\begin{tabular}{lcc}
\multirow{2}{*}{\multicolumn{1}{c}{ Índice }} & \multicolumn{2}{c}{ Resultados } \\
\cline { 2 - 3 } & Absoluto & Corrigido \\
\hline IMUS $_{\mathrm{g}}$ & 0,578 & 0,578 \\
\hline IMUS $_{\text {Social }}$ & 0,196 & 0,196 \\
\hline IMUS $_{\text {Econômico }}$ & 0,193 & 0,193 \\
\hline IMUS $_{\text {Ambiental }}$ & 0,190 & 0,190 \\
\hline
\end{tabular}

Os resultados obtidos para as Dimensões do IMUS (Ambiental, Econômica e Social) e sua contribuição para o resultado global do índice (IMUSg), bem como uma comparação entre os resultados obtidos para as três Dimensões, são mostrados na Figura 9.4. No ANEXO I Cálculo do IMUS para São Carlos -SP constam ainda gráficos que mostram os resultados globais dos Indicadores classificados por Domínio do IMUS. Estes resultados permitem visualizar melhor o impacto de cada indicador sobre o resultado global, uma vez que agrega 
informação referente ao peso (do Indicador, do Domínio e do Tema a que pertence) e score obtido.

IMUS

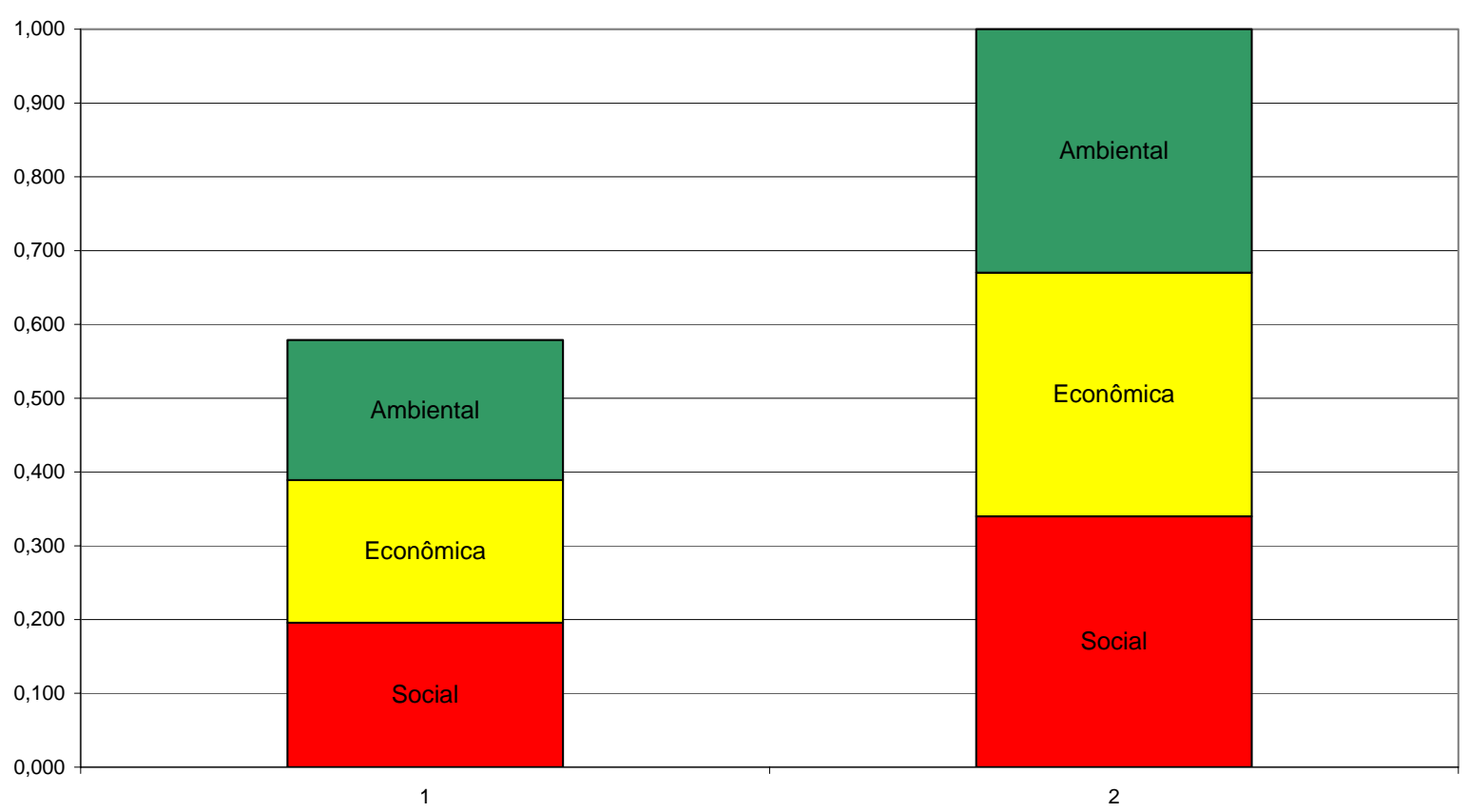

Figura 9.4: Resultados para o IMUSg e IMUS setorial.

O resultado global, através do processo de cálculo, mostra que o IMUS para a cidade de São Carlos atingiu valor igual a 0,578, valor intermediário na escala de avaliação do índice, cujos limites inferior e superior são, respectivamente 0,00 e 1,00. Este é um resultado que não pode ser considerado baixo, porém, mostra que vários aspectos podem ser melhorados no sentido de se obter melhores resultados para os índices setoriais e global e, conseqüentemente, melhores resultados em termos de sustentabilidade dos sistemas de mobilidade urbana, segundo os critérios avaliados.

No que diz respeito às Dimensões, a área Social apresentou a melhor avaliação $(0,196)$ seguida pela Dimensão Econômica $(0,193)$. A Dimensão Ambiental, por sua vez, apresentou o pior resultado, igual 0,190. Ainda que tenham apresentados resultados discretamente diferentes, a Figura 9.4 permite observar que, para o município de São Carlos, as três Dimensões estão praticamente equilibradas. Cabe destacar que o sistema de pesos definido para o IMUS a partir de um painel de especialistas resulta em uma contribuição equilibrada das Dimensões Social, Econômica e Ambiental para o resultado global do IMUS, uma vez que as mesmas podem atingir, respectivamente, os scores máximos de 0,34, 0,33 e 0,33. Desta forma, este equilíbrio entre as Dimensões é desejável para o município, uma vez que reflete o sistema de pesos adotados para os critérios que compõem o índice. 


\subsubsection{Análise dos Resultados para os Indicadores}

Neste item são analisados aspectos específicos para cada Dimensão, com enfoque nos resultados obtidos para os indicadores, classificados por Domínio.

As Figuras 9.5 e 9.6 mostram os resultados obtidos para os indicadores que compõem o IMUS, através de seus scores normalizados (entre 0,00 e 1,00). A Figura 9.5 apresenta os resultados para os oitenta indicadores calculados, os quais são identificados pelo seu ID, conforme Tabela 8.4. A Figura 9.6 mostra os resultados para os dez indicadores que apresentam os maiores pesos globais e para as Dimensões Social, Econômica e Ambiental.

Uma vez que o indicador "Qualidade de vida" não pôde ser calculado, em função da indisponibilidade de dados de base, e que o mesmo encontra-se entre os dez indicadores com maiores pesos global e para as três Dimensões, foi incorporado na análise o indicador que ocupa a $11^{\mathrm{a}}$ posição segundo a classificação apresentada na Tabela 8.15. Assim, para cada situação, o seguinte indicador foi incorporado na análise:

- Análise global - Indicador 3.4.1 "Participação na tomada de decisão";

- Dimensão Social - 8.4.1 Indicador "Violação das leis de trânsito";

- Dimensão Econômica - 4.1.2 Indicador "Parcerias público-privadas";

- Dimensão Ambiental - Indicador 3.1.1 "Informação disponível ao cidadão". 
Indicadores - IMUS

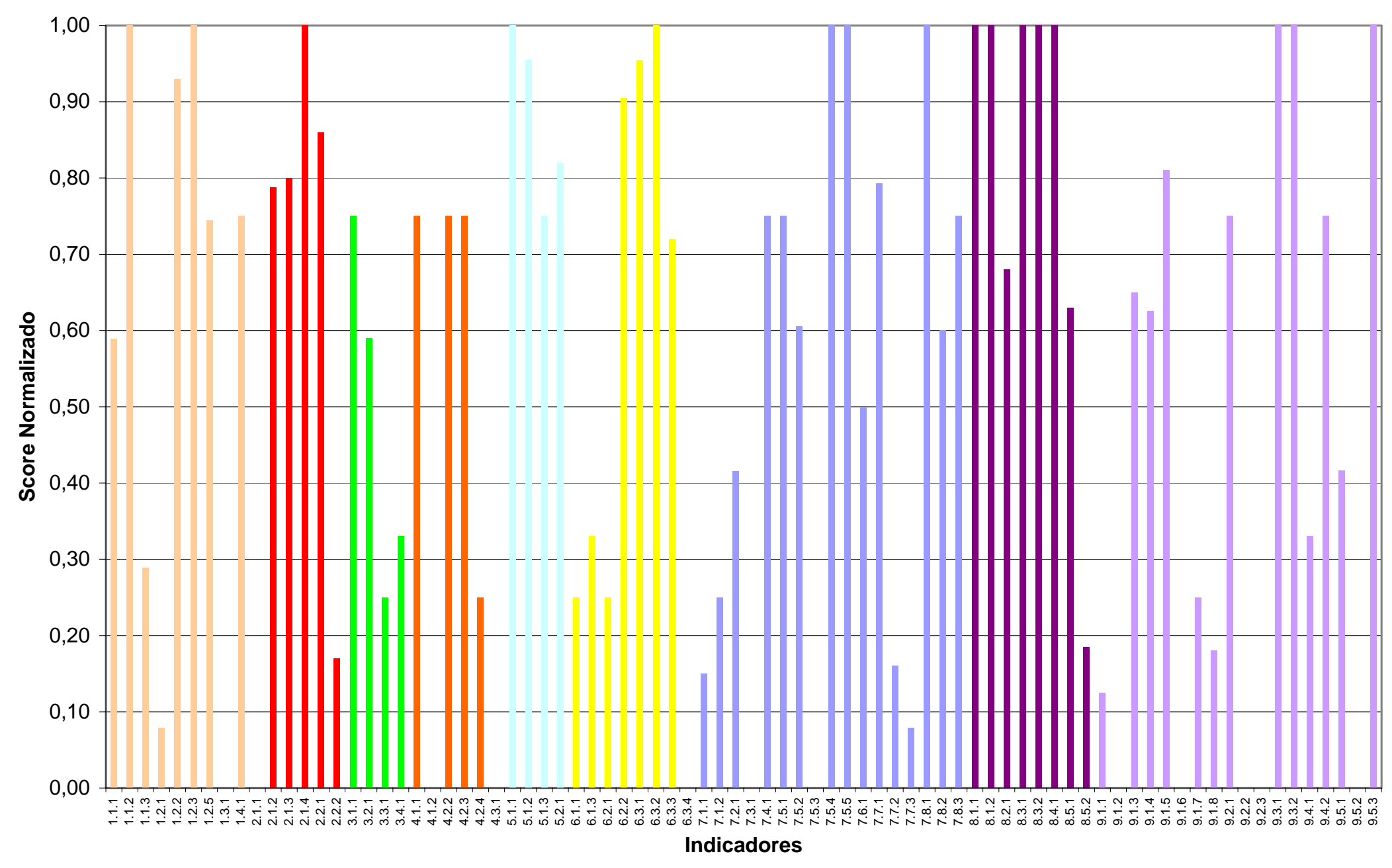

Figura 9.5: Resultados normalizados para os indicadores do IMUS, calculados para a cidade de São Carlos. 


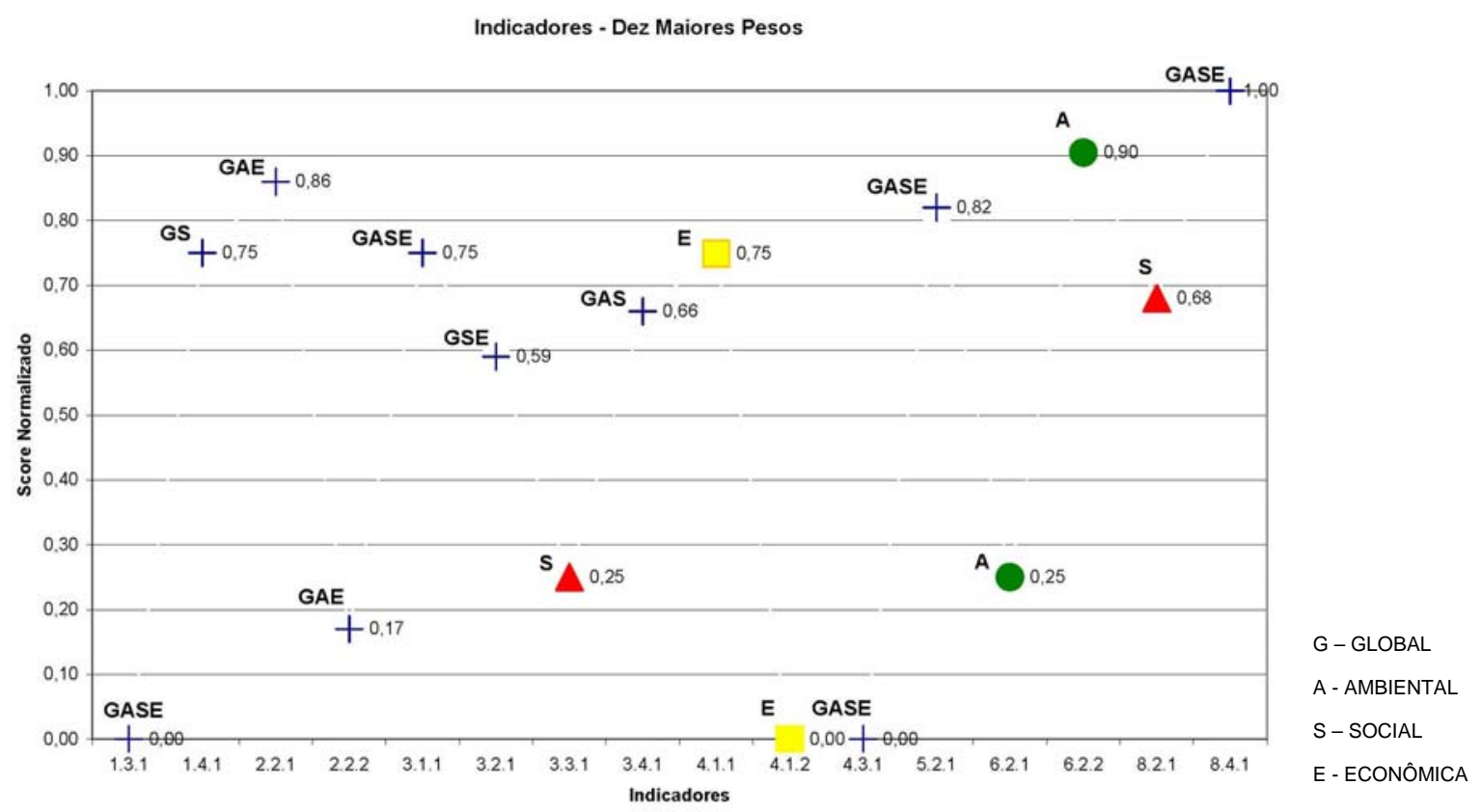

Figura 9.6: Resultados normalizados para os dez indicadores com maiores pesos global e por Dimensões, calculados para São Carlos.

Em termos globais, dos oitenta indicadores avaliados para a cidade de São Carlos, somente dezesseis indicadores ( $20 \%$ do conjunto) atingiram o score máximo, igual a 1,00, o que representa um ótimo desempenho em termos de sustentabilidade, segundo a escala de avaliação proposta para avaliação indicador. Doze indicadores (15\% do conjunto) apresentaram score mínimo, igual a 0,00. Os demais $(66,25 \%)$ apresentaram scores com valores intermediários.

No que diz respeito aos dez indicadores com maiores pesos globais, somente o Indicador 8.4.1 - "Violação das leis de trânsito" apresentou score máximo, ou seja, apresentou uma excelente avaliação para o município, segundo critérios definidos para o indicador. Os indicadores 1.3.1 - "Fragmentação Urbana" e 4.3.1 - "Política de Mobilidade Urbana" apresentaram o score mínimo. Os demais indicadores deste grupo apresentaram scores variando entre 0,17 e 0,86.

Os resultados para as Dimensões da sustentabilidade foram, de um modo geral, semelhantes, uma vez que vários indicadores com maiores pesos globais, também apresentam maior importância relativa dentro de cada Dimensão, conforme mostrado na Figura 9.6.

Para os dez indicadores com maiores pesos para a Dimensão Social, o indicador 8.4.1 apresentou score máximo, ao mesmo tempo que os indicadores 1.3.1 e 4.3.1 apresentaram 
scores mínimos, tal como observado na avaliação global. Os demais indicadores apresentaram scores variando entre 0,25 e 0,82.

$\mathrm{Na}$ Dimensão Econômica, novamente o indicador 8.4.1 apresentou score máximo. Apresentaram score mínimo, os indicadores 1.3.1 e 4.3.1, tal como observado nas situações anteriores, além do indicador 4.1.2 - "Parcerias público-privadas". Os demais indicadores do grupo apresentaram scores variando entre 0,17 e 0,86.

Para Dimensão Ambiental, o indicador 8.4.1 também é o único a apresentar score máximo, assim como os indicadores 1.3.1 e 4.3.1 apresentam score mínimo. Os demais indicadores apresentam scores variando entre 0,17 e 0,90.

A análise dos scores obtidos para os indicadores classificados por Domínio é feita a seguir, por meio das Tabelas 9.6 a 9.14. Nestas tabelas, são apresentados os scores absoluto (com a respectiva unidade de medida, quando for o caso) e normalizado, para os indicadores de cada um dos Domínios que compõem o IMUS.

Os indicadores com scores normalizados iguais a 1,00 são identificados pela cor verde. Em função dos bons resultados apresentados indicam, portanto, aspectos que contribuem para a mobilidade urbana sustentável na cidade de São Carlos, não necessitando de intervenções imediatas para sua melhoria. Exigem, no entanto, ações visando a manutenção dos níveis obtidos.

Os indicadores com scores normalizados iguais a 0,00 são identificados pela cor vermelha. Esses indicam, portanto, fatores críticos que necessitam ser promovidos de forma mais urgente, com o intuito de melhorar as condições de mobilidade, visando a sustentabilidade.

Os indicadores que atingiram scores intermediários e que estão relacionados entre os indicadores com maiores pesos para avaliação global e setorial são destacados em amarelo. Ainda que não apresentem o score mínimo, também merecem ser contemplados por políticas e estratégias específicas, em função de sua elevada importância relativa e, por conseqüência, dos impactos que variações nos seus scores podem produzir para os resultados global e setorial do IMUS. 
Tabela 9.6: Scores absoluto e normalizado para os indicadores do Domínio Acessibilidade, calculados para São Carlos.

\begin{tabular}{|c|c|c|c|c|}
\hline TEMA & ID & INDICADOR & SCORE & $\begin{array}{l}\text { SCORE } \\
\text { NORMAL. }\end{array}$ \\
\hline \multirow{3}{*}{$\begin{array}{l}\text { Acessibilidade aos sistemas de } \\
\text { transportes }\end{array}$} & 1.1 .1 & Acessibilidade ao transporte público & $63,00 \%$ & 0,59 \\
\hline & 1.1 .2 & $\begin{array}{l}\text { Transporte público para pessoas com } \\
\text { necessidades especiais }\end{array}$ & 1,00 & 1,00 \\
\hline & 1.1 .3 & Despesas com transporte & $19,22 \%$ & 0,29 \\
\hline \multirow{4}{*}{ Acessibilidade universal } & 1.2 .1 & $\begin{array}{l}\text { Travessias adaptadas a pessoas com } \\
\text { necessidades especiais }\end{array}$ & $7,90 \%$ & 0,08 \\
\hline & 1.2 .2 & Acessibilidade a espaços abertos & $93,00 \%$ & 0,93 \\
\hline & 1.2 .3 & $\begin{array}{l}\text { Vagas de estacionamento para } \\
\text { pessoas com necessidades especiais }\end{array}$ & 1,00 & 1,00 \\
\hline & 1.2 .5 & Acessibilidade aos serviços essenciais & $77,00 \%$ & 0,74 \\
\hline Barreiras físicas & 1.3 .1 & Fragmentação urbana & 23,00 & 0,00 \\
\hline $\begin{array}{l}\text { Legislação para pessoas com } \\
\text { necessidades especiais }\end{array}$ & 1.4 .1 & Ações para acessibilidade universal & 0,75 & 0,75 \\
\hline
\end{tabular}

Tabela 9.7: Scores absoluto e normalizado para os indicadores do Domínio Aspectos Ambientais, calculados para São Carlos.

\begin{tabular}{|c|c|c|c|c|}
\hline TEMA & ID & INDICADOR & SCORE & $\begin{array}{c}\text { SCORE } \\
\text { NORMAL. }\end{array}$ \\
\hline \multirow{4}{*}{$\begin{array}{l}\text { Controle dos impactos no meio } \\
\text { ambiente }\end{array}$} & 2.1 .1 & Emissões de CO & $111,13 \%$ & 0,00 \\
\hline & 2.1 .2 & Emissões de $\mathrm{CO}_{2}$ & $21,24 \%$ & 0,79 \\
\hline & 2.1 .3 & População exposta ao ruído de tráfego & $20,00 \%$ & 0,80 \\
\hline & 2.1 .4 & Estudos de Impacto Ambiental & 1,00 & 1,00 \\
\hline \multirow{2}{*}{ Recursos naturais } & 2.2 .1 & Consumo de combustível & $\begin{array}{c}234,00 \\
\text { L/hab/ano }\end{array}$ & 0,86 \\
\hline & 2.2 .2 & $\begin{array}{l}\text { Uso de energia limpa e combustíveis } \\
\text { alternativos }\end{array}$ & $17,00 \%$ & 0,17 \\
\hline
\end{tabular}

Tabela 9.8: Scores absoluto e normalizado para os indicadores do Domínio Aspectos Sociais, calculados para São Carlos.

\begin{tabular}{lclccc}
\multicolumn{1}{c}{ TEMA } & ID & \multicolumn{1}{c}{ INDICADOR } & SCORE & $\begin{array}{c}\text { SCORE } \\
\text { NORMAL. }\end{array}$ \\
\hline Apoio ao cidadão & 3.1 .1 & Informação disponível ao cidadão & 0,75 & 0,75 \\
\hline Inclusão social & 3.2 .1 & Eqüidade vertical (renda) & 0,59 & 0,59 \\
\hline Educação e cidadania & 3.3 .1 & $\begin{array}{l}\text { Educação para o desenvolvimento } \\
\text { sustentável }\end{array}$ & 0,25 & 0,25 \\
\hline Participação popular & 3.4 .1 & Participação na tomada de decisão & 0,66 & 0,66 \\
\hline
\end{tabular}

Tabela 9.9: Scores absoluto e normalizado para os indicadores do Domínio Aspectos Políticos, calculados para São Carlos.

\begin{tabular}{|c|c|c|c|c|}
\hline TEMA & ID & INDICADOR & SCORE & $\begin{array}{l}\text { SCORE } \\
\text { NORMAL. }\end{array}$ \\
\hline \multirow{2}{*}{ Integração de ações políticas } & 4.1 .1 & Integração entre níveis de governo & 0,75 & 0,75 \\
\hline & 4.1 .2 & Parcerias público/privadas & 0,00 & 0,00 \\
\hline \multirow{3}{*}{$\begin{array}{l}\text { Captação e gerenciamento de } \\
\text { recursos }\end{array}$} & 4.2 .2 & $\begin{array}{l}\text { Investimentos em sistemas de } \\
\text { transportes }\end{array}$ & 0,75 & 0,75 \\
\hline & 4.2 .3 & $\begin{array}{l}\text { Distribuição dos recursos (público x } \\
\text { privado) }\end{array}$ & 1,00 & 0,75 \\
\hline & 4.2 .4 & $\begin{array}{l}\text { Distribuição dos recursos (motorizados } \\
\text { x não-motorizados) }\end{array}$ & 0,25 & 0,25 \\
\hline Política de mobilidade urbana & 4.3 .1 & Política de mobilidade urbana & 0,00 & 0,00 \\
\hline
\end{tabular}


Tabela 9.10: Scores absoluto e normalizado para os indicadores do Domínio Infra-estrutura de Transportes, calculados para São Carlos.

\begin{tabular}{lclcc}
\multicolumn{1}{c}{ TEMA } & ID & \multicolumn{1}{c}{ INDICADOR } & SCORE & $\begin{array}{c}\text { SCORE } \\
\text { NORMAL. }\end{array}$ \\
\hline \multirow{2}{*}{$\begin{array}{l}\text { Provisão e manutenção da infra- } \\
\text { estrutura de transportes }\end{array}$} & 5.1 .1 & $\begin{array}{l}\text { Densidade e conectividade da rede } \\
\text { viária }\end{array}$ & 1,00 & 1,00 \\
\cline { 2 - 6 } & 5.1 .2 & Vias pavimentadas & $96,00 \%$ & 0,96 \\
\hline $\begin{array}{l}\text { Distribuição da infra-estrutura de } \\
\text { transportes }\end{array}$ & 5.1 .3 & $\begin{array}{l}\text { Despesas com manutenção da infra- } \\
\text { estrutura de transportes }\end{array}$ & 0,75 & 0,75 \\
\hline
\end{tabular}

Tabela 9.11: Scores absoluto e normalizado para os indicadores do Domínio Modos Nãomotorizados.

\begin{tabular}{cclcc}
\hline TEMA & ID & \multicolumn{1}{c}{ INDICADOR } & SCORE & $\begin{array}{c}\text { SCORE } \\
\text { NORMAL. }\end{array}$ \\
\hline \multirow{2}{*}{ Transporte cicloviário } & 6.1 .1 & Extensão e conectividade de ciclovias & 0,25 & 0,25 \\
\cline { 2 - 5 } & 6.1 .3 & Estacionamento para bicicletas & $33,00 \%$ & 0,33 \\
\hline \multirow{2}{*}{ Deslocamentos a pé } & 6.2 .1 & Vias para pedestres & $0,25 \%$ & 0,25 \\
\hline & 6.2 .2 & Vias com calçadas & $91,43 \%$ & 0,90 \\
\hline \multirow{2}{*}{ Redução de viagens } & 6.3 .1 & Distância de viagem & $2,37 \mathrm{~km}$ & 0,95 \\
\hline & 6.3 .2 & Tempo de viagem & $10,76 \mathrm{~min}$ & 1,00 \\
\hline & 6.3 .3 & Número de viagens & 1,44 viagens & 0,72 \\
\hline
\end{tabular}

Tabela 9.12: Scores absoluto e normalizado para os indicadores do Domínio Planejamento Integrado.

\begin{tabular}{|c|c|c|c|c|}
\hline TEMA & ID & INDICADOR & SCORE & $\begin{array}{l}\text { SCORE } \\
\text { NORMAL. }\end{array}$ \\
\hline \multirow{2}{*}{ Capacitação de gestores } & 7.1.1 & $\begin{array}{l}\text { Nível de formação de técnicos e } \\
\text { gestores }\end{array}$ & $8,00 \%$ & 0,15 \\
\hline & 7.1.2 & Capacitação de técnicos e gestores & $\begin{array}{c}16,00 \\
\text { horas/func./ano }\end{array}$ & 0,25 \\
\hline $\begin{array}{l}\text { Áreas centrais e de } \\
\text { interesse histórico }\end{array}$ & 7.2 .1 & Vitalidade do centro & 0,83 & 0,42 \\
\hline Integração regional & 7.3 .1 & Consórcios intermunicipais & 0,00 & 0,00 \\
\hline $\begin{array}{l}\text { Transparência do } \\
\text { processo de planejamento }\end{array}$ & 7.4 .1 & Transparência e responsabilidade & 0,75 & 0,75 \\
\hline \multirow{5}{*}{$\begin{array}{l}\text { Planejamento e controle } \\
\text { do uso e ocupação do } \\
\text { solo }\end{array}$} & 7.5 .1 & Vazios urbanos & $20,00 \%$ & 0,75 \\
\hline & 7.5 .2 & Crescimento urbano & 1,21 & 0,61 \\
\hline & 7.5 .3 & Densidade populacional urbana & 2684,00 hab/km & 0,00 \\
\hline & 7.5 .4 & Índice de uso misto & $90,93 \%$ & 1,00 \\
\hline & 7.5 .5 & Ocupações irregulares & 0,05 & 1,00 \\
\hline $\begin{array}{l}\text { Planejamento estratégico } \\
\text { e integrado }\end{array}$ & 7.6 .1 & $\begin{array}{l}\text { Planejamento urbano, ambiental e de } \\
\text { transportes integrado }\end{array}$ & 0,50 & 0,50 \\
\hline \multirow{3}{*}{$\begin{array}{l}\text { Planejamento da infra- } \\
\text { estrutura urbana e } \\
\text { equipamentos urbanos }\end{array}$} & 7.7 .1 & Parques e áreas verdes & $20,85 \mathrm{~m}^{2} / \mathrm{hab}$ & 0,79 \\
\hline & 7.7 .2 & Equipamentos urbanos (escolas) & 0,41 esc/1000hab & 0,16 \\
\hline & 7.7.3 & $\begin{array}{l}\text { Equipamentos urbanos (postos de } \\
\text { saúde) }\end{array}$ & $\begin{array}{c}13,14 \\
\text { postos/100000hab }\end{array}$ & 0,08 \\
\hline \multirow{3}{*}{$\begin{array}{l}\text { Plano Diretor e legislação } \\
\text { urbanística }\end{array}$} & 7.8 .1 & Plano Diretor & 1,00 & 1,00 \\
\hline & 7.8 .2 & Legislação urbanística & 0,60 & 0,60 \\
\hline & 7.8 .3 & Cumprimento da legislação urbanística & 0,75 & 0,75 \\
\hline
\end{tabular}


Tabela 9.13: Scores absoluto e normalizado para os indicadores do Domínio Tráfego e Circulação Urbana.

\begin{tabular}{lclcc}
\hline \multicolumn{1}{c}{ TEMA } & ID & \multicolumn{1}{c}{ INDICADOR } & SCORE & $\begin{array}{c}\text { SCORE } \\
\text { NORMAL. }\end{array}$ \\
\hline Acidentes de trânsito & 8.1 .1 & Acidentes de trânsito & mortos/100000hab/ano & 1,00 \\
\hline & 8.1 .2 & Acidentes com pedestres e ciclistas & $3,33 \%$ & 1,00 \\
\hline Educação para o trânsito & 8.2 .1 & Educação para o trânsito & $68,00 \%$ & 0,68 \\
\hline Fluidez e circulação & 8.3 .1 & Congestionamento & 0,16 horas/dia & 1,00 \\
\hline $\begin{array}{l}\text { Operação e fiscalização } \\
\text { de trânsito }\end{array}$ & 8.3 .2 & Velocidade média de tráfego & $38,51 \mathrm{~km} / \mathrm{h}$ & 1,00 \\
\hline Transporte individual & 8.4 .1 & Violação das leis de trânsito & $0,10 \%$ & 1,00 \\
\hline & 8.5 .1 & Índice de motorização & 324,00 autos/1000 hab & 0,63 \\
\hline
\end{tabular}

Tabela 9.14: Scores absoluto e normalizado para os indicadores do Domínio Sistemas de Transporte Urbano.

\begin{tabular}{|c|c|c|c|c|}
\hline TEMA & ID & INDICADOR & SCORE & $\begin{array}{l}\text { SCORE } \\
\text { NORMAL. }\end{array}$ \\
\hline \multirow{8}{*}{$\begin{array}{l}\text { Disponibilidade e } \\
\text { qualidade do transporte } \\
\text { público }\end{array}$} & 9.1 .1 & Extensão da rede de transporte público & $30,00 \%$ & 0,13 \\
\hline & $\overline{9.1 .2}$ & $\begin{array}{l}\text { Freqüência de atendimento do transporte } \\
\text { público }\end{array}$ & $60,00 \mathrm{~min}$ & 0,00 \\
\hline & 9.1 .3 & Pontualidade & $93,00 \%$ & 0,65 \\
\hline & 9.1 .4 & Velocidade média do transporte público & $22,50 \mathrm{~km} / \mathrm{h}$ & 0,63 \\
\hline & 9.1 .5 & Idade média da frota de transporte público & 6,09 anos & 0,81 \\
\hline & 9.1 .6 & Índice de passageiros por quilômetro & 2,00 & 0,00 \\
\hline & 9.1 .7 & Passageiros transportados anualmente & $0,25 \%$ & 0,25 \\
\hline & 9.1 .8 & $\begin{array}{l}\text { Satisfação do usuário com o serviço de } \\
\text { transporte público }\end{array}$ & $18,00 \%$ & 0,18 \\
\hline \multirow{3}{*}{ Diversificação modal } & 9.2 .1 & Diversidade de modos de transporte & 4,00 modos & 0,75 \\
\hline & 9.2 .2 & Transporte coletivo $\mathrm{x}$ transporte individual & 0,60 & 0,00 \\
\hline & 9.2 .3 & $\begin{array}{l}\text { Modos não-motorizados x modos } \\
\text { motorizados }\end{array}$ & 0,47 & 0,00 \\
\hline \multirow{2}{*}{$\begin{array}{l}\text { Regulação e fiscalização } \\
\text { do transporte público }\end{array}$} & 9.3 .1 & Contratos e licitações & $100,00 \%$ & 1,00 \\
\hline & 9.3 .2 & Transporte clandestino & 1,00 & 1,00 \\
\hline \multirow{2}{*}{$\begin{array}{l}\text { Integração do transporte } \\
\text { público }\end{array}$} & 9.4 .1 & Terminais intermodais & $33,00 \%$ & 0,33 \\
\hline & 9.4 .2 & Integração do transporte público & 1,00 & 1,00 \\
\hline \multirow{3}{*}{ Política tarifária } & 9.5 .1 & Descontos e gratuidades & $33,34 \%$ & 0,42 \\
\hline & 9.5 .2 & Tarifas de transportes & 0,00 & 0,00 \\
\hline & 9.5 .3 & Subsídios públicos & 1,00 & 1,00 \\
\hline
\end{tabular}

\subsubsection{Análise de Sensibilidade}

De forma a avaliar o impacto de melhorias nos scores de determinados indicadores para os resultados do IMUS e, portanto, identificar possíveis áreas de intervenção visando a mobilidade urbana sustentável na cidade de São Carlos, foi desenvolvida uma análise de sensibilidade, buscando verificar os impactos de tais variações sobre os resultados global e setoriais do índice.

Esta análise foi realizada considerando-se, para os dez indicadores de maiores pesos global e setoriais apresentados na Tabela 8.15, scores iguais a 1,00, ou seja, considerando-se o 
valor máximo que pode ser obtido para cada indicador. Esta simulação foi feita em cinco etapas, assim definidas:

- Na Etapa 1 foi atribuído o score 1,00 para os dez indicadores com maiores pesos globais;

- Na Etapa 2 foi atribuído o score 1,00 para os dez indicadores com maiores pesos para a Dimensão Social;

- Na Etapa 3 foi atribuído o score 1,00 para os dez indicadores com maiores pesos para a Dimensão Econômica;

- Na Etapa 4 foi atribuído o score 1,00 para os dez indicadores com maiores pesos para a Dimensão Ambiental;

- Na Etapa 5 foi atribuído o score 1,00 para todos os indicadores que constam na relação de maiores pesos em âmbito global e para as três Dimensões, totalizando dezesseis indicadores, conforme mostrado na Figura 9.15.

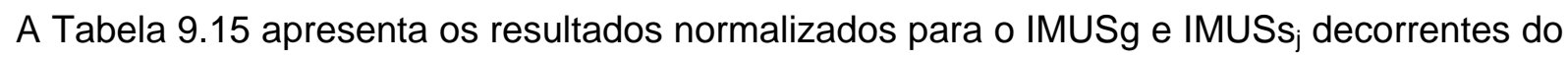
processo de cálculo. Estes valores servem para comparação com os demais resultados obtidos. Nas demais colunas são apresentados os resultados para o IMUSg e IMUSs cada uma das cinco etapas de análise de sensibilidade desenvolvidas nesta fase do estudo.

Tabela 9.15: Resultados normalizados para IMUSg e IMUSs s segundo processo de cálculo e análise de sensibilidade.

\begin{tabular}{lcccccc}
\hline \multirow{2}{*}{ Índice } & \multirow{2}{*}{ Cálculo } & \multicolumn{5}{c}{ Análise de Sensibilidade } \\
\cline { 5 - 8 } & & Etapa 1 & Etapa 2 & Etapa 3 & Etapa 4 & Etapa 5 \\
\hline IMUS $_{\mathrm{g}}$ & 0,578 & 0,708 & 0,708 & 0,708 & 0,708 & 0,773 \\
\hline IMUS $_{\text {Social }}$ & 0,196 & 0,241 & 0,245 & 0,239 & 0,239 & 0,265 \\
\hline IMUS $_{\text {Econômico }}$ & 0,193 & 0,234 & 0,233 & 0,236 & 0,234 & 0,254 \\
\hline IMUS $_{\text {Ambiental }}$ & 0,190 & 0,233 & 0,230 & 0,233 & 0,235 & 0,254 \\
\hline
\end{tabular}

A Figura 9.7 ilustra os resultados obtidos para o IMUSg e para o IMUSs, para o processo de cálculo e para as cinco etapas de análise de sensibilidade.

Com base nos resultados obtidos pode-se observar que em todas as etapas de análise de sensibilidade os resultados globais passam para nível 0,708, com exceção da última etapa, onde o valor para o IMUSg atinge 0,773. Isto é natural, uma vez que um número maior de indicadores receberam a pontuação máxima. Esta variação implica, portanto, que os resultados do IMUS passem de valores intermediários para valores elevados na escala de avaliação definida para o índice, cujo limite superior é igual a 1,00. Já os resultados para as Dimensões passaram de 0,196 para a Dimensão Social, até valores iguais a 0,265 na última etapa de avaliação. Para as Dimensões Econômica e Ambiental, os valores máximos obtidos foram iguais a 0,254. 


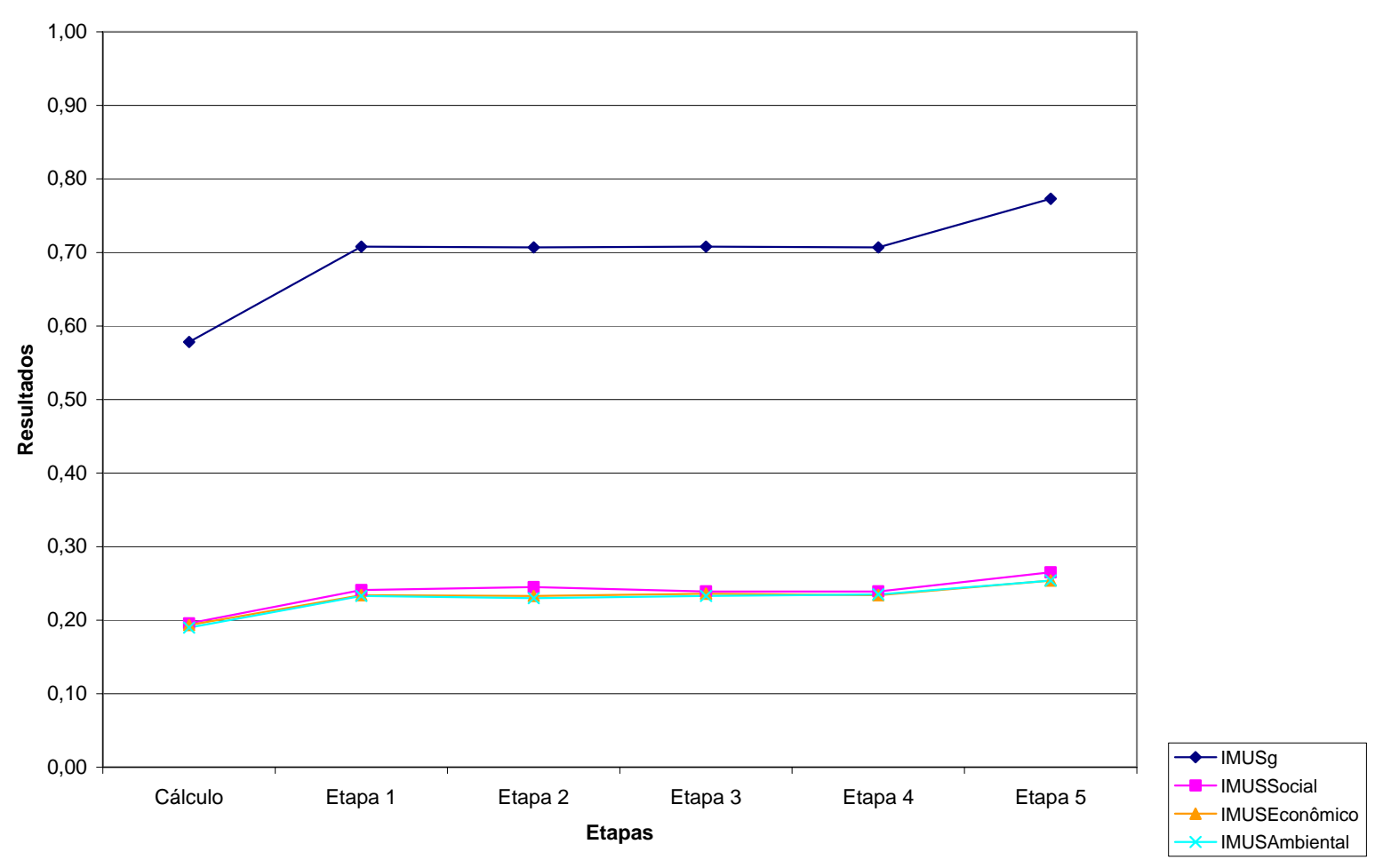

Figura 9.7: Resultados da análise de sensibilidade para o IMUSg.

Em todas as etapas de análise de sensibilidade, a Dimensão Social apresentou os melhores resultados, mantendo o padrão observado inicialmente. A Dimensão Econômica manteve-se como a segunda melhor Dimensão avaliada nas Etapas 1, 2 e 3. A Dimensão Ambiental, somente atingiu melhores resultados na Etapa 4, quando justamente seus indicadores foram promovidos. Na Etapa 5, ambas (Ambiental e Econômica) atingiram os mesmos resultados. A análise de sensibilidade mostrou ainda que, em cada etapa, a relação entre as Dimensões foi alterada. Na etapa final, foi observado equilíbrio entre as Dimensões Econômica e Ambiental.

Conclui-se deste modo que, promovendo-se em uma primeira etapa os dez indicadores com maiores pesos globais e por Dimensões, é possível obter resultados significativos para os resultados do IMUS, melhorando assim a avaliação global e setorial da mobilidade urbana. Desta forma, recomenda-se que, em um primeiro momento, estes indicadores, os quais são relacionados na Figura 9.6, sejam alvo de estratégias específicas, assim como os indicadores grifados em vermelho nas Tabelas 9.6 a 9.14 .

A Tabela 9.16 mostra, em termos percentuais, as variações ocorridas para o IMUSg e IMUSs $s_{j}$ em cada uma das etapas de análise de sensibilidade. 
Tabela 9.16: Variações ocorridas no IMUSs ${ }_{j}$ nas etapas de análise de sensibilidade.

\begin{tabular}{lccccc}
\hline \multirow{2}{*}{ Dimensões } & \multicolumn{5}{c}{ Análise de Sensibilidade } \\
\cline { 2 - 6 } & Etapa 1 & Etapa 2 & Etapa 3 & Etapa 4 & Etapa 5 \\
\hline IMUS $_{\mathrm{g}}$ & $22 \%$ & $22 \%$ & $22 \%$ & $22 \%$ & $34 \%$ \\
\hline IMUS $_{\text {Social }}$ & $23 \%$ & $25 \%$ & $22 \%$ & $22 \%$ & $35 \%$ \\
\hline IMUS $_{\text {Econômico }}$ & $21 \%$ & $21 \%$ & $22 \%$ & $21 \%$ & $32 \%$ \\
\hline IMUS $_{\text {Ambiental }}$ & $23 \%$ & $21 \%$ & $23 \%$ & $24 \%$ & $34 \%$ \\
\hline
\end{tabular}

Os resultados mostraram ainda que ao se promover somente os Indicadores com maiores pesos globais (Etapa 1) o ganho para o $\mathrm{IMUS}_{\mathrm{g}}$ é de $22 \%$, conforme mostrado na Tabela 9.15. Ao se melhorar os indicadores de maiores pesos somente para uma das Dimensões (Etapas 2,3 e 4) os ganhos variam entre 22\% e 25\% para a Dimensão Social, $21 \%$ e 22\% para Dimensão Econômica e 21\% e 24\% para a Dimensão Ambiental. Maiores ganhos para os resultados do IMUS são observados quando promovidos os dezesseis indicadores com maiores pesos (Etapa 5), variando entre 32\% e 35\%.

\subsubsection{Avaliação expedita}

Além do processo de cálculo, foi realizada uma avaliação expedita dos indicadores que compõem o IMUS, conforme previsto no item 6.4.1 do Método. A avaliação expedita foi realizada com o objetivo de verificar os resultados do IMUS para a cidade de São Carlos, uma vez que não há outro índice para comparação ou dados para outras cidades que permitam aferir a consistência dos resultados obtidos. Além disso, a análise expedita foi desenvolvida de forma a fornecer subsídios para aprimoramento do processo de cálculo dos indicadores, permitindo identificar eventuais discrepâncias entre os resultados obtidos através dos dois métodos de avaliação.

A avaliação expedita foi feita a partir de consulta a especialista com amplo conhecimento das questões de mobilidade e desenvolvimento urbano do município, o qual desempenhou recentemente e durante quatro anos a função de Secretário Municipal de Trânsito, Transportes e Vias Públicas, além de ter participado ativamente do processo de elaboração do Plano Diretor Municipal.

Ao especialista foram apresentadas fichas contendo o resumo das informações referentes aos oitenta indicadores que compõem o IMUS, os quais puderam ser calculados para a cidade de São Carlos. Estas fichas incluíram a definição dos indicadores e sua respectiva escala de avaliação. Uma vez compreendida a definição do indicador e analisada sua respectiva escala de avaliação, o especialista indicava, com base em seu conhecimento sobre a questão, o nível ou score para o mesmo. Alguns indicadores, no entanto, não puderam ser avaliados, uma vez que o avaliador indicou não ter condições de atribuir um 
score para os mesmos, em função do seu desconhecimento sobre a questão. Desta forma, dos oitenta indicadores submetidos à avaliação do especialista, setenta e um foram avaliados para obtenção dos respectivos scores.

Os resultados foram registrados nas fichas e posteriormente inseridos na Planilha de Cálculo do IMUS obtendo-se, do mesmo modo como foi realizado para o processo de cálculo, os resultados global (IMUSg) e setorial (IMUSs $s_{j}$ ) para o índice. Para situações em que o avaliador indicou valores intermediários aos apresentados na escala de avaliação, foram adotados valores médios entre os limites indicados.

Uma vez que somente setenta e um dos oitenta indicadores calculados para a cidade de São Carlos foram avaliados pelo especialista, a análise comparativa foi desenvolvida em duas etapas, contemplando: na primeira, o cruzamento dos resultados para os oitenta indicadores calculados e os setenta e um indicadores avaliados pelo método expedito; na segunda, o cruzamento dos resultados obtidos somente para os setenta e um indicadores avaliados através dos dois métodos.

Além dos resultados para o IMUSg e IMUSs foram analisados também os resultados obtidos para os indicadores, conforme discutido no item a seguir.

\subsubsection{Comparação dos Resultados do Processo de Cálculo e Avaliação Expedita}

A Tabela 9.17 apresenta os resultados do IMUS g e IMUSs, segundo o processo de cálculo (para os conjuntos com oitenta e setenta e um indicadores) e avaliação expedita. Dos oitenta indicadores calculados para a cidade de São Carlos, mostrados na Tabela 9.3, o especialista deixou de avaliar os seguintes:

- Indicador 1.3.1 - Fragmentação urbana;

- Indicador 2.1.1 - Emissões de CO;

- Indicador 2.1.2 - Emisões de $\mathrm{CO}_{2}$;

- Indicador 2.2.1 - Consumo de combustível;

- Indicador 3.2.1 - Eqüidade vertical (renda);

- Indicadores 7.2.1 - Vitalidade do centro;

- Indicador 7.8.2 - Legislação urbanística;

- Indicador 8.1.2 - Acidentes com pedestres e ciclistas; 
- Indicador 9.2.3 - Modos não-motorizados x modos motorizados.

Tabela 9.17: Comparação entre os resultados obtidos para o IMUS segundo os dois métodos de avaliação dos indicadores.

\begin{tabular}{lccc}
\hline \multirow{2}{*}{ Índice } & \multicolumn{3}{c}{ Resultados } \\
\cline { 2 - 4 } & $\begin{array}{c}\text { Cálculo } \\
\mathbf{8 0} \text { Indicadores }\end{array}$ & $\begin{array}{c}\text { Cálculo } \\
\mathbf{7 1} \text { Indicadores }\end{array}$ & $\begin{array}{c}\text { Avaliação Expedita } \\
\mathbf{7 1} \text { indicadores }\end{array}$ \\
\hline IMUS $_{\mathrm{g}}$ & 0,578 & 0,595 & 0,572 \\
\hline IMUS $_{\text {Social }}$ & 0,196 & 0,202 & 0,197 \\
\hline IMUS $_{\text {Econômico }}$ & 0,193 & 0,198 & 0,191 \\
\hline IMUS $_{\text {Ambiental }}$ & 0,190 & 0,195 & 0,184 \\
\hline
\end{tabular}

Os resultados mostram que a avaliação expedita dos indicadores produziu resultados globais e setoriais semelhantes aos observados segundo o processo de coleta de dados e cálculo dos indicadores que compõem o IMUS. Se comparados os resultados obtidos para os setenta e um indicadores avaliados pelos dois métodos, a variação para o resultado global ficou em torno de $4 \%$.

Para as Dimensões Social, Econômica e Ambiental esta variação foi, respectivamente, de 2,5\%, 3,5\% e 5,6\%. A maior variação observada, para a Dimensão Ambiental, se deve em grande parte, pela impossibilidade do avaliador em julgar alguns indicadores incluídos no Domínio (somente 50\% dos indicadores foram avaliados, a menor proporção entre todos os Domínios), em função de sua complexidade e de sua menor familiaridade com o tema.

$\mathrm{Na}$ avaliação expedita, a Dimensão Social se manteve com os melhores resultados, tal como foi observado no processo de cálculo dos indicadores. O que se observa ainda, é que há um maior desequilíbrio entre as Dimensões avaliadas, se comparados com os resultados observados através do processo de cálculo dos indicadores.

Esta análise sugere, portanto, que os resultados obtidos para o IMUS são consistentes, uma vez que estes se mostraram compatíveis, dentro de um intervalo de tolerância aceitável, com os resultados da análise expedita, feita por especialista com profundo conhecimento das questões urbanas e de mobilidade do município.

Uma vez verificados os resultados global e setorial para o índice, foi feita ainda a comparação dos resultados obtidos para os indicadores, de forma a evidenciar eventuais discrepâncias entre os valores observados nas duas análises. Neste sentido, a Figura 9.17 apresenta a comparação dos resultados obtidos segundo o processo de cálculo (eixo das abscissas) e avaliação expedita (eixo das ordenadas), para o conjunto de setenta e um indicadores avaliados pelos dois métodos. 
Para verificar a compatibilidade destes resultados, foi estabelecido um intervalo de tolerância para os valores obtidos, definido como uma variação do score normalizado de até no máximo 0,12 para mais ou para menos (que em geral corresponde ao intervalo médio entre dois níveis da escala de avaliação). Assim, os resultados iguais para os dois métodos e aqueles que se encontram dentro desta faixa de tolerância aparecem na porção central da Figura 9.8 e na Tabela 9.18.

\section{Análise Comparativa}

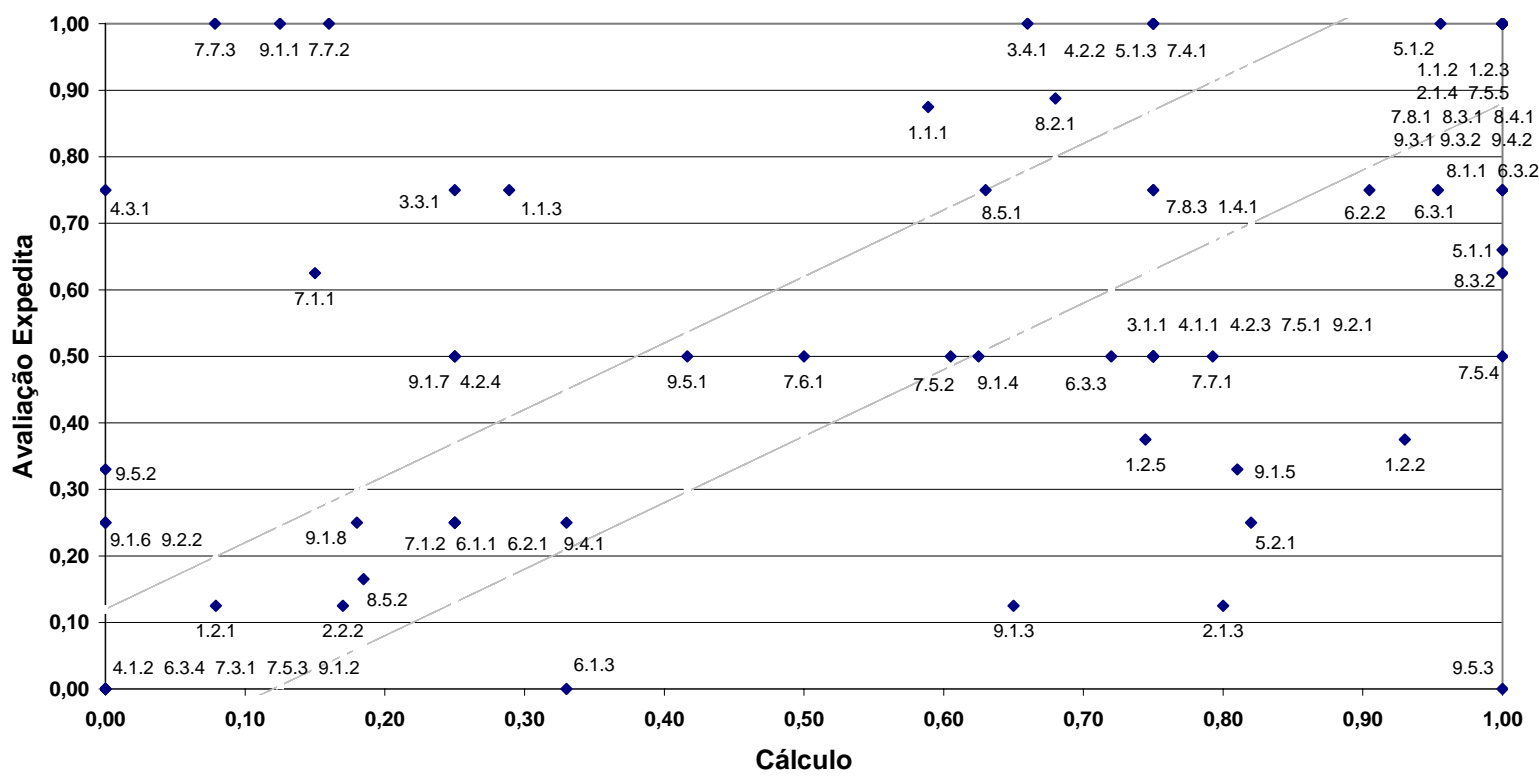

Figura 9.8: Resultados para os indicadores segundo processo de cálculo e avaliação expedita.

Tabela 9.18: Indicadores com resultados semelhantes nos dois processos de avaliação.

\begin{tabular}{|c|c|c|c|}
\hline Domínio & Tema & & Indicador \\
\hline \multirow{4}{*}{ Acessibilidade } & $\begin{array}{l}\text { Acessiblidade aos } \\
\text { sistemas de transportes }\end{array}$ & 1.1 .2 & $\begin{array}{l}\text { Transporte público para pessoas com } \\
\text { necessidades especiais }\end{array}$ \\
\hline & \multirow{2}{*}{ Acessibilidade universal } & 1.2 .1 & $\begin{array}{l}\text { Travessias adaptadas a pessoas com } \\
\text { necessidades especiais }\end{array}$ \\
\hline & & 1.2 .3 & $\begin{array}{l}\text { Vagas de estacionamento para pessoas } \\
\text { com necessidades especiais }\end{array}$ \\
\hline & $\begin{array}{l}\text { Legislação para pessoas } \\
\text { com necessidades } \\
\text { especiais }\end{array}$ & 1.4 .1 & Ações para acessibilidade universal \\
\hline \multirow{2}{*}{ Aspectos Ambientais } & $\begin{array}{l}\text { Controle dos impactos no } \\
\text { meio ambiente }\end{array}$ & 2.1 .4 & Estudos de Impacto Ambiental \\
\hline & Recursos naturais & 2.2 .2 & $\begin{array}{l}\text { Uso de energia limpa e combustíveis } \\
\text { alternativos }\end{array}$ \\
\hline Aspectos Políticos & $\begin{array}{l}\text { Integração de ações } \\
\text { políticas }\end{array}$ & 4.1 .2 & Parcerias público/privadas \\
\hline $\begin{array}{l}\text { Infra-estrutura de } \\
\text { Transportes }\end{array}$ & $\begin{array}{l}\text { Provisão e manutenção } \\
\text { da infra-estrutura de } \\
\text { transportes }\end{array}$ & 5.1 .2 & Vias pavimentadas \\
\hline \multirow{3}{*}{$\begin{array}{l}\text { Modos Não- } \\
\text { Motorizados }\end{array}$} & Transporte cicloviário & 6.1 .1 & Extensão e conectividade de ciclovias \\
\hline & Modos não-motorizados & 6.2 .1 & Vias para pedestres \\
\hline & Redução de viagens & 6.3 .4 & Ações para redução do tráfego motorizado \\
\hline Planejamento Integrado & Capacitação de gestores & 7.1 .2 & Capacitação de técnicos e gestores \\
\hline
\end{tabular}




\begin{tabular}{|c|c|c|c|}
\hline Domínio & Tema & & Indicador \\
\hline & Integração regional & 7.3 .1 & Consórcios intermunicipais \\
\hline & Planejamento e controle & 7.5 .2 & Crescimento urbano \\
\hline & do uso e ocupação do & 7.5 .3 & Densidade populacional urbana \\
\hline & solo & 7.5 .5 & Ocupações irregulares \\
\hline & $\begin{array}{l}\text { Planejamento estratégico } \\
\text { e integrado }\end{array}$ & 7.6 .1 & $\begin{array}{l}\text { Planejamento urbano, ambiental e de } \\
\text { transportes integrado }\end{array}$ \\
\hline & Plano Diretor e legislação & 7.8 .1 & Plano Diretor \\
\hline & urbanística & 7.8 .3 & Cumprimento da legislação urbanística \\
\hline \multirow{4}{*}{$\begin{array}{l}\text { Tráfego e Circulação } \\
\text { Urbana }\end{array}$} & Fluidez e circulação & 8.3 .1 & Congestionamento \\
\hline & $\begin{array}{l}\text { Operação e fiscalização } \\
\text { de trânsito }\end{array}$ & 8.4 .1 & Violação das leis de trânsito \\
\hline & \multirow{2}{*}{ Transporte individual } & 8.5 .1 & Índice de motorização \\
\hline & & 8.5 .2 & Taxa de ocupação dos veículos \\
\hline \multirow{7}{*}{$\begin{array}{l}\text { Sistemas de Transporte } \\
\text { Urbano }\end{array}$} & $\begin{array}{l}\text { Disponibilidade e } \\
\text { qualidade do transporte } \\
\text { público }\end{array}$ & 9.1 .2 & $\begin{array}{l}\text { Freqüência de atendimento do transporte } \\
\text { público }\end{array}$ \\
\hline & $\begin{array}{l}\text { Disponibilidade e } \\
\text { qualidade do transporte } \\
\text { público }\end{array}$ & 9.1 .8 & $\begin{array}{l}\text { Satisfação do usuário com o serviço de } \\
\text { transporte público }\end{array}$ \\
\hline & \multirow{2}{*}{$\begin{array}{l}\text { Regulação e fiscalização } \\
\text { do transporte público }\end{array}$} & 9.3 .1 & Contratos e licitações \\
\hline & & 9.3 .2 & Transporte clandestino \\
\hline & \multirow{2}{*}{$\begin{array}{l}\text { Integração do transporte } \\
\text { público }\end{array}$} & 9.4 .1 & Terminais intermodais \\
\hline & & 9.4 .2 & Integração do transporte público \\
\hline & Política tarifária & 9.5 .1 & Descontos e gratuidades \\
\hline
\end{tabular}

Os resultados mostram que, para $42 \%$ dos indicadores avaliados pelos dois métodos, os scores obtidos foram idênticos ou se encontravam dentro dos limites de tolerância admitidos. A grande divergência observada, equivalente a $58 \%$, pode ser atribuída a três aspectos fundamentais: a primeira, à dificuldade do avaliador em associar scores para determinados indicadores; a segunda, ao fato da avaliação ter sido feita por apenas um avaliador, que pode não ter conhecimento detalhado de todos os aspectos avaliados pelo índice; a terceira, a eventuais imprecisões no método de cálculo e dados de base para cálculo dos indicadores.

A dificuldade em avaliar determinados indicadores pode ser explicada por dois fatores. $\mathrm{O}$ primeiro, relacionado a escassez de informações sobre os indicadores, uma vez que as fichas continham uma informação sintética sobre os mesmos, não contemplando o detalhamento metodológico nem demais informações que pudessem levar a uma melhor compreensão dos parâmetros mensurados. O segundo, relacionado a complexidade de determinados indicadores e à diversidade de variáveis que envolvem, além do desconhecimento por parte do avaliador de alguns temas contemplados pelos mesmos. Neste sentido, o avaliador chegou mesmo a indicar a impossibilidade de proceder à avaliação de alguns tópicos, em função da indisponibilidade de dados exatos e ferramentas adequadas no momento da avaliação.

Em relação ao número de avaliadores, por sua vez, entende-se que uma avaliação feita com um número superior de avaliadores, que atuam em diversas áreas relacionadas ao 
planejamento urbano e da mobilidade, pode proporcionar uma aferição mais completa dos resultados obtidos, permitindo cobrir todos os indicadores avaliados para o município.

Ainda que os aspectos mencionados anteriormente expliquem, de um modo geral, as divergências encontradas, uma análise pormenorizada dos resultados obtidos através dos dois métodos pode auxiliar na identificação de indicadores que necessitam de revisão ou adequação de seus aspectos metodológicos, permitindo assim uma melhor avaliação dos mesmos. Neste sentido, a Tabela 9.19 apresenta a proporção de indicadores que obtiveram resultados compatíveis por Domínio do IMUS nos dois processos de avaliação.

Tabela 9.19: Proporção de indicadores com resultados compatíveis nos dois processos de avaliação.

\begin{tabular}{clc}
\hline ID & \multicolumn{1}{c}{ Domínio } & \% de Indicadores \\
\hline 1 & Acessibilidade & $50 \%$ \\
\hline 2 & Aspectos Ambientais & $67 \%$ \\
\hline 3 & Aspectos Sociais & 0 \\
\hline 4 & Aspectos Políticos & $17 \%$ \\
\hline 5 & Infra-estrutura de Transportes & $25 \%$ \\
\hline 6 & Modos Não-motorizados & $38 \%$ \\
\hline 7 & Planejamento Integrado & $53 \%$ \\
\hline 8 & Tráfego e Circulação Urbana & $57 \%$ \\
\hline 9 & Sistemas de Transporte Urbano & $41 \%$ \\
\hline
\end{tabular}

Ainda que para a Dimensão Ambiental uma menor proporção de indicadores tenha sido avaliada, conforme mencionado anteriormente, esta foi a Dimensão que apresentou os melhores resultados em termos de compatibilidade entre os dois métodos de avaliação (67\% de concordância). Isso sugere que, embora tenha havido dificuldade em avaliar determinados indicadores (relacionados a emissões e consumo de combustível) em função de sua complexidade, os indicadores do grupo podem ser avaliados com razoável confiabilidade, a partir da metodologia proposta e dos dados e informações disponíveis atualmente no município. Além disso, indica que os aspectos metodológicos e procedimentos para sua avaliação estão bem definidos, o que proporcionou uma boa compreensão dos aspectos mensurados.

Os Domínios Tráfego e Circulação Urbana, Planejamento Integrado e Acessibilidade apresentaram também boa compatibilidade entre os resultados obtidos para seus indicadores, superior a 50\%. Acredita-se que estes bons resultados se deram em função da predominância de indicadores quantitativos. Seus métodos de cálculo foram estruturados e detalhados adequadamente, os dados para seu cálculo são facilmente acessíveis e apresentam em grande parte alta qualidade, além de estarem vinculados a áreas de grande conhecimento por parte do avaliador. As divergências observadas foram atribuídas, em sua 
maioria, ao desconhecimento do avaliador de dados mais atualizados e a dificuldade de se avaliar alguns indicadores pela indisponibilidade de ferramentas adequadas no momento da avaliação.

Para os Domínios Sistemas de Transporte Urbano, Modos Não-motorizados, Infra-estrutura de Transportes e Aspectos Políticos foi observada grande incompatibilidade entre os resultados obtidos através dos dois métodos de avaliação. Estes Domínios envolvem tanto indicadores quantitativos como qualitativos, o que impede desta forma concluir com precisão as razões da grande divergência observada.

Para o Domínio Sistemas de Transporte Urbano, divergências foram observadas especialmente nos indicadores de desempenho dos serviços de transporte coletivo. No entanto, esta divergência se justifica mais pelo desconhecimento de dados atualizados pelo avaliador do que por deficiências no método de avaliação dos indicadores.

Para o Domínio Modos Não-motorizados, divergências foram observadas em relação aos indicadores dependentes de dados e informações provenientes de estudos específicos de transportes e mobilidade. Uma vez que pesquisas desta natureza, tais como a Pesquisa de Origem e Destino, ainda encontram-se em desenvolvimento no município, acredita-se que os indicadores destes Domínios possam ser avaliados de forma mais clara assim que os resultados da pesquisa sejam plenamente divulgados.

Para o Domínio Infra-estrutura de Transportes, atenção especial deve ser dada ao indicador 5.2.1 - "Vias para transporte coletivo". Em função de sua semelhança com o indicador 9.1.1 - "Extensão da rede de transporte público", sua metodologia deve ser melhor definida e as fichas metodológicas devem conter informação mais detalhada, de forma a distinguir corretamente os indicadores e evitar equívocos na sua avaliação.

Em relação ao Domínio Aspectos Políticos foi observada dificuldade em se avaliar os indicadores relacionados à distribuição de recursos entre os diferentes modos de transporte, em parte, devido a indisponibilidade de dados confiáveis (os dados de base desses indicadores já haviam sido apontados como de baixa qualidade, conforme Tabela 9.2), como também devido à sua forma de avaliação. Assim, estes indicadores devem ter suas metodologias revistas, especialmente com definição clara em relação aos critérios para utilização de infra-estrutura por modos coletivos e individuais, de forma a auxiliar na sua avaliação futura.

Para o Domínio Aspectos Sociais houve total incompatibilidade entre os resultados obtidos. Como grande parte de seus indicadores são avaliados de forma qualitativa, com alto grau de 
subjetividade, a metodologia de avaliação dos mesmos deve ser revista, com a melhor definição dos parâmetros qualitativos, visando reduzir a subjetividade e ambigüidade na sua avaliação.

Ainda que os resultados individuais para os indicadores não tenham sido plenamente satisfatórios, o número significativo de indicadores avaliados e a propriedade do índice de permitir a compensação entre os critérios contribuiu para que os resultados globais e setoriais para os dois métodos de avaliação apresentassem variação dentro de limites toleráveis, em média, de 4\%. No entanto, a análise pormenorizada dos indicadores sugere que uma revisão de aspectos metodológicos relacionados especialmente a indicadores dos Domínios Aspectos Sociais e Aspectos Políticos pode ser conduzida, no sentido de identificar possíveis adaptações que venham a clarificar os aspectos abordados pelos mesmos, bem como seu processo de cálculo e/ou análise qualitativa.

Deve-se destacar ainda que aplicações futuras do índice em outras cidades poderão indicar melhores caminhos para adequação do processo de cálculo dos indicadores, na medida em que permitirão analisar diferentes situações em termos de disponibilidade e forma de apresentação dos dados de base.

Assim, o desenvolvimento e adequação do índice deve se dar de forma gradual, à medida que for sendo utilizado como ferramenta de monitoração da mobilidade em cidades de portes e características diferenciadas. Entre os aspectos que podem ser aprimorados encontram-se a metodologia de cálculo e avaliação dos indicadores e os valores limites para as escalas de avaliação. 


\section{CONCLUSÕES E SUGESTÕES PARA TRABALHOS FUTUROS}

Neste capítulo são apresentadas as principais conclusões deste trabalho, relacionadas ao referencial de mobilidade urbana sustentável em cidades brasileiras, ao processo de construção de ferramenta para monitoração da mobilidade urbana e sua aplicação para uma cidade média. Na etapa final, são feitas sugestões para desenvolvimento da ferramenta e trabalhos futuros.

\subsection{Referencial de Mobilidade Urbana Sustentável}

A atividade de capacitação conduzida em onze cidades brasileiras através do Método MCDA-C, permitiu identificar aspectos importantes em relação ao referencial de mobilidade urbana sustentável no país.

Com relação ao enfoque dados às questões de mobilidade, as diferenças existentes entre a abordagem tradicional de planejamento e o novo paradigma, caracterizado pela incorporação de novos valores e preocupações na formulação de políticas públicas de mobilidade, foram evidenciadas nas cinco regiões por meio dos indicadores gerados nas duas fases da atividade. A forma como foi conduzida a identificação dos indicadores da segunda fase, desvinculada da primeira e com base nos conceitos gerados durante o exercício, permitiu revelar tais diferenças, e apontou a assimilação dos novos conceitos pelos técnicos que participaram da atividade de capacitação.

Com base nos resultados obtidos observa-se que o conceito de sustentabilidade tem sido incorporado de forma gradativa nas atividades de gestão e planejamento urbano no Brasil, especialmente no que se refere à mobilidade. Tal situação foi evidenciada através da ênfase dada às questões de planejamento integrado e preocupações sociais e ambientais, destacadas na grande maioria das cidades avaliadas durante o exercício de capacitação. Cabe lembrar que historicamente estes temas foram colocados em segundo plano no tratamento das questões de mobilidade urbana no país. Sua inserção no processo de planejamento reflete, em parte, a assimilação dos novos conceitos e dimensões que 
norteiam as noções de sustentabilidade e de desenvolvimento sustentável, já amplamente difundidos em países desenvolvidos e ainda em construção no Brasil.

Em função das dimensões continentais e das diferenças físicas, econômicas, sociais e culturais entre as regiões brasileiras, a noção de sustentabilidade assumiu diferentes enfoques, associada às particularidades e especificidades locais. Assim, a importância atribuída às questões ambientais, econômicas e sociais em cada contexto é distinta (como mostrou a Figura 7.40), reflexo inclusive do grau de desenvolvimento de cada região. Ao mesmo tempo, questões bastante específicas foram enfatizadas nas diferentes localidades, conforme mostrou o conjunto de noventa e seis PVFs identificados na atividade de capacitação (Tabela 7.3), refletindo problemas particulares ou mesmo potencialidades que inibem ou facilitam, respectivamente, o processo de desenvolvimento urbano sustentável.

Com base nestes fatores pode-se concluir que o método desenvolvido, baseado na metodologia MCDA-C, é sensível às diferenças de enfoque e abordagem na formulação do conceito de mobilidade urbana sustentável, uma vez que revelou significativas diferenças entre as regiões analisadas. Assim, o mesmo pode ser utilizado como base para a formulação de políticas públicas ou desenvolvimento de ferramentas voltadas a monitorar as condições de mobilidade urbana, à medida que permite identificar os fatores-chave considerados em diferentes contextos geográficos e temporais.

\section{2. Índice de Mobilidade Urbana Sustentável - IMUS}

Ao mesmo tempo em que a atividade de capacitação permitiu destacar os diferentes enfoques no tratamento das questões de mobilidade nas cinco regiões do país, permitiu identificar aspectos fundamentais que estruturam o referencial de mobilidade urbana sustentável em cidades brasileiras. Este referencial foi representado pelo seguinte conjunto de critérios, comuns no âmbito das onze cidades pesquisadas:

- Planejamento;

- Aspectos ambientais;

- Transporte público;

- Tráfego;

- Acessibilidade;

- Aspectos sociais;

- Modos não-motorizados;

- Infra-estrutura;

- Aspectos políticos. 
O conjunto de critérios identificados serviu de ponto de partida para a estruturação de uma ferramenta voltada a monitoração dos progressos em direção à sustentabilidade, denominada de IMUS.

A hierarquia de critérios em torno da qual se estrutura o IMUS sintetiza, portanto, o referencial de mobilidade urbana sustentável em cidades brasileiras. No entanto, em função da abrangência e natureza dos critérios nela incluídos, integrando tanto questões tradicionais como relacionadas ao novo paradigma da mobilidade, a possibilidade de sua adoção em outras regiões é grande, já que permite uma visão detalhada do sistema de mobilidade urbana, cobrindo temas que são relevantes em diferentes contextos geográficos. Além disso, o método de construção do IMUS estabelece procedimentos para o levantamento de todos os conceitos que estruturam o índice, aplicáveis em diferentes contextos espaciais ou temporais, permitindo assim desenvolver ferramentas inteiramente adaptadas para contextos específicos.

O primeiro nível hierárquico, representado pelos Domínios, sintetiza as grandes áreas de preocupação relacionados ao conceito de mobilidade urbana sustentável. O nível seguinte da hierarquia de critérios agrupa os Temas, que representam aspectos mais específicos que caracterizam cada Domínio. Estes foram facilmente identificados durante a atividade de capacitação desenvolvida nas cidades brasileiras, conforme já foi mencionado no item anterior, e agrupados constituindo uma estrutura comum. No entanto, foi observada certa dificuldade em se identificar indicadores para monitoração dos conceitos-chave relacionados, uma vez que as ferramentas identificadas nos exercícios desenvolvidos nas onze cidades tratavam-se muitas vezes de medidas de difícil operacionalização.

Assim, para a identificação de indicadores adequados a monitorar os conceitos que estruturam o IMUS, foi necessário o estabelecimento de um referencial baseado em sistemas desenvolvidos no Brasil e no exterior, de forma a dispor de medidas operacionais adequadas para a monitoração dos Temas que compõem o índice. Este referencial, agregou aproximadamente 3200 indicadores de diversas áreas e temas relacionados à mobilidade urbana sustentável, de enfoques quantitativo e qualitativo, se constituindo em uma ampla fonte de pesquisa destes instrumentos.

No que diz respeito ao sistema de pesos definido para o IMUS, este permitiu revelar a importância relativa dos critérios, em todos os níveis hierárquicos. Uma particularidade desse sistema foi a forma como o mesmo foi definido, através de um painel de especialistas nas áreas de planejamento urbano, transportes, mobilidade e sustentabilidade, do Brasil e de outros países da América do Norte, Europa e Oceania. Assim, os pesos definidos para os 
critérios foram totalmente desvinculados de qualquer contexto geográfico mais específico, se constituindo em um sistema de pesos neutro, que pode ser adotado em diferentes situações. Esta neutralidade ou imparcialidade permitiu ainda não descartar domínios tradicionais, intercalando sua importância relativa com domínios relacionados ao novo paradigma de tratamento das questões de mobilidade, conforme foi visto no Capítulo 8 (Figura 8.7).

Outra particularidade deste sistema foi a possibilidade de se identificar o peso dos Temas para cada Dimensão da sustentabilidade. Assim, a forma como o IMUS avalia as Dimensões Social, Econômica e Ambiental é inovadora, na medida em que considera que cada elemento da estrutura urbana e dos sistemas de transportes que compõe o índice apresenta uma contribuição relativa para cada uma das dimensões da sustentabilidade.

Com isso, é possível avaliar o impacto de ações em diferentes áreas para as três Dimensões, além de identificar os indicadores de maior impacto para os resultados do IMUS, tanto em âmbito global como setorial, conforme mostrado nas Tabelas 8.14 e 8.15. Desta forma, o índice pode ser utilizado tanto para a formulação de políticas integradas de mobilidade urbana, como políticas direcionadas a Domínios e Dimensões específicos. Em ambos os casos, ao identificar as áreas mais deficientes, permite a planejadores e gestores priorizar e direcionar suas políticas e estratégias, especialmente em situações de escassez de recursos, que impeçam o desenvolvimento de ações mais abrangentes.

Com relação ao processo de normalização definido para os indicadores que compõem o IMUS, a forma como o mesmo foi estruturado permite sua adaptação de acordo com a natureza da análise a ser desenvolvida, bem como a metas e objetivos definidos em cada contexto geográfico em que o mesmo for aplicado.

Neste sentido, em análises com foco na comparação entre cidades em termos de sustentabilidade de seus sistemas de mobilidade, os valores constantes nas Escalas de Avaliação propostas, as quais definem o processo de normalização dos indicadores, podem ser adaptados de forma a proporcionar esta visão comparativa, através da identificação de valores mínimo e máximo que refletem os resultados obtidos para o grupo de cidades avaliadas. Ou ainda, pode-se estabelecer uma Escala de Avaliação única, que permita a comparação entre diferentes cidades.

Em situações onde o município ou aglomeração urbana dispõe de metas para a mobilidade sustentável, estas podem definir os limites da Escala de Avaliação, permitindo ao município acompanhar os progressos em direção às metas pré-definidas. Neste caso, o índice pode ser usado para avaliação e monitoração das condições de mobilidade ao longo do tempo, 
permitindo ajustar os limites da Escala de Avaliação dos Indicadores, a medida que os objetivos pré-definidos forem sendo alcançados.

A indicação de Escalas de Avaliação para os indicadores é, portanto, outra característica inovadora da ferramenta. Em estudos desenvolvidos em nível internacional, geralmente os autores se abstêm de determinar parâmetros para as medidas de performance, se limitando a indicadores meramente descritivos, implicando em uma interpretação de tendências em termos de sustentabilidade totalmente aberta (Gudmundsson, 2004). Ao determinar os valores mínimo e máximo para a avaliação global do IMUS, bem como de suas Dimensões, e definir parâmetros de controle para normalização dos scores dos indicadores, segundo as Escalas de Avaliação, o índice proporciona uma interpretação fechada em termos de sustentabilidade. Ou seja, indica metas e objetivos a serem atingidos e revela o estado atual do sistema em relação aos parâmetros pré-estabelecidos.

No que se refere ao método de agregação dos critérios, o método proposto, baseado em uma combinação linear ponderada, permite a compensação entre critérios bons e ruins. Neste sentido, premia as cidades que apresentam bons indicadores, aumentado os resultados globais do índice, ao mesmo tempo em que permite identificar os indicadores deficitários, que estão contribuindo para baixar os valores globais e setoriais do índice.

Finalmente, as características do IMUS relacionadas à sua flexibilidade, possibilidade de adaptação para diferentes tipos de análise, imparcialidade do sistema de pesos e, principalmente, sua abrangência, incluindo temas de áreas diversas relacionadas à mobilidade urbana, permitem que a ferramenta possa ser aplicada em diferentes contextos com pequenas adaptações, incluindo cidades de menor porte e cidades de outros países.

\subsection{Aplicação do IMUS na Cidade de São Carlos}

Uma vez estruturado o IMUS, a etapa posterior consistiu em sua validação como ferramenta de monitoração da mobilidade, através de sua aplicação num caso concreto, para a cidade de São Carlos, interior do estado de São Paulo.

Neste sentido, foi avaliada primeiramente a viabilidade de aplicação do índice na cidade, verificando a disponibilidade e qualidade dos dados de base para cálculo dos indicadores. A coleta de dados realizada através de entrevistas com técnicos de órgãos e secretarias municipais, e pesquisa a bases de dados e informações estatísticas indicou que é possível calcular grande parte dos indicadores do IMUS (92\%) em curto prazo para a cidade de São Carlos. A avaliação mostrou ainda que a maioria dos indicadores (68\%) apresentam dados de base com alta qualidade, o que contribui para a confiabilidade dos resultados do índice. 
Dos oitenta indicadores efetivamente avaliados, 17\% e 7\% apresentaram, respectivamente, dados com média e baixa qualidade. Muitos dos indicadores com dados de base de média qualidade, no entanto, são dependentes dos resultados da Pesquisa Origem e Destino em desenvolvimento para a cidade. Deste modo, poderão ter a qualidade aumentada, assim que a pesquisa for totalmente tabulada e disponibilizada. Para os indicadores que apresentaram dados de baixa qualidade (conforme Tabela 9.2), recomenda-se o estabelecimento de procedimentos de coleta e atualização dos dados visando dispor de informações mais precisas para avaliação dos mesmos.

Para os indicadores identificados como mensuráveis somente em longo prazo, são necessários levantamentos de campo de grande abrangência (vias locais e edificações públicas), pesquisas de opinião (qualidade de vida e qualidade da sinalização viária) e sistematização de dados e informações produzidas pela Prefeitura Municipal (especialmente no que se refere à aplicação de recursos públicos), de forma a prover os dados necessários para cálculo dos indicadores incluídos neste grupo.

O grande número de indicadores avaliados e a alta qualidade dos dados de base sugerem, portanto, que o índice pode ser aplicado em cidades de médio porte, realizando-se pequenas adaptações nos indicadores. No entanto, os resultados obtidos para a aplicação do IMUS na cidade de São Carlos devem ser observados com cautela. O desenvolvimento da Pesquisa Origem e Destino, inédita em grande parte dos municípios brasileiros, sobretudo desse porte, e a recente conclusão do processo de revisão do Plano Diretor Municipal, ainda não realizado em muitas cidades brasileiras, implicou na produção e principalmente atualização de dados, viabilizando a construção de muitos dos indicadores que compõem o IMUS. O que se observa, no entanto, na grande maioria das cidades médias brasileiras é uma grande carência de recursos humanos, econômicos e tecnológicos que impedem ou restringem a coleta e produção de dados para monitoração das condições urbanas e de mobilidade. Neste sentido, as principais barreiras a serem superadas para a efetiva aplicação do IMUS como ferramenta de suporte às atividades de planejamento e gestão é sua adequação às condições de limitação de dados e recursos humanos e tecnológicos para sua formulação.

Sobre os resultados propriamente ditos, pôde-se observar que o IMUS atingiu um valor global intermediário para a cidade de São Carlos, equivalente a 0,578, enquanto que suas Dimensões apresentaram resultados praticamente equilibrados, com leve preponderância da Dimensão Social, em função inclusive do sistema de pesos definido para os critérios. 
Os resultados indicam, portanto, que para a melhoria dos valores global e setoriais, devem ser empreendidas ações especialmente no campo Ambiental, seguido pelos campos Econômico e Social. A análise pormenorizada dos indicadores calculados para a cidade de São Carlos permitiu ainda visualizar os aspectos que contribuem para a mobilidade urbana sustentável e os fatores críticos, que inibem ou impedem a implementação do conceito.

A análise de sensibilidade mostrou que, ao se promover os indicadores com os dez maiores pesos globais e por Dimensão, é possível obter aumento significativo nos resultados do IMUS. Nas quatro primeiras etapas de análise de sensibilidade desenvolvidas, o valor global do IMUS foi elevado a 0,708 (considerado alto em relação à escala de avaliação com limites inferior e superior de 0,00 e 1,00, respectivamente). Os resultados para as Dimensões da sustentabilidade também apresentaram sensível aumento.

A análise mostrou ainda que, tanto para o resultado global como para os resultados setoriais, maiores scores são obtidos com a promoção simultânea dos dezesseis indicadores que apresentam os maiores pesos (Etapa 5), chegando a valores do IMUS em torno de 0,773 . Nesta situação, há sensível melhora dos resultados para as Dimensões Social, Econômica e Ambiental que atingem, respectivamente, valores de 0,265, 0,254 e 0,254. Nesta situação, é observado maior equilíbrio entre as Dimensões Econômica e Social, o que reflete o sistema de pesos definido para o IMUS.

Assim, é possível, através da melhoria dos indicadores que obtiveram resultados críticos a partir da análise realizada para São Carlos e daqueles que exercem maior impacto sobre os resultados do IMUS em âmbito global e setorial, melhorar a avaliação da mobilidade urbana sustentável para o município. Neste sentido, são apresentados na Tabela 10.1 dois conjuntos de indicadores: o primeiro se refere aos fatores críticos à mobilidade sustentável, representados pelos indicadores que obtiveram score nulo, conforme análise desenvolvida para o município; o segundo se refere aos fatores de maior impacto para os resultados do IMUS, representados pelos indicadores com maiores pesos global e setorial, que não obtiveram score igual a 1,00, segundo a análise desenvolvida para o município, e que, portanto, podem ter seus resultados melhorados.

A análise destes conjuntos proporciona, portanto, alguns direcionamentos para 0 desenvolvimento de políticas públicas e ações para a mobilidade urbana sustentável na cidade de São Carlos. Ainda que muitos aspectos associados aos mesmos não dependam somente de ações em nível municipal para sua melhoria (como é o caso de consumo de combustível, emissões de poluentes, integração entre níveis de governo, etc.), a 
identificação destes já se constitui em uma etapa fundamental para a monitoração, planejamento e gestão da mobilidade urbana.

Tabela 10.1: Aspectos a serem observados na formulação de políticas públicas para a mobilidade urbana sustentável na cidade de São Carlos.

\begin{tabular}{|c|c|}
\hline Fatores Críticos & Fatores de Maior Impacto \\
\hline $\begin{array}{l}\text { Fragmentação urbana } \\
\text { Emissões de CO } \\
\text { Parcerias público/privadas } \\
\text { Política de mobilidade urbana } \\
\text { Ações para redução do tráfego motorizado } \\
\text { Consórcios intermunicipais } \\
\text { Densidade populacional urbana } \\
\text { Freqüência de atendimento do transporte } \\
\text { público } \\
\text { Índice de passageiros por quilômetro } \\
\text { Transporte coletivo x transporte individual } \\
\text { Modos não-motorizados x modos motorizados } \\
\text { Tarifas de transportes }\end{array}$ & $\begin{array}{l}\text { Ações para acessibilidade universal } \\
\text { Consumo de combustível } \\
\text { Uso de energia limpa e combustíveis } \\
\text { alternativos } \\
\text { Informação disponível ao cidadão } \\
\text { Eqüidade vertical (renda) } \\
\text { Educação para o desenvolvimento sustentável } \\
\text { Participação na tomada de decisão } \\
\text { Integração entre níveis de governo } \\
\text { Vias para pedestres } \\
\text { Vias com calçadas } \\
\text { Educação para o trânsito }\end{array}$ \\
\hline
\end{tabular}

Em uma última etapa, de forma a verificar a consistência dos resultados obtidos, foi realizada uma análise expedita dos indicadores calculados para São Carlos, por profissional com conhecimento do processo de planejamento e gestão da mobilidade no município. A compatibilidade dos resultados globais e setoriais obtidos, que apresentaram variação em torno de $4 \%$, sugere que os resultados do IMUS são consistentes, uma vez que não apresentaram variação significativa em relação à análise feita por um especialista com ampla visão do sistema de mobilidade urbana. No entanto, as divergências observadas de forma pontual para os indicadores, de aproximadamente $58 \%$, alertam para algumas situações de revisão da metodologia de cálculo dos mesmos, especialmente dos indicadores qualitativos, visando reduzir a subjetividade e ambigüidade do processo de avaliação.

Finalmente, a experiência conduzida para a cidade de São Carlos indicou que algumas adequações devem ser feitas no IMUS, para que o mesmo possa ser amplamente utilizado em cidades de grande e médio porte. Porém, um aspecto fundamental para que a ferramenta se constitua em um instrumento efetivo para o planejamento e gestão da 
mobilidade urbana consiste no desenvolvimento de processos periódicos e sistemáticos de coleta de dados que permitam a avaliação de todos os seus indicadores.

\subsection{Sugestões para Trabalhos Futuros}

As sugestões para trabalhos futuros se concentram principalmente no aprimoramento da ferramenta, a partir dos aspectos discutidos nos Capítulos 8 e 9, além de potenciais aplicações da mesma como instrumento efetivo de monitoração da mobilidade urbana.

No que diz respeito ao aprimoramento do índice, alguns aspectos fundamentais devem ser contemplados:

- Revisão de aspectos metodológicos de cálculo de alguns indicadores, de forma a prover uma estimativa mais precisa dos mesmos e adequá-los às características de disponibilidade e desagregação dos dados de base, conforme discutido no Capítulo 9. Isto se aplica principalmente a indicadores qualitativos, visando reduzir a subjetividade associada ao seu processo de avaliação;

- Incorporação de indicadores relacionados a temas que têm se destacado recentemente no contexto das cidades, incluindo aspectos mais diretamente relacionados aos impactos ambientais de novas infra-estruturas de transportes, mudanças no perfil da frota, incluindo crescimento da frota de motocicletas e impactos relacionados;

- Incorporação de procedimentos para coleta sistemática de dados para construção dos indicadores do IMUS, visando padronizar esta atividade, permitir dispor de dados adequados em termos de desagregação e atualização e possibilitar o acompanhamento constante das condições de mobilidade urbana.

Sobre as potencialidades de aplicação da ferramenta, sua utilização pode se dar em análises de natureza diversa, incluindo:

- Em contextos de escassez de dados para cálculo do IMUS de forma global, a análise específica de Domínios e Temas ainda se constitui em um instrumento útil para monitoração da mobilidade urbana e auxílio às atividades de planejamento e formulação de políticas públicas;

- Acompanhamento de metas e objetivos pré-definidos por municípios, aglomerações urbanas e regiões metropolitanas, principalmente auxiliando na elaboração e implementação de Planos de Mobilidade Urbana;

- Análises comparativas entre cidades em termos de sustentabilidade do sistema de mobilidade, através do estabelecimento de rankings, divulgação de boas práticas ou através de benchmarking de cidades; 
- Adoção do índice como critério para atribuição de recursos financeiros e desenvolvimento de políticas públicas no nível das cidades;

- Adaptação do índice para análise em nível intra-urbano e metropolitano.

Ainda que o IMUS tenha sido concebido de forma a se constituir em uma ferramenta de fácil aplicação e de amplo acesso a qualquer usuário ou instituição, não necessitando de pacote computacional específico para sua operacionalização, uma evolução da ferramenta poderia se dar através do desenvolvimento de software. Entre outros, o pacote permitiria sistematizar o processo de cálculo dos indicadores, fazer adaptações na estrutura do índice, gerar resultados automáticos e proceder a análises de sensibilidade de forma mais dinâmica, incluindo a disponibilização de recursos gráficos. No entanto, é importante que na concepção deste pacote sejam mantidas as características de simplicidade, fácil compreensão e manuseio da ferramenta. 


\section{REFERÊNCIAS BIBLIOGRÁFICAS}

ABAE (2006). ECO XXI: Um Compromisso pela Sustentabilidade. Associação Bandeira Azul da Europa. Lisboa, $2^{a}$ edição, maio de 2006. Disponível em: <http://abae.pt/ECOXXI/ 2006/ECOXXI_2006.htm>. Acesso em: 20 mar. 2007.

Álvares Jr., O. M. e Linke. R. R. A. (2001). Metodologia Simplificada de Cálculo das Emissões de Gases do Efeito Estufa de Frotas de Veículos no Brasil. São Paulo: CETESB. Disponível em: <http://www.ambiente.sp.gov.br/proclima/PDF/inventario_efeitoestufa.pdf>. Acesso em: 04 dez. 2007.

Andrade, A. R.; Balassiano, R. e Santos, M. P. S. (2005). Gerenciamento da Mobilidade: Princípios para sua Aplicação com Base na Informação. Revista do CETRAMA, Centro de Estudos de Transporte e Meio Ambiente, Universidade Federal da Bahia, n.2, v., p. 15-24.

ANTP (2003). Mobilidade e Cidadania. São Paulo: Associação Nacional de Transportes Públicos.

ANTP (2003b). Secretaria Diz como Trabalhará pela Mobilidade Sustentável. Informativo ANTP, São Paulo, n. 101, maio.

ANTP (2006). Sistema de Informações da Mobilidade. Associação Nacional de Transporte Público. Disponível em:<http://www.antp.org.br/simob/Lists/cstmbldd/rlt.aspx>. Acesso em: 14 jan. 2008.

Audit Comission e IDeA (2007). Library of Local Performance Indicators. Audit Comission and Improvement e Development Agency, UK. Disponível em: <http://www.local-pilibrary.gov.uk/library.asp>. Acesso em: 24 mar. 2007.

Bana e Costa, C. A. e Vincke, P. (1990). Multiple Criteria Decision Aid: An Overview. In: Bana e Costa, C. A. (ed). Readings in Multiple Criteria Decision Aid. Berlin : Springer-Verlag, p.3-14.

Bana e Costa, C. A. (1992). Structuration, Construction et Exploitation d'un Modèle Multicritère d'aide à la Décioson. Tese (Doutorado) - Universidade Técnica de Lisboa, Portugal, 1992.

Bana e Costa, C. A., Vansnick, J.C. (1995). Uma Nova Abordagem ao Problema de Construção de uma Função de Valor Cardinal: MACBETH. In: Investigação Operacional, v.15, junho, p.15-35. 
Bana e Costa (2001). Modelos Multicritério de Apoio à Decisão. Lisboa: Instituto Superior Técnico.

Bana e Costa (2001a). Metodologias de Análise de Decisão. Lisboa: Instituto Superior Técnico.

Bertolini, L.; le Clercq, F. e Straatemeier, T. (2008). Urban Transportation Planning in Transition (Editorial). Transporte Policy, n.15, p. 69-72. Disponível em: <www.elsevier.com/l cate/tranpol>. Acesso em: 10 mar. 2008.

Black J.A.; Paez A.; Suthanaya P.A. (2002). Sustainable Urban Transportation: Performance Indicators and Some Analytical Approaches. Journal of Urban Planning and Development, v.128, n. 4, p. 184-209. Disponível em: <http://scitation.aip.org/getabs/servlet/GetabsServlet? prog=normal\&id=JUPDDM000128000004000184000001\&idtype=cvips\&gifs=yes $>$. Acesso em: 10 mar. 2008.

Bossel, H. (1999). Indicators for Sustainable Development: Theory, Method, Applications. A Report to the Balaton Group. International Institute for Sustainable Development. Disponível em: <http://www.iisd.org/publications/ ub.aspx?pno=275>. Acesso em 27 mar. 2007.

Bouyssou, D. (1990). Building Criteria: a Prerequisite for MCDA. In: Bana e Costa, C. A. (ed). Readings in Multiple Criteria Decision Aid. Berlin : Springer-Verlag, p.58-79.

Campos, V. B. G.; Ramos, R. A. R. (2005). Proposta de Indicadores de Mobilidade Urbana Sustentável Relacionando Transporte e Uso do Solo. In: PLURIS - Congresso LusoBrasileiro para o Planejamento Urbano, Regional, Integrado e Sustentável, 1, 2005, São Carlos, SP, Brasil,. Anais... (CDRom). São Carlos: EESC/USP.

Caratti, P. et al. (2001). Sustainable Urban Transportation - SUTRA. First Interim Report Rel. January 2001. Disponível em: <http://www.ess.co.at/SUTRA/DELIVERABLES/D08a.pdf>. Acesso em: 23 mar. 2007.

Cardiff Council (2002). Better Communities - Brighter Lives: A Community Strategy for Cardiff. Second Draft, March 2002. Disponível em: <http://www.cardiff.gov.uk/>. Acesso em 30 mar. 2007.

Centre for Sustainable Transportation (2001). Sustainable Transportation Performance Indicators. Synopsis Report. Disponível em: <http://cst.uwinnipeg.ca/documents/ TPI_synopsis.pdf>. Acesso em: 20 mar. 2007. 
Comissão das Comunidades Européias (2007). Livro Verde: Por uma Nova Cultura de Mobilidade Urbana. Documento de Trabalho da Comissão, Bruxelas, 25 set. 2007. Disponível em: <http://ec.europa.eu/transport/clean/green_paper_urban_transport/docl 2007_09_25_gp_urban_mobility_pt.pdf>. Acesso em: 10 mar. 2008.

Costa, M. S. (2003). Mobilidade Urbana Sustentável: um Estudo Comparativo e as Bases de um Sistema de Gestão para Brasil e Portugal. Dissertação (Mestrado) - Escola de Engenharia de São Carlos, Universidade de São Paulo, São Carlos, 2003.

CST (2003). Sustainable Transportation Performance Indicators. Centre for Sustainable Transportation. Disponível em: <http://cst.uwinnipeg.ca/completed.html>. Acesso em: 11 mai. 2008.

DEINFRA (2008). Plataforma Catarinense de Mobilidade Sustentável. Departamento Estadual de Infra-estrutura, Governo do Estado de Santa Catarina. Disponível em: <http://www.deinfra.sc.gov.br/pcms/>. Acesso em: 06 abr. 2008.

Diniz, P. C. (2003). Construção de um Modelo para Análise e Avaliação de Projetos de Investimentos em uma Empresa Agroindustrial: um Estudo de Caso. Dissertação (Mestrado) - Programa de Pós-graduação em Engenharia de Produção, Universidade Federal de Santa Catarina, Florianópolis, 2003.

Direcção Geral do Ambiente (2000). Sistema de Indicadores de Desenvolvimento Sustentável. Lisboa, Portugal: Direcção de Serviços de Informação e Creditação. Disponível em:<http://www.iambiente.pt/sids/sids.pdf> Acesso em: 10 mai. 2008.

Eastman, J. R. (1997). IDRISI for Windows: User's Guide. Version 2.0. Clark University, Graduate School of Geography, Worcester, MA, USA.

Ensslin, L.; Montibeller, G. N.; Noronha, S. M. (2001). Apoio à Decisão - Metodologias para Estruturação de Problemas e Avaliação Multicritério de Alternativas. Florianópolis: Editora Insular.

EPTC (2006). MOVIMAN Porto Alegre. MOVIMAN e EUROPE AID Serviço de Cooperação. Disponível em: <http://uww.eptc.com.br/moviman/index.asp?cod_ctd=277\&tipo=conteudo\&item=Início> . Acesso em: 06 abr. 2008.

European Comission (2002). Para um Perfil da Sustentabilidade Local: Indicadores Comuns Europeus. Fichas Metodológicas. Disponível em:<http://ec.europa.eu/environment/urban/ pdf/methodology_sheet_pt.pdf>. Acesso em: 07 jan. 2008. 
EUROFORUM (2007). Draft paper State of the Art of Research and Development in the Field of Urban Mobility. The European Research Forum for Urban Mobility (EUROFORUM). Disponível em: <http://www.eurforum.net/html/fileadmin/SoA_FinalDraft_160207_FINAL.PD>. Acesso em: 10 mar. 2008.

Ferraz, A. C. P. e Torres, I. G. E. (2001). Transporte Público Urbano. São Carlos: Editora Rima.

GEIPOT (2001). Transportes no Brasil: História e Reflexões. Oswaldo Lima Neto (coord.). Empresa Brasileira de Planejamento de Transportes. Recife: Ed. Universitária da UFPE.

Gilbert, R. e Tanguay, H. (2000). Sustainable Transportation Performance Indicators Project: Brief Review of Some Relevant Worldwide Activity and Development of an Initial Long List of Indicators. Canada: The Centre of Sustainable Transportation. Disponível em: <http://cst.uwinnipeg.ca/completed.html\#indicators>. Acesso em: 20 mar. 2007.

Gobierno Vasco (2007). Sistema de Informacion del Transporte. Departamento de Transportes Y Obras Publicas. Disponível em: <http://www1.euskadi.net/sistrans/ temas.apl?idioma=c>. Acesso em: 27 mar. 2007.

Gomide, A. A. (2003). Transporte Urbano e Inclusão Social: Elementos para Políticas Públicas. Texto para Discussão $\mathrm{N}^{0}$ 960, IPEA, Julho, 2003. Disponível em: <http://www.ipea.gov.br/pub/td/2003/td_0960.pdf>. Acesso em: 06 mai. 2006.

Goodwin, P.; Wright, G. (1991). Decision Analysis for Management Judgement. Chichester: John Wiley \& Sons.

Gudmundsson, H. (2001). Indicators and Performance Measures for Transportation, Environment and Sustainability in North America. Report from a German Marshall Fund Fellowship 2000, Individual Study Tour October 2000. National Environmental Research Institute, Denmark. 87 p. - Research Notes from NERI number 148.

Gudmundsson, H. (2004). Sustainable Transport and Performance Indicators. In: Hester, R.E. \& Harrison, R.M. (Eds). Issues in Environmental Science and Technology, n. 20, p. 3563. Disponível em: <http://forskningsbasen.deff.dk/ddf/rec.external?id=ruc20876>. Acesso em 21 jan. 2008.

Hall, P.; Pfeiffer, U. (2000). Urban Future 21: a Global Agenda for Twenty-First Century Cities. London: Spon. 
Hertfordshire County Council (1999). Hertfordshire's Local Transport Plan. Disponível em: <http://enquire.hertscc.gov.uk/ltp/>. Acesso em: 30 mar. 2007.

Hertfordshire County Council (2005). Hertfordshire's LTP Annual Progress Report 2005. Disponível em: <http://www.hertsdirect.org/yrccouncil/civic_calendar/archive/older_meetings/ eports/103/555/5.PDF>. Acesso em: 30 mar. 2007.

IBAM e Ministério das Cidades (2005). Mobilidade e Política Urbana: Subsídios para uma Gestão Integrada. Lia Bergman e Nídia Inês Albesa de Rabi (coord.). Rio de Janeiro: IBAM; Ministério das Cidades.

IBGE (2000). Censo Demográfico 2000. Instituto Brasileiro de Geografia e Estatística. Disponível em: <http://www.ibge.gov.br/>. Acesso em: 10 nov. 2006.

IBGE (2004a). Indicadores Sociais. Instituto Brasileiro de Geografia e Estatística. Disponível em: <http://www.ibge.gov.br/>. Acesso em: 10 nov. 2006.

IBGE (2004b). Indicadores de Desenvolvimento Sustentável. Instituto Brasileiro de Geografia e Estatística. Disponível em: <http://www.ibge.gov.br/home/geociencias/ recursosnaturais/ids/defaulttab.shtm>. Acesso em: 27 mar. 2007.

IBGE (2008). Cidades. Disponível em: <http://www.ibge.gov.br/cidadesat/default.php>. Acesso em: 19 jul. 2008.

ITRANS (2004). Mobilidade e Pobreza: Relatório Final. Instituto de Desenvolvimento e Informação em Transporte, Abril de 2004. Disponível em: <http://www.itrans.org.br/ pload/home/item/M\&P\%20Relatorio\%20Final\%20270304.pdf>. Acesso em 17 abr. 2008.

Jackson, T. e Roberts, P. (2000). A Review of Indicators of Sustainable Development: a Report for Scottish Enterprise Tayside. Final Report, february 2000. Geddes Centre for Planning ResearchSchool of Town and Regional Planning, University of Dundee. Disponível em: <http://www.trp.dundee.ac.uk/library/pubs/SETreport.pdf>. Acesso em: 19 mar. 2007.

Keeney, R. L., Raiffa, H. (1993). Decision with Multiple Objectives, Preferences and Value Tradeoffs. Cambridge: Cambridge University Press.

Landmann. M. C. (2004). Estimativa das Emissões de Poluentes dos Automóveis da RMSP Considerando as Rotas de Tráfego. In: ANPPAS - Associação Nacional de Pós-Graduação e Pesquisa em Ambiente e Sociedade, 2, 2004, Indaiatuba, SP, Brasil. Disponível em: <http://www.anppas.org.br/encontro_anual/encontro2/GT/GT11/marcelo_camilli.pdf>. Acesso em: 04 dez. 2007. 
Lautso, K. et al. (2004). PROPOLIS: Planning and Research of Policies for Land Use and Transport for Increasing Urban Sustainability. Final Report, Second Edition. Disponível em: <http://www.Itcon.fi/propolis>. Acesso em: 22 mar. 2007.

Lingayah, S. e Sommer, F. (2001). Communities Count: The LITMUS Test. Reflecting Community Indicators in the London Borough of Southwark. New Economics Fundation and Southwark Council. Disponível em: <http://www.neweconomics.org/gen/uploads/ Litmus\%20booklet(1).pdf>. Acesso em 20 mar.2007.

Litman, T. (2003). The Online TDM Encyclopedia: Mobility Management Information Gateway. Transport Policy, n. 10, p. 245-249. Disponível em: <http://www.sciencedirect.com/>. Acesso em: 11 mar. 2008.

Litman, T. (2007). Well Measured: Developing Indicators for Comprehensive and Sustainable Transport Planning. Victoria Transport Policy Institute, Disponível em: <www.vtpi.org/wellmeas.pdf>. Acesso em: 11 mai. 2008.

Macário, M. R. M. .R (2005). Quality Management in Urban Mobility Systems: an Integrated Approach. 362 p. Dissertação (Doutoramento) - Instituto Superior Técnico, Universidade Técnica de Lisboa, Lisboa. 2005.

Maclaren, V. W. (1996). Urban Sustainability Reporting. Journal of the American Planning Association, Chicago, v.62, n.2, p.184-202.

Malczewski, J. (1999). Gis and multicriteria decisioan analysis. New York: John Willey \& Sons.

Marsden, G. et al. (2005). Appraisal of Sustainability: Environmental Indicators. Institute for Transport Studies, University of Leeds. Disponível em: <www.its.leeds.ac.uk/projects/ sustainability/resources/Appraisal\%20of\%20Sustainability\%20in\%20Transport\%20\%20Environment\%20Indicators.pdf>. Acesso em 11 mai. 2008.

Martinez, T.L.; Leiva, F.M. (2003). Avaliação Comparativa de Indicadores Urbanos. Oficina Técnica de Planejamento Estratégico de Granada - Granada Metrópole 21. Disponível em: $<$ http://www.granada.org/obj.nsf/in/CIHNBPA/\$file/INDICADORES_URBANOS.pdf>. Acesso em: 08 ago. 2006.

Mendes, J. F. C. (1999). Onde Viver em Portugal - Uma Análise da Qualidade de Vida nas Capitais de Distrito. Lisboa: Ordem dos Engenheiros - Região Centro. 
Mendes, F. E. (2004). Avaliação de Programas de Controle de Poluição Atmosférica por Veículos Leves no Brasil. 179p.Tese (Doutorado) - Universidade Federal do Rio de Janeiro, COPPE, Rio de Janeiro, 2004. Disponível em: <http://www.ppe.ufrj.br/ppe/production/tesis/ femendes.pdf>. Acesso em: 12 dez. 2007.

Mendip District Council (2006). Annual Monitoring Report 2005/2006: Mendip District Local Development Framework. Dezembro, 2006. Disponível em: <www.mendip.gov.uk>. Acesso em: 30 mar. 2007.

Ministério das Cidades (2006a). Curso Gestão Integrada da Mobilidade Urbana. Módulo II: Cidade, Cidadão e Mobilidade Urbana Sustentável. Ministério das Cidades, Programa Nacional de Capacitação das Cidades, Brasília, Março, 2006.

Ministério das Cidades (2006b). Guia PlanMob para Elaboração dos Planos Diretores de Transporte e Mobilidade. Secretaria Nacional de Transportes e da Mobilidade Urbana, Brasília, Maio, 2006.

Ministério das Cidades (2007a). Projeto de Lei da Política de Mobilidade Urbana. Ministério das Cidades, Secretaria Nacional de Transporte e da Mobilidade Urbana (SEMOB). Disponível em: <http://www.cidades.gov.br/secretarias-nacionais/transporte-e-mobilidade/ projeto-de-lei-da-mobilidade-urbana/PL\%201867-2007\%20Mobilidade.pdf>. Acesso em: 28 abr. 2008.

Ministério das Cidades (2007b). Caderno de Referência para Elaboração de: Plano de Mobilidade por Bicicletas nas Cidades. Programa Bicicleta Brasil, Ministério das Cidades, Secretaria Nacional de Transportes e Mobilidade Urbana. Disponível em: $<$ http://www.cidades.gov.br/secretarias-nacionais/transporte-e-mobilidade/arquivos/Livro\%20 Bicicleta\%20Brasil.pdf $>$.

Minken, H.; Samstad, H. e Putz, K. (2001). Task 11 Report: Proposal for Objectives and Indicators in Urban Land Use and Transport Planning for Sustainability. PROSPECTS Procedures for Recommending Optimal Sustainable Planning of European City Transport Systems. TØI Working Report 1183/2001. Oslo.

Minken, H. et al. (2002). Evaluation Tools. PROSPECTS - Procedures for Recommending Optimal Sustainable Planning of European City Transport Systems. Version 2, January 2002. Leeds, Institute for Transport Studies.

Moreira, A. C. M. (2003). Um Método para Identificação e Priorização de Oportunidades / Ameaças e Pontos Fortes / Fracos no Planejamento Estratégico Utilizando uma Metodologia 
MCDA-Construtivista. Dissertação (Mestrado) - Programa de Pós-graduação em Engenharia de Produção, Universidade Federal de Santa Catarina, Florianópolis, 2003.

MOST (2003). Mobility Management Strategies for the Next Decades. Final Report, D-9. Disponível em: <http://mo.st/index_msie.html>. Acesso em: 01 abr. 2008.

Mourelo, A. C. A. (2002). Un Sistema de Indicadores para Avanzar en la Movilidad Sostenible. In: Congreso de Ingeniería del Transporte, 5., 2002 Santander, Espanha. Memórias...Santander, p.171-180.

Noronha, S. M. D. (2003). Heurística para Decisões em Grupo Utilizando Modelos Multicritério de Apoio à Decisão - Uma Abordagem Construtivista. Tese (Doutorado) Programa de Pós-graduação em Engenharia de Produção, Universidade Federal de Santa Catarina, Florianópolis, 2003.

NTU (2006). Pesquisa Mobilidade da População Urbana. Associação Nacional das Empresas de Transportes Urbanos. Disponível em: <http://www.ntu.org.br/ novosite/arquivos/RelatorioMobilidade2006.pdf>. Acesso em: 10 out. 2006.

Observatório Cidadão Nossa São Paulo (2008). Indicadores. Disponível em: <http://www.nossasaopaulo.org.br/observatorio/indicadores.php?tema=12>. Acesso em: 11 mai. 2008.

OECD (1999). Indicators for the Integration of Environmental Concerns into Transport Policies. Environment Policy Committee, Working Group on the State of the Environment. Disponível em: <http://www.olis.oecd.org/olis/1998doc.nsf/linkto/env-epoc-se(98)1-final>. Acesso em: 03 mar. 2007.

Ostanello, A. (1990). Action Evaluation and Action Structuring: Different Decision Aid Situations Reviewed Through Two Actual Cases. In: Bana e Costa, C. A. (ed). Readings in Multiple Criteria Decision Aid. Berlin : Springer-Verlag, p.36-57.

Paula, J. (2005). Diagnóstico do Potencial Ecoturístico: Estudo de Caso em Ivaí - PR. Dissertação (Mestrado) - Programa de Pós-graduação em Engenharia de Produção, Universidade Federal de Santa Catarina, Florianópolis, 2005.

Pereira, L. F.; Aquino, W.; Maia, N. M. A. (2004). Mobilidade e Qualidade de Vida. Revista dos Transportes Públicos, ANTP, ano 26, $2^{\circ}$ trimestre, p.109-113.

Pereira Neto, W. A. (2001). Modelo Multicritério de Avaliação de Desempenho Operacional do Transporte Coletivo por Ônibus no Município de Fortaleza. Dissertação (Mestrado) - 
Programa de Mestrado em Engenharia de Transportes, Universidade Federal do Ceará, Fortaleza, 2001.

PNDU (2000). Atlas do Desenvolvimento Humano no Brasil. Programa das Nações Unidas para o Desenvolvimento. Disponível em: <http://www.pnud.org.br/atlas/>. Acesso em: 10 nov. 2006.

Prefeitura Municipal de Belo Horizonte (1994). Índice de Qualidade de Vida Urbana. Disponível em: <http://portal1.pbh.gov.br/pbh/pgEDOCUMENT_VisualizaConteudo_ Header.html?query=pp_conteudo.id=8250>. Acesso em: 06 out. 2007.

Prefeitura Municipal de São Paulo (2008). São Paulo em Movimento. Disponível em: <http://www9.prefeitura.sp.gov.br/spMovimento/>. Acesso em 25 abr. 2008.

Ramos, R. A. (2000). Localização Industrial: um Modelo Especial para o Noroeste de Portugal. Tese (Doutorado). Escola de Engenharia, Universidade do Minho, Braga, Portugal.

Richardsson, B. C. (2005). Sustainable transport: analysis frameworks. Journal of Transport Geography, 13, p. 29-39. Disponível em: <http://www.sciencedirect.com/>. Acesso em: 10 mar.2008.

Rodrigues, M. O. (2006). Avaliação da Qualidade do Transporte Coletivo na Cidade de São Carlos - SP. Dissertação (Mestrado) - Escola de Engenharia de São Carlos, Universidade de São Paulo, São Carlos, 2006.

Roy, B. (1990). Decision-aid and Decision-making. In: Bana e Costa, C. A. (ed). Readings in Multiple Criteria Decision Aid. Berlin: Springer-Verlag, p.17-35.

Roy, B. (1993). Decision Science or Decision-Aid Science? European Journal of Operational Research. v.66, n.2, p. 184-203. Disponível em: $<$ http://www.sciencedirect.com/science/article/B6VCT-48MYGW953/2/c405b8292d9fe4fd2aa6f522d10b78e9>. Acesso em: 20 nov. 2006.

Roy, B. (1996). Multicriteria Methodology for Decision Aiding. London: Kluwer Academic Publishers.

Saaty, T.L. (1980). The Analytic Hierarchy Process. New York: McGraw Hill.

Saboya, R. T. (2005). Sistema de Suporte à Elaboração de Planos Diretores. Exame de Qualificação (Doutorado) - Universidade Federal de Santa Catarina, Florianópolis, 2005. 
Santoro, P. e Cymbalista, R. (2001). Estatuto da Cidade: Guia para Implementação pelos Municípios e Cidadãos. São Paulo: Instituto Pólis. Disponível em: <http://www.polis.org.br/obras/arquivo_160.zip>. Acesso em: 08 out. 2007.

Santos, L. D. e Martins, I. (2002). A Qualidade de Vida Urbana: O caso da Cidade do Porto. Working Papers da FEP, Investigação, Trabalhos em curso, $\mathrm{n}^{\circ} 116$. Faculdade de Economia, Universidade do Porto. Disponível: <http://www.fep.up.pt/investigacao/ workingpapers/wp116.pdf>. Acesso em: 13 out. 2006.

Scottish Executive Central Research Unit (2001). Sustainability Indicators for Waste, Energy and Travel for Scotland. Disponível em: <http://www.scotland.gov.uk/Resource/ Doc/156654/0042093.pdf>. Acesso em: 30 mar. 2007.

SEMOB (2008). Secretaria Nacional de Transporte e da Mobilidade Urbana. Disponível em: $<$ http://www.cidades.gov.br/secretarias-nacionais/transporte-e-mobilidade/>. Acesso em: 3 abr. 2008.

Silva, A. N. R. et al. (2004). SIG - Uma Plataforma para Introdução de Técnicas Emergentes no Planejamento Urbano, Regional e de Transportes: uma Ferramenta 3D para Análise Ambiental Urbana, Avaliação Multicritério, Redes Neurais Artificiais. São Carlos, SP, Edição dos Autores, $227 \mathrm{p}$.

Silva, A. N. R.; Costa, M. S. e Macedo, M. H. (2005). Do Planejamento de Transportes ao Planejamento da Mobilidade. Revista CETRAMA - Centro de Estudos de Transportes e Meio Ambiente, v.2, n.2, p. E1-E8.

Silva, A. N. R.; M. S. Costa e M. H. Macedo (2007). Multiple Views of Sustainable Urban Mobility in a Developing Country - The Case of Brazil. In: 11th World Conference on Transport Research, WCTR, Berkeley. Proceedings... (CD-ROM).

SNIU (2002). Sistema Nacional de Indicadores Urbanos. Programa de Gestão da Política de Desenvolvimento Urbano. Brasil, Governo Federal. Disponível em: $<$ http://www.cidades.gov.br/index.php?option=content\&task=section\&id=49>. Acesso em: 25 mar. 2007.

SUMMA (2004). Operationalising Sustainable Transport and Mobility: The System Diagram and Indicators. Sustainable Mobility, Policy Measures and Assessment. Deliverable 3, Workpackage 2, Final - Version 1.1. Disponível em: <http://www.summa-eu.org/>. Acesso em: 21 mar. 2007. 
Sustainable Measures (2006). Indicators of Sustainability. Disponível em: <http://www.sustainablemeasures.com>. Acesso em: 06 mai. 2008.

Sustainable Seattle (1998). Indicators of Sustainable Community. Disponível em:<http://www.sustainableseattle.org/Programs/Regionallndicators/1998IndicatorsRpt.pdf>. Acesso em: 28 fev. 2007.

TERM (2001). Indicators - Key Massages by Theme. Transport and Environment Reporting Mechanism. European Environment Agency. Disponível em: <http://themes.eea.europa.eu/ ndicators/keymessages?thetheme=transport>. Acesso em: 23 mar. 2007.

TERM (2002). Indicators - Key Massages by Theme. Transport and Environment Reporting Mechanism. European Environment Agency. Disponível em: <http://themes.eea.europa.eu/ ndicators/keymessages?thetheme=transport>. Acesso em: 23 mar. 2007.

TERM (2003). Indicators - Key Massages by Theme. Transport and Environment Reporting Mechanism. European Environment Agency. Disponível em: <http://themes.eea.europa.eu/ ndicators/keymessages?thetheme=transport>. Acesso em: 23 mar. 2007.

TRANSPLUS (2002). Analysis of Land Use and TransportIntegration Indicators (excerpt from reports D2.2 and D3). Transport Planning Land-Use and Sustainability. Disponível em: <http://www.transplus.net/>. Acesso em: 23 mar. 2007.

TRB (2001). Transportation, Energy and environmental Policy: Managing Transitions. Transportation Research Board, VIII Biennial Asilomar Conference. Disponível em: <http://onlinepubs.trb.org/onlinepubs/conf/asilomar.pdf>. Acesso em: 02 abr. 2008.

TRB (2008). Sustainable Transportation Indicators: a Recommended Program to Define a Standard Set of Indicators for Sustainable Transportation Planning. Transportation Research Board (TRB), Sustainable Transportation Indicators (STI), Subcommittee (TRB Subcommittee ADD40 [1]), janeiro, 2008. Disponível em: <http://www.vtpi.org/sustain/sti.pdf>. Acesso em: 24 mar. 2008.

UK Government Sustainable Development (2000). Local Quality of Life Counts: A Handbook for a Menu of Local Indicators of Sustainable Development. Disponível em: <http://www.sustainable-development.gov.uk/publications/pdf/localqolc.pdf>. Acesso em: 20 mar. 2007.

UK Government Sustainable Development (2004). Indicators of Sustainable Development. Disponível em: < http://www.sustainable-development.gov.uk/index.asp>. Acesso em: 20 mar. 2007. 
UNCHS (2004). Urban Indicators Guidelines. Monitoring the Habitat Agenda and the Millennium Development Goals. United Nations Human Settlements Programme. Disponível em: $<$ http://ww2.unhabitat.org/programmes/guo/documents/urban_indicators_guidelines.pdf>. Acesso em: 27 mar. 2007.

UNCSD (2001). Agenda 21. CSD Indicators of Sustainable Development. United Nations Commission on Sustainable Development. Disponível em: <http://www.un.org/esa/sustdev/ natlinfo/indicators/indisd/indsearch/indchapter.html>. Acesso em: 7 ago. 2007.

União Européia (1998). System for Planning and Research in Towns and Cities for Urban Sustainability (SPARTACUS). Disponível em: <http://www.Itcon.fi/spartacus>. Acesso em: 3 jul. 2003.

U. S. Department of Transportation (2002). Transportation Indicators. Bureau of Transportation Statistics. Disponível em: <http://www.bts.gov/publications/ transportation_indicators/december_2002/highlights.html>. Acesso em: 26 set. 2007.

VTPI (2007). Transportation Statistics: Online TDM Encyclopedia. Victoria Transport Policy Institute. Disponível em: <www.vtpi.org/tdm/tdm80.htm>. Acesso em: 01 abr. 2008.

WBCSD (2004). Mobility 2030: Meeting the Challenges to Sustainability. World Business Council for Sustainable Development. The Sustainable Mobility Project, Full Report 2004. Disponível em: <http://www.wbcsd.org/web/publications/mobility/mobility-full.pdf>. Acesso em: 21 mar. 2007.

WCED (1987). Our Common Future (The Brundtland Report). United Nations, World Comission on Environment and Development. Oxford: Oxford University Press.

Wolff, P. R. (2005). Construção de um Modelo de Avaliação de um Restaurante no Ramo de Fast-food: um Estudo de Caso. 167 p. Dissertação (Mestrado) - Programa de Pósgraduação em Engenharia de Produção, Universidade Federal de Santa Catarina, Florianópolis, 2005.

Wood, J. (2003). Hertfordshire's Local Transport Plan: Annual Progress Report. Volume I. Hertfordshire County Council, County Hall. Disponível em: <http://www.hertsdirect.org/ envroads/roadstrans/transplan/ltp/>. Acesso em: 30 mar. 2007.

WORLD BANK (1996). Sustainable Transport: Priorities for Policy Reform. Washington: World Bank. 